TOWARDS AN ACCURATE PROCESS DESIGN TOOL FOR LASER ASSISTED TAPE WINDING

ISBN: 978-90-365-5115-1

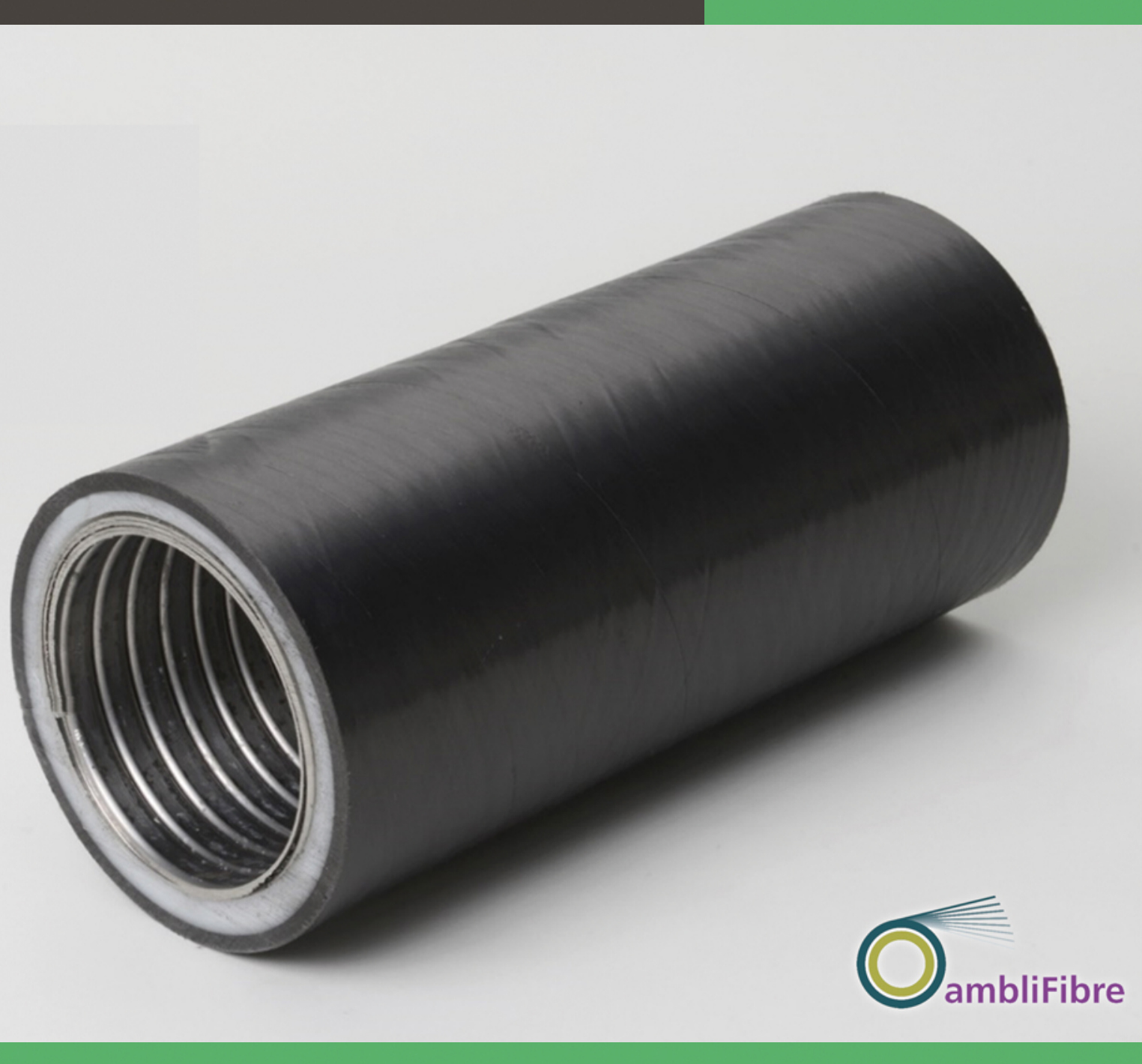

UNIVERSITY OF TWENTE.
TOWARDS AN ACCURATE PROCESS DESIGN TOOL FOR

$L$ A $S$ E $R$ ASSISTED TAPE WINDING 


\section{TOWARDS AN ACCURATE PROCESS DESIGN TOOL FOR LASER-ASSISTED TAPE WINDING}

Seyed Mohammad Amin Hosseini 


\title{
TOWARDS AN ACCURATE PROCESS DESIGN TOOL FOR LASER-ASSISTED TAPE WINDING
}

\section{DISSERTATION}

\author{
to obtain \\ the degree of doctor at the University of Twente, \\ on the authority of the rector magnificus, \\ Prof. dr. ir. A. Veldkamp, \\ on account of the decision of the graduation committee, \\ to be publicly defended \\ on Thursday, 21 January 2020 at 16:45
}

by

Seyed Mohammad Amin Hosseini

born on 27 December 1989

in Tehran, Iran 
This dissertation has been approved by:

\author{
Supervisor \\ Prof. dr. ir. R. Akkerman Co-Supervisors \\ dr. I. Baran \\ dr. ir. M. van Drongelen
}

This research was financially supported by the European Union's Horizon 2020 research and innovation program under Grant Agreement 678875 called as ambliFibre project.

Cover Design: Hassan Amoui

Printed by: Ipskamp Drukkers BV, Enschede, The Netherlands

ISBN: 978-90-365-5115-1

DOI: $\quad 10.3990 / 1.9789036551151$

(C) 2021 Seyed Mohammad Amin Hosseini, The Netherlands. All rights reserved. No parts of this thesis may be reproduced, stored in a retrieval system or transmitted in any form or by any means without permission of the author. Alle rechten voorbehouden. Niets uit deze uitgave mag worden vermenigvuldigd, in enige vorm of op enige wijze, zonder voorafgaande schriftelijke toestemming van de auteur.

The front cover shows the setup of adjacent hoop LATW process during production of flexible pipe reinforced with C/PA12 prepregs at Fraunhofer IPT. The back cover shows the final manufactured part. 
Graduation committee:

Chairman and Secretary:

Prof. dr. ir. H.F.J.M. Koopman

University of Twente

Supervisor:

Prof. dr. ir. R. Akkerman

University of Twente

Co-supervisors:

dr. I. Baran

dr. ir. M. van Drongelen

University of Twente

University of Twente

Committee Members:

prof.dr.ir. A.H. van den Boogaard prof.dr.ir. G.R.B.E. Römer

University of Twente

prof. dr. ir. R. Benedictus

University of Twente

Delft University of Technology

prof. dr. J.H. Hattel

Technical University of Denmark 
Of you, those who are faithful will be elevated a degree, and those with knowledge many.

An interpretation form The holy Quran, Al-Mujadila, verse 11 



\section{Summary}

Laser-assisted tape winding (LATW) is an automated process to manufacture tubular fiber reinforced thermoplastic composites having a high strength-to-weight ratio. A considerable time saving without an additional consolidation step can be achieved by the in-situ consolidation in the LATW process. The application of a laser as heat source offers advantages in terms of higher accuracy, repeatability, quality and reduced cycle time compared to conventional methods using hot air, gas or flame. The pre-impregnated (prepreg) thermoplastic tapes are bonded to a liner or an already placed substrate by means of laser heating and a compaction roller during the LATW processes. Some of the products which can be manufactured by the LATW process are the rings used for flywheels, pipes used for the deep sea risers and pressure vessels for gas storage.

LATW is a complex process in which multiple physical phenomena take place simultaneously, including kinematics, optics, heat transfer, tape deformation, intimate contact development at the interface of the deposited tapes, and crystallization kinetics of the matrix material. The local temperature and consolidation pressure history dominate the mechanical performance (a.o. interface strength) of the parts produced by the LATW process. The winding pattern and the laser heat flux distribution in time determine the temperature evolution. The laser heat flux is governed by the position and orientation of the laser head as well as the local substrate curvature and deformed state of the roller. In order to eliminate the trial-and-error approaches to predict the temperature field, a thermal model coupled to an optical model and a kinematic model is required. The process window and optimum process settings can then be determined with the help of the simulation models. The focus of this thesis is on the investigation of the process temperature during the LATW production of thermoplastic composite parts. The research was performed in the framework of the EU funded ambliFibre project with the ambition of developing an accurate off-line process simulation tool for LATW processes. The main goal of this thesis is therefore to take the first steps to develop a generic and quantitatively accurate process design tool leading to predictable part properties and performance which is suited for product and process optimization.

In this thesis, firstly, a coupled kinematic-optical-thermal (KOT) model is presented to predict the temperature evolution during multi-layer hoop winding of composite rings. The continuing heat accumulation during consecutive winding resulted in a gradually increasing process temperature which was also observed by the thermal camera measurements. It was also shown that the roller deformation altered the temperature field 
by changing the heating length and heat flux distribution.

Next, the adjacent hoop winding process used to manufacture composite pipes was studied by taking the growing-in-time thermal domains in the KOT model. Multiple heating and cooling cycles at the edges of the already wound substrate result in a nonuniform temperature history and gradients along the width of the substrate. More specifically, the temperature increase at the substrate edges was relatively higher than for the central region. The predicted temperature distributions in time were found to agree well with the temperature measurements by thermocouples embedded in the substrate. The obtained temperature history was used in a nonisothermal crystallinity model to predict the degree of crystallinity distribution during the adjacent hoop winding process. The predicted trends for the crystallinity distribution along the width of the substrate agreed well with the measured crystallinity by the differential scanning calorimetry tests.

Afterwards, a generic KOT model was developed to capture the heat flux and temperature histories in LATW processes for an arbitrary tooling geometry and winding pattern. Helical winding of the dome part of a pressure vessel was studied as an application case by incorporating a varying local tooling curvature and a winding speed. The surface curvature-dependent heat flux distributions were predicted and it was found that an increase in surface curvature resulted in a larger substrate temperature. More specifically, the process temperature changed up to $17-20 \%$ due to the local surface curvature and process speed which was also validated with the thermal camera measurements.

Finally, a new process optimization framework was introduced by using an inverse KOT (IKOT) model. The optimal laser power distribution was obtained while maintaining the process. For this purpose, a grid of independent laser cells was used as the heat source which was inspired by the vertical-cavity surface-emitting laser technology. An optimized time-dependent laser power distribution was obtained for both the hoop and helical winding cases. It was shown that the IKOT model was capable of maintaining the nip point temperature close to the target temperature distributions by using the optimized laser power distributions. The optimized laser power distribution pattern remained the same during the consecutive hoop winding process while the total power reduced to compensate the heat accumulation. A more non-uniform time-dependent laser power distribution was obtained for the helical winding case because the substrate curvature changed drastically at the dome section of the pressure vessel.

The developed KOT models are suitable for any tooling geometry, winding angle and process parameters. The roadmap towards achieving an accurate process design tool for the LATW processes is evaluated at the end of this thesis. The thesis finalizes with the conclusions and future recommendations based on the performed research and obtained scientific results. 


\section{Samenvatting}

Cilindervormige composieten producten kunnen geautomatiseerd worden vervaardigd met behulp van het laser-ondersteund tape-omwinding (LATW) proces. Dergelijke producten zijn zeer interessant voor de industrie vanwege de uitstekende balans tussen sterkte en gewicht. Daarnaast kan er tijdswinst geboekt worden doordat met het LATWproces al een sterke binding tussen de verschillende geplaatste lagen bereikt kan worden, er is geen nabewerkingsstap nodig. Het gebruik van een laser als warmtebron geeft verschillende voordelen in vergelijking tot meer traditionele bronnen, zoals warme lucht, gas of een vlam, namelijk een grotere nauwkeurigheid, reproduceerbaarheid, kwaliteit en kortere verwerkingstijden. Geïmpregneerde (prepreg) thermoplastische tapes worden gewikkeld en verbonden aan een ondergrond door middel van de laser en een roller waarmee de bovenste laag wordt aangedrukt. Producten die met behulp van dit LATWproces worden gemaakt zijn onder andere vliegwielen, leidingen die gebruikt worden in diepzee applicaties en drukvaten voor de opslag van gas.

Tijdens het LATW-proces spelen diverse fysica tegelijktijdig een rol, zoals kinematica, warmtetransport, optica, vervorming van de tape, ontwikkeling van contactoppervlaktes en het kristallisatiegedrag van het matrixmateriaal. De plaatselijke temperatuur- en druk geschiedenis hebben hierbij een zeer sterke invloed op de mechanische eigenschappen van het uiteindelijke product. De windingshoek en de warmteflux van de laser beïnvloeden deze temperatuurgeschiedenis. De genoemde warmteflux wordt bepaald door de positie en oriëntatie van de laser ten opzichte van het product, alsook door de lokale kromming van het product en de deformatie van de roller.

Om een correcte temperatuurverdeling te verkrijgen, heeft het niet de voorkeur een gecompliceerde en tijdrovende 'trial-en-error' studie uit te voeren, het alternatief is dat er een voorspellend model voorhanden komt. Hierbij is het noodzakelijk om een thermisch model te koppelen aan een optisch én een kinematisch model. Geschikte procescondities en optimale instellingen kunnen zo worden bepaald aan de hand van een simulatiemodel. Het doel van dit proefschrift is om de procestemperatuur tijdens het LATW-maakproces van thermoplastische composieten te onderzoeken. Dit onderzoek werd uitgevoerd in het kader van het EU gesubsidieerde ambliFibre project, welke tot doel heeft een nauwkeurig offline simulatiemodel te ontwikkelen voor het LATW-proces. Het hoofddoel van dit proefschrift is de eerste stappen te nemen richting een generiek en kwantitatief voorspellend model voor het LATW-proces, waarmee de product eigenschappen en proces condities geoptimaliseerd kunnen worden.

In dit proefschrift wordt een gekoppeld kinematisch-optisch-thermisch (KOT) model gepresenteerd om de temperatuurontwikkeling te voorspellen tijdens het cilindrisch 
omwikkelen van meerlaags composieten producten. De continue toevoeging van warmte aan het materiaal tijdens het herhaaldelijk omwinden van de buis heeft als resultaat dat de temperatuur geleidelijk toeneemt, welke experimenteel ook gedetecteerd werd door een thermische camera. Het is ook aangetoond dat de deformatie van de roller invloed heeft op de temperatuur verdeling, dit doordat de grootte van het verwarmde oppervlak en de verdeling van de warmteflux niet constant blijven in de tijd. Vervolgens is een cilindervormig en aangrenzend omwindingsproces voor het produceren van composieten buizen bestudeert met behulp van een groeiend thermisch domein in het KOT model. De meerdere opwarm- en afkoel cycli aan de randen van de bevestigde tape zorgen voor een niet-uniforme temperatuurgeschiedenis en gradiënten door de gehele onderlaag. Meer in detail gezien was de toename van de temperatuur aan de randen van de tape in de onderlaag relatief hoger dan in het centrum. De voorspelde temperatuurgeschiedenis kwam goed overeen met de experimentele waarden zoals verkregen door de aanwezige thermokoppels. Dit temperatuurprofiel is vervolgens gebruikt in een niet-isotherm kristallisatiemodel om de lokale kristallisatiegraad te berekenen. De verkregen trend door de gehele breedte van de onderlaag komt goed overeen met experimentele waarden verkregen door middel van calorimetrie onderzoek.

In een volgende stap is een generiek KOT model ontwikkeld om de warmteontwikkeling en temperatuurgeschiedenis tijdens LATW te kunnen voorspellen voor een willekeurige geometrie van de ondergrond en windingshoek. Schroefvormige windingen ter plaatse van de bolvormige afsluitingen van een drukvat zijn hierbij als studieobject genomen, gezien hier een sterke variatie in de kromming van het oppervlak en de windingssnelheid plaatsvindt. De warmteontwikkeling is voorspeld voor het gehele oppervlak en het is aangetoond dat een sterkere kromming van het oppervlak resulteert in een hogere temperatuur. De proces temperatuur nam toe met $17-20 \%$, welke overeenkomt met de metingen door de thermische camera.

Tenslotte is in dit werk een nieuwe optimalisatie methode gepresenteerd door gebruik te maken van een invers KOT model (IKOT). Met deze methode kan een optimale laser intensiteitsverdeling worden behaald door gebruik te maken van een raster aan onafhankelijk aanstuurbare laser cellen. Hiermee is een geoptimaliseerd en tijdsafhankelijke laserflux distributie bepaald voor zowel het cirkelvormige en schroefvormige windingsproces. Het IKOT-model is in staat om tijdens het gehele proces een laser intensiteitsverdeling te berekenen waarmee de temperatuur op het raakvlak tussen de tape en de substraatlagen de ingestelde temperatuur benadert. Het geoptimaliseerde intensiteit patroon bleef constant tijdens het cilindervormige omwindingsproces, terwijl de totale intensiteit afnam om te compenseren voor de geleidelijke toename van de temperatuur in het materiaal. Een niet-uniform en tijdsafhankelijke laser intensiteitsverdeling werden bereikt tijdens het schroefvormige omwindingsproces, dit door de sterke kromming aan weerszijden van het drukvat.

De ontwikkelde KOT modellen zijn geschikt voor producten met een willekeurig oppervlak, omwindingshoek en variabele proces parameters. Het opgestelde plan richting een nauwkeurig voorspellend model voor het LATW-proces is geëvalueerd aan het einde van dit proefschrift. Dit proefschrift eindigt met conclusies en enkele aanbevelingen voor toekomstig onderzoek, welke zijn gebaseerd op het uitgevoerde onderzoek en de behaalde resultaten. 


\section{Contents}

Summary

Samenvatting iii

Nomenclature vii

1 Introduction 1

1.1 Background and motivations . . . . . . . . . . . . 1

1.2 Scientific challenges . . . . . . . . . . . . . . 4

1.3 Scope and objectives $\ldots \ldots \ldots \ldots$. . . . . . . . . . . 6

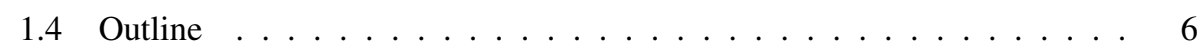

2 Hoop winding 9

2.1 Introduction . . . . . . . . . . . . . . . . . . . 10

2.2 Experimental . . . . . . . . . . . . . . . . . . 14

2.3 Thermal-optical model . . . . . . . . . . . . . . . . . . . 18

2.4 Results and discussions . . . . . . . . . . . . . . . . 22

2.5 Conclusion . . . . . . . . . . . . . . . . . . 34

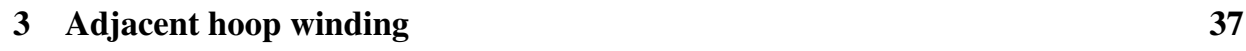

3.1 Introduction . . . . . . . . . . . . . . . . . . . . . 38

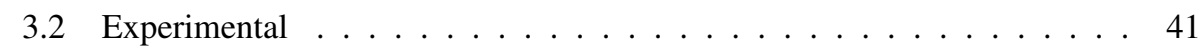

3.3 Kinematic-optical-thermal (KOT) model coupled with the crystallinity

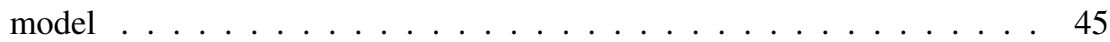

3.4 Results and discussions . . . . . . . . . . . . . . . 52

3.5 Conclusion . . . . . . . . . . . . . . 62 
4 Helical winding $\quad 65$

4.1 Introduction . . . . . . . . . . . . . . . . . 66

4.2 Experimental . . . . . . . . . . . . . . . . . 68

4.3 Generic kinematic-optical-thermal (KOT) . . . . . . . . . . . . . 71

4.4 Case studies . . . . . . . . . . . . . . . . . . . . . . . 79

4.5 Results and discussions $\ldots \ldots \ldots \ldots$. . . . . . . . . . . 83

4.6 Conclusion . . . . . . . . . . . . . . . . . . . . . . . 93

5 Optimization of LATW process

5.1 Introduction . . . . . . . . . . . . . . . . . . 96

5.2 Summary of the case studies to be optimized . . . . . . . . . . . . . . . . 98

5.3 Inverse Kinematic-Optical-Thermal (IKOT) model . . . . . . . . . . . . 101

5.4 Process optimization studies . . . . . . . . . . . . . . . . . . . . 109

5.5 Results and discussions . . . . . . . . . . . . . . . . . . . 110

5.6 Conclusion . . . . . . . . . . . . . . . . . 122

6 Discussion 123

6.1 Overview of main achievements . . . . . . . . . . . . . . 123

6.2 Roadmap towards accurate process design tool . . . . . . . . . . . 125

7 Conclusions and recommendations

7.1 Conclusions . . . . . . . . . . . . . . . . . . . . . . 129

7.2 Recommendations . . . . . . . . . . . . . . . . . . 130

\begin{tabular}{|l|l|}
\hline Uncertainties in model parameters: A stochastic analysis & 131
\end{tabular}

B Local geometrical irregularities: the cross-over phenomenon 137

$\begin{array}{ll}\text { References } & 141\end{array}$

$\begin{array}{ll}\text { Acknowledgments } & 153\end{array}$

$\begin{array}{ll}\text { Publications } & 155\end{array}$ 


\section{Nomenclature}

This nomenclature lists the most important abbreviations, entity names and symbols. Symbols may be used for multiple quantities, the intended meaning follows from the textual context. All units are SI by default unless overridden in the main text.

$\begin{array}{ll}\text { Abbreviations } & \\ \text { ATW } & \text { Automated Tape Winding } \\ \text { ATP } & \text { Automated Tape Placement } \\ \text { BRDF } & \text { Bidirectional Reflectance Distribution Function } \\ \text { CAD } & \text { Computer-Aided-Design } \\ \text { CAM } & \text { Computer-Aided-Manufacturing } \\ \text { CDF } & \text { Cumulative Distribution Functions } \\ \text { COV } & \text { Coefficients Of Variation } \\ \text { CV } & \text { Control Volume } \\ \text { DoC } & \text { Degree of Crystallinity } \\ \text { FRP } & \text { Fiber-Reinforced Polymer } \\ \text { FV-FD } & \text { Finite Volume-Finite Difference } \\ \text { HDPE } & \text { High-Density PolyEthylene } \\ \text { HMI } & \text { Human-Machine-Interface } \\ \text { IF } & \text { Illuminated Facets } \\ \text { IFOV } & \text { Instantaneous Field of View } \\ \text { MCS } & \text { Monte-Carlo simulations } \\ \text { (N)IR } & \text { (Near-)InfraRed } \\ \text { KOT } & \text { Kinematic-Optical-Thermal } \\ \text { LATP } & \text { Laser-Assisted Tape Placement } \\ \text { LATW } & \text { Laser-Assisted Tape Winding } \\ \text { TCC } & \text { Thermal Contact Conductance coefficient } \\ \text { PA12 } & \text { Poly(Amide) 12 } \\ \text { PEEK } & \text { Poly(Ether Ether Ketone) } \\ \text { PTFE } & \text { PolyTetraFluoroEthylene } \\ \text { STL } & \text { STereoLithography (file format) } \\ \text { TC } & \text { ThermoCouple } \\ \text { TFR } & \text { Tape Feeding Rate } \\ \text { TLH } & \text { Tape Laying Head } \\ \text { VCSEL } & \text { Vertical-Cavity Surface-Emitting Laser } \\ & \end{array}$




\section{Roman Symbols}

A

C

$c_{p}$

$h$

$h$

$\Delta H_{f}^{\circ}$

$\Delta H_{c}$

I

$k$

$K_{G}$

$K_{0}$

$L$

$\hat{\mathbf{k}}_{i}, \hat{\mathbf{k}}_{r}$

$n$

$\hat{\mathbf{n}}$

$N_{0}$

$N_{r}$

$N_{d}$

$P$

$q^{\prime \prime}$

$R$

$R$

$R$

$t$

$t$

$t_{1 / 2}$

$T$

$T_{g}, T_{m}, T_{\infty}$

$U$

$\hat{\mathbf{V}}_{\text {width }}, \hat{\mathbf{V}}_{\text {wind }}$

$v$

$\mathbf{x}$

$x, y, z$
Surface area

Arc length of roller contact with substrate

Specific heat capacity

Height

Heat transfer convection coefficient

Heat of fusion of $100 \%$ crystalline polymer at the equilibrium melting temperature

Integrated melting enthalpy during heating process

Indention of the roller into tooling surface

Thermal conductivity

Growth rate constant

Nucleation rate constant

Length

Unit vector in incident, reflected direction

Refractive index, Avrami exponent

Unit normal vector

Number of initial rays

Number of reflections

Number distributed rays per incident ray

Laser power

Absorbed heat flux

Reflectance

Radius

Universal gas constant

Time

Thickness

Isothermal crystallization half time

Temperature

Glass transition, melting, and Vogel temperatures

Activation energy for crystallization

Unit vectors in width and winding directions

Placement/winding velocity

Position $(x, y, z)$

Spatial coordinates

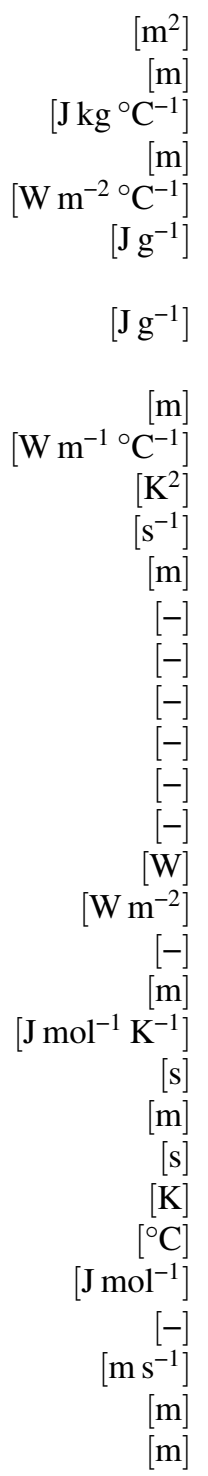




\section{Greek Symbols}

$\begin{array}{ll}\alpha & \text { Laser, thermal camera angle } \\ \alpha & \text { Thermal diffusivity } \\ \theta & \text { Polar angle (with respect to normal) } \\ \theta & \text { Winding angle } \\ \theta & \text { Camera pixel angle (with respect to roller centerline) } \\ \kappa & \text { Curvature } \\ \kappa & \text { Crystallization rate constant } \\ \mu & \text { Mean value } \\ \xi & \text { Relative degree of crystallinity } \\ \rho & \text { Density } \\ \sigma & \text { Standard deviation } \\ \phi & \text { Fiber orientation } \\ \phi_{0} & \text { relative crystallized volume if no impingement occurs for } \\ \chi_{v(\infty)} & \text { 3D spherulitic growth } \\ & \text { Crystallized volume (in equilibrium condition) }\end{array}$

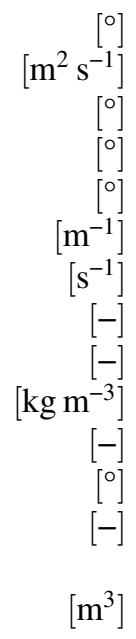

\section{Subscripts}

$\begin{array}{ll}c & \text { Camera } \\ f & \text { Fiber } \\ i & \text { Incident light } \\ l & \text { Laser spot } \\ m & \text { Mandrel } \\ m & \text { Matrix } \\ p & \text { Prepreg } \\ r & \text { Reflected light } \\ r & \text { Roller } \\ s & \text { Substrate } \\ t & \text { Incoming Tape } \\ t & \text { Tooling } \\ w & \text { Width }\end{array}$

\section{Vector notation}

The following notations are used to indicate non-scalar quantities:

$\begin{array}{ll}\mathbf{x} & \text { Dimensionful vector } \\ \hat{\mathbf{x}} & \text { Unit vector }\end{array}$




\section{CHAPTER 1}

\section{INTRODUCTION}

\subsection{Background and motivations}

Fiber-reinforced polymer (FRP) composite materials satisfy the need to fabricate parts in complex shapes while combining high performance with low weight. FRP materials efficiently carry the load in the fiber direction, where the fibers are embedded in a matrix material that holds them in place. The composite parts are typically designed to align the fibers in the direction of the principal loads, known as elastic tailoring. The FRP composite materials are considered as a great alternative for the traditional metals in harsh working conditions due to their higher corrosion and abrasion resistance than the metals [1].

The reinforcing fiber types, e.g. glass, carbon and aramid fibers, within the FRP composite part are surrounded by a plastic matrix which can be made of a thermoset or thermoplastic polymer. Thermoset polymers are crosslinked via a chemical reaction which enables the polymer being cured and solidified. Therefore, it is not possible for thermoset polymers to return to their original uncured form. On the other hand, thermoplastic polymers can be melted, processed and remelted again without changing the physical properties which make them recyclable as well [2]. Thermoplastic composites typically have better damage tolerance, impact resistance and fracture toughness compared to their thermoset counterpart.

One of the continuous processes to fabricate FRP composites is the filament winding. Fiber reinforcements such as filament, wire, tape and yarn, which are preimpregnated or impregnated by the matrix material during winding, are placed over a rotating tool or mandrel [3, 4, 5, 6]. Among the filament winding processes, the laser-assisted tape winding (LATW) is a highly automated composite processing technology to manufacture a wide range of tubular fiber-reinforced thermoplastic products. The incoming tape material is in the form of unidirectional fiber reinforced thermoplastic prepreg. The tape and the already wound substrate are brought in melt condition by the laser heat and touch each other at the 'nip point' as shown in Fig. 1.1. In-situ consolidation (i.e. achieving sufficient mechanical performance without post-winding treatment) is expected to be possible with the application of sufficient pressure of the roller (depicted in Fig. 1.1) 


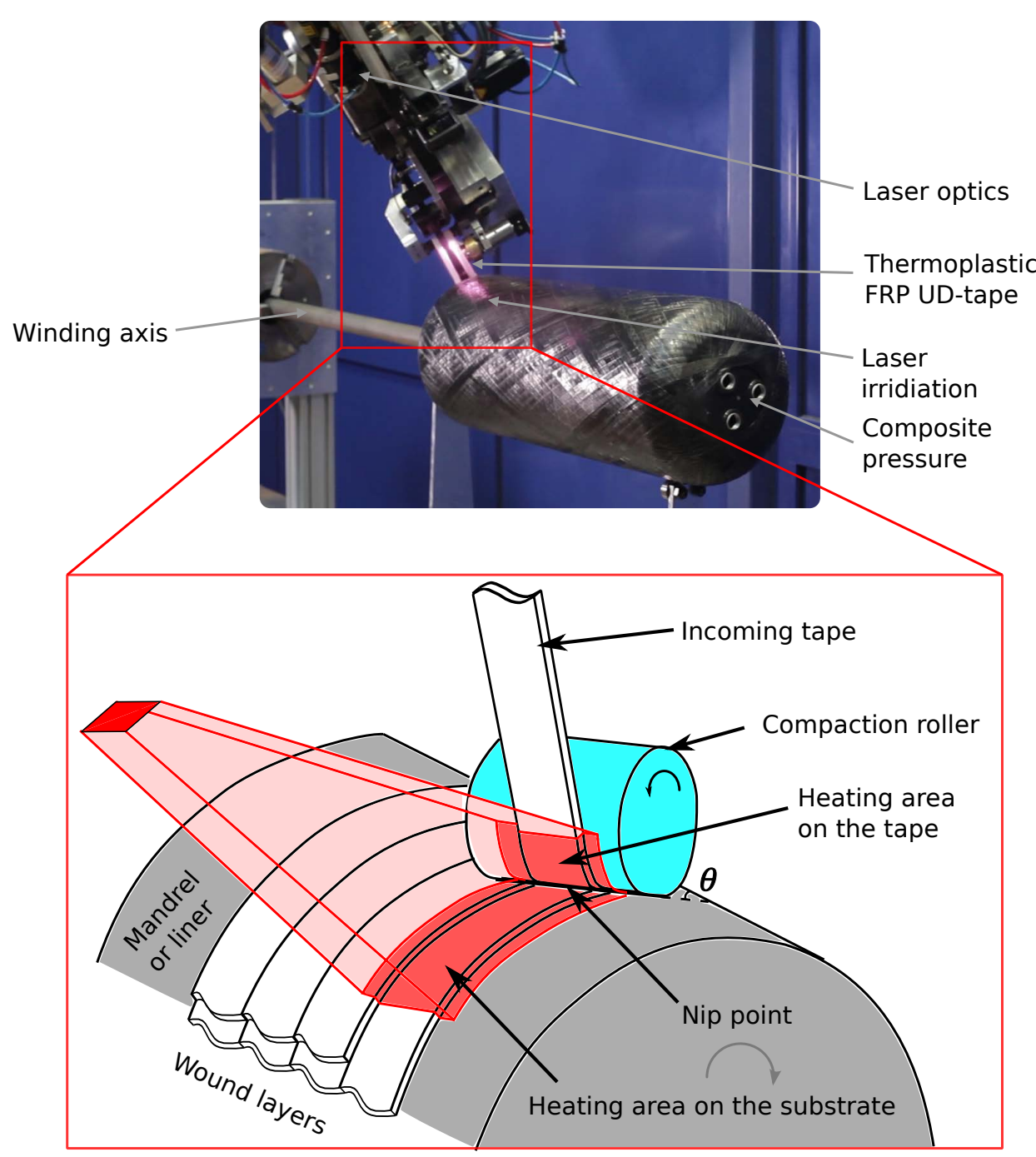

Figure 1.1 A view of the LATW process. Image courtesy of Fraunhofer IPT.

and tape tension.

Fig. 1.2 illustrates some of the types of composite parts which can be manufactured by the LATW process. Different winding patterns can be generated based on the winding angle $(\theta)$ as depicted in Fig. 1.2a namely the hoop, the adjacent hoop and the helical winding patterns. The composite flywheel seen in Fig. $1.2 \mathrm{~b}$ could be manufactured by hoop winding with $|\theta|=90^{\circ}$ where the layers are wound on top of each other. The adjacent hoop and helical winding patterns are used for pipe and pressure vessel production in general as seen in Figs. $1.2 \mathrm{c} \mid 1.2 \mathrm{~d}$. Some examples for the application of the pipes and pressure vessels made of fiber reinforced thermoplastic composites are the 


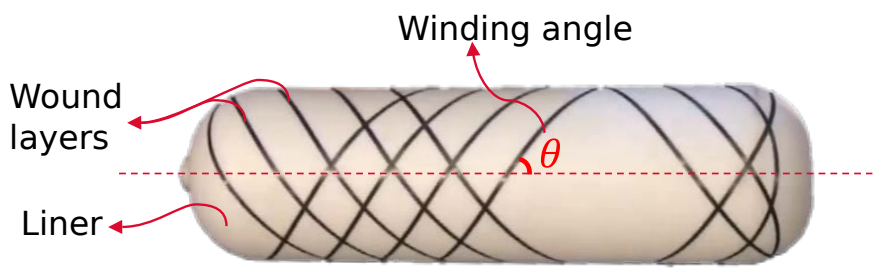

(a)

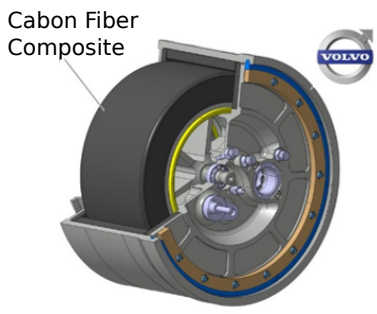

(b)

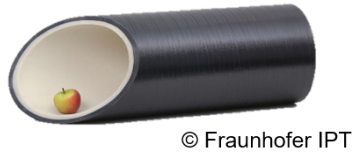

(c)

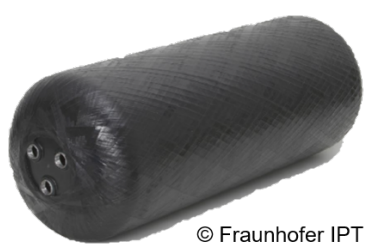

(d)

Figure 1.2 (a) Illustration of the winding angle in a LATW process in which a thermoplastic liner used. (b) Hoop or circumferential winding: fixed winding angle of $|\theta|=90$. (c) Adjacent hoop winding: tapes are wound next to each other with a fixed winding angle. (d) Helical or polar winding: variable winding angle.

deep sea risers and hydrogen storage tanks, respectively. Despite the benefits and variety of products manufactured by the LATW process, the product quality is determined based on a trial-and-error approach which is a time, energy and material-consuming procedure. Defining optimal process settings is challenging for new material combinations and parts with complex geometries. In addition, obtaining the desired high production rates at a reasonable cost together with low energy consumption narrows the process window even further. Therefore, an accurate simulation tool can help to overcome these challenges and bring the LATW technology one step forward.

Having said that, a research consortium consisting of twelve partners collaborated within the European research program ambliFibre, which stands for "adaptive modelbased control for laser-assisted fiber-reinforced tape winding" [7]. The ambliFibre project aimed to develop the first intelligent model-based controlled LATW system for FRP thermoplastic components. This system includes in-line non-contact quality monitoring tools and innovative Human-Machine-Interfaces (HMI), which are easily manageable for the operator. Based on integral process simulation tools combined with novel machine and laser technologies, for the first time, a tape winding system was realized which allows a system-reconfiguration to rapidly change product design and material demands. Two $\mathrm{Ph} . \mathrm{D}$. projects were defined in ambliFibre for the global process design tool and local in-line control tool which are embedded in the HMI system:

i) Ph.D. 1: Developing a fast in-line local model for in-line process control to regulate the process temperature by continuously altering/adapting the process settings to their current optimum values. 
ii) Ph.D. 2: Developing the off-line global modeling for process design tool to accurately analyze the process temperature trends and process optimizations for new materials and products.

This thesis covers the second Ph.D. project in which the focus is on the development and validation of an off-line global physics-based process design tool for the LATW process by analyzing the temperature distribution in relation to the optics and kinematics of the process and materials. This can be used to determine the processability and process settings upfront for new product designs with new materials.

\subsection{Scientific challenges}

The mechanical performance (a.o. interface strength) of the composite products manufactured by the LATW is determined by the local temperature and consolidation pressure history. The temperature evolution depends on the winding pattern and the laser heat flux distribution in time. The position and orientation of the laser head determines the laser heat flux on tape and substrate. Besides, the local tooling curvature and the deformed state of the roller also play an important role on the heat flux for the tape and substrate surfaces. Therefore, a simulation of the temperature field will require a thermal model coupled to an optical model and a kinematic model, where:

1. The kinematic model translates the requirements of the part design such as $3 \mathrm{D}$ tooling geometry and the required layup stacking sequence into the input for both the optical and thermal models, i.e. the trajectory of the deposited tape, thickness growth of the substrate, the position of the tape laying head (TLH) dubbed as "timedependent geometry and thickness growth".

2. The optical model determines the absorbed laser heat flux distribution on the tape and the substrate surfaces, which depends on the local geometry and the optical material properties which might be temperature-dependent. The ray-tracing technique, capable of considering the effects of surface curvatures and non-uniform laser power distribution together with non-specular anisotropic reflections of FRP materials, is one of the methods used for an accurate optical model.

3. The thermal model predicts the process temperature evolution of the tape and substrate using the calculated laser heat fluxes from the optical model and the geometrical properties e.g. thickness evolution from the kinematic model. Besides, the temperature-dependent thermal and optical material properties and thermal boundary conditions are updated in a coupled manner with the transient temperature distribution which is a requirement for a accurate thermal model. The thermal model can be based on the mass deposition during the winding process, which is in principal the same as in additive manufacturing simulations [8].

A flowchart showing the interrelations between the kinematic, optical and thermal models is depicted in Fig. 1.3. The resulting time- and location-dependent temperature history obtained from the coupled kinematic-optical-thermal (KOT) model can be used 


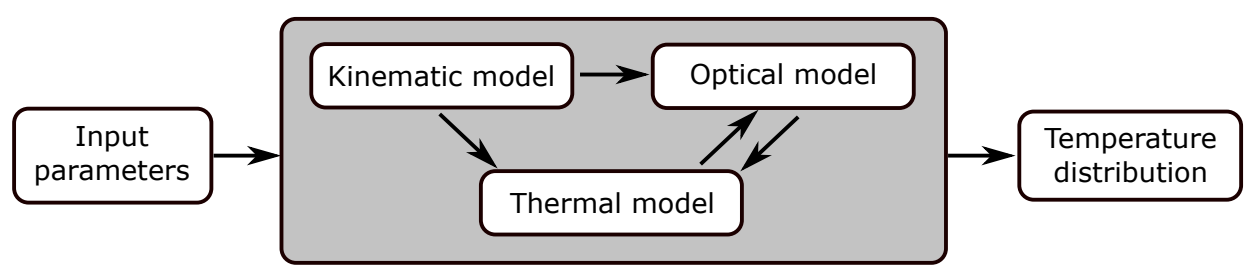

Figure 1.3 Flowchart showing the interrelations between the kinematic, optical and thermal models.

to evaluate the non-isothermal crystallinity evolution during the automated tape winding and placement (ATW and ATP) processes [9, 10, 11, 12, 13]. The process window and optimum process settings can be realized with the help of the simulation models. There has been several studies focusing on computational modelling of the ATW and ATP processes. Kinematic models were developed to optimize the winding path for the ATW process of T-joints in [14], pressure vessels in [15, 16], and pipes in [17]. To prevent the formation of gaps and overlaps on doubly-curved free-formed surfaces in the AFP processes, kinematic design tools were developed in [18, 19, 20].

The ray-tracing technique has been widely utilized in the optical modelling of the ATW and AFP processes to estimate the heat flux distributions on the tape and substrate surfaces [21, 22, 23, 24, 25, 26, 27, 28]. The anisotropic reflection of the fiber-reinforced composites tapes influences the heat flux distribution which was modelled by i) physically modeling the microstructure of surface defined by micro-half cylinders and applying a specular ray tracing approach as done in [24, 25], ii) defining a special function or material model that takes the fiber orientation into account and using it within the ray tracing approach as done in [26]. The obtained heat fluxes were subsequently used in thermal models [24, 27, 28] to predict the temperature history.

The ATW and AFP processes can be optimized by using the KOT models. However, there has been very limited research reported in literature regarding the model based process optimization. An inverse analytical thermal model was developed to tailor the power of the individual emitters of a vertical-cavity surface-emitting laser (VCSEL), which was validated by a simplified test setup in [29]. The transient total power of a VCSEL was introduced during the AFP process of a single-curved tooling with a uniform process temperature [30]. An inverse thermal model was developed in [31] to calculate the required heat fluxes to achieve a target temperature profile on the substrate surface for an ATP process.

Process design and optimization for arbitrary ATW products require a fully coupled model, including kinematics, optics, thermal and mechanical analysis. Only then it is possible to achieve predictable product performance without extensive trial and error experience. In addition, the currently available process design tools for ATW processes are limited to discontinuous (single-layer deposition) processes for simple cases of hoop winding. Therefore, complex products manufactured by various winding patterns as mentioned in Section 1.1 are still in the developing phase and accurate process design tools are needed for new products to predict and control the temperature history. 


\subsection{Scope and objectives}

This work focuses on the investigation of the process temperature for hoop, adjacent and helical winding of different thermoplastic composite parts manufactured by the LATW process. The main goal of this thesis is to take the first steps to develop a generic and quantitatively accurate process design tool leading to predictable part properties and performance which is suited for product and process optimization.

The specific research objectives (ROs) are:

1. To determine the role of roller deformation and heat accumulation during multilayer hoop winding of C/PEEK parts

2. To describe the temperature non-uniformity and resulting crystallinity distribution during adjacent hoop winding of C/PA12 parts

3. To quantify the effects of doubly-curved tooling geometry together with a timedependent winding angle and tape feeding rate on the process temperature for G/HDPE parts

4. To optimize the process by determining the optimum time-dependent laser power distribution

The current work concentrates on the integral thermal analysis incorporating a KOT model, leaving the mechanical analysis out of consideration. This implies that, e.g., nip point temperatures and crystallinity evolutions are within the scope of the current work, but that accurate predictions of the interface quality involving interlaminar voids, intimate contact and healing [32, 33, 34] are to be addressed in further research.

\subsection{Outline}

An outline of the research performed in this thesis is shown in Fig. 1.4 Chapter 2

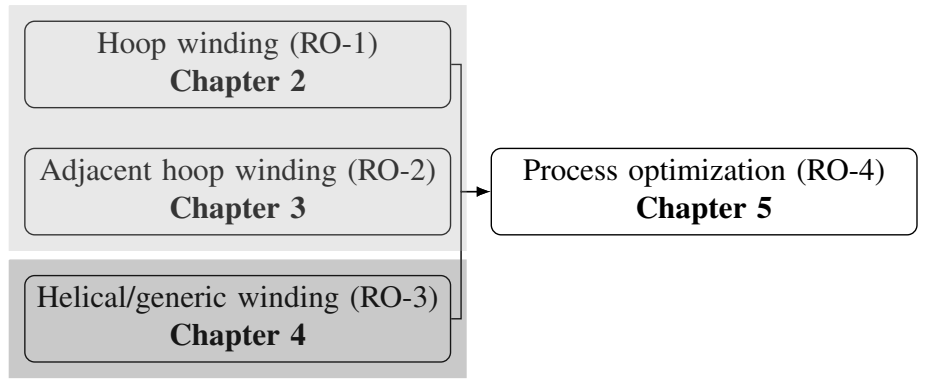

Figure 1.4 Brief outline of the research performed in this thesis with previously defined research objective (RO). 
addresses the simplest case of LATW, i.e. hoop winding used for manufacturing of FRP rings. This chapter explains the heat accumulation during the continuous winding of subsequent layers on top of each other. During this process, the roller deformation has a large effect on the flux distribution which is investigated critically.

A new 2D thermal model is presented to describe tape deposition during adjacent hoop winding to manufacture pipes in Chapter 3 This chapter investigates the effect of extra heating cycles on the previously wound adjacent tape. The temperature and crystallinity non-uniformity across the substrate width is shown to be considerable.

In Chapter 4, a new kinematic-optical-thermal model is presented to capture the temperature evolution during the LATW process with arbitrary tooling geometry, arbitrary fiber path, and time-dependent process settings. To validate this implementation, a comparison is made with the outputs of previous AFP models in the literature. Convergence analyses are carried out to find the optimum parameter values, e.g. the number of rays used in the ray tracing procedure to achieve reliable results. The effect of varying substrate curvature and process speed is quantified in a case study of helicalwound pressure vessels.

Dedicated experiments were performed during the production of rings, pipes, and pressure vessels as presented in Chapters 2,4. The in-line temperature measurements by the IR thermal camera and thermocouples were analyzed. The experimental data were compared to the results obtained with the numerical model, to verify and evaluate the capabilities of the developed models.

Chapter 5 then presents inverse modeling of the developed KOT models to estimate an optimized laser power distribution for the desired surface temperature distribution of hoop and helical winding cases.

The whole work is put into a broader perspective in Chapter 6 to demonstrate the roadmap for developing an accurate process design model. Global thermal modeling approaches are reviewed and justified. Issues inherent to the process and material, such as flash temperatures and statistical effects are addressed. Finally, Chapter 7 provides an overview of the important conclusions and presents the recommendations for further research. 


\title{
CHAPTER 2
}

\section{HOOP WINDING}

\begin{abstract}
Laser-assisted tape winding (LATW) is a highly automated process for manufacturing tubular-like fiber-reinforced thermoplastic composites such as flywheels and pipes. One of the crucial parameters in the LATW process is the temperature of the nip point at which the incoming prepreg tape is bonded with the substrate by a compaction roller. Therefore, the temperature evolution of the nip point plays a significant role to have a proper consolidation at the tape-substrate interface. The nip point temperature is highly affected by the time-dependent geometry of the substrate and roller during continuous LATW of thick composite rings. In this paper, a critical assessment of the substrate and tape surface temperature evolution is investigated experimentally by means of a thermal camera during the LATW process of a 26-layers thick carbon/PEEK composites. A three-dimensional (3D) optical model is coupled with a thermal model in which the substrate computational domain is updated with respect to the deposited tapes. A good agreement is found between the measured and predicted tape and substrate temperatures. The total absorbed heat and heated length of the substrate and tape are described based on the roller deformation. An increase in tape and substrate nip point temperatures is found with an increase in roller deformation during consecutive winding. It is also found that the consolidation pressure and contact length at the rollersubstrate interface increases during the winding process. Accordingly, the heat transfer coefficient at the roller-substrate interface is studied using the developed process model.
\end{abstract}




\subsection{Introduction}

Continuous fiber-reinforced thermoplastic composites such as C/PEEK (carbon/poly ether-ether-ketone) are considered in potential applications where high mechanical performance and lightweight design are required for structural elements used in e.g. aerospace, aircraft or energy storage [35]. There are various manufacturing techniques to produce continuous fiber-reinforced thermoplastic composites such as press and/or stamp forming, automated fiber placement (AFP), automated tape winding (ATW), autoclave consolidation, etc.

The ATW technique is highly automated and used to manufacture tubular-like structures such as flywheel rotors [36, 37], tanks for energy storage, pipes for oil and gas industry [38, 39], tubes for bikes, etc. The heating source can be a hot gas torch [40, 41, 9], infrared lamp [42, 43, 44], near-infrared (NIR) diode lasers [45, 46, 47, 48], and recently LED heating [49]. The parts are built up layer by layer onto a rotating mandrel in the ATW processes. The prepreg tape and the laid down substrate are locally molten by the heat source before touching each other at the nip point which can be seen schematically in Fig. 2.1 In-situ consolidation which is the main mechanism to form the final product takes place at the nip point vicinity where the melted incoming tape and substrate bond to each other by means of a compaction roller [50]. Consolidation includes the development of intimate contact and then healing of the polymeric matrix. Both phenomena are highly temperature-dependent processes and especially it is very challenging during depositing multiple layers since the substrate is exposed to multiple heating and cooling cycles during the manufacturing process. In addition, the absorption and reflection of the laser light by the substrate and tape material is highly anisotropic due to the presence of the fibers which influences the heating behavior of the materials. It is therefore a difficult task to control the process temperature which together with the applied pressure and the corresponding dwell time affects the consolidation quality and the mechanical performance of the final part. It was shown in [51] that a high process temperature resulted in a reduction in the wedge peel strength of the carbon-reinforced polyamide 6 (C/PA6) composites manufactured by the LATP process. On the other hand, a proper bonding was achieved for consolidation temperatures lower than the melting point of the C/PEEK material produced by LATP process in [52]. Several experimental and numerical modeling studies were conducted to understand, describe and predict the process temperature during the AFP and ATW processes. An in-situ thermographic analysis was carried out in [53, 54, 55, 56] by utilizing an AFP process. Significant temperature gradients were found for the deposited regions having overlapped tows, gaps and twists. The through-thickness temperature in between the deposited layers was measured by using thermocouples in [57] for a LATW process. The measured temperature was compared with the optical-thermal model predictions. An analytical thermal model was developed in [58] for a LATP process. It was found that the through-thickness temperature was significantly affected by the high process speed. The same analytical approach was used in [29] and an inverse analytical method was developed to obtain the desired heat flux distribution on the tape surfaces for a desired processing temperature. The heat power and placement speed were correlated with the process temperature considering the roller deformation in [59]. A semi-empirical thermal model was developed and validated with the experiments. An optical-thermal 


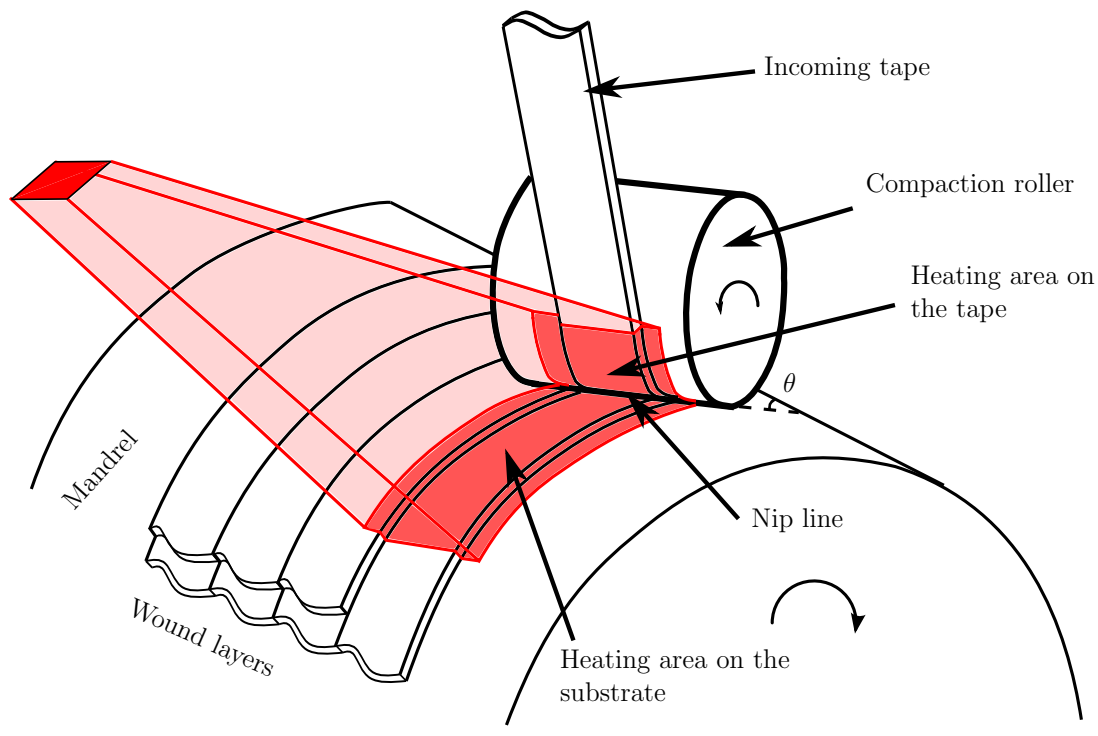

Figure 2.1 A schematic view of the LATW process.

model was developed in [60] for a LATW process. The effect of winding angle on the nip point temperature was investigated. The effect of the deformed geometry, temperature and thermal contact resistance of the roller on the process temperature was studied in [61] by using a thermal process model. The presence of the shaded region for the non-deformed roller resulted in a lower surface temperature prior to the nip point.

Specific attention was given to the placement and winding of multiple layers in the literature to investigate the effect of previously placed or wound layer on the process temperature as summarized in the following. The continuous hoop winding of glass/polypropylene and carbon/epoxy tapes was studied in [62] and [40], respectively. The temperature evolution during continuous deposition of multiple layers on a cylindrically shaped mandrel was captured by a thermal model and the predictions were compared with the measurements. The analysis of the temperature and degree of cure for hoop-wound cylinders was carried out in [43] for graphite/epoxy and glass/epoxy composites. The radiative surface heating was found to be more significant for the glass/epoxy composites than the graphite/epoxy composites. The in-situ curing of graphite/epoxy taped during continuous winding was modeled in [42] by using a thermochemical process model. It was found that the winding speed had a significant effect on the degree of cure of the material. A thermo-mechanical model was developed in [22] to predict the process-induced thermal residual stresses in a continuous winding of multiple carbon/PEEK layers. The mandrel properties and the tape tension were found to be effective parameters for the development of residual stress. The effect of growing thickness in a continuous LATW process was studied numerically in [63]. The evolution of peak temperature was investigated during continuous deposition of C/PEEK tapes. The adjacent placement of a carbon epoxy prepreg with an IR heater was studied in 
[64]. A significant temperature increase perpendicular to the placement path was obtained experimentally and numerically. A surrogate process model was developed in [23] for the simulation of multiple placement of C/PA6 tapes. The laser power and placement velocity were found to be the most effective parameters.

Recently, the anisotropic reflection behavior of the laser beams was considered in the process modeling studies [25, 24, 26, 65]. A comprehensive 3D reflection model was developed in [25] for carbon fiber reinforced thermoplastic composite tapes. A "micro-half-cylinder" model was implemented in a CAD model which was subsequently used in OptiCAD software to simulate the anisotropic reflective behavior of tapes. The same optical model was used in [24] to predict the temperature distribution in an AFP process in which the roller deformation was taken into account. The anisotropic reflection behavior of the prepreg tapes for the LATW process was studied in [26] in which a bidirectional reflectance distribution function (BRDF) was employed to estimate the heat flux distributions on the substrate and tape by taking the fiber orientation into account. The effect of specular and anisotropic reflection of the laser irradiation on the process temperature was studied numerically in [65].

A summary of the aforementioned literature survey focusing on multiple placement/winding taking the roller deformation into account is listed in Table 2.1 with important aspects based on the utilized experimental techniques and process models. Although there have been several works carried out to analyze the temperature evolution during ATW and AFP processes, the influence of the roller deformation evolution and local geometry change during winding of multiple layers on the temperature history has not been studied as seen from Table 2.1

A critical assessment of the temperature development in the vicinity of the nip point by taking the local geometry change into account is essential to ensure a proper final product quality. In this paper, the temperature near the nip point region is analyzed by employing a thermal camera. The change in the nip point location due to the roller deformation is captured by performing an image analysis. The roller deformation and resulting increase in the consolidation pressure and length are described by using a pressure-sensitive film. A coupled optical-thermal process model is developed to predict the influence of the roller deformation on the temperature evolution. The already developed optical model [26] is used to estimate the anisotropic reflection behavior of the incoming laser rays. The roller deformation and the local geometry change near the nip point are considered in the 3D optical model. The growing substrate thickness during the multiple winding of the incoming C/PEEK tapes is taken into account in the 2D thermal model by updating the computational domain. A parameter study is performed based on the heat transfer at the interface between the roller and substrate using the developed process model and results are compared with the temperature measurements. 
Table 2.1 Overview of the studies focusing on the multiple placement/winding of layers and the roller deformation for the investigation of temperature development in AFP and ATW processes.

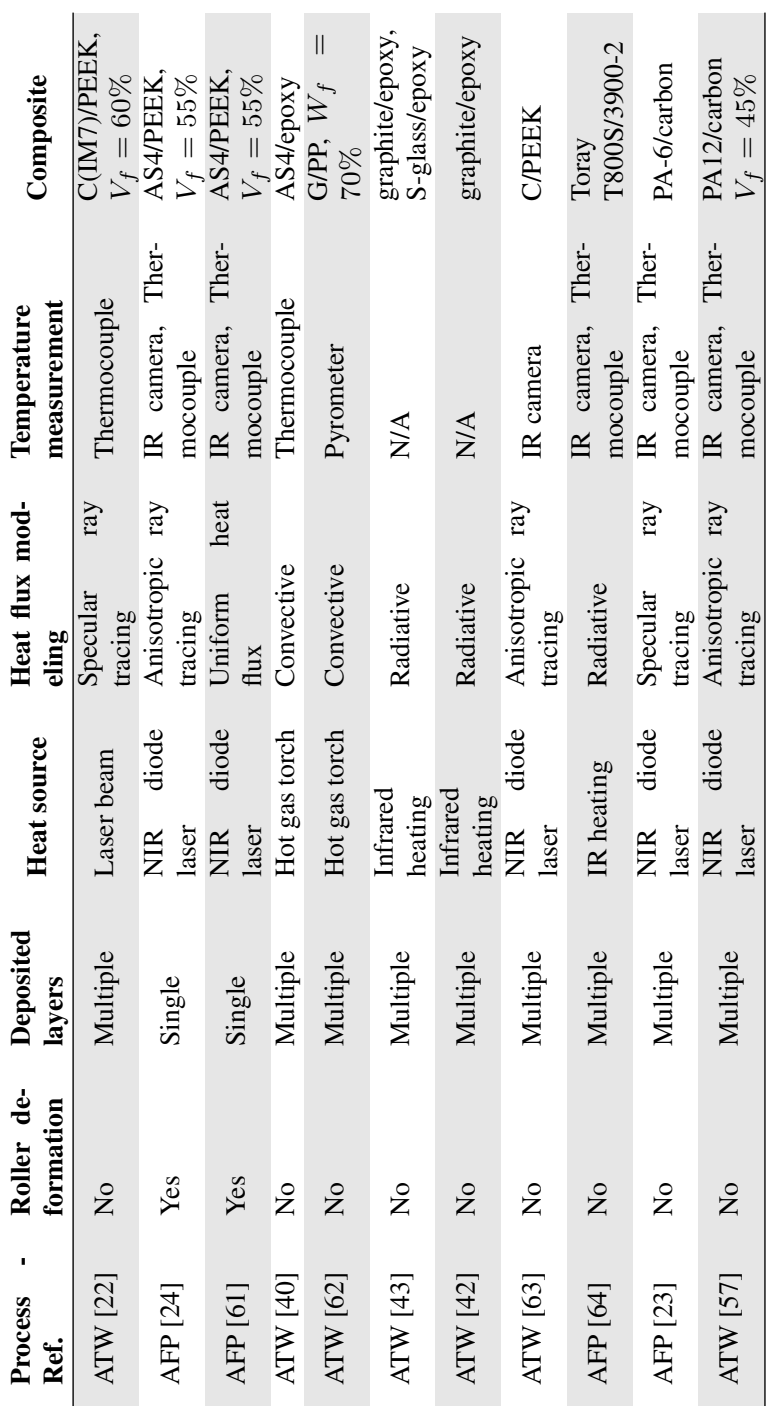




\subsection{Experimental}

The prepreg material used in the LATW process was TC1200 AS-4/PEEK provided by TenCate with a fiber volume content of $59 \%$ and a nominal thickness and width of $t_{p}=0.15 \mathrm{~mm}$ and $w_{p}=6.35 \mathrm{~mm}$, respectively. The roller was made of solid polytetrafluoroethylene (PTFE) with 40 shore hardness. The mandrel was made from Al-6082-T6 anodized aluminum. The winding surface was covered by a polyimide $\left(\right.$ Kapton $^{\circledR}$ ) tape with a silicone adhesive coating to improve the adhesion for the first layer [66]. Three thick rings were manufactured using the Coriolis Composites AFP machine for reliability and repeatability of the temperature measurements. The AFP machine consisted of an industrial robot with six degrees of freedom, onto which a tape laying head (end-effector) was mounted. A side view of the tape laying head and its components during the winding process are shown in Fig. 2.2. A schematic view of the tape laying head describing the position of individual parts is depicted in Fig. 2.3. The reference values for geometrical parameters are listed in Table 2.2 .

The NIR laser with a wavelength of $980 \mathrm{~nm}$ was used. The laser beam was homogenized to yield a near-uniform (top-hat) power distribution. The roller was pressed onto the substrate using a controlled nominal force of $435 \mathrm{~N}$. A maximum of 5 continuous layers was allowed to be deposited due to the limitation of the AFP machine. After every 5 layers, the machine cut the tape, shut down the laser and moved to the starting position. Once the ring temperature reached approximately room temperature the winding process was resumed. A total of 26 layers were wound for each ring including one layer as the base and 5 continuous layers repeated 5 times.

The temperature on the substrate and tape surface, at the heating region close to the nip point was measured by an IR thermal camera. The thermal camera was a MicroEpsilon thermalIMAGER TIM 400 with a resolution of $382 \times 288$ pixels. The thermal

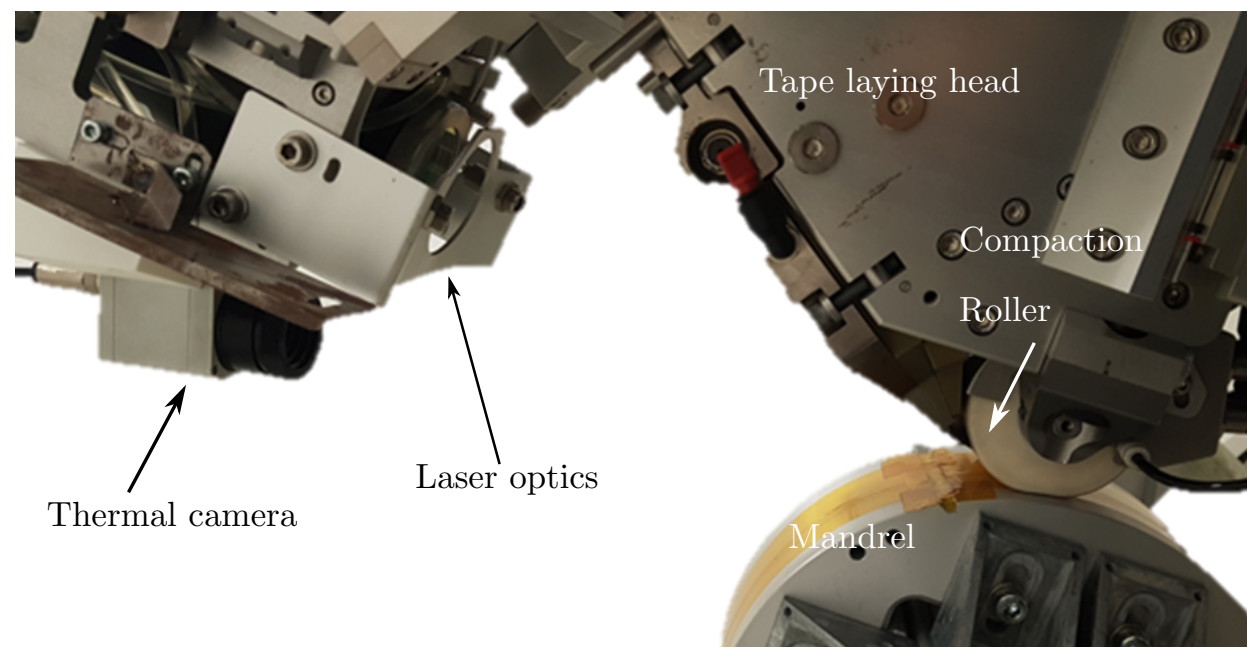

Figure 2.2 A view of the AFP machine during LATW process. 


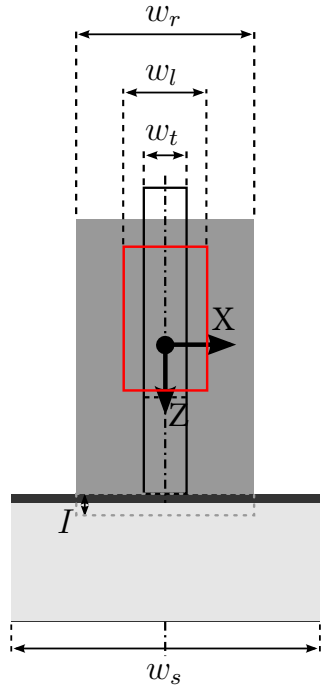

Front view
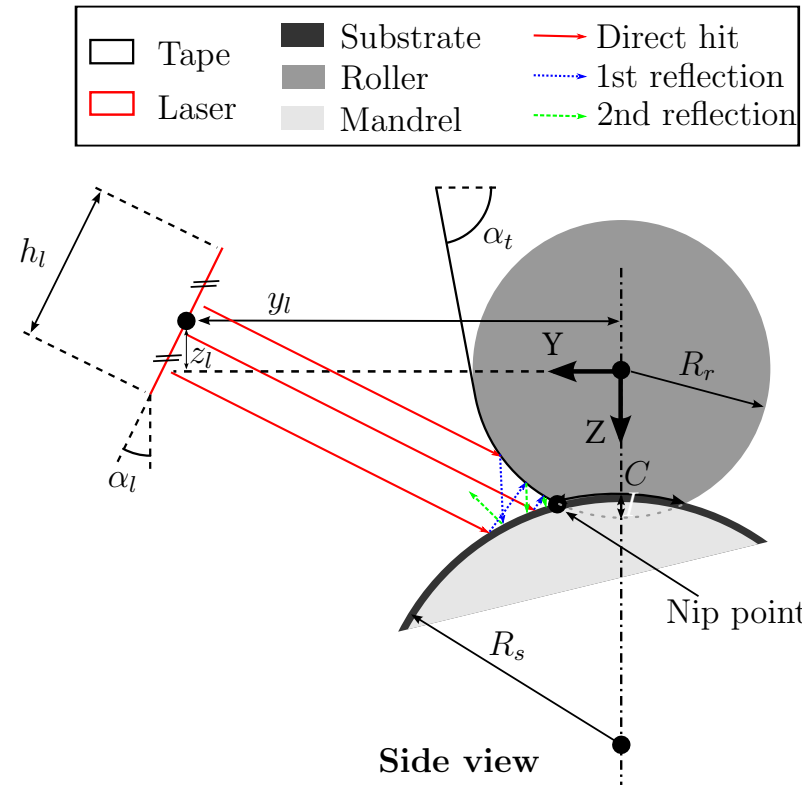

Figure 2.3 Model geometry used for the optical model (reproduced with permission from [26]).

Table 2.2 Optical and geometrical reference values used in simulating the LATW process.

\begin{tabular}{|c|c|c|c|}
\hline & Symbol & Value & Description \\
\hline \multirow{5}{*}{ 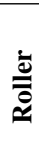 } & $R_{r}$ & $35 \mathrm{~mm}$ & Roller radius \\
\hline & $w_{r}$ & $50 \mathrm{~mm}$ & Roller width \\
\hline & $n_{r}$ & 1.4 & Roller refractive index [26] \\
\hline & $I$ & $2 \mathrm{~mm}$ & Roller indentation into mandrel surface \\
\hline & $C$ & $22 \mathrm{~mm}$ & Arc length of roller contact with substrate \\
\hline \multirow{4}{*}{ 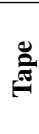 } & $w_{t}$ & $6.35 \mathrm{~mm}$ & Tape width \\
\hline & $L_{\text {tape }}$ & $40 \mathrm{~mm}$ & Considered length of the tape \\
\hline & $\alpha_{t}$ & $45^{\circ}$ & Laying tape angle \\
\hline & $n_{t}$ & 1.8 & Tape refractive index 47] \\
\hline \multirow{5}{*}{ 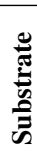 } & $R_{s}$ & $122 \mathrm{~mm}$ & Substrate radius \\
\hline & $w_{s}$ & $6.35 \mathrm{~mm}$ & Substrate width \\
\hline & $L_{\text {subs }}$ & $767 \mathrm{~mm}$ & Considered length of the substrate (Mandrel circumference) \\
\hline & $\phi_{s}$ & $0^{\circ}$ & Substrate fiber orientation \\
\hline & $n_{s}$ & 1.8 & Substrate refractive index 47 \\
\hline \multirow{7}{*}{ 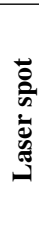 } & $y_{l}$ & $-308.61 \mathrm{~mm}$ & Laser spot y-position (of centroid) \\
\hline & $z_{l}$ & $76.43 \mathrm{~mm}$ & Laser spot z-position (of centroid) \\
\hline & $h_{l}$ & $28 \mathrm{~mm}$ & Laser spot height \\
\hline & $w_{l}$ & $11 \mathrm{~mm}$ & Laser spot width \\
\hline & $\alpha_{l}$ & $-20.79^{\circ}$ & Laser beam angle \\
\hline & $N_{0}$ & 4000 & Number of rays launched from the laser source \\
\hline & $N_{r}$ & 5 & Number of reflected rays per incident used in optical model [26] \\
\hline
\end{tabular}


camera spectrum range $(7.5-13 \mu \mathrm{m})$ did not interfere with the laser beam wavelength $(0.98 \mu \mathrm{m})$, therefore, the reflectance of the laser beam toward the thermal camera did not affect the temperature readings. The camera was mounted to the tape laying head just below the laser source (visible in Fig. 2.2). It constantly measured the infrared radiation emitted by the material near the nip point vicinity with $80 \mathrm{~Hz}$. Continuous video streams of the thermal field for the substrate and tape surfaces were extracted from the camera. To illustrate, a single frame of the measured temperature distribution is shown in Fig. 2.4a The temperature was logged and averaged in time over a $3 \times 1$ pixels (width $\times$ height) at the center of tape and substrate width, as seen by rectangular boxes in Fig. 2.4a. The size of a pixel at object level is known as Instantaneous Field of View (IFOV) which is defined based on the lens type and the distance to object [67]. Due to the curvature of the substrate and tape, the distance to the thermal camera lens varied, therefore the actual pixel size also varied in the winding direction. Moreover, the orientation of the camera with respect to the measuring pixel (IFOV) caused extra nonlinearity to the actual pixel size. The schematic position of the thermal camera together with two exemplary measuring pixels are plotted in Fig. $2.4 \mathrm{~b}$ for the substrate. The covered arc length by the two selected pixels are shown by $P_{1}$ (red) and $P_{2}$ (green) which correspond to the actual size of the pixels on the object. The actual pixel length $P_{1}$ was closer to the nip point and covered larger area of the substrate than $P_{2}$ which was located further from the nip point. The arc length for each pixel $i$ was calculated by the following expression:

$$
P_{i}=R_{s}\left(\theta_{i}-\theta_{i-1}\right)
$$

where $R_{s}$ was the substrate radius, $\theta_{i}$ and $\theta_{i-1}$ were the current and previous pixel angle in radians $\left(\theta_{i=0}=0\right.$ radians). In order to calculate $\theta_{i}$, the corresponding length of the line segment $\left(y_{i}\right)$ seen in Fig. $2.4 \mathrm{~b}$ was calculated as:

$$
y_{i}=2 R_{s} \sin \left(\theta_{i} / 2\right)
$$

The length of the line segment $y_{i}$ was represented also based on the size of the measuring pixel $(I F O V)$ and the rotation angle of the camera with respect to the $Z$-axis $\alpha_{c}$ as:

$$
y_{i}=\frac{i \times I F O V}{\sin \left(\theta_{i} / 2+\alpha\right)}
$$

By combining Eq. 2.2 and Eq. 2.3, the following expression can be derived for $\theta_{i}$ :

$$
\sin (\theta / 2) \sin \left(\theta_{i} / 2+\alpha\right)=\frac{i \times I F O V}{2 R_{s}}
$$

The calculated nonlinear pixel size variation for $\alpha=10^{\circ}$ is depicted in Fig. 2.4c for the current experimental setup.

Finally, the pressure-sensitive films were used to estimate the roller deformation and the resulting increase in the consolidation pressure and length for different substrate thicknesses. 


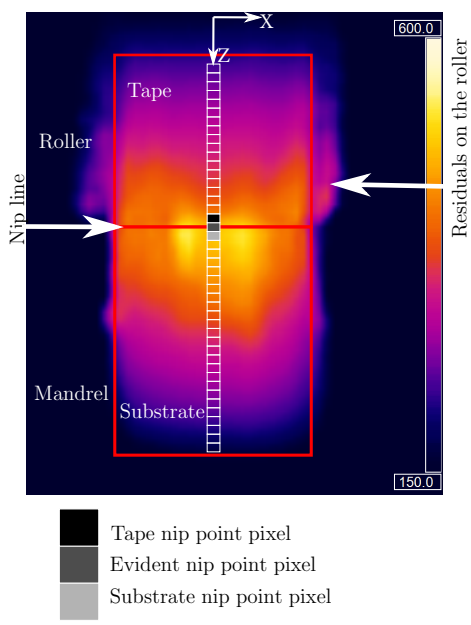

(a)

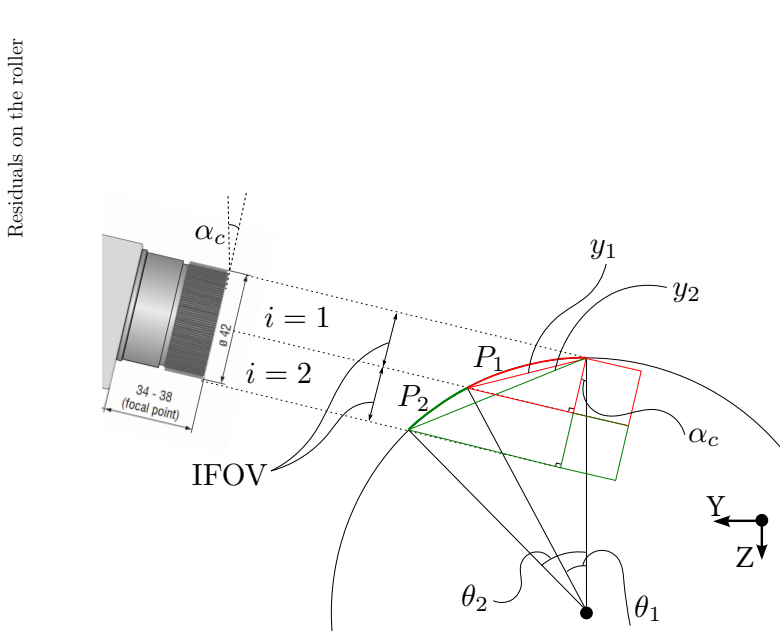

(b)

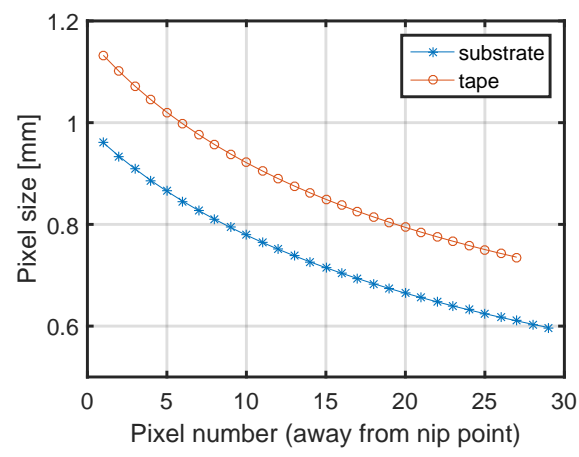

(c)

Figure 2.4 (a) Thermographic image captured by IR thermal camera. White boxes are the schematic measuring areas where the temperature is averaged with 3 pixels in width $(x)$ and 1 pixel in winding (y) directions. (b) A schematic view of the pixels with respect to the camera position and the actual size of the pixel due to curved geometry. (c) The actual pixel size distribution on the tape and substrate surface. 


\subsection{Thermal-optical model}

\subsubsection{Optical model}

The anisotropic reflection behavior of the fiber-reinforced composites tapes can be modeled either $i$ ) by physically modeling the microstructure of surface defined by microhalf cylinders and applying a specular ray tracing approach as done in [24, 25] by using the non-sequential ray tracing software (OptiCAD 10), or ii) by defining a special function or material model that takes the fiber orientation into account and using it within the ray tracing approach as done in [26]. The first approach takes relatively long computation time, however relatively high accuracy can be obtained for the reflection behavior. On the other hand, the second approach is relatively fast, however, it requires input parameters to define the reflection behavior. The work carried out by Reichardt et al. [26] was the basis of the current 3D optical model since it was computationally fast. The anisotropic reflection behavior of the laser rays reflection and varying beam incident angle due to the cylindrical curvature was considered on the optical model.

A total of 4000 laser rays were defined at the location of the laser source using the Sobol sampling [68]. The ray incident location was then calculated based on the ray tracing technique considering the tape, substrate, and roller triangulated geometries. Then, the anisotropic reflection and absorption at the material surface were calculated. The reflected light was modeled by generating new rays considering the bidirectional reflectance distribution function (BRDF) which is based on microfacet theory [69]. Two consecutive reflections were considered using the BRDF in the present paper. The details of the optical model and its implementation can be found in [26]. The output of the optical model was a 2D surface heat flux distribution $q_{i}^{\prime \prime}$ (laser power per unit area) with a mesh size of $1 \mathrm{~mm}$ in width and winding directions. The obtained heat flux from the optical model was used as an input boundary condition in the thermal model.

The roller deformation was considered in this study as a geometrical effect. The roller deformation was modeled by introducing the indentation parameter $I$ in the $3 \mathrm{D}$ optical model as seen in Fig. 2.3. The local geometry change at the nip point vicinity affects the laser heat flux distribution calculated by the 3D optical model, e.g. the shadow area formed by the roller on the substrate reduces as the roller deformation increases. The direction of the indentation was in the $Z$-direction. The location of the nip point, therefore, changed both in $Z$ - and $Y$-direction. Note that the location of the laser spot was also changed since the laser had moved simultaneously with the roller as seen in Fig. 2.2. The resulting consolidation length (i.e. the arc length denoted as $C$ in Fig. 2.3 of the interface between the roller and substrate was estimated based on the geometrical configuration and $I$ by using the following equation:

$$
C=R_{s} \cos ^{-1}\left(\frac{R_{s}+R_{r}-I}{2 R}+\frac{R_{s}^{2}-R_{r}^{2}}{2 R_{s}\left(R_{s}+R_{r}-I\right)}\right)
$$

The initial value of $I$ was determined experimentally for layer 2, i.e. winding on a 1layer substrate. After winding of each layer it was assumed that $I$ increased with $0.15 \mathrm{~mm}$ which was the thickness of a single layer. To illustrate, the total indentation was therefore 
defined as $I+25 \times 0.15 \mathrm{~mm}$ for layer 26 .

\subsubsection{Heat transfer model}

Multiple slices of tape and substrate thermal domains were defined adjacent to each other in the width direction, i.e. $x$-direction as seen in Fig 2.5. Thus, a 2.5D thermal model was obtained in which the 3D temperature distribution was predicted while the in-plane conduction in the width direction ( $x$-direction) was neglected. Note that a local coordinate system was used specifically for the substrate. For each layer, the tape temperature was calculated before the substrate calculation. The tape nip point temperature was then forwarded to the growing substrate model. The substrate 2D cylindrical thermal domain was simplified to a Cartesian coordinate system via unfolding the cylindrical domain. The 1D tape domains in thickness $(z-)$ direction traveling in winding $(y-)$ direction were considered in each slice of the incoming tape as shown in Fig. 2.5. The $2 \mathrm{D}$ transient heat conduction problem in Cartesian $y$ - and $z$-directions is based on the following governing equation:

$$
\rho c_{p} \frac{\partial T}{\partial t}=\frac{\partial}{\partial y}\left(k_{y} \frac{\partial T}{\partial y}\right)+\frac{\partial}{\partial z}\left(k_{z} \frac{\partial T}{\partial z}\right)
$$

where $\rho$ is the density, $c_{p}$ is the specific heat capacity, $k_{y}$ and $k_{z}$ are the thermal conductivity in the winding and transverse direction, respectively. The influence of radiation terms and crystallization enthalpy were also neglected since the effects were insignificant compared to laser heat flux [61]. For the tape, the $\frac{\partial}{\partial y}\left(k_{y} \frac{\partial T}{\partial y}\right)$ term was omitted from Eq. 2.6 since the 1D tape domains neglect the in-plane thermal conductivity. Note that a local coordinate system different than the substrate was used specifically for the tape.

A schematic view of the computational domain for the substrate and tape is depicted in Fig. 2.6. It is seen that a 3D domain was obtained by considering the sliced geometry in Fig. 2.5 for the tape and substrate. The control volume-based finite difference (CV/FD) model was developed using an explicit scheme considering a Lagrangian frame to solve the governing equation. Total of $5 \mathrm{CVs}$ per layer were used in $z$-direction. A constant time step of $\Delta t=2 \mathrm{~ms}$ was chosen to have a stable solution for the explicit solver. A similar optical mesh size of $1 \mathrm{~mm}$ was used in the $x$ - and $y$-directions. Therefore, the consistency of the coupling between the optical and thermal model was maintained. To model incoming tape deposition, 4 new $\mathrm{CVs}$ were added to the substrate computational domain based on the defined $\Delta t$ and $v$. Accordingly, the applied heat flux on the substrate surface was shifted in $y$-direction to simulate the moving heat flux. As indicated in Fig. 2.6a the nip point at the next step is shown by the triangle and the tape temperature is indicated as a yellow circle. The nip point temperature was updated by averaging of the already calculated tape and the substrate temperature at the nip point.

The computational description of the tape domain is depicted in Fig. 2.6b where the tape initial temperature was equal to the $T\left(t_{1}\right)=T_{\text {surr }}$. The 1D thermal domain moved in winding $(y-)$ direction for $v \times \Delta t$ in each time step. As the 1D thermal domain traveled toward the nip point, the temperature distribution evolved at each timestamp $\left(t_{i}\right)$. 
Substrate computational domains

Tape computational domains

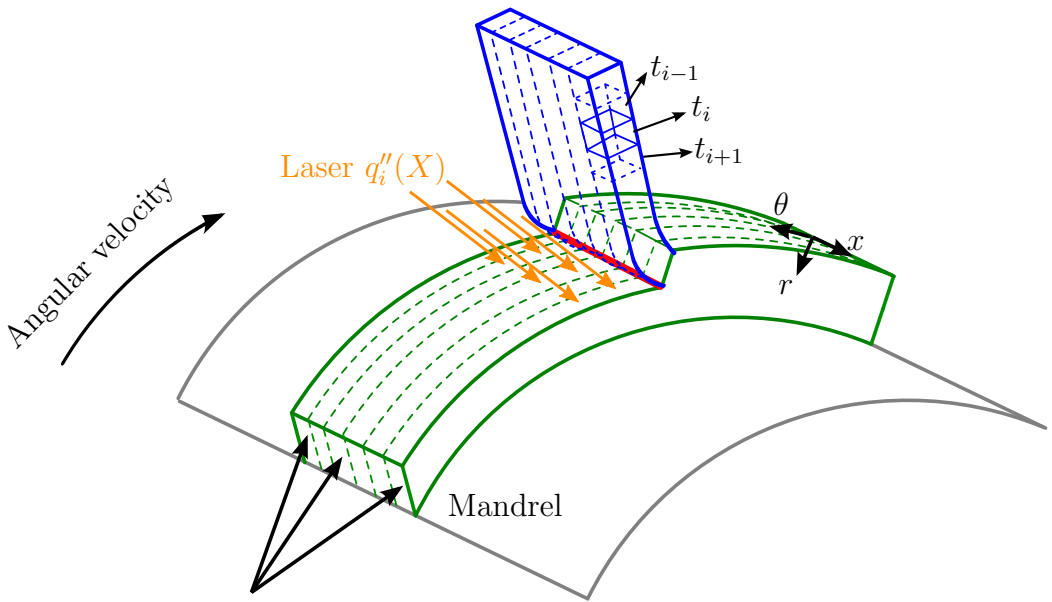

Slices of 2D thermal model

Figure 2.5 A schematic view of the 2.5D substrate and tape thermal domains.

The physical body of the roller and mandrel were not modeled, however, their effect was taken into account by defining a convective heat transfer at the tape-roller, substrateroller, and substrate-mandrel interfaces. Perfect thermal contact between the deposited layers was assumed in the thermal model since the thermal contact resistance between the layers is negligible [70]. The boundary conditions used in the thermal model are summarized in the following:

- Laser irradiation $\left(-k \nabla T=q_{i}^{\prime \prime}(x, y)\right)$ : The heat flux obtained from the optical model $\left(q_{i}^{\prime \prime}(x, y)\right)$ was applied at the tape and substrate surfaces.

- Tape-roller interface $\left(-k \nabla T=h_{t r}\left(T-T_{\text {roller }}\right)\right)$ : Convective heat transfer was defined at the tape-roller interface ( $\left.L_{\text {tape }}\right)$ using a heat transfer coefficient of $h_{t r}$ and roller temperature $T_{\text {roller }}$. The tape was always in contact with the roller at $z=t_{p}$ during heating.

- Substrate-roller interface $\left(-k \nabla T=h_{r}\left(T-T_{\text {roller }}\right)\right)$ : Convective heat transfer was defined at the substrate-roller interface using a heat transfer coefficient $h_{r}$.

- Substrate-mandrel interface $\left(-k \nabla T=h_{m}\left(T-T_{\text {mandrel }}\right)\right)$ : Convective heat transfer using a heat transfer coefficient of $h_{m}$ and mandrel temperature $T_{\text {mandrel }}$.

- Convective cooling to air $\left(-k \nabla T=h_{a}\left(T-T_{\text {surr }}\right)\right)$ : Convective heat transfer using a heat transfer coefficient of $h_{a}$ and surrounding temperature $T_{\text {surr }}$ was applied at the tape and substrate surfaces. 


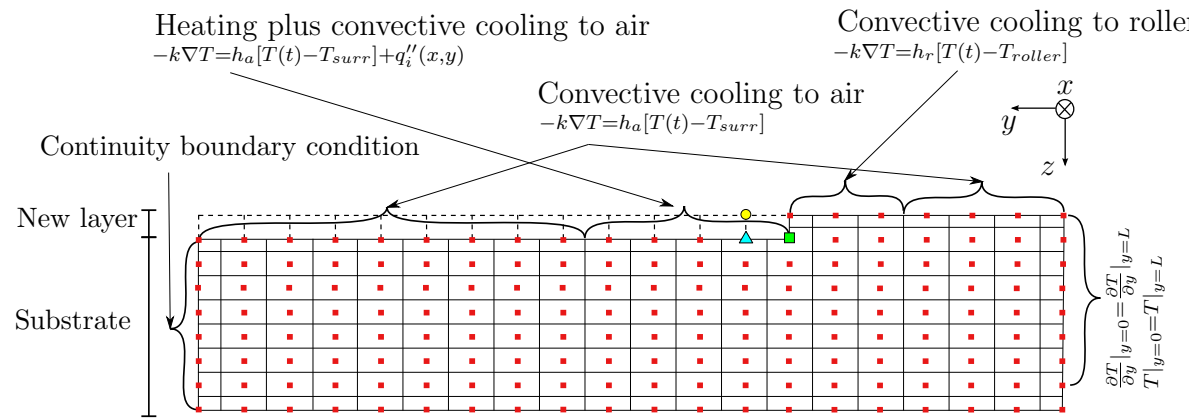

Convective cooling to roller

Heating plus convective cooling to air $\nabla T=h_{r}\left[T(t)-T_{\text {roller }}\right.$

Convective cooling to mandrel $-k \nabla T=h_{m}\left[T(t)-T_{\text {mandrel }}\right]$

$\mathrm{L}=$ Mandrel circumference

- Current nip point

- Tape temperature at next material step

$\Delta$ Nip point at the next step $=($ substrate temperature + tape temperature $) / 2$

(a)

Feeding direction

Convective cooling to the roller: $-k \nabla T=h_{t r}\left[T(t)-T_{\text {roller }}\right]$
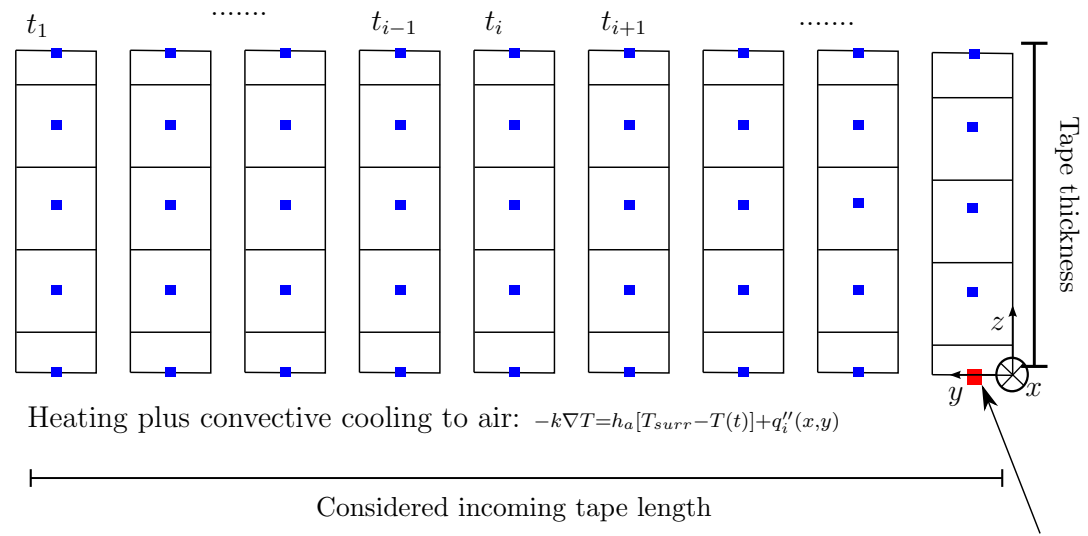

Considered incoming tape length

Nip point on the tape

(b)

Figure 2.6 Schematic view of the thermal model in winding and thickness direction for (a) the growing substrate and (b) the incoming tape together with the applied boundary conditions. 
Table 2.3 Overview of the prepreg thermal properties. 24, 61]

\begin{tabular}{ccccc}
\hline $\begin{array}{c}\text { Temperature } \\
\left({ }^{\circ} \mathrm{C}\right)\end{array}$ & $\begin{array}{c}\text { Specific heat } \\
\text { capacity } \\
\left(\mathrm{J} \mathrm{kg}^{-1}{ }^{\circ} \mathrm{C}^{-1}\right)\end{array}$ & $\begin{array}{c}\text { Density } \\
\left(\mathrm{kg} \mathrm{m}^{-3}\right)\end{array}$ & $\begin{array}{c}\text { Conductivity in } \\
\text { fiber direction } \\
\left(\mathrm{W} \mathrm{m}^{-1}{ }^{\circ} \mathrm{C}^{-1}\right)\end{array}$ & $\begin{array}{c}\text { Conductivity } \\
\text { transverse to fiber } \\
\text { direction } \\
\left(\mathrm{W} \mathrm{m}^{-1}{ }^{\circ} \mathrm{C}^{-1}\right)\end{array}$ \\
\hline 0 & 800 & 1601 & 3.5 & 0.42 \\
50 & 930 & 1598 & 4.6 & 0.52 \\
100 & 1040 & 1593 & 5.1 & 0.6 \\
150 & 1260 & 1586 & 5.9 & 0.7 \\
200 & 1300 & 1575 & 5.9 & 0.7 \\
250 & 1400 & 1563 & 6.1 & 0.7 \\
300 & 1550 & 1551 & 6.7 & 0.75 \\
350 & 1650 & 1537 & 6.8 & 0.68 \\
400 & 1700 & 1524 & 7.0 & 0.65 \\
\hline
\end{tabular}

Table 2.4 Overview of the reference values for the input parameters in the thermal simulation [61. 24. 9.627.

\begin{tabular}{cccc} 
Symbol & Value & Unit & Description \\
\hline$T_{\text {surr }}$ & 30 & ${ }^{\circ} \mathrm{C}$ & Surrounding temperature \\
$T_{\text {roller }}$ & $50[24]$ & ${ }^{\circ} \mathrm{C}$ & Incoming tape and substrate initial temperature \\
$T_{\text {mandrel }}$ & 30 & ${ }^{\circ} \mathrm{C}$ & Roller temperature \\
$h_{a}$ & $20[62]$ & $\mathrm{W} \mathrm{m}^{-2}{ }^{\circ} \mathrm{C}^{-1}$ & Mandrel temperature \\
$h_{t r}$ & $40[9]$ & $\mathrm{W} \mathrm{m}^{-2}{ }^{\circ} \mathrm{C}^{-1}$ & Tape-roller convection coefficient \\
$h_{r}$ & $1000[61]$ & $\mathrm{W} \mathrm{m}^{-2}{ }^{\circ} \mathrm{C}^{-1}$ & Substrate-roller convection coefficient \\
$h_{m}$ & 4000 & $\mathrm{~W} \mathrm{~m}^{-2}{ }^{\circ} \mathrm{C}^{-1}$ & Substrate-mandrel convection coefficient \\
\hline
\end{tabular}

- Continuity boundary condition: The temperatures and corresponding temperature gradients for the substrate surfaces at $y=0$ and $y=s u b s$ were defined as equal.

The temperature-dependent thermal properties of the C/PEEK tape were used in the thermal model which were taken from [24, 61] and listed in Table 2.3. The input parameters for the thermal model is listed in Table 2.4. The heat transfer coefficients and the corresponding temperatures were selected based on the reported values in the literature [61, 24, 9, 62]. A near-perfect contact was assumed at the substrate-mandrel interface, therefore a relatively high value for $h_{m}=4000 \mathrm{~W} \mathrm{~m}^{-2}{ }^{\circ} \mathrm{C}^{-1}$ was used. Although the roller temperature changes during the process due to laser heating, in this study $T_{\text {roller }}$ was assumed to be constant with a value of $50^{\circ} \mathrm{C}$ as used also in [24]. Besides [24], it was shown in [61] that a lower roller temperature was found to be closer to the experimental data based on the slope of the cooling curves in the consolidation region. In the present work, the total laser power was set to $400 \mathrm{~W}$ and the linear winding speed was $100 \mathrm{~mm} \mathrm{~s}^{-1}$ as taken from the experiments.

\subsection{Results and discussions}

Three composite rings were manufactured and Fig. 2.7 shows the resulting cross-section. It is seen that the top surface was slightly curved due to a non-linear distribution of the 


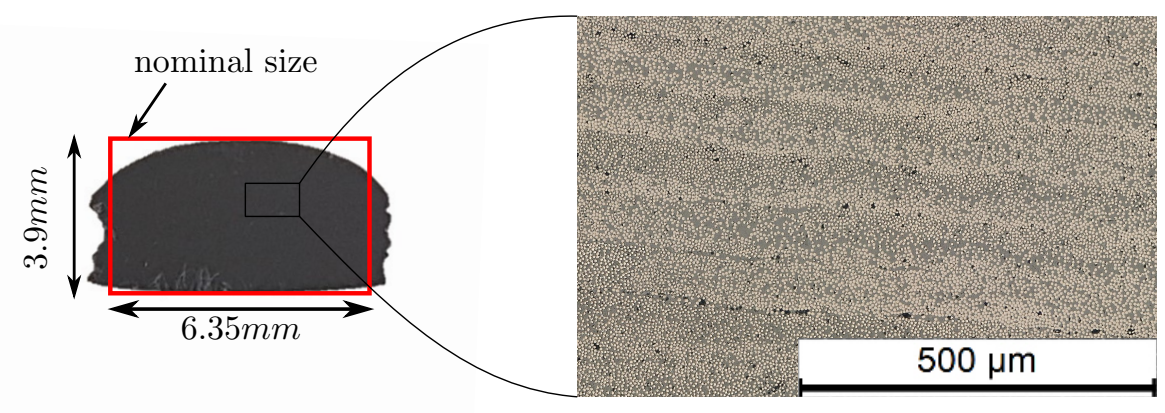

Figure 2.7 Cross-section of the produced ring.

compaction force. As the ring got thicker during winding, the edges were prone to deform by the deformable roller at relatively high temperatures. This yielded a slightly wider composite ring than the expected nominal width of $6.35 \mathrm{~mm}$. The thickness of the crosssection at the center was found to be the same as the expected nominal thickness which was $26 \times 0.15 \mathrm{~mm}=3.9 \mathrm{~mm}$. However, the thickness at the edges was found to be approximately $2.9 \mathrm{~mm}$. Although the curved substrate surface might affect the absorbed laser heat flux across the width, the change in the substrate geometry was not taken into account in the process simulations. Based on the micrograph of the ring cross section as seen in Fig. 2.7, there was no void or porosity observed in between the wound layers. The measured tape and substrate temperatures are presented in the following.

\subsubsection{Temperature measurements}

The surface temperature of the substrate and tape was measured continuously by the thermal camera as indicated in Fig. 2.4a To illustrate, the measured temperature as a function of time is shown in Fig. 2.8 for the continuous winding of layers 22 to 26 . Note that the substrate and tape temperatures are plotted for the 5th pixel away from the nip point at the width mid-plane. It took approximately $7.7 \mathrm{~s}$ to wind one layer as shown in Fig. 2.8. There was an increase of approximately $25^{\circ} \mathrm{C}$ for the tape temperature while winding layers 22 to 26 . On the other hand, a larger increase in substrate and visible nip point temperatures were observed which were approximately $100{ }^{\circ} \mathrm{C}$ and $55{ }^{\circ} \mathrm{C}$, respectively. The overall increase in the temperature was mainly due to the continuous heating of the system during multiple windings. As expected, the increase in nip point temperature was in between the increase in substrate and tape temperatures. The temperature during the winding of the first layer of the five consecutive layers (e.g. layer 22 in Fig. 2.8 was found to vary because the winding was started after waiting the system got cooled to room temperature. After winding the other layers (e.g. layers 23-26), the substrate, tape and nip point temperature were found to vary less as compared with the first layer (e.g. layer 22). The peaks in between the layers were related to the overlapping of the incoming tape with the already deposited substrate [55]. The trend in temperature evolution presented in Fig. 2.8 was the same as in winding of layers 2-6, 


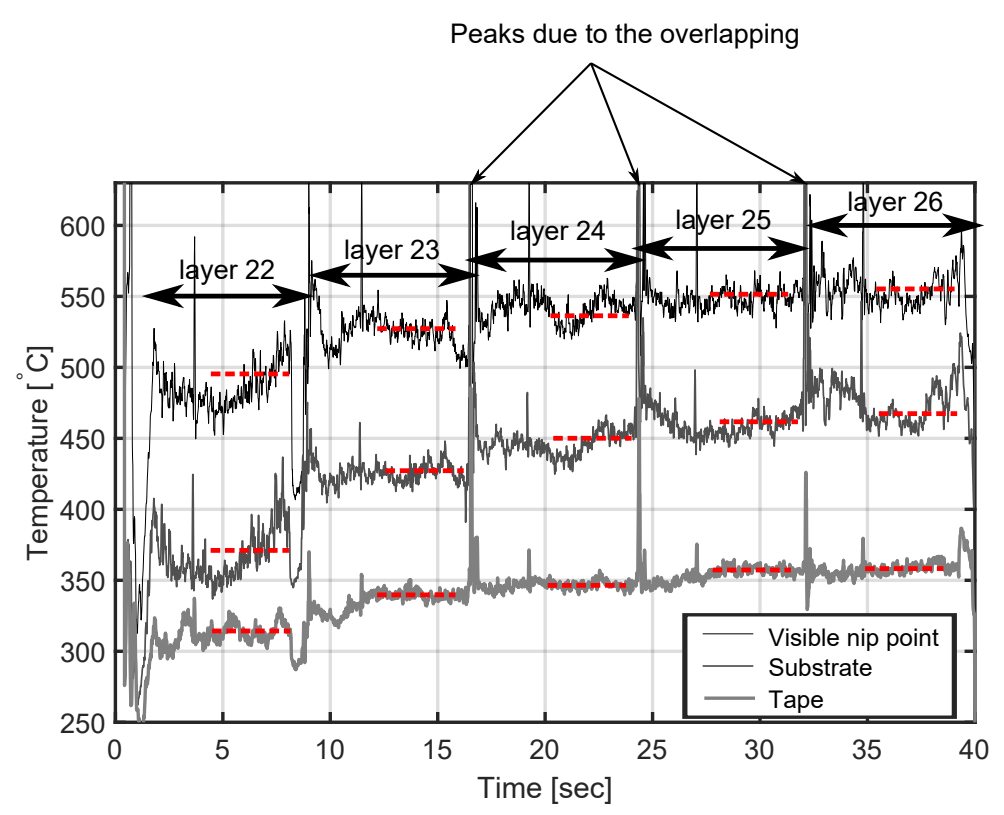

Figure 2.8 Thermal camera measurement during continuous winding of layers 22 to 26 for the visible nip point and at the 5th pixel away from the nip point on the tape and substrate surfaces. The 5th pixel roughly located at $4 \mathrm{~mm}$ and $2.2 \mathrm{~mm}$ away from the nip point for the substrate and tape, respectively. The dashed lines show the value and the duration where the temperature was averaged for the corresponding layer.

\section{7-11, 12-16 and 17-21.}

In order to evaluate the substrate and tape temperature distribution per layer, the measured temperature during winding of each layer was averaged with respect to time. To illustrate, the temperature evolution was averaged at horizontal dashed lines indicated in Fig. 2.8 for layer 22 to 26 and this procedure was applied to all other layers for three winding experiments. The time-averaged temperature distributions on the substrate and tape are depicted in Fig. 2.9a for layers 6, 11 and 26 to demonstrate the temperature distribution trend based on the pixel distribution presented in Fig. 2.4 in the $y$-direction. It is seen that the tape temperature increased rapidly near nip point which could be due to the IR rays reflected by the tape surface. In other words, the thermal camera receives both the IR rays emitted by the relatively cold tape surface and the reflected IR rays emitted from the relatively hot substrate surface close to the nip point [32]. In addition, it was also found in Fig. 2.9a that the location of the visible nip point became closer to the tape side as the substrate got thicker. This was due to the fact that the position of the roller center was fixed by the AFP machine as the substrate radius became larger. This mechanism is explained schematically in Fig. $2.9 \mathrm{~b}$ from the thermal camera point of view. The initial roller indentation was measured approximately as $2 \mathrm{~mm}$ for a 1-layer thick substrate. It became larger as the new layers wound on top of the already placed layers which locally changed the visible nip point location. Therefore, the change in the visible nip point location has to be taken into account for a reliable analysis of the nip point temperature 


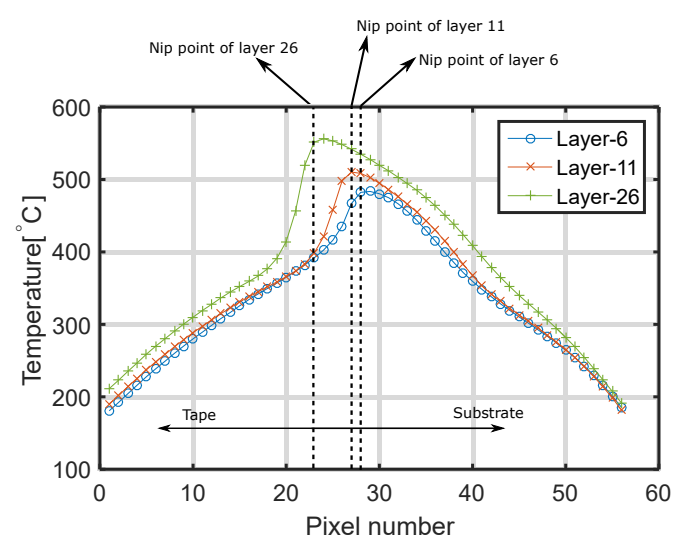

(a)

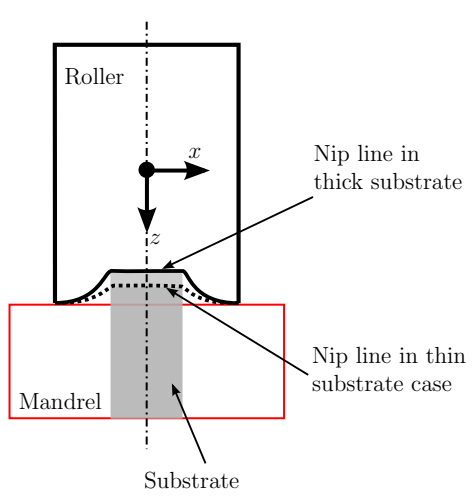

(b)

Figure 2.9 (a) Pixel based temperature distribution in the winding (y-) direction. (b) A schematic view showing the movement of the nip point location as the substrate thickness grew from a $x-z$ view.

by using the thermal camera. Another consequence of the increase in substrate thickness was the change in the consolidation area and the applied pressure on the substrate. The applied consolidation pressure was qualitatively obtained by using the pressure-sensitive films as shown in Fig. 2.10a for the layers 6, 11, 16, 21, and 26. It is seen that the darker images were observed as the layer number increased and hence the applied force on the substrate increased as well, although, the compaction force was maintained constant by the pneumatic system. The increase in consolidation area and change in nip point position are schematically explained in Fig. $2.10 \mathrm{~b}$. The consolidation area increased from $16.8 \mathrm{~mm}$ for layer 6 to $24.4 \mathrm{~mm}$ for layer 26 .

The time-averaged visible, substrate, and tape nip point temperature evolution are depicted in Fig. 2.11 for consecutive winding of layers 2-6, 7-11, 12-16, 17-21 and 22-26. The tape and substrate nip point temperatures were extracted from the 1st pixel away from the nip point as shown in Fig. 2.4a The error bars indicate the standard deviation of the temperature values obtained during winding of three rings and the center of the error bars shows the corresponding mean temperature. It is seen that the timeaveraged substrate nip point temperature of the first layers, i.e. layer 2, 7, 12, 17 and 22, reduced due to an increase in substrate thickness. On the other hand, these temperatures for the tape were almost the same because the thickness of the incoming tape remained the same. It is seen that as the substrate got thicker, the overall visible, tape, and substrate nip points temperatures increased. The increase in temperature during consecutive winding of 5 layers became larger as the layer number increased. For instance, the substrate temperature increase was found to be approximately $98{ }^{\circ} \mathrm{C}$ during winding of layers $22-26$, whereas it was approximately $42{ }^{\circ} \mathrm{C}$ for layers $7-11$. This was due to the less heat loss to the mandrel as the substrate got thicker which resulted in a larger through-thickness thermal resistance. The increase in tape temperature during consecutive winding of 5 layers was found to be in the range of $40-50{ }^{\circ} \mathrm{C}$. This variation 


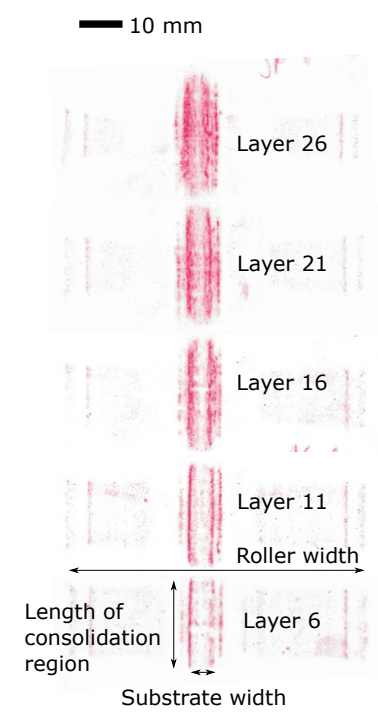

(a)

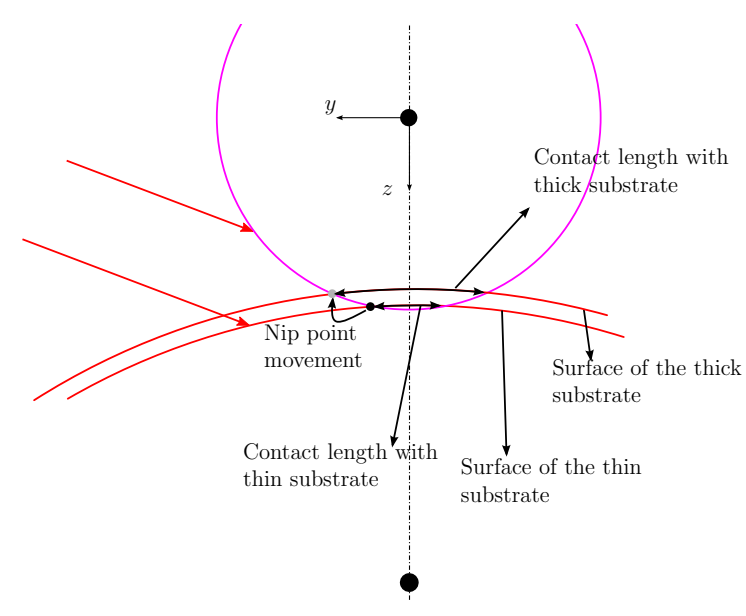

(b)

Figure 2.10 (a) The consolidation pressure distribution measured by pressure sensitive films placed between the compaction roller and substrate. (b) A schematic view to show the change in the consolidation region length of the thin and thick substrate and the nip point location from $y-z$ view.

was less than the variation in substrate temperature since the incoming tape thickness was constant during winding. The maximum and minimum variation in substrate and tape temperatures among the three winding experiments was found to be $80{ }^{\circ} \mathrm{C}$ for layer22 and $10{ }^{\circ} \mathrm{C}$ for layer-7, respectively. The possible reasons for the variations in the temperature measurements within three rings production could be related to the local variation in material properties of the prepreg [39], local deconsolidation in the heated region and varying emissivity coefficient as a function of temperature [32] which was constant in the current configuration of the thermal camera.

\subsubsection{Process model predictions}

\section{Heat flux and temperature}

The predicted distribution of the absorbed heat flux using the 3D optical model is shown in Figs. 2.12a and $2.12 \mathrm{~b}$ for winding of layer-2 $(I=2 \mathrm{~mm})$ in order to illustrate the typical output of the optical simulation. The utilized mesh size of $2 \mathrm{~mm}$ and the total number of rays $N_{0}=4000$ were found to have a sufficient accuracy as compared with the finer mesh size of $0.5 \mathrm{~mm}$ and $N_{0}=40000$ as also seen in Fig. 2.12c and 2.12d It is seen that the length of the heated regions was $21 \mathrm{~mm}$ and $24 \mathrm{~mm}$ for the substrate and tape, respectively. Higher heat flux was predicted for the substrate than the tape due to a more perpendicular incident angle of laser rays at the direct hit which resulted in 


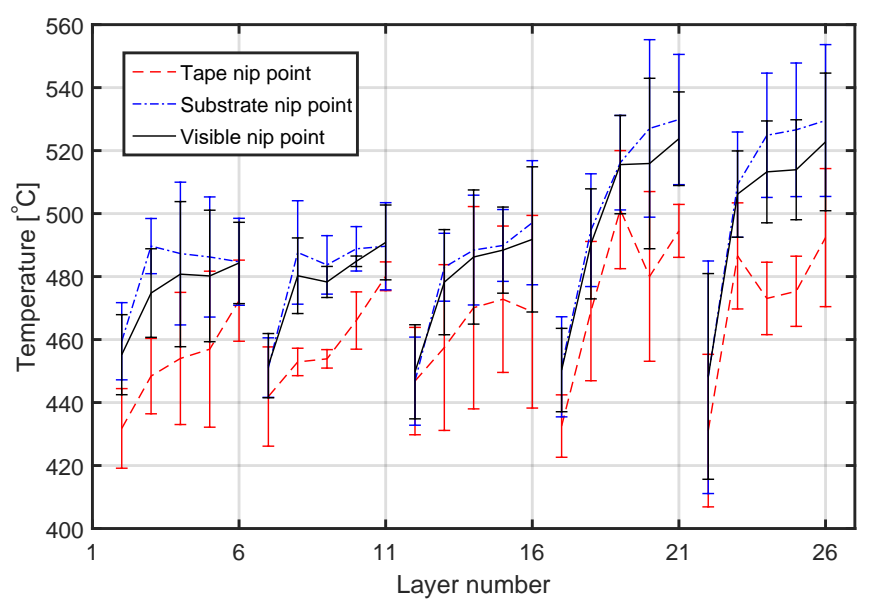

Figure 2.11 The nip point temperature evolution during consecutive ring winding. The measured tape and substrate nip point temperatures are belonging to 1st pixel away from the visible nip point. Refer to Fig. 2.9a for pixel based temperature distribution and the location of the visible nip point for selected layers.

larger ray energy absorption according to Fresnel law [26]. The magnitude of heat flux reduced near the nip point region both for substrate and tape because the incident angle of the direct hit decreased as depicted in Fig. 2.3. The corresponding normalized heat flux distributions at the centerline of substrate and tape along the winding direction are shown in Figs. 2.12c and 2.12d. The normalization was done based on the power intensity of the laser source which was $1.3 \mathrm{~W} \mathrm{~mm}^{-2}$. The total energy absorbed by the substrate surface consisted of the direct hit from the laser source and the rays from the first and second reflection as shown in Fig. 2.3. It is seen from Figs. 2.12c and $2.12 \mathrm{~d}$ that the direct hit for substrate and tape contained approximately the $80 \%$ of the total heat flux. The first reflection covered a $15 \mathrm{~mm}$ length from the nip point for substrate and tape with approximately $28 \%$ of the total heat flux. On the other hand, the second reflection had approximately $2 \%$ of the total heat flux.

The corresponding temperature distribution for the substrate and tape obtained from the thermal model are shown in Fig. 2.13a and 2.13b for the current default mesh (mesh size of $1 \mathrm{~mm}$ and $N_{0}=4000$ ) and the finer mesh (mesh size of $0.5 \mathrm{~mm}$ and $N_{0}=40000$ ). It is seen that the results obtained from the default mesh and the finer mesh yielded a very close temperature distribution. The resulting temperature distribution was not uniform in the width direction, i.e. in the $x$-direction, due to anisotropic reflections. The tape temperature prior to the nip point was found to be lower than the substrate temperature due to a lower heat flux distribution for the tape, see Figs. $2.12 \mathrm{c}$ and $2.12 \mathrm{~d}$. This observation was also the case in the measured temperature distribution depicted in Fig. 2.11

The temperature predictions were made for all the layers from 2 to 26 using the opticalthermal model in which the roller indentation was increasing linearly from $2 \mathrm{~mm}$ to $5.75 \mathrm{~mm}$ to be compared with the experimental data. The corresponding results are 


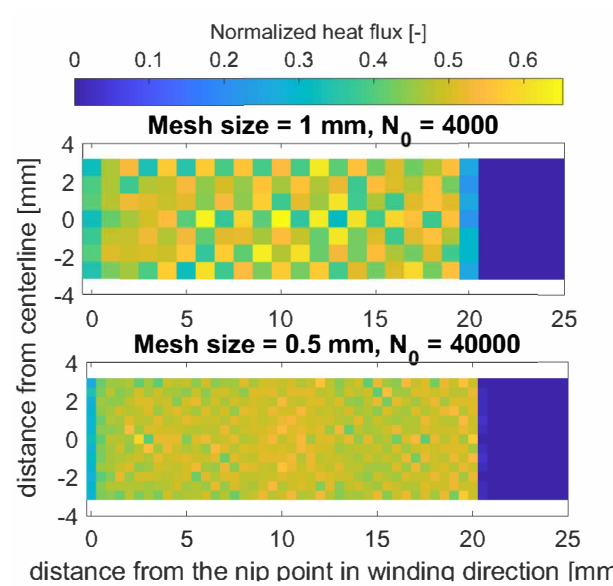

(a)

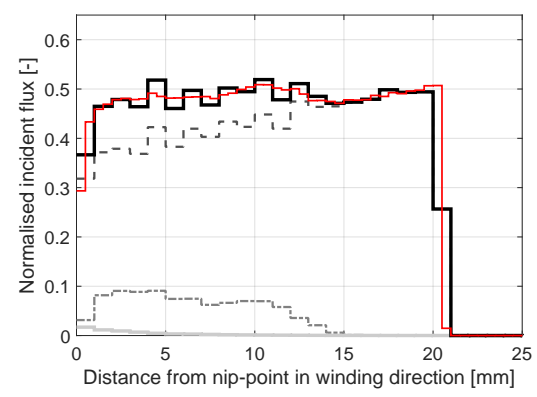

(c)

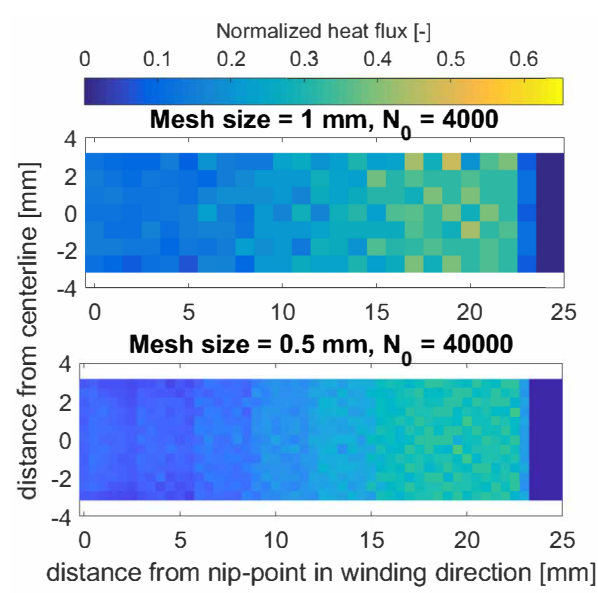

(b)

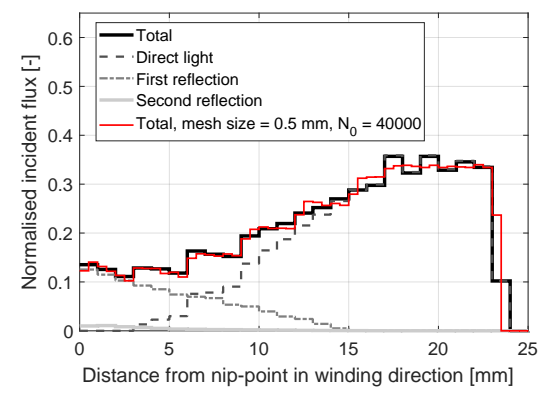

(d)

Figure 2.12 Normalized incident flux considering the anisotropic reflection of the (a) substrate and (b) tape surface with $I=2 \mathrm{~mm}$. The averaged heat flux values along the width as a function of distance to the nip point for the (c) substrate and (d) tape considering individual energies absorbed in each reflection.

presented in Figs. 2.14a and 2.14b for the substrate and tape nip points. The predictions confirm the experimental observation that the increase in substrate temperature was found to be larger during winding on thicker substrates. For instance, the predicted substrate temperature increase was $89{ }^{\circ} \mathrm{C}$ and $26^{\circ} \mathrm{C}$ during winding of layers 22-26 and layers 7-11, respectively. In general, the developed process model captured the measured temperature evolution trend quite well for the substrate with overprediction up to $51{ }^{\circ} \mathrm{C}$ as the ring got thicker. According to Fig. 2.14b the increase in tape temperature during consecutive winding was found to lower than the increase in substrate temperature as also observed by the measurements. The predicted tape temperature increase was $5{ }^{\circ} \mathrm{C}$ during winding of layers 7-11 and it was almost constant during winding of layers 22-26. A larger mismatch in the measured and predicted nip point temperature was found for the tape with a range of $38-98{ }^{\circ} \mathrm{C}$. The measured and predicted centerline temperature profiles 


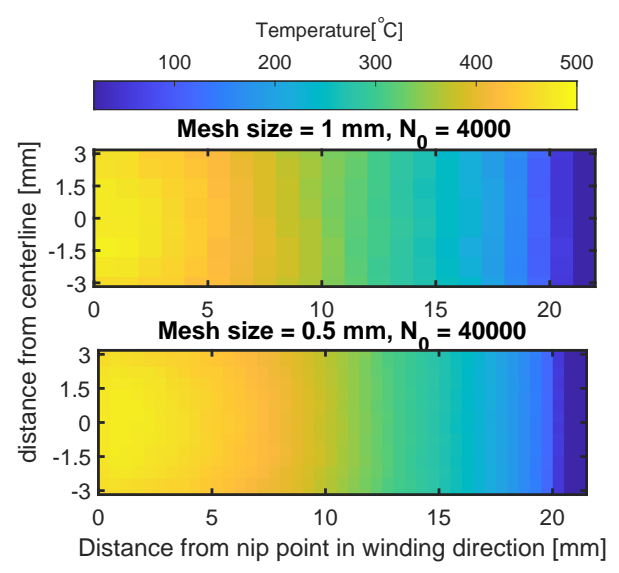

(a)

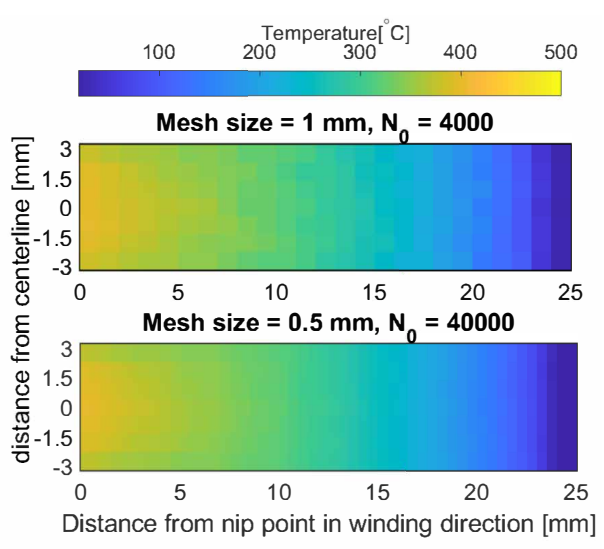

(b)

Figure 2.13 The predicted temperature distribution on the (a) substrate and $(b)$ tape surface at the heating region during winding of the second layer.

along the winding direction is given in $2.14 \mathrm{c}$ during winding of layer 6 . It is seen that the predicted substrate temperature distribution agreed well with the measurement. On the other hand, the predicted tape distribution was lower than the measured one near the nip point. This could be due to the employment of relatively simple roller geometry and deformation which was more complex in reality, i.e. the deformation is non-circular. Besides, the utilized tape-roller convection coefficient value could also play a role for the obtained mismatch in the predicted and measured tape temperature near the nip point. In addition, a constant roller temperature $T_{\text {roller }}=50{ }^{\circ} \mathrm{C}[24]$ was used in the thermal model, however it can increase up to $300^{\circ} \mathrm{C}$ [61]. This would affect the heat transfer at the tape-roller interface significantly though the averaged nip point temperature would not be affected significantly according to [61]. To illustrate this, the process simulations were conducted with $T_{\text {roller }}=300{ }^{\circ} \mathrm{C}$ and the results are depicted in Figs. 2.14a and $2.14 \mathrm{~b}$ for the nip point temperature of the substrate and tape for each layer, respectively. It is seen that the overall tape temperature at the nip point increased approximately $17^{\circ} \mathrm{C}$ as compared to the case with $T_{\text {roller }}=50{ }^{\circ} \mathrm{C}$. A maximum of $20^{\circ} \mathrm{C}$ difference was obtained for the substrate temperature during winding of layer 26 with varying roller indentation. The temperature difference was negligible during winding of layers 2-11. This indicated that the effect of roller temperature on the substrate nip point temperature was more dominant for larger roller indentation values.

\section{Effect of roller indention}

The influence of the roller deformation on the temperature evolution was investigated using the proposed optical-thermal model. Three constant roller indentation values $I=0$, 2 and $4.5 \mathrm{~mm}$ were considered in the parameter analysis. To illustrate the predicted temperature distribution, the results from winding of layer-7 on a 6-layers thick substrate 


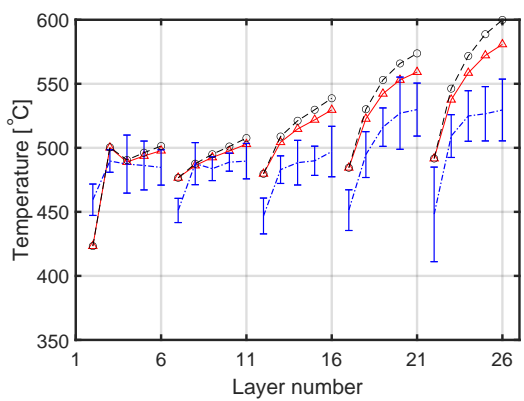

(a)

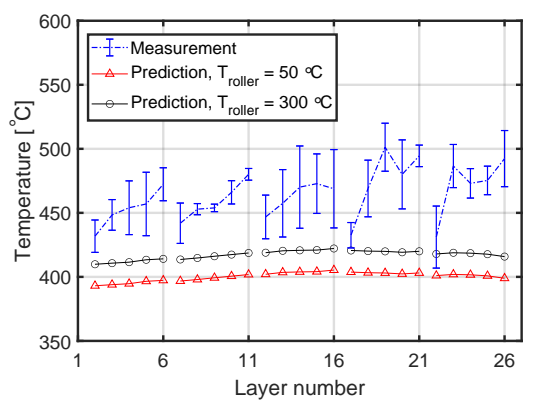

(b)

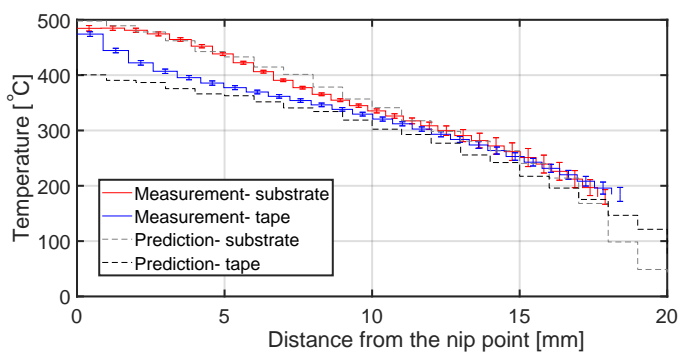

(c)

Figure 2.14 Predicted and measured nip point temperatures for the (a) substrate and (b) tape. (c) Predicted and measured temperature distributions in the winding direction along the centerline of the substrate and tape during winding the 6th layer.

are depicted in Figs. 2.15a and 2.15b for the substrate and tape surface, respectively. A schematic description of roller indention is plotted in Fig. 2.16 where the substrate is stationary and the roller together with the laser source moved toward the substrate. This modeling approach is basically the same as the case of growing substrate with stationary roller and laser source (refer to Fig. 2.10b). The nip point temperature increased approximately by $167^{\circ} \mathrm{C}(51 \%)$ for the substrate, i.e. from $325^{\circ} \mathrm{C}$ to $492^{\circ} \mathrm{C}$, and by $35^{\circ} \mathrm{C}$ (9\%) for the tape, i.e. from $367^{\circ} \mathrm{C}$ to $402^{\circ} \mathrm{C}$, by increasing $I$ from $0 \mathrm{~mm}$ to $4.5 \mathrm{~mm}$. It is seen that the shadow area where the temperature drops close to the nip point diminished for $I=2 \mathrm{~mm}$ and $4.5 \mathrm{~mm}$ both for tape and substrate. Therefore, roller indentation resulted in a shift in the nip point location which was approximately $15 \mathrm{~mm}$ and $16 \mathrm{~mm}$ by increasing $I$ from $0 \mathrm{~mm}$ to $4.5 \mathrm{~mm}$ for substrate and tape, respectively. In addition, the roller indentation affected also the total consolidation length as mentioned in Fig. 2.10a The contact length of the consolidation region for $I=2 \mathrm{~mm}$ and $4.5 \mathrm{~mm}$ was $21 \mathrm{~mm}$ and $31 \mathrm{~mm}$, respectively. An increase of $7 \mathrm{~mm}$ in the substrate heating region was obtained as $I$ was increased from $0 \mathrm{~mm}$ to $4.5 \mathrm{~mm}$. This was due to the movement of the laser source which was connected to the roller center via the tape laying head as schematically depicted in Fig. 2.16. Considering both the nip point and laser movement effects the heating length reduced from 27 to $19 \mathrm{~mm}$ on the substrate and from 33 to $17 \mathrm{~mm}$ on the 


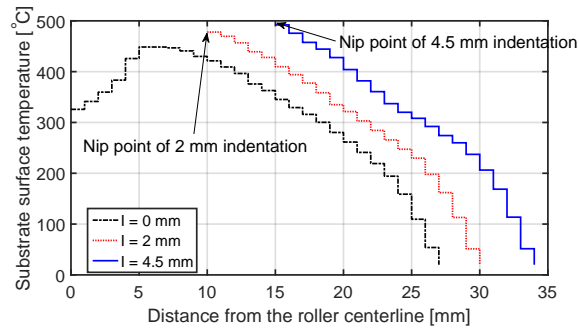

(a)

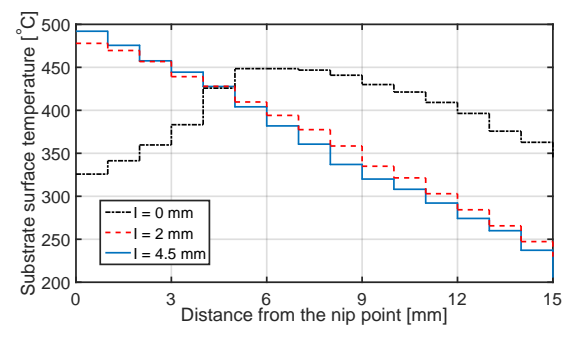

(c)

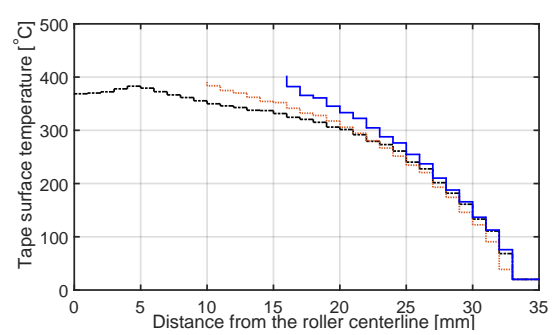

(b)

Figure 2.15 Predicted temperature distribution on the surface in the winding direction at the width mid-plane during winding of layer 7 from the roller centerline for the (a) substrate and (b) tape. (c) The substrate temperature distribution from the actual nip point.

tape surfaces by increasing $I$ from 0 to $4.5 \mathrm{~mm}$. Although the heated lengths of tape and substrate decreased as the roller deformation increased, the laser incident angles near the nip point became more perpendicular to the tape and substrate surfaces which resulted in larger temperatures.

The substrate temperature distribution shown in 2.15a is re-plotted in Fig. 2.15c by locating the nip point at $y=0 \mathrm{~mm}$. The temperature at the nip point was lower for lower indention values as explained earlier, however, after approximately $5 \mathrm{~mm}$, lower indentation values resulted in higher temperatures since the heating length before this point was larger. The mean surface temperature was approximately $427^{\circ} \mathrm{C}$ for all the roller indentation values approximately at $4-5 \mathrm{~mm}$ away from the nip point as seen in Fig. 2.15c. In other words, the mean surface temperature in the range of $4-5 \mathrm{~mm}$ from the nip point was not affected by the roller indentation and the effect of change in the input heat flux distribution was therefore negligible.

The corresponding evolution of the substrate nip point temperature during continuous winding with different roller indentation values are depicted in Fig. 2.17. It is seen that the nip point temperature increased with an increase in $I$. The increase in temperature during 5 consecutive windings was found to be highest for $I=0 \mathrm{~mm}$ because there was no heat loss at the substrate-roller interface which resulted in higher heat accumulation in the substrate. The predicted variation in substrate nip point temperature due to the change in $I$ was found to be approximately in the range of $20-30^{\circ} \mathrm{C}$. This was approximately $5^{\circ} \mathrm{C}$ 


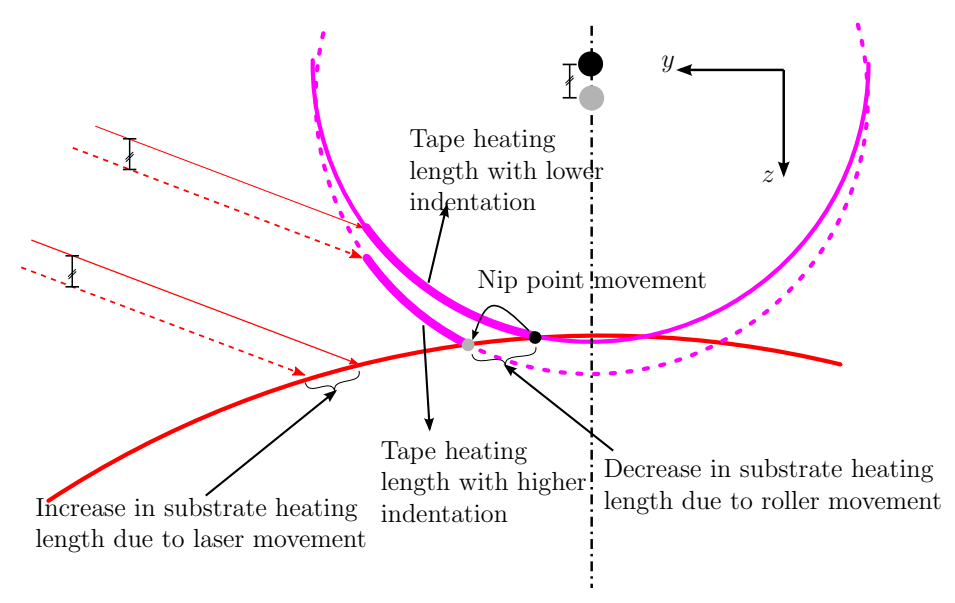

Figure 2.16 A schematic view of the change in the heating length of the tape and substrate considering the effect of roller indentation. The dashed geometry corresponds to higher value of roller indentation.

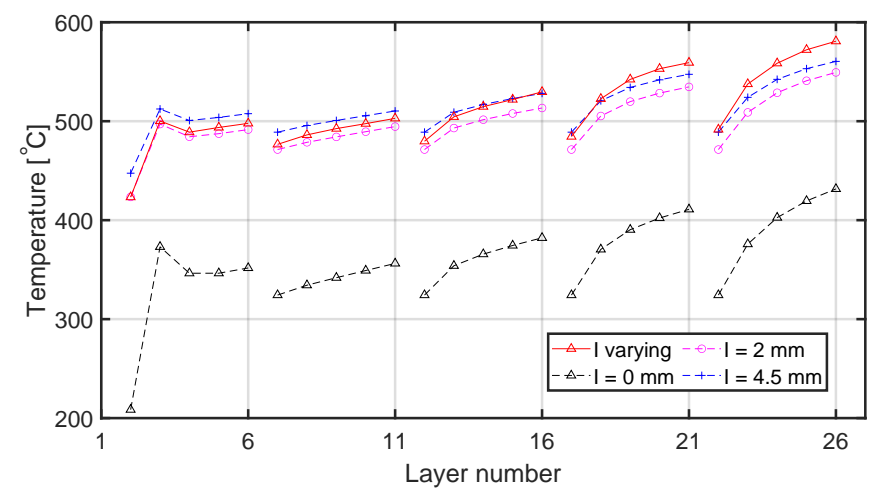

Figure 2.17 The evolution of the substrate nip point temperature for various roller indentation (I) values.

for the tape nip point temperature.

In order to interpret the effect of roller indentation on the process temperature more elaborately, the total heated length, the total absorbed power and the local absorbed power at the nip point were investigated for different indentation values as shown in Fig. 2.18 As aforementioned, the total heated length of the tape and substrate decreased, however the local absorbed heat at the nip point increased due to an increase in the incident angle of the incoming rays as well as the reduction in the shadowed region. The increase in the incident angle was larger for the substrate than the tape due to position of the laser source which was oriented more towards the substrate as seen in Fig. 2.3. As a result, the total absorbed heat slightly increased for the substrate though the total heated length decreased. On the other hand, a slight decrease in the total absorbed heat was the case for the tape 

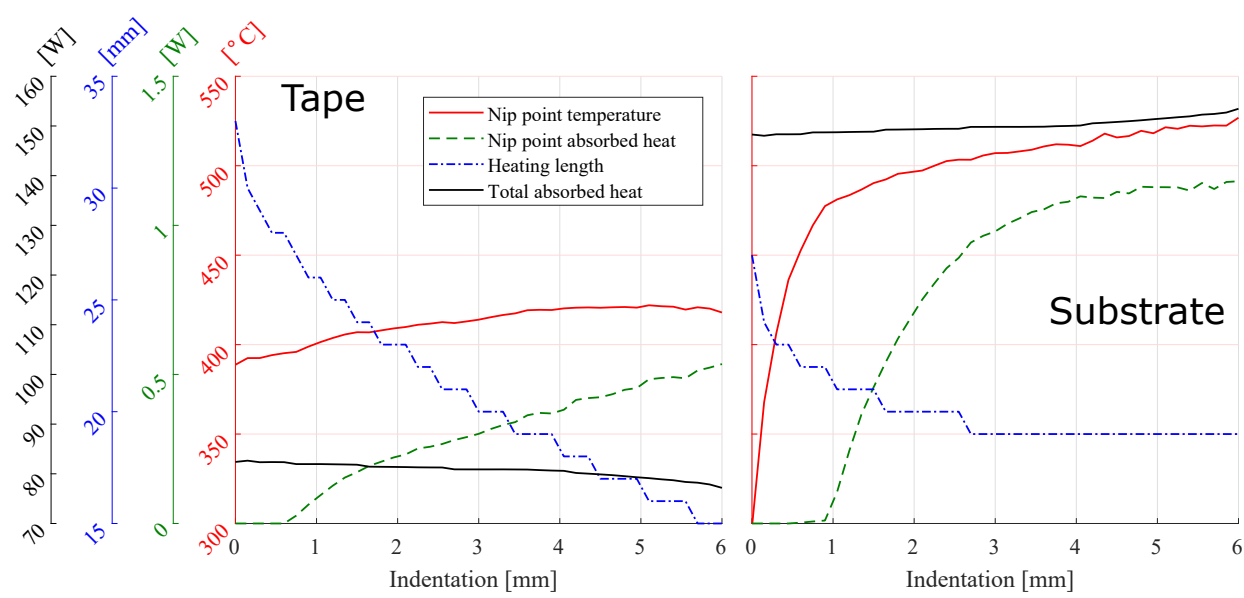

Figure 2.18 The effect of the roller indentation on the nip point temperature (averaged along the width direction), total heated length, total absorbed heat and local absorbed heat at the nip point (averaged along the width direction) for the tape (le ft) and substrate

(right).

as the roller indentation increased due to larger decrease in the total heated length. This yielded a more rapid increase in the substrate temperature than the tape temperature as the roller indented more. Note that until $1 \mathrm{~mm}$ of roller indentation, the shadowing effect was present for both tape and substrate. The step-wise decrease in the total length was due to the used mesh size in the thermal model. Finer mesh would result in a finer total length evolution as the roller indentation increases. The effect of roller indentation on the temperature variation is quantified in Table 2.5 for the substrate and tape nip point temperature during continuous windings. By the increment of $I$ from 0 to $2 \mathrm{~mm}$, a more noticeable change in temperature was predicted as compared with the increment from 2 to $4.5 \mathrm{~mm}$. For the tape nip point, the change in the temperature was constant for all the layers since the tape thickness remained constant and a steady-state temperature was the case for the tape. However, the substrate temperature variation due to the change in $I$, tended to smaller values (not necessarily the absolute value) as the substrate got thicker. For instance, by increasing the indentation from 0 to $2 \mathrm{~mm}$, the temperature increment dropped from 139.9 to $117.7{ }^{\circ} \mathrm{C}(39.6 \%$ to $27.4 \%)$ during the continuous winding of layers 6 and 26, respectively. The roller compaction length was larger with larger $I$ values, therefore, the consecutive heat loss to the roller was also higher leading to the mentioned drop in the temperature difference.

\section{Effect of substrate-roller convection coefficient $\left(h_{r}\right)$}

In section 2.4.1. it was observed that the growth in substrate thickness affected the applied force and consolidation length on the substrate substantially. This can result in a change in $h_{r}$ at the roller-substrate interface which directly influences the heat loss from the substrate to the roller. The effect of $h_{r}$ on the predicted substrate temperature 
Table 2.5 The predicted temperature difference for the selected layers as a function of roller indentation (I) change for tape and substrate nip points.

\begin{tabular}{|c|cc|cc|}
\hline \multirow{3}{*}{ Layer number } & \multicolumn{4}{|c|}{ Measuring area } \\
\cline { 2 - 5 } & Tape nip point & \multicolumn{4}{|c|}{ Substrate nip point } \\
\cline { 2 - 5 } & $0 \rightarrow 2$ & $2 \rightarrow 4.5$ & $0 \rightarrow 2$ & $2 \rightarrow 4.5$ \\
\hline 6 & & & $139.9^{\circ} \mathrm{C}$ & $16.1^{\circ} \mathrm{C}$ \\
11 & & & $138.3^{\circ} \mathrm{C}$ & $15.8^{\circ} \mathrm{C}$ \\
16 & $26^{\circ} \mathrm{C}$ & $9^{\circ} \mathrm{C}$ & $131.2^{\circ} \mathrm{C}$ & $14.8^{\circ} \mathrm{C}$ \\
21 & & & $123.7^{\circ} \mathrm{C}$ & $12.7^{\circ} \mathrm{C}$ \\
26 & & & $117.7^{\circ} \mathrm{C}$ & $11.1^{\circ} \mathrm{C}$ \\
\hline
\end{tabular}

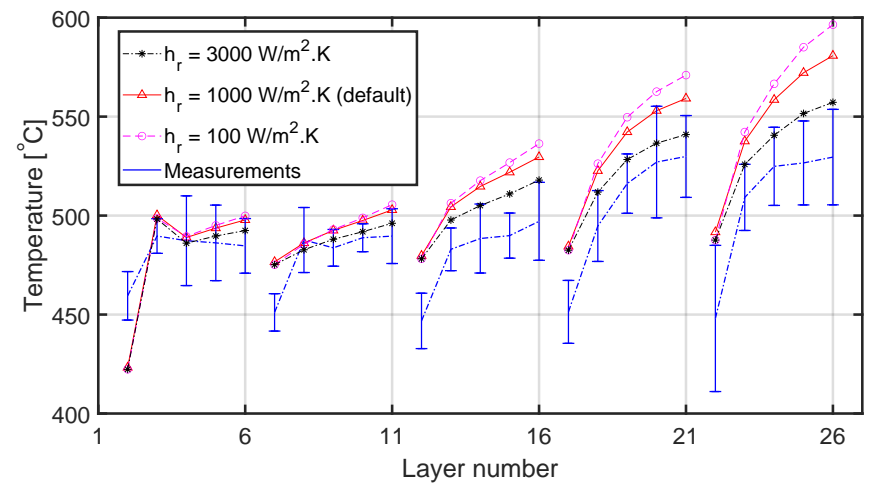

Figure 2.19 Measured and predicted substrate nip point temperatures with different substrate-roller convection coefficient $\left(h_{r}\right)$ during continuous winding.

for each layer during continuous winding is shown in Fig. 2.19 The effect of $h_{r}$ on the temperature variation was found to be more dominant for the thicker substrates as compared with thinner substrates since the major heat loss for thinner substrates took place at the substrate-mandrel interface instead of the substrate-roller interface. For instance, the substrate nip point temperature difference for layers 21 and 26 were $47^{\circ} \mathrm{C}$ $(9.5 \%)$ and $31^{\circ} \mathrm{C}(5.7 \%)$ considering $h_{r}=100 \mathrm{~W} \mathrm{~m}^{-2}{ }^{\circ} \mathrm{C}^{-1}$ and $h_{r}=3000 \mathrm{~W} \mathrm{~m}^{-2}{ }^{\circ} \mathrm{C}^{-1}$. The measured temperature evolutions agreed better with the predictions with higher $h_{r}$ as the substrate got thicker. This confirms the increase in consolidation pressure for thicker substrates observed by the pressure-sensitive films in Fig 2.10a Higher consolidation pressure indicates a lower thermal contact resistance at the roller-substrate interface which results in higher $h_{r}$ values.

\subsection{Conclusion}

The evolution of the temperature distribution during consecutive winding of multiple C/PEEK prepreg layers was investigated experimentally and numerically. Relatively thick C/PEEK rings with 26 layers were manufactured using the LATW process with 
inline temperature measurements using a thermal camera. A coupled optical-thermal model was used to predict the laser irradiation and reflections, heat flux distributions and resulting temperature distributions on the incoming tape and substrate surfaces. The anisotropic reflections of the incoming laser light were considered in the optical model. The process model was first validated and verified by comparing the measured surface temperature with numerical predictions. The trends of the predicted tape and substrate temperatures were found to agree well with the measurements. The increase in substrate temperature was found to be larger during winding on thicker substrates due to the fact that the heat loss to the mandrel became smaller. The tape temperature increase during consecutive winding was found to be lower than the substrate temperature increase as a general trend. The varying roller deformation or indention had a significant effect on the surface heat flux distribution together with the total heated length and consequently on the nip point temperatures. The tape nip point temperature increased slightly with an increase in roller deformation during consecutive winding. On the other hand, a larger temperature increase was found for the substrate with an increase in roller deformation mainly due to the reduction in the shadow region and the larger increase in the incident angle of the incoming rays near the nip point. However, in the range of $4-5 \mathrm{~mm}$ from the nip point the effect of roller indentation variation on the temperature was negligible. The pressuresensitive films indicated that the consolidation pressure and the contact length between the substrate and roller increased during the winding process. The effect of the variation in the substrate-roller convection coefficient $\left(h_{r}\right)$ was found to be more dominant on the variation in substrate nip point temperature for relatively thick substrates. 


\title{
CHAPTER 3
}

\section{ADJACENT HOOP WINDING}

\begin{abstract}
The nonuniform temperature and crystallinity distributions present in carbon fiber reinforced PA12 composite pipes, produced via laser assisted tape winding (LATW), are investigated in this paper. The width of the laser source is usually larger than the substrate width which causes multiple heating and cooling of some regions of the (neighboring) substrate and hence temperature and crystallinity gradients during the adjacent hoop winding. A kinematic-optical-thermal (KOT) model coupled with a nonisothermal crystallinity model is developed to capture the transient temperature and crystallinity distributions for growing substrate thickness and width. The predicted temperature trends are validated with thermocouple and thermal camera measurements. The substrate temperature varies in the width direction up to $52 \%$. This will lead to extra polymer remelting and possible degradation. The maximum variation of the crystallinity degree across the width is found to be $270 \%$ which shows agreement with the trend of the measured crystallinity degree. It is found that a more realistic description of the melting behavior of the matrix is needed to obtain a more accurate prediction of the crystallinity distribution.
\end{abstract}




\subsection{Introduction}

There is a growing need for several kilometers long continuous pipes for offshore oil and gas applications such as risers, used to convey hydrocarbons from unexploited reserves to the main land. Since the structure should be self-supporting, the heavy weight is a challenge in terms of mechanical performance [71]. Continuous fiber-reinforced polymer (FRP) composites are a suitable alternative for traditional metals due to the high specific strength, corrosion-, and fatigue resistance [72, 73, 74]. Moreover, thermoplastic composites avoid the post-process step for curing in an autoclave which is a barrier for manufacturing such long structures with thermoset composites.

Automated tape winding (ATW) is one of the state-of-the-art processes to manufacture thermoplastic tubular structures such as the mentioned pipes and risers [71]. These tubular composite products are built layer by layer onto a mandrel or liner in the ATW processes. The prepreg tape and the laid down substrate are locally molten by a heat source before coming into contact at the nip point which can be seen schematically in Fig. 3.1a To achieve the desired processing temperature at the nip line, it is very important to preheat the tape and substrate surfaces because the material is advected or the heat input is transported towards the bonding region with the tape feeding rate. The heat source in ATW processes can be a hot gas torch [62], infrared lamp [64, 44], or recently, near-infrared (NIR) diode lasers better known as laser-assisted tape winding (LATW) [29, 22, 75, 57, 27]. In case of the adjacent hoop winding process which is used to manufacture thermoplastic pipes as seen in Fig. 3.1b, tapes are wound adjacently with a consistent winding angle forming one layer, the following layer is manufactured with a different winding angle. This process is repeated until the desired composite layup is reached. In-situ consolidation, which is the main mechanism to form the final product, takes place at the nip point where the melted incoming tape and substrate bond due to pressure applied by a compaction roller. The consolidation process includes several highly temperature-dependent steps such as the development of intimate contact followed by the healing of the polymeric matrix, which was studied for the automated fiber placement (AFP) and laser assisted tape placement (LATP) processes in [33, 76, 77, 78, 46, 52]. The inter-molecular diffusion or healing phenomenon describes the entanglement of polymer chains from one surface to the opposite one. Therefore, for a proper healing at the interfaces the polymer needs to be melted to some extent in the depth of the tape and substrate [79]. The absorbed heat at the illuminated surfaces is mainly dissipated in the thickness direction due to the heat sink behavior of the roller and liner, therefore the melting temperature can be easily achieved in the sufficient depth of the substrate and tape for a proper consolidation. There have been several studies to evaluate the in-situ consolidation development during LATP of carbon reinforced thermoplastics [52, 32, 76, 80, 81, 47] and LATW of glass fiber/phenolic resin thermoset [78]. Also, the mechanical performance of the composite pipes was studied for various loading conditions [82, 83, 84]. The degree of crystallinity (DoC) is another temperature-dependent structural parameter which affects the mechanical performance of the crystalline FRP products [85, 86, 87, 88, 89, 90]. The desired DoC depends on the application of the manufactured thermoplastic part. For the parts with a high interlaminar fracture toughness and large plastic deformation, a low level of DoC is required. Whereas 
for the parts with high tensile modulus and strength a high DoC is desired [90, 87]. During the LATW process, multiple intensive heating and cooling cycles take place due to a localized heat input by the high-powered laser which affect the final DoC throughout the product. In the past, the nonuniform DoC distribution was predicted in the thickness direction for carbon fiber reinforced PEEK (C/PEEK) laminates manufactured by AFP process [10, 9].

It has become clear that understanding and predicting the temperature evolution are key aspects in ensuring a proper consolidation and the manufacturing of high-quality parts. To illustrate this, a fitting example is found in the adjacent hoop winding studied here. Generally, the width of the laser spot is larger than the tape width to fully irradiate the incoming tape and substrate surfaces. As a consequence, some regions of the substrate layers contain extra heating and cooling cycles during adjacent placement of the incoming tape [64] leading to DoC variation across the tape width. To illustrate, the substrate layers sub-a, -c and -d are also heated while winding the incoming tape on top of sub$\mathrm{b}$ as indicated in Fig. 3.1a The multiple heating and cooling of the adjacent layers can therefore cause a non-uniform temperature and crystallinity distribution across the substrate width. Thus, the substrate temperature evolution together with the crystallinity behavior in the width direction needs to be measured and described properly. This is a challenging task in adjacent hoop winding and fiber placement processes because the growing-in-time thermal domain with adjacent paths needs to be considered in the process analysis.

Several studies have focused on monitoring the temperature during AFP or ATW processes where multiple tapes are deposited on top of each other [75, 22, 57, 91, 81, 39]. However, the critical analysis of the adjacent AFP/ATW process of fiber reinforced polymer composites has received less attention in the literature. The temperature evolution during a continuous hoop filament winding process of thermoplastic composites, in which an infrared heat source was used, was measured and simulated in [44]. The temperature variation in the width direction was found to be negligible since the heat source width occupied one-third of the total mandrel length which provided a nearly uniform surface temperature distribution. In a second example, Glass/polypropylene (G/PP) cylinders were manufactured using an automated hoop winding process using a hot gas torch in [62]. Two pyrometers were used to measure the tape and substrate temperatures just before the nip point. An almost-constant nip point temperature history was observed with a good agreement with the numerical predictions. The AFP process with adjacent placement paths was studied in [64]. The temperature evolution of prepreg slit-tape having a width of $3.2 \mathrm{~mm}$ was measured by using thermocouples. In addition to the experiments, a 1D finite difference (FD) model and a 3D finite element (FE) model were developed to predict the process temperature.

Considering the current literature, the temperature and crystallinity variation across the width of relatively wide substrate/tape has not been studied for the continuous laserassisted adjacent hoop winding of thermoplastic composites. In this process, the multiple heating and cooling cycles of the substrate layers directly affect the temperature history of the material during manufacturing. The process temperature can eventually become higher than the thermal stability temperature of the material which may cause material degradation, even within a short time [92]. Therefore, the distribution and evolution of 


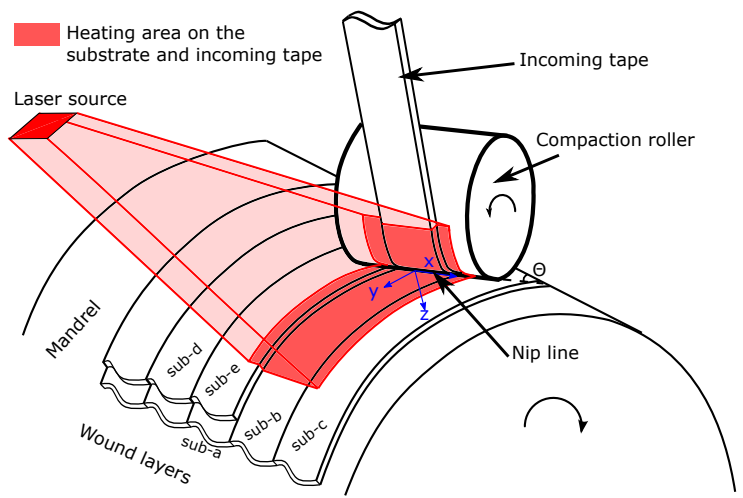

(a)

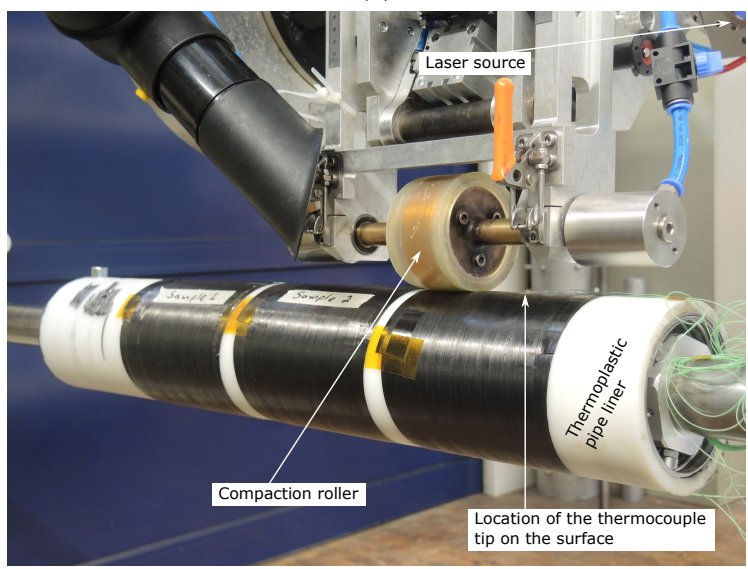

(b)

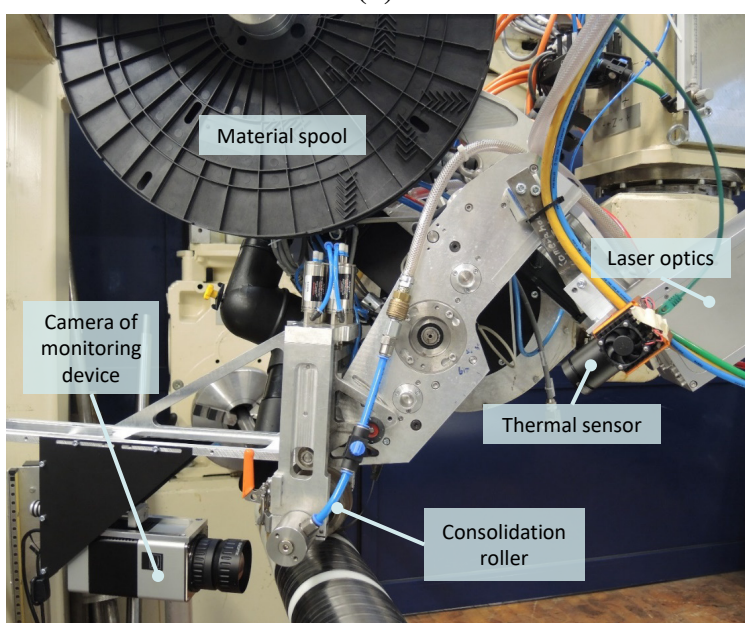

(c)

Figure 3.1 (a) Schematic view of the LATW process. Different substrate layers are denoted as sub-a to sub-d. (b) A photograph of the LATW setup and (c) and the operating units of the tape laying head. 
the substrate temperature has to be described and predicted properly in order to optimize the continuous LATW processes with adjacent paths. The objective of this work is to critically analyze the effect of multiple heating and cooling cycles on the temperature and crystallinity distributions during continuous LATW process with adjacent paths. To achieve this a global kinematic-optical-thermal (KOT) model is developed. The 2D kinematic-thermal model is developed by means of an explicit finite difference method. The growing-in-time thermal domains are defined to capture the additive manufacturing of the deposited tape. A 3D optical model is used to estimate the anisotropic reflection of the laser rays which is coupled with the thermal model to provide the heat flux distribution as a surface boundary condition. The semi-crystalline PA12 was chosen for our investigation since the material is well available and currently gaining attention in the oil and gas industry [93]. During the manufacturing of C/PA12 pipes, the temperature distribution on the prepreg surfaces is measured by a thermal imaging camera. Thermocouples are used to capture the temperature evolution in the substrate due to multiple heating and cooling. The crystallinity distribution of the pipe cross section is investigated by employing a nonisothermal crystallinity model and also taking the melting kinetics into account. The predicted crystallinity distribution across the width is compared with the crystallinity of several cut-out sections of the manufactured pipe, obtained using differential scanning calorimetry (DSC).

\subsection{Experimental}

The continuous adjacent hoop winding experiments were performed by using the gantrybased laser-assisted tape placement system developed at Fraunhofer IPT. The main units are shown in Fig. 3.1c including the material storage, tape feed unit, cutting unit, consolidation unit with water-cooled consolidation roller and optional silicone sleeve, and the zoom-homogenization laser optics as the heating unit. The diode laser was an LDF1000-2500 by Laserline (max. laser power: $2500 \mathrm{~W}$, wavelengths $940 \mathrm{~nm}$ and 980 $\mathrm{nm}$ ). The optical section consisted of a Zoom Homogenizer OTZ by Laserline. The prepreg material was a carbon fiber-reinforced polyamide-12 (PA12) from Evonik with a fiber volume fraction of $V_{f}=45 \%$ or mass fraction $m_{f}=55 \%$. The thermoplastic liner was manufactured with a similar thermoplastic material, i.e. PA12, to ensure proper bonding of the first tape layer. The relative positions of the laser source, incoming tape, roller, and the substrate are depicted in Fig. 3.2. The reference value of the geometrical parameters in Fig. 3.2 are presented in Table 3.1 and were used in the KOT model. The constant tape feeding rate i.e. linear winding velocity, laser power, consolidation force, and tape tension were $v=200 \mathrm{~mm} \mathrm{~s}^{-1}, P=1650 \mathrm{~W}, 100 \mathrm{~N}$, and $5 \mathrm{~N}$, respectively. The laser source had a top-hat power distribution. A total of 3 composite parts were manufactured with a thickness of 5 layers and a length of $150 \mathrm{~mm}$. Layers 1,2 , and 5 were wound on top of each other, while, layers 3 and 4 were wound with an offset of half a tape width as compared with layers 1 and 2, as schematically shown in Fig. 3.3

The trajectory of the tape on the liner was a helical path which defined the gap between the adjacent layers accordingly. To avoid possible overlaps at the tape edges, the helix pitch should be a bit larger than the as-received prepreg width since the tape width expands 


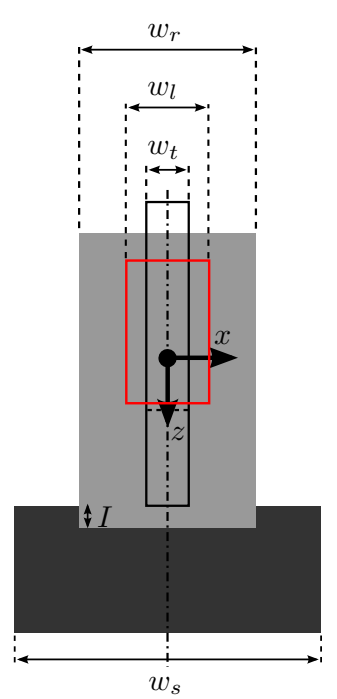

Front view
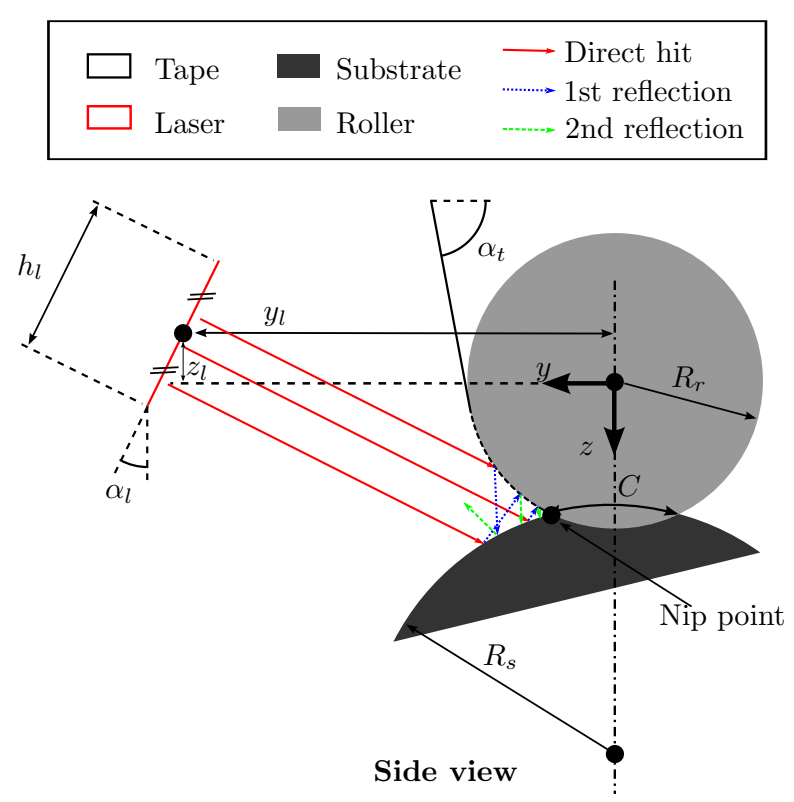

Figure 3.2 Schematic view of the geometry used for the optical model (reproduced with permission from [26]).

Table 3.1 Reference values used in the LATW process.

\begin{tabular}{ccc} 
Symbol & Value & Description \\
\hline$R_{r}$ & $45 \mathrm{~mm}$ & Roller radius \\
$w_{r}$ & $50 \mathrm{~mm}$ & Roller width \\
$I$ & $10 \mathrm{~mm}$ & Roller indentation into liner surface \\
$C$ & $46 \mathrm{~mm}$ & Arc length of roller contact with substrate \\
$w_{p}$ & $20 \mathrm{~mm}$ & Prepreg width \\
$t_{p}$ & $0.15 \mathrm{~mm}$ & Prepreg thickness \\
$\alpha_{t}$ & $67^{\circ}$ & Incoming tape angle \\
$R_{s}$ & $62.5 \mathrm{~mm}$ & Substrate (Liner) radius \\
$y_{l}$ & $430 \mathrm{~mm}$ & Laser spot y-position (of centroid) \\
$z_{l}$ & $230 \mathrm{~mm}$ & Laser spot z-position (of centroid) \\
$h_{l}$ & $65 \mathrm{~mm}$ & Laser spot height \\
$w_{l}$ & $28 \mathrm{~mm}$ & Laser spot width \\
$\theta$ & $86.8^{\circ}$ & Winding angle \\
$\alpha_{l}$ & $33.5^{\circ}$ & Laser beam angle \\
\hline
\end{tabular}


during the heating and consolidation phases [32, 94]. The tape laying head moved in lateral $(x-)$ direction with a distance being equal to the tape width $(w)$ for each full rotation. Hence, the winding angle was calculated based on the following equation [62]:

$$
\theta= \pm \arctan \left(\frac{2 \pi R_{s}}{w_{p}}\right)
$$

where the $R_{s}$ was the substrate radius and $w_{p}$ was the prepreg width. The corresponding stacking sequence of the cylinder wall layup was determined as $[86.8 /-86.8 / 86.8 /-$ $86.8 / 86.8]$ for $R_{s}=2.5 \mathrm{~mm}$ and $w_{p}=20 \mathrm{~mm}$.

\subsubsection{Temperature measurements}

K-type wire thermocouples of the Omega 5TC series with an accuracy of $1.5^{\circ} \mathrm{C}$ were used to provide contact temperature measurement at the plies interfaces through the substrate thickness (Fig. 3.3a). The thermocouples were insulated with PFA (Perfluoroalkoxy alkanes) tapes and had a diameter of $0.13 \mathrm{~mm}$. The stripped leads of the thermocouples were connected to a Graphtec GL220 data logger capable of the simultaneous recording of 10 signals with a frequency of $10 \mathrm{~Hz}$. In each trial, 3 thermocouples (TC1-TC3) were used to study the temperature distribution in thickness and width direction. After winding each layer the whole system was stopped to install the thermocouples on the newly formed substrate. Therefore, the temperature of the system reached room temperature before winding of the next layer. The thermocouple tips were placed manually at 2 to $3 \mathrm{~mm}$ away from the tape edge in the width direction $(x$-direction), therefore the exact positions were kept within a tolerance of a few millimeters during the manual installation. In terms of measurement location with respect to depositing tape width, the TC1 had an offset of half a tape as schematically demonstrated in Fig. 3.3b. When the thermocouples were positioned on the top surface of the substrate, e.g. TC1 during winding of layer 1 as seen in Fig. 3.3a the temperature measurements may not be reliable because the laser light directly hits the thermocouple. This can lead to a significant temperature increase in the thermocouple which may not represent the actual substrate temperature. Therefore, the temperature evolution on the surface was captured by employing a thermal camera.

The thermal camera was mounted on the tape winding head with a fixed distance of $326 \mathrm{~mm}$ to the nip point was a Pyroview 160L compact+ by DIAS Infrared. It exhibited a measurement frequency of $35 \mathrm{~Hz}$, an image resolution of $160 \times 120$ pixels and a maximum measurement deviation of $2 \%$. The temperature obtained by this non-contact device was extracted by the software Pyrosoft Professional by DIAS Infrared assuming an emission coefficient of 0.9 and an ambient temperature of $20{ }^{\circ} \mathrm{C}$ based on previously performed calibrations. Characteristic temperature values for incoming tape, substrate and nip point were evaluated as the average value in a rectangular box with a size of $6 \times 3$ pixels (tape/substrate) and $8 \times 2$ pixels (nip point), respectively. The tape and substrate boxes were located with a distance of approximately $15 \mathrm{~mm}$ from the nip point (see Fig. 3.4a). 


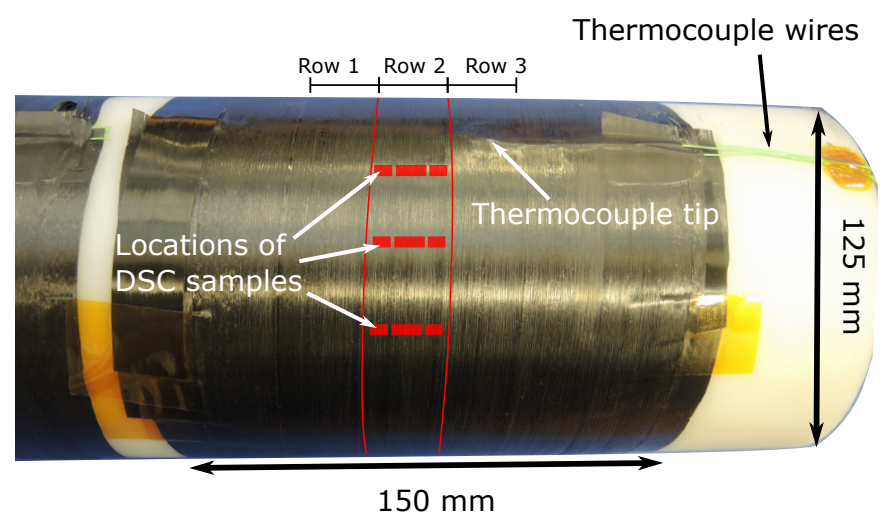

(a)

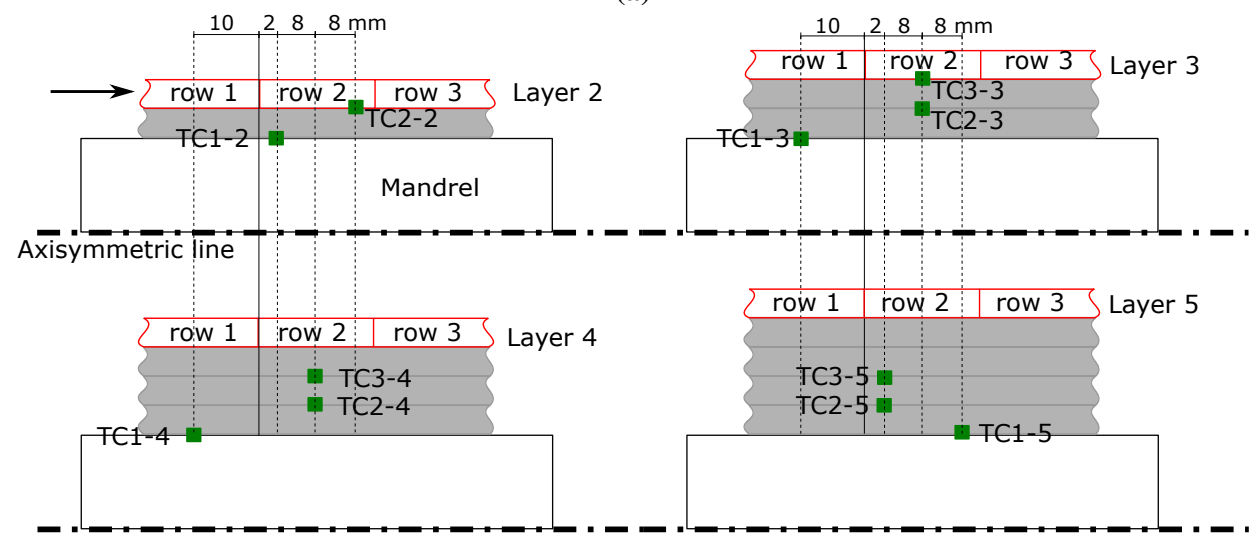

(b)

Figure 3.3 (a) A view of the thermocouple embedded in the substrate. The locations of the DSC samples extracted across the substrate width, i.e. from left, center and right zones.

(b) The corresponding schematic view of the thermocouples location during winding each layer which is shown separately for layers 1 to 4.

\subsubsection{DSC test for crystallization measurement}

Differential scanning calorimetry (DSC) tests were performed with a TA Instruments Discovery 250. The samples were extracted across the substrate width of row 2 as shown in Fig. 3.3a for left, central, and right zones. Three trials of sample were extracted for repeat-ability purposes which makes 9 samples in total with an average mass of $9 \mathrm{mg}$ each. The final crystallinity across the substrate width after winding of 5 layers was obtained by integrating the total melting enthalpy (compensating for any cold crystallization) upon a first heating cycle using the TA Trios software. The samples were heated from room temperature up to $210{ }^{\circ} \mathrm{C}$ with a heating rate of $10{ }^{\circ} \mathrm{C} \mathrm{min}-1$. The mass fraction of the fiber reinforcement $\left(m_{f}\right)$ was subtracted from the total sample mass in order to correctly 


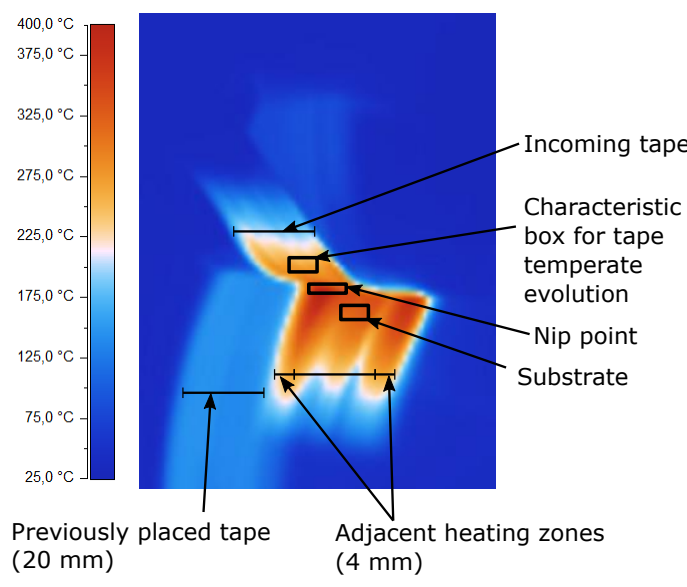

(a)

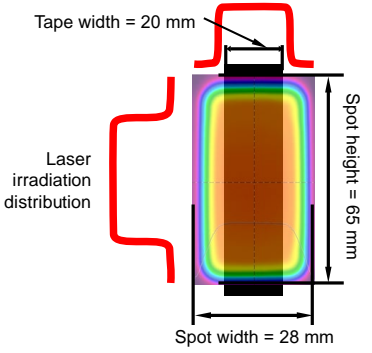

(b)

Figure 3.4 (a) A snapshot of the thermal imaging camera and the extraction of characteristic values from infrared thermal imaging camera. The adjacent heating zones (4 $\mathrm{mm})$ on the left and right hand side of the heating zone are shown as strips as shown in Fig. 4a. (b) Top-hat laser irradiation distribution along length and width of the deposited tape.

determine the crystallinity using [95]:

$$
\chi_{v}=\frac{\Delta H_{c}}{\Delta H_{f}^{\circ}\left(1-m_{f}\right)}
$$

where $\Delta H_{f}^{\circ}=209.3 \mathrm{~J} \mathrm{~g}^{-1}$ [96, 97] was the heat of fusion of $100 \%$ crystalline neat PA12 at the equilibrium melting temperature, and $\Delta H_{c}$ was the integrated melting enthalpy during heating. Finally, a peak crystallization temperature of $151{ }^{\circ} \mathrm{C}$ was obtained by cooling the sample back to room temperature at $20^{\circ} \mathrm{C} \mathrm{min}^{-1}$.

\subsection{Kinematic-optical-thermal (KOT) model coupled with the crystallinity model}

\subsubsection{Optical model}

The optical model was based on the work carried out by Reichardt et al. [26] in which a non-specular ray-tracing approach was utilized. The varying incident angle of the incoming rays due to the substrate and tape cylindrical curvature was considered in the model assuming a winding angle of $90^{\circ}$. Moreover, the anisotropic reflection of the laser rays caused by the fibers was modelled to obtain the heat flux distribution. The optical model consisted of a macro-model launching a set of collimated rays from the laser position with uniform constant intensity across the width and length of the laser spot which did not consider the top-hat distribution as shown in Fig. 3.4b The laser 
source was modeled with $N_{0}=10000$ light rays from the laser position using Sobol sampling. In the optical macro-model, the location where each ray directly hit on the tape, substrate, or roller was calculated. The curved surfaces were approximated using a finite number of triangular mesh elements. The interactions between a specific coming ray and the tape or substrate geometry were described using the optical micro-model. The reflected and absorbed energy together with reflection directions were calculated at the material surface. The anisotropic reflection behavior of the composite surface was described using a bidirectional reflectance distribution function (BRDF). The reflected light was modeled by generating new rays, which were forwarded to the macro-model. This iterative process was terminated after a set number of reflections defined by the user. The total number of reflections were set to two in the present study. Since the cylindrical liner was a single curved surface, the curved surface was unfolded and the heat flux distribution was demonstrated in the unfolded 2D Cartesian domain. To do so, the absorbed light was collected to the nearest square bins of $1 \mathrm{~mm}^{2}$ where the incoming or reflected ray incident point fell in. The location of the bins in the winding direction was defined based on the arc-distance to the nip line. The output of the optical model was a 2D heat flux field $q_{i}^{\prime \prime}$ (laser power per unit area) applied to the substrate and tape surface. This information was then forwarded to the thermal model as a heat flux boundary condition to calculate the temperature distribution.

\subsubsection{Heat transfer model}

The substrate computational domain was defined as a cross-sectional slice of the substrate and liner with a Cartesian coordinate system as shown in Fig. 3.5. In this domain, the liner rotated and the tape laying head moved laterally along the centerline of the liner axis. Therefore, the computational domain was assumed to rotate with the liner and the thermal domain of the substrate was defined to grow both in thickness ( $z$-direction) and width direction ( $x$-direction). The tape temperature distribution was calculated with the same approach as the substrate domain. However, the incoming tape thickness and the corresponding thermal boundary conditions were assumed constant for all layers as also observed previously [62]. A schematic view of the 2D model in width and throughthickness directions is given in Fig. 3.6 together with the considered control volumes for the substrate and tape. The corresponding governing equation for the $2 \mathrm{D}$ transient heat conduction thermal domain is as follows [98]:

$$
\rho c_{p} \frac{\partial T}{\partial t}=\frac{\partial}{\partial x}\left(k_{x} \frac{\partial T}{\partial x}\right)+\frac{\partial}{\partial z}\left(k_{z} \frac{\partial T}{\partial z}\right)
$$

where $\rho, c_{p}, k_{x}$ and $k_{z}$ were the density, specific heat capacity, thermal conductivity in width and through-thickness direction, respectively. The thermal properties of the used materials are listed in Table 3.2. The prepreg tape properties were considered as temperature-dependent. The density of the PA12 matrix was also a function of absolute crystallinity which was assumed constant $(\chi=12 \%)$ in the process to avoid extra complexity to the model. The polymer conductivity depended on the crystallization onset temperature which was also assumed constant $\left(T_{c}=162{ }^{\circ} \mathrm{C}\right)$. The conductivity and density of the prepreg were derived by the rule of mixture. The thermal degradation 
temperature of PA12 is determined at $350{ }^{\circ} \mathrm{C}$ [99]. The in-plane heat transfer rate due to conduction in the winding direction is much lower than the relative velocity of the laser source and heating surface [79]. It was therefore assumed that the in-plane heat conduction in winding direction was neglected in the present study. An explicit control volume-based finite difference (CV/FD) scheme [100] was used to solve Eq. 3.3. A relatively small time step was used $(\Delta t \approx 5 \mathrm{~ms})$ to have a stable solution of the explicit solver. For each layer of the substrate and the incoming tape, 4 and 21 control volumes were defined in the thickness and width direction, respectively. A total of 5 control volumes were defined in the through-thickness direction for the liner having a thickness of $5 \mathrm{~mm}$.

The substrate and tape computational domains were initially located at $t=t 1$ (refer to Fig. 3.5, just at the beginning of the heated region and with an initial ambient temperature. As the substrate domain rotated in the same direction as the liner, the surface of the substrate $(S 1)$ and tape $(S 4)$ were irradiated by the laser and the heat fluxes were calculated by the optical model during $t=t 1-t 2\left(-k \nabla T=q_{i}^{\prime \prime}\right)$. The corresponding computational domains in the heating region are illustrated in Fig. 3.6a As explained in Fig. 3.1a, extra heating zones on the left and right sides of the substrate ( $S 2$ and $S 3$ as seen in Fig. 3.5 were also heated in addition to the region where the incoming tape was deposited. The air convection boundary condition $\left(-k \nabla T=h_{a}\left[T_{\text {surr }}-T(t)\right]\right)$ was defined on the surfaces $S 1-S 4$, where $h_{a}$ was the air heat transfer coefficient and $T_{\text {surr }}$ was the surrounding (ambient) temperature. The heat transfer between the roller and tape was modeled as a convective boundary condition on the $S 5$ surface $\left(-k \nabla T=h_{t r}\left[T_{\text {roller }}-T(t)\right]\right)$ where $h_{t r}$ was the heat transfer coefficient at the tape-roller interface and $T_{\text {roller }}$ was the roller temperature. Since the roller was water-cooled, a lower value of $T_{\text {roller }}=25^{\circ} \mathrm{C}$ was used compared to an air-cooled roller with a temperature of $50{ }^{\circ} \mathrm{C}$ [24].

The tape temperature was calculated in a separated domain (Fig. 3.6a) prior to the substrate to provide the tape temperature for the substrate at the nip point. At the nip point $(t=t 2)$, the substrate thermal domain grew in the thickness direction equal to the tape thickness (Fig. 3.6b). At the interface of the tape and the substrate at $t=t 2$, the nodal temperatures were updated based on the averaged temperature of the tape and substrate. From $t=t 2$ to $t=t 3$, the consolidated substrate lost heat to the roller. The roller thermal effect was simulated by the convection heat loss on the $S 6$ surface $\left(-k \nabla T=h_{r}\left[T_{\text {roller }}-T(t)\right]\right)$ where $h_{r}$ was the heat transfer coefficient at the substrate-roller interface. The length $(C=46 \mathrm{~mm})$ and duration $(C / v=0.23 \mathrm{~s})$ of the roller contact area depended on the roller indentation $(I=10 \mathrm{~mm})$ into the liner surface (refer to Table 3.1).

Finally, the air convection heat loss was applied after $t=t 3$ on the substrate top surface (S7) until the thermal domain reached the heating region again at $t=t 1$. The liner was considered as a physical body instead of a convection boundary condition for the substrate model. By this assumption, the heat loss distribution to the liner in the thickness- and width-direction was predicted with higher accuracy compared to convection heat loss. A thermal contact conductance between the liner and substrate was utilized with a value of $T C C_{m}=4000 \mathrm{~W} \mathrm{~m}^{-2}{ }^{\circ} \mathrm{C}^{-1}$ which was in the range of the reported values in [70].

The coefficients needed for the explained boundary conditions and the domain mesh sizes are provided in Table 3.3 . The mesh size variation in the thickness direction was 
Table 3.2 Overview of prepreg and liner thermal properties. $\chi$ is the absolute crystallinity of the PA12 assumed $12 \%$ on average in this process. $T_{c}=162{ }^{\circ} \mathrm{C}$ is the crystallization onset temperature for PA12 [101] 102]

\begin{tabular}{|c|c|c|c|c|c|}
\hline \multicolumn{2}{|c|}{ Component } & $\begin{array}{l}\text { Specific heat } \\
\text { capacity } \\
\left(\mathrm{J} / \mathrm{kg} /{ }^{\circ} \mathrm{C}\right)\end{array}$ & Density $\left(\mathrm{Kg} / \mathrm{m}^{3}\right)$ & $\begin{array}{l}\text { Conductivity } \\
\text { longitudinal } \\
\left(\mathrm{W} / \mathrm{m} /{ }^{\circ} \mathrm{C}\right)\end{array}$ & $\begin{array}{l}\text { Conductivity } \\
\text { transverse } \\
\left(\mathrm{W} / \mathrm{m} /{ }^{\circ} \mathrm{C}\right)\end{array}$ \\
\hline \multirow[t]{2}{*}{ Prepreg } & Matrix & \multirow[t]{2}{*}{$\begin{array}{l}2.197 T[K]+ \\
607.6\end{array}$} & $\begin{array}{l}0.34 \chi(1056-0.8591 T)+ \\
(1-0.34 \chi)(1018- \\
0.5282 T)\end{array}$ & \multicolumn{2}{|c|}{$\begin{array}{l}0.22+5.8 \times 10^{-3}\left(T_{c}-T\right)^{1 / 3} \\
\text { if } T \leqslant T_{c}\end{array}$} \\
\hline & Fiber & & $1 /(565+0.02 T)$ & 17 & 2.3 \\
\hline \multicolumn{2}{|c|}{ Liner } & 2400 & 1030 & 0.23 & 0.23 \\
\hline
\end{tabular}

considered in the formulation. In the model, a perfect bonding between the rest of the layers was assumed since thermal contact resistance between the layers is negligible [70].

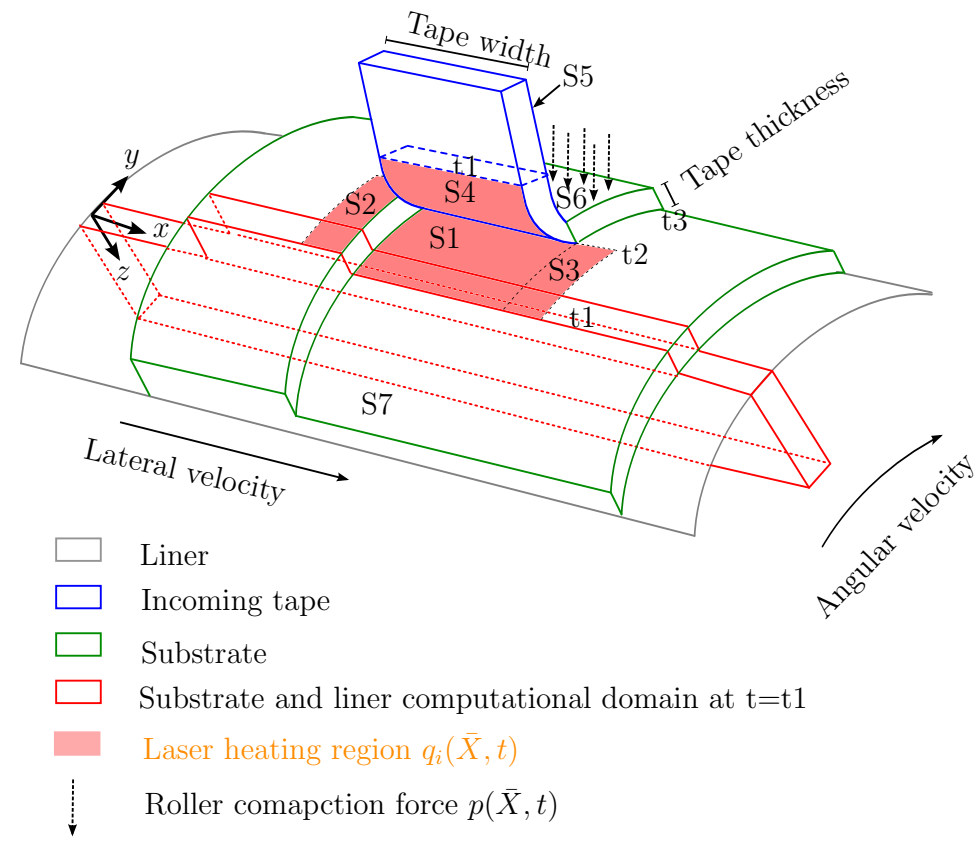

Figure 3.5 Thermal model approach in width and thickness direction. $v$ is the winding velocity and $\theta$ is the winding angle i.e. the angle of velocity direction and liner axis. 


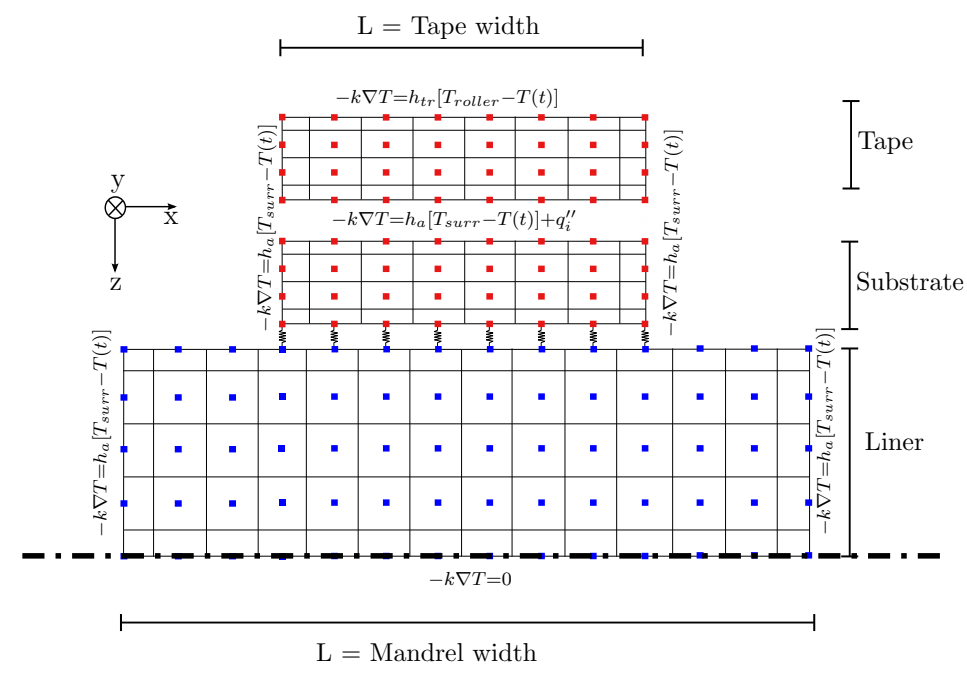

(a)

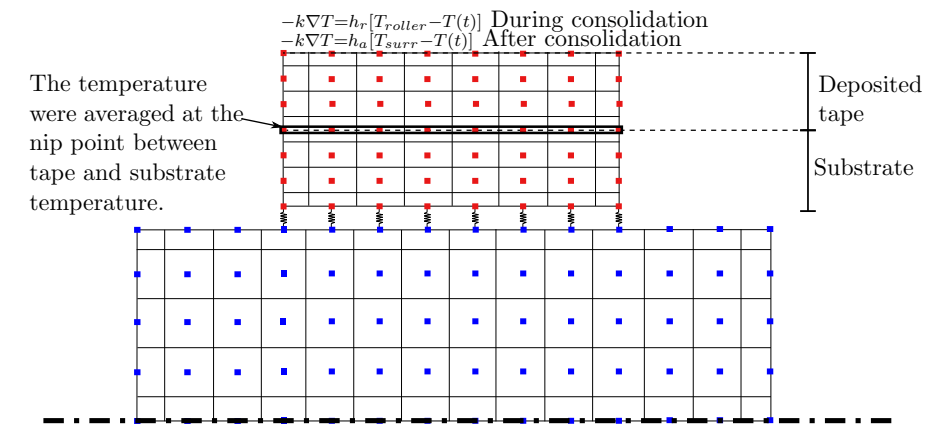

(b)

Figure 3.6 A schematic view of the computational thermal model in width and thickness direction at the (a) heating region ( $t 1-t 2)$ and $(b)$ consolidation ( $t 2-t 3)$ and cooling regions ( $t 3-t 1)$. Tape also had the same computational domain except that the liner was removed and instead convection boundary condition was applied as the roller heat loss effect.

\subsubsection{Kinematic model}

The kinematic model for the hoop winding process is schematically shown in Fig. 3.7 for adjacent winding of three tapes (Row 1, 2 and 3) in the $x$-direction with three layers (Layer 1, 2, and 3) in the -z-direction. The winding velocity was defined as a vector sum of the lateral tape laying head velocity and liner linear rotational velocity. The lateral 
Table 3.3 Overview of reference values for numerical parameters in the thermal simulation.

\begin{tabular}{|c|c|c|c|c|}
\hline & Symbol & Value & Unit & Description \\
\hline \multirow{6}{*}{$\begin{array}{l}\text { Boundary } \\
\text { conditions }\end{array}$} & $T_{\text {surr }}$ & 25 & ${ }^{\circ} \mathrm{C}$ & Surrounding / initial temperature \\
\hline & $T_{\text {roller }}$ & 25 [24] & ${ }^{\circ} \mathrm{C}$ & Water-cooled roller temperature \\
\hline & $h_{a}$ & $20[\overline{62}$ & $\mathrm{W} \mathrm{m}{ }^{-2}{ }^{\circ} \mathrm{C}^{-1}$ & Composite-air convection coefficient \\
\hline & $h_{t r}$ & $40[9]$ & $\mathrm{W} \mathrm{m}{ }^{-2}{ }^{\circ} \mathrm{C}^{-1}$ & Tape-roller convection coefficient \\
\hline & $h_{r}$ & $1000[61]$ & $\mathrm{W} \mathrm{m}{ }^{-2}{ }^{\circ} \mathrm{C}^{-1}$ & Substrate-roller convection coefficient \\
\hline & $T C C_{m}$ & $4000[70]$ & $\mathrm{W} \mathrm{m}^{-2}{ }^{\circ} \mathrm{C}^{-1}$ & $\begin{array}{l}\text { Substrate-liner thermal contact conduc- } \\
\text { tance coefficient }\end{array}$ \\
\hline \multirow[t]{3}{*}{ Mesh sizes } & $\Delta z_{1}$ & 0.05 & $\mathrm{~mm}$ & $\begin{array}{l}\text { Substrate and tape mesh size in thick- } \\
\text { ness direction }\end{array}$ \\
\hline & $\Delta z_{2}$ & 1 & $\mathrm{~mm}$ & Liner mesh size in thickness direction \\
\hline & $\Delta x$ & 0.5 & $\mathrm{~mm}$ & Width direction mesh size \\
\hline
\end{tabular}

velocity value was calculated as $v \cos \theta=11.16 \mathrm{~mm} \mathrm{~s}^{-1}$, and the linear rotational velocity was defined by $v \sin \theta=199.69 \mathrm{~mm} \mathrm{~s}^{-1}$ as shown in Fig. 3.5. The duration for one full rotation of the liner is then $\frac{2 \pi R_{s}}{v \sin \theta}=2 \mathrm{~s}$. The discussed time-dependent boundary condition on the top surface of substrate in the section 3.3.2 was therefore directly dependent on the liner rotational velocity.

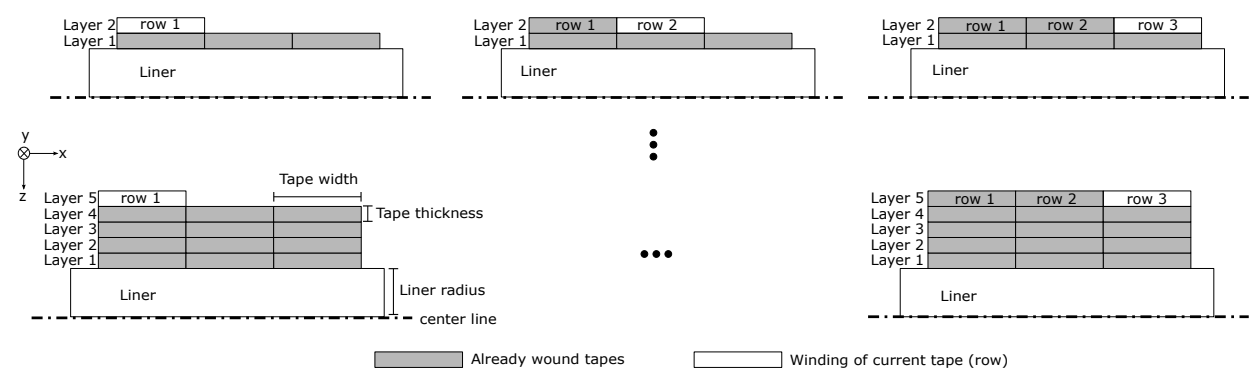

Figure 3.7 Global numerical strategy of hoop winding for manufacturing a cylinder with a thickness of 5 layers and a width of 3 tapes. The deposition of the incoming tape is visualized at each $360^{\circ}$ of winding in the growing computational model. Each figure represents the geometry of the computational domain for one full rotation. The schematics do not represent the actual size of computational domain.

In Fig. 3.7, the growing computational thermal domain of the substrate is demonstrated during the process. At $t=2 s$, the deposition of the tape at row 1 is illustrated corresponding to the start of the process for each layer. At $t=4 \mathrm{~s}$, the next tape was placed adjacent to the first tape after one full rotation of the liner. Winding continued until the tape laying head reached the end of the pipe length. Then the process stopped due to the thermocouple installation and the system reached to the ambient temperature and then tape laying head started to wind the second layer as shown in Fig. 3.7 This process continued until all tapes were wound to reach the desired layup of the pipe which consisted of 5 layers as aforementioned. 


\subsubsection{Crystallization model}

The predicted temperature distribution was forwarded to a non-isothermal crystallization model. The crystallization model was not fully coupled to the KOT model, e.g. to take into account latent heat release, as this would over complicate our selected approach. In this work, the model developed by Nakamura et al. [103] was employed, as it allows a relatively simple description of the evolution of the crystallinity under non-isothermal conditions. The relative degree of crystallinity (DoC) $\xi$ was calculated based on the Avrami analytical theory [103, 104]:

$$
\xi(t)=\frac{\chi_{v}(t)}{\chi_{v \infty}}=1-\exp \left(-\phi_{0}(t)\right)
$$

where $\chi_{v}$ was the crystallized volume at time $t$ and $\chi_{v \infty}$ was the crystallized volume in equilibrium conditions which was defined as the maximum value of crystallinity. Here, $\phi_{0}(t)$ was the expected relative crystallized volume if no impingement occurs for 3D spherulitic growth [105] and defined as:

$$
\phi_{0}(t)=\left(-\int_{0}^{t} \kappa(T) d t\right)^{n}
$$

where $\kappa$ was the temperature-dependent crystallization rate constant and the Avrami constant, $n$, was a measure for the nucleation and growth mechanism, e.g. $\mathrm{n}=3$ for spherulitic growth and heterogeneous nucleation. By substituting Eq. 3.5 into Eq. 3.4 the differential form of the Nakamura model can be achieved, which is convenient for computational implementation:

$$
\frac{d \xi(t)}{d t}=n \kappa(T)(1-\xi)(-\log (1-\xi))^{(n-1) / n}
$$

Rate constant $\kappa$ is conveniently related to the isothermal crystallization half time $t_{1 / 2}$, at which $\xi\left(t_{1 / 2}\right)=0.5$, according to:

$$
\kappa(T)=(\ln 2)^{1 / n} \frac{1}{t_{1 / 2}(T)}
$$

The crystallization rate can be expressed in terms of the crystallization half-time using the classical Hoffman-Lauritzen theory. For PA12, isothermal crystallization experiments were used to express the $t_{1 / 2}$ of the pure polymer [106, 107].

$$
\frac{1}{t_{1 / 2}}=K_{0} \times \exp \left(-\frac{U}{R\left(T-T_{\infty}\right)}\right) \times \exp \left(-\frac{K_{G}\left(T+T_{m}\right)}{2 T^{2}\left(T_{m}-T\right)}\right)
$$

where $U$ was the activation energy for crystallization, $R$ was the universal gas constant, $T_{g}$ was the glass transition temperature, $T_{m}$ was the equilibrium melting temperature while $T_{\infty}$ was the so called Vogel temperature. The experimentally fitted parameters, i.e. $K_{G}$ and $K_{0}$, were the growth rate constant and nucleation rate constant, respectively. All the required values were taken from [106] as $U=6270 \mathrm{~J} \mathrm{~mol}^{-1}, R=8.314 \mathrm{~J} \mathrm{~mol}^{-1} \mathrm{~K}^{-1}$, $T_{\infty}=T_{g}-30 K, T_{g}=60{ }^{\circ} \mathrm{C}, T_{m}=190{ }^{\circ} \mathrm{C}, K_{G}=109,258 \mathrm{~K}^{2}$, and $K_{0}=8639 \mathrm{~s}^{-1}$. 
The data in the literature concerning neat PA12 of type PA 2200 indicated an Avrami exponent was taken approximately as 2.82 [106, 107] suggesting a mixture of $2 \mathrm{D}$ and $3 \mathrm{D}$ crystal growth. Note that $\mathrm{Eq} 3.6$ was used between $T_{g}$ and $T_{m}$ to describe the non-isothermal crystallization growth. In this work, the influence of the fiber content in the prepreg tape on the crystallization behavior of PA12 is not taken into account. The model parameters were verified by comparing the modeled and the experimentally obtained peak-crystallization temperature from DSC. Good agreement was obtained since a thermal profile with a constant cooling rate of $20{ }^{\circ} \mathrm{C} \mathrm{min}-1$ yielded a computed peakcrystallization temperature of $151^{\circ} \mathrm{C}$ while experimentally a value of $148{ }^{\circ} \mathrm{C}$ was shown.

During the LATW process the temperature reaches well above melting temperature quite frequently. Thus, it is needed to describe the crystallization kinetics during the melting phase as studied in [12,10, 108]. To simplify the melting kinetics, it was assumed that when the temperature was higher than $T_{m}$, the $\mathrm{DoC}$ was set to $1 \%$,i.e. almost all the crystals were melted instantaneously. Although this was an extreme assumption, i.e. polymers typically show a melting trajectory with a peak temperature $T_{m}$, the basic trends could be predicted as illustrated in [10].

\subsection{Results and discussions}

\subsubsection{KOT model output}

The normalized absorbed heat flux by the substrate and tape surface along the winding direction is plotted in Fig. 3.8. The normalization was done based on the power intensity of the laser source which was $0.91 \mathrm{~W} \mathrm{~mm}^{-2}$. It is seen that the length of the heated regions was $35 \mathrm{~mm}$ and $70 \mathrm{~mm}$ for the substrate and tape, respectively. The substrate, tape, and roller received approximately $46.6 \%, 31.1 \%$, and $13.6 \%$ of the total incident energy, respectively. The laser orientation was more perpendicular to the substrate surface than the tape, therefore, a higher heat flux was predicted for the substrate according to Fresnel's law [26]. The magnitude of the heat flux considerably reduced near the nip point region for the tape due to the shadowing effect as well as the rapid reduction in the incident angle of the direct hit. The shadow region which is not irradiated by the laser may be present prior to the nip point depending on the local geometry as well as the position of the laser source [32, 24, 61].

The predicted temperature distribution in the thickness and width directions for the liner and the substrate is plotted in Fig. 3.9 during winding of rows 1 to 3 for layer 2 at the nip point, i.e. when the tape was deposited on the substrate. The substrate reached the maximum temperature as the substrate surface was fully irradiated by the laser source. The thermal contact resistance effect at the liner/layer 1 interface was visible from the large temperature gradient. The effect of adjacent heating is seen at the already deposited tape edges by the high temperature values. At the indicated left (point P2) and right zones (point P18), the substrate temperature reached a higher temperature than at the central zones (point P10) due to the adjacent heating. Since the laser spot width i.e., $28 \mathrm{~mm}$ was larger than the tape width i.e., $20 \mathrm{~mm}$, the sides of adjacent rows were also heated for $4 \mathrm{~mm}$, as clearly seen in Figs. 3.9p,c. 


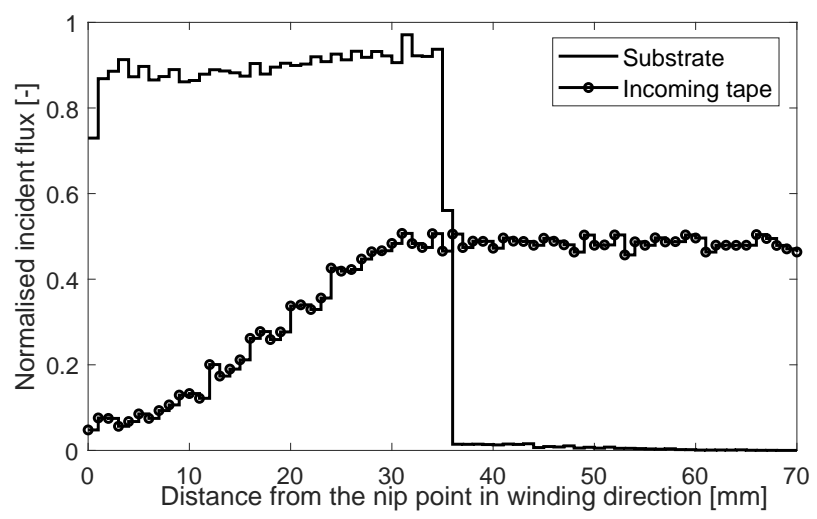

Figure 3.8 The substrate and tape averaged heat flux across the width as a function of distance to the nip point in the heating region. After $70 \mathrm{~mm}$ the tape heat flux dropped to zero.

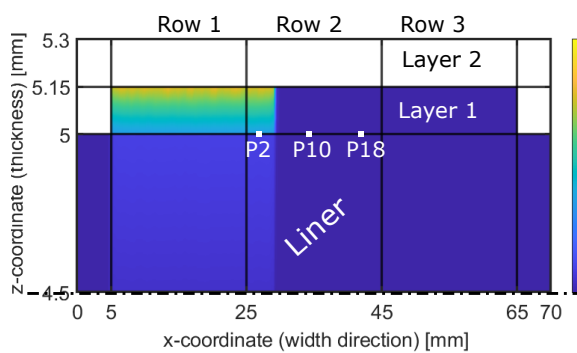

(a)

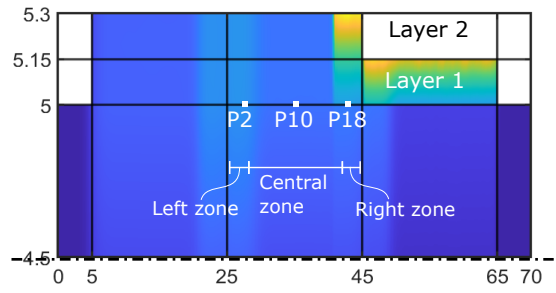

(c)

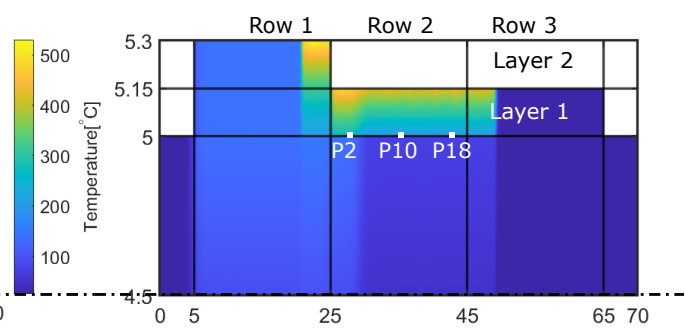

$\mathrm{y}_{\otimes} \longrightarrow \mathrm{x} \quad$ (b)

P2: $2 \mathrm{~mm}$ of row 2 width $=27 \mathrm{~mm}$ of $x$-axis P10: $10 \mathrm{~mm}$ of row 2 width $=35 \mathrm{~mm}$ of $x$-axis P18: $18 \mathrm{~mm}$ of row 2 width $=43 \mathrm{~mm}$ of $x$-axis

Figure 3.9 Temperature distribution at the nip point during winding (a) row 1/layer $2(b)$ row 2/layer 2, and (c) row 3/layer 2 . 


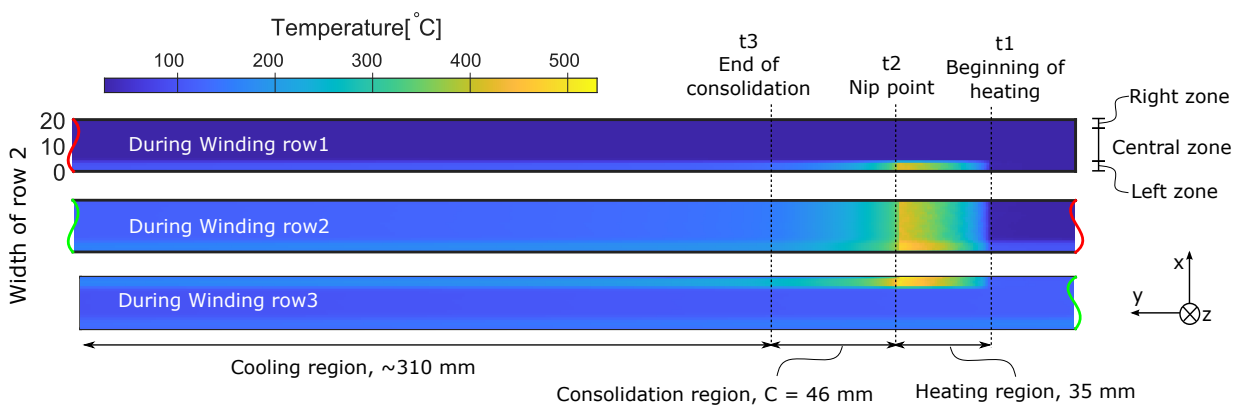

(a)

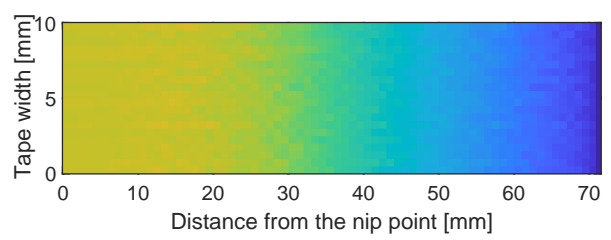

(b)

Figure 3.10 The row 2 surface temperature distribution during winding of rows 1 to 3 of layer 2 indicating the heating, consolidation, and cooling regions. (b) The incoming tape surface temperature during heating phase.

By unfolding the cylindrical domain, the tape and substrate surface temperature distributions in the winding and width directions are depicted in Fig. 3.10. The surface temperature of row 2 during winding of rows 1 to 3 of layer 2 is presented by three contour plots. The heating region ( $\mathrm{t} 1$ to $\mathrm{t} 2$ ), consolidation region ( $\mathrm{t} 2$ to $\mathrm{t} 3$ ), and cooling region ( $\mathrm{t} 3$ to t1) are annotated accordingly. The temperature non-uniformity in the width direction of the heating region was more pronounced up to $530{ }^{\circ} \mathrm{C}$ compared to the consolidating and cooling regions. During winding of row 1, only the left zone (point P2) was heated as shown in Fig. 3.10a(top). During winding of row 2, all the zones (points P2, P10 and P18) were heated at the same time. The temperature of left (point P2) and right (point P18) zones were higher than central zone (point P10) during winding of row 3 as shown in Fig. 3.10a (bottom). The tape temperature distribution in the width direction was found to be almost constant throughout the process as shown in Fig. $3.10 \mathrm{~b}$ with a maximum temperature of $400{ }^{\circ} \mathrm{C}$ at the nip point.

\subsubsection{Surface temperature}

The surface temperature history measured by the thermal imaging camera was used to get an insight into the inline surface temperature during the process and also verify the predictions presented in Section 3.4.1. Once the winding process was started, the tape accelerated to the intended feed rate i.e. run-in phase. After this transition period, the 


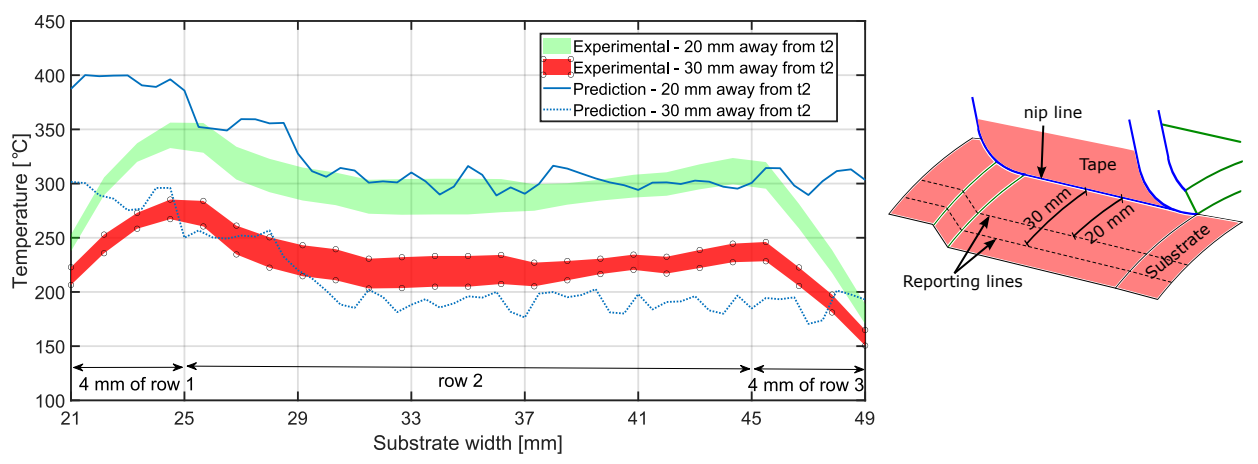

Figure 3.11 Comparison of the thermal imaging camera measurements with the model predictions across the substrate width during winding layer 5.

temperature distribution reached a steady-state phase since all the geometrical, optical and thermal parameters were constant during winding of a specific layer. Therefore, the temperature history was averaged based on 3 winding experiments in the steady-state duration with the assigned standard deviation as shown in Fig. 3.11

The measured temperature distributions across the substrate width are plotted for two locations prior to the nip point, i.e. $20 \mathrm{~mm}$ and $30 \mathrm{~mm}$ away from the nip point in Fig. 3.11. The corresponding predicted temperature distribution included the entire of row 2 and $4 \mathrm{~mm}$ of row 1 and 3 to cover the laser width spot i.e. around $28 \mathrm{~mm}$ which can be also seen in Fig. 3.4a with the annotated adjacent heating zones. The temperature nonuniformity was clearly observed with a higher temperature on the left zone of row 2 (25-29 $\mathrm{mm})$ and a part of row $1(21-25 \mathrm{~mm})$. However, the central zone $(29-41 \mathrm{~mm})$ and right zone (41-45 $\mathrm{mm}$ ) of row 2 and part of row $3(45-49 \mathrm{~mm})$ had almost the same temperature according to the model predictions. Relatively lower temperatures were measured at the sides of the laser spot i.e. 21-22 mm and 48-49 mm in Fig. 3.11, which was considered mainly due to the top-hat laser power distribution used in the experiments as depicted in Fig. 3.4b, In general, the developed KOT process model captured the experimentally observed phenomena quite well. The centerline temperature at $20 \mathrm{~mm}$ prior to the nip point was found to be approximately $75{ }^{\circ} \mathrm{C}$ higher than the temperature at $30 \mathrm{~mm}$ prior to the nip point. The scatter in the predicted temperature distribution was due to the scatter in the heat flux distribution obtained from the optical model as seen in Fig. 3.8 The KOT model overpredicted the temperature at the left zone as compared with the measured surface temperature. This was due to the fact that a uniform power distribution was employed in the KOT model whereas it was a sort of top-hat distribution for the laser source.

\subsubsection{Interface temperature}

In addition to the temperature non-uniformity on the substrate surface, the temperature distribution was also studied through the thickness to understand and explain the thermal history more elaborately. The temperature history of the computational nodes across the 

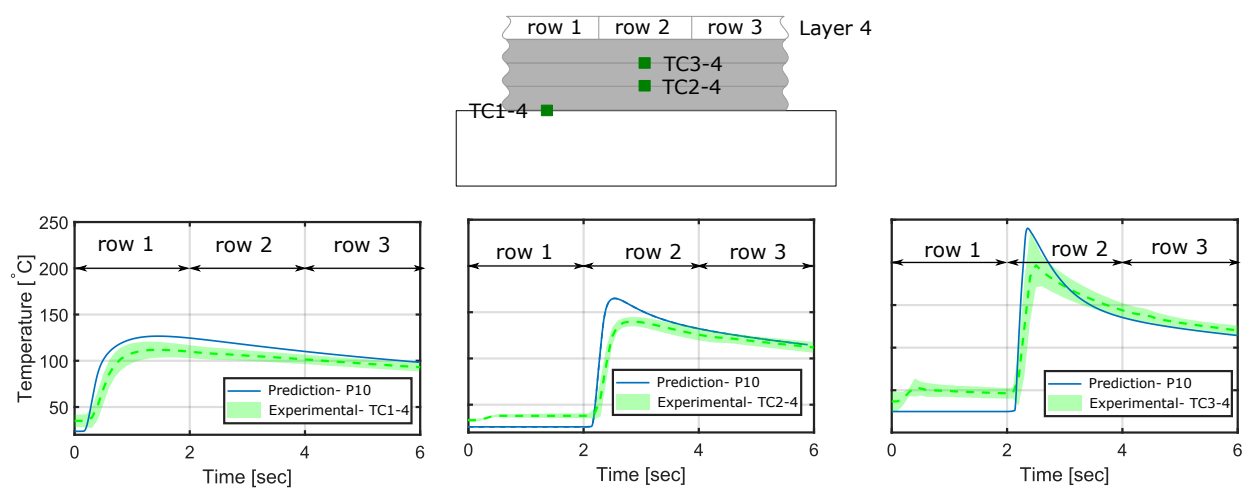

Figure 3.12 Comparing the temperature history of the thermocouple measurements with the predictions for single peak behavior of TC1 to 3 during winding layer 5. The experimental shaded area includes the information of the standard deviation of three trials.

substrate width was a straightforward way to quantify the temperature non-uniformity as a function of time and eventually compare with the thermocouple measurements. During winding of layer 4 , one temperature peak, i.e. single peak behavior, was observed as shown in Fig. 3.12 by the thermocouples TC1-TC3. The TC1 was heated during winding of row $1(0-2 \mathrm{~s})$, while TC2 and TC3 were heated during winding of row 2 (2-4 s). Considering the width of row 2 in Fig. 3.9, the temperature histories were predicted based on the location of point P10 which represents the central zone. On the other hand, two temperature peaks, i.e. double peak behavior, were observed in the temperature history of TC1-TC3 during winding of layer 5 as seen in Fig. 3.13. The TC1 was heated two times during winding of row 2 and 3 (2-6 s), while TC2 and TC3 were heated during winding of row 1 and $2(0-4 \mathrm{~s})$. The double peak behavior was due to the shift of layer 5 with respect to layer 4 in the axial winding direction as explained in Section 3.2. The corresponding predictions for the left (point P2) and right (point P18) zones were compared with TC2/TC3 and TC1, respectively. The shaded area for the measured temperature by the thermocouples covered the standard deviation of the three trials in Figs. 3.12 and 3.13 . It is seen that the thermoplastic liner acted as an insulator which resulted in a relatively slower cooling after the peak temperature for TC1 than TC2 and TC3. It is also seen that the experimentally observed trends for the single and double peak behavior of the temperature evolution were captured quite well with the developed KOT model. The discrepancies between the measured and predicted temperature values might be due to the uncertainties in the thermocouple locations during the winding experiments, the simplification of the winding angle and/or the model parameters which were taken from literature.

The predicted single and double peak behaviors for the temperature histories are summarized in Fig. 3.14 based on the maximum temperature distribution for row 2 during the winding of layer 4 . Here, the maximum temperature was reported at the layer $1 /$ layer 2 interface for each control volume node used in the KOT model. For the nodes on the left zone of row 2 i.e. 0 to $4 \mathrm{~mm}$, two temperature peaks (approximately $150^{\circ} \mathrm{C}$ and 210 


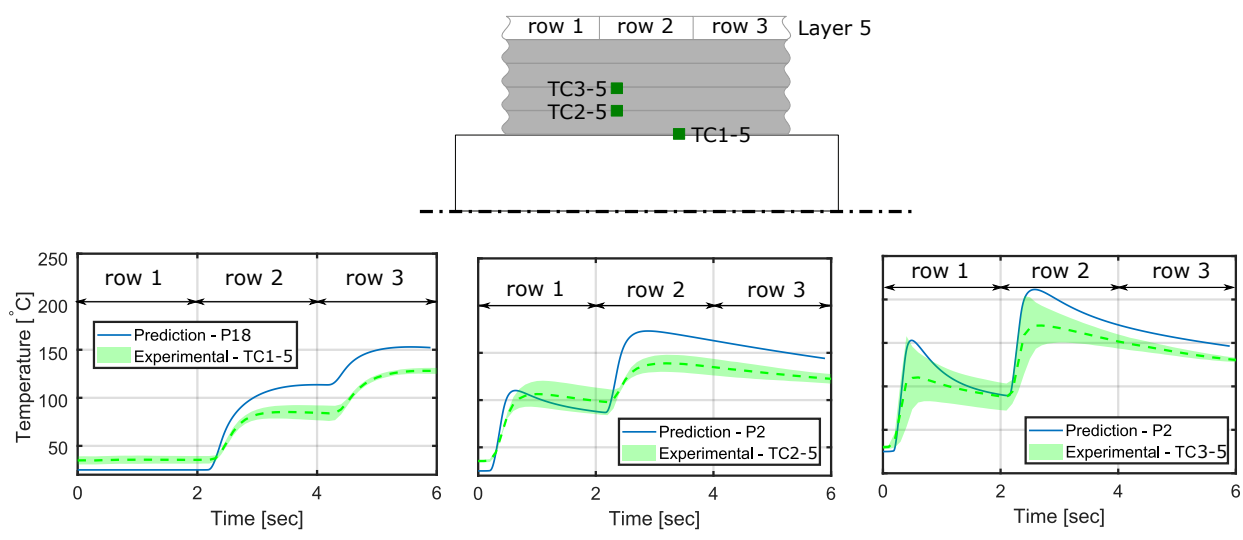

Figure 3.13 Comparing the temperature history of the thermocouple measurements with the predictions for double peaks behavior of TC1 to 3 during winding layer 5. The experimental shaded area includes the information of the standard deviation of three trials.

${ }^{\circ} \mathrm{C}$ ) were predicted during winding of row 1 and 2 . The second temperature peak was higher approximately $60{ }^{\circ} \mathrm{C}$ than the first temperature peak. In the central zone i.e. 5 to $14 \mathrm{~mm}$, the single temperature peak behavior was predicted with a peak temperature of approximately $165^{\circ} \mathrm{C}$ during winding of row 2 . Two temperature peaks were also the case for the right zone i.e. 15 to $20 \mathrm{~mm}$ with a value of $165^{\circ} \mathrm{C}$ for the first peak and $195{ }^{\circ} \mathrm{C}$ for the second peak. However, the second temperature peak of the right zone was found to be lower compared to the left zone because the left zone was heated at the layer 3/layer 4 interface while for the right zone this was at the layer 4/layer 5. Therefore, less heat was conducted to the layer 1/layer 2 interface at the right zone since it was more into the depth as illustrated at the top of Fig. 3.14. The peak temperatures at both the 4 and $16 \mathrm{~mm}$ locations were found to be lower than the average of the left and right zones, respectively. This was due to the heat conduction in the width direction toward the relatively colder central zone.

In Fig. 3.15, the predicted temperature peaks for all the interfaces from liner/layer 1 to layer 4/layer 5 are plotted during winding of layer 5 from left to right. The temperature of single peaks dropped approximately from $420{ }^{\circ} \mathrm{C}$ at the layer 4 surface to $105{ }^{\circ} \mathrm{C}$ at the interface of liner/layer 1 . On the left zone of all interfaces, the second peaks were always higher than the first peaks except for the corner node at $0 \mathrm{~mm}$. This was also the case for the right zone except at the layer 4/layer 5 interface where the second peaks were lower than the first peaks. The second peaks in the right zone took place only after the deposition of the incoming tape. Since the calculated deposited tape temperature at the nip line of $400{ }^{\circ} \mathrm{C}$ was lower than the temperature of the heated substrate surface i.e. $420^{\circ} \mathrm{C}$, the value of the second peaks dropped for the layer 4/layer 5 and layer 3/layer 4 interfaces at the right zone. 


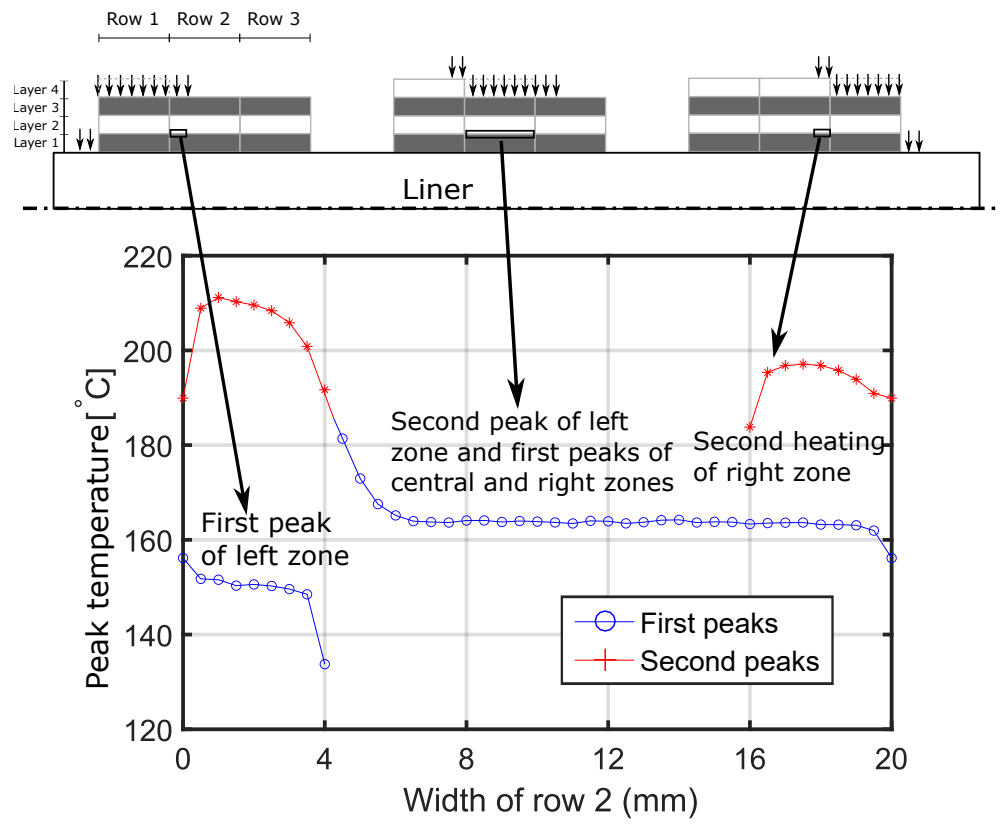

Figure 3.14 Temperature peaks predicted across the width of row 2 at layer 1/layer 2 interface during winding layer 4.

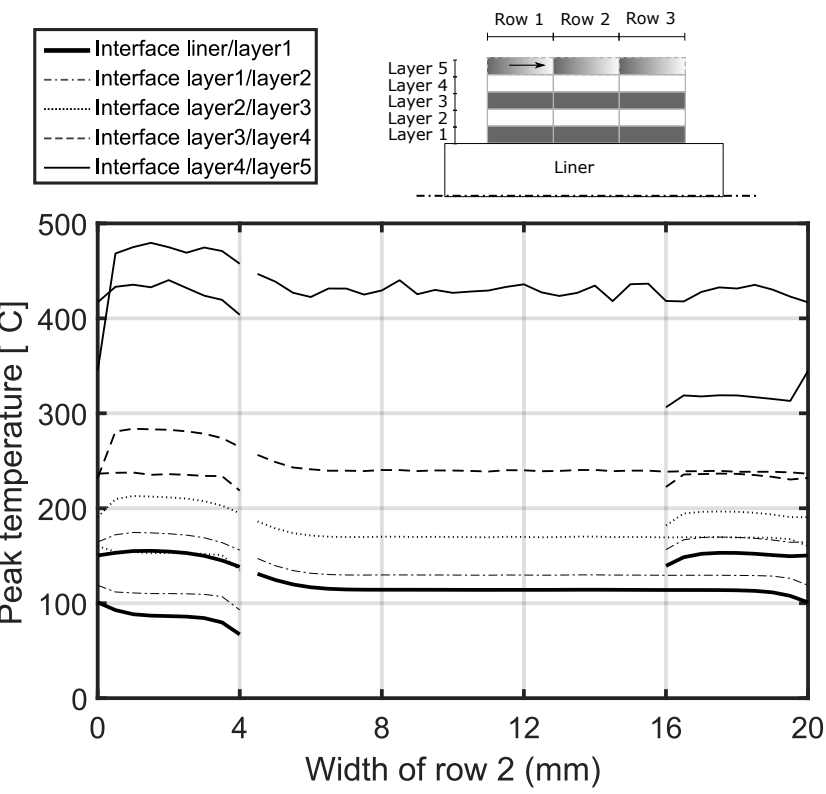

Figure 3.15 Predicted temperature peaks across the width of row 2 at various interfaces during winding rows 1 to 3 of layer 5 in the left to right direction. 


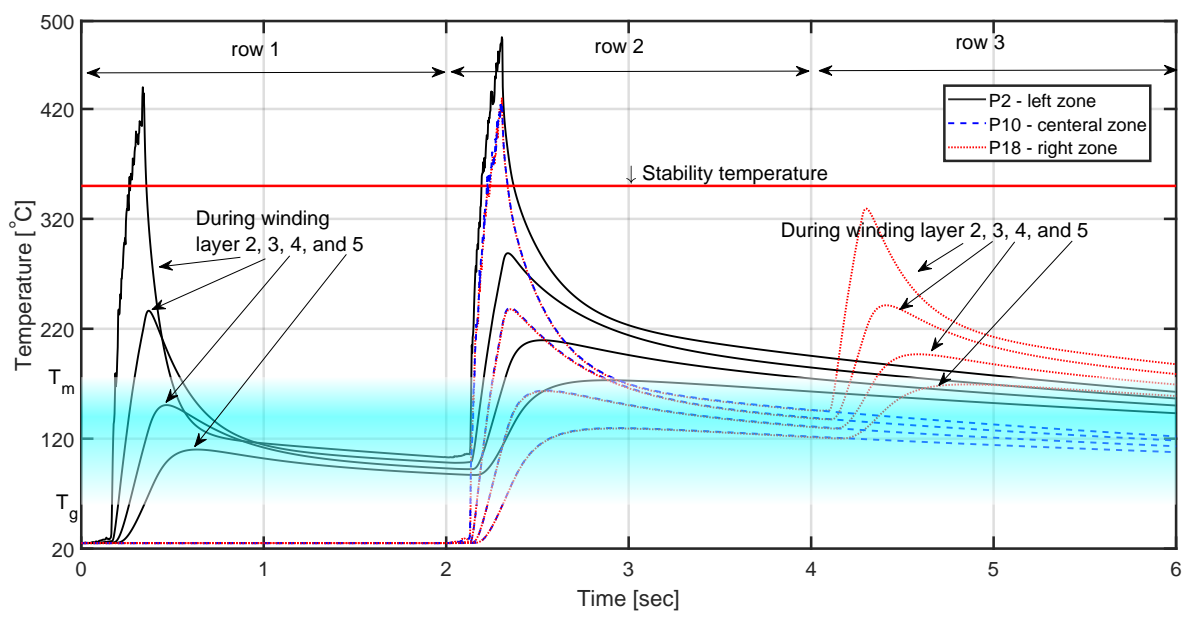

Figure 3.16 Temperature history of computational nodes at the layer 1/layer 2 interface during winding layers 2 to 5 layer for three zones of the row 2 with respect to the crystallization window shown as the shaded area. The PA12 is thermally stable below $350{ }^{\circ} \mathrm{C}[99]$.

\subsubsection{Crystallinity evolution}

An insight on the DoC development was gained by employing the predicted temperature history in the non-isothermal crystallinity model. The temperature histories and corresponding crystallinity evolution of points P2, P10, and P18 of row 2 at layer 1/layer 2 interfaces are shown in Fig. 3.16 during winding of layers 2-5. The PA12 polymer crystallizes between $T_{g}$ and $T_{m}$ with various growth rates [109, 106] which is shown as the shaded area in Fig. 3.16

The temperature of point P2 was found to be higher than $T_{m}$ for two times while winding row 1 of layers 2 and 3. This was the same case also for points P10 and P18 during winding of row 2 (note the large overlap between both points), however, the point P2 was remelted for three more times during the second heating of layers 2 to 4 . In addition, point P18 was heated above $T_{m}$ also for three times during winding of row 3 . Therefore, points P2 and P18 were remelted for 5 times in total and point P10 only for 2 times.

It is worth to mention that the temperature can reach above the thermal degradation or stability temperature as depicted in Fig. 3.16 due to multiple heatings. The temperature of point P2 was found to be above the stability temperature for about $0.19 \mathrm{~s}$ and this was approximately $0.068 \mathrm{~s}$ for points $\mathrm{P} 10$ and P18.

A closer look at the crystallinity evolution is provided in Fig. 3.17 as an exemplary result for the interface between layer 1 and 2. Only the relevant temperatures above $T_{g}$ are considered, therefore, the cumulative time above $T_{g}$ for each point is shown. The plotted temperature range on the y-axis was limited to temperatures that displayed relatively high crystal growth rates [106]. The temperature of point P2 was above $T_{m}$ during the second 


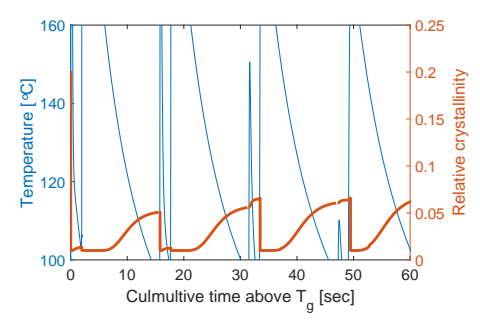

(a)

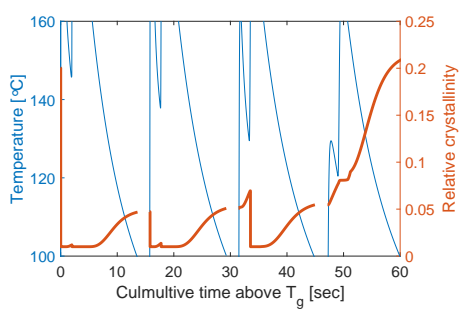

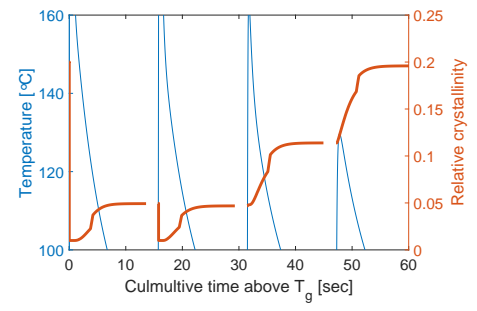

(b)

(c)

Figure 3.17 Temperature and crystallinity evolution history of points (a) $P 2$, (b) P10, and (c) P18 at the interface of the layer 1/layer 2.

heating for all the layers for a certain time period. Hence, for point P2 it is assumed that the DoC reached to the minimum value of $1 \%$ at the end of winding of each layer and the crystals started to grow again during cooling phase. Therefore, only the last cooling cycle of point P2 contributed to the final DoC i.e. 51-60 s. For point P18, a slightly different history was recorded and the re-crystallization took place after winding of layer 4 and during layer 5. Although, the point P10 re-crystallized during three consecutive layers of 3 to 5, almost the same DoC was predicted as point P18. This was due to the slower cooling rate after the second peak for point $\mathrm{P} 18$ than point $\mathrm{P} 10$ within the crystallization window. The temperature of initial sharp cooling was way above $T_{m}$ for point 18 and the subsequent moderate cooling fell in the crystallization window while for point P10 the sharp cooling after the nip point was within the crystallization window, resulting in slower growth of crystals which was captured by the implemented crystallization model.

The resulting crystallization distribution of row 2 is visualized in Fig. 3.18 at the end of each layer which gives a global understanding of how the crystals were developed as a function of winding layers. The DoC variations in the through thickness direction with the highest DoC close to the liner were $14 \%$ (0.08 to 0.07 ) and $875 \%(0.78$ to 0.08$)$ at the end of winding layers 2 and 5, respectively. Thus, the DoC variation in the through the thickness direction was found to be considerably larger as the number of wound layers increased. The winding of the subsequent layers annealed the first layer which allowed the crystals to grow from $\mathrm{DoC}=0.08$ at the end of winding layer 2 up to $\mathrm{DoC}=0.78$ at the end of winding layer 5 at $x=15.5 \mathrm{~mm}$. Besides, the liner was pure thermoplastic acting as a thermal barrier leading to lower cooling rate and therefore higher DoC. 


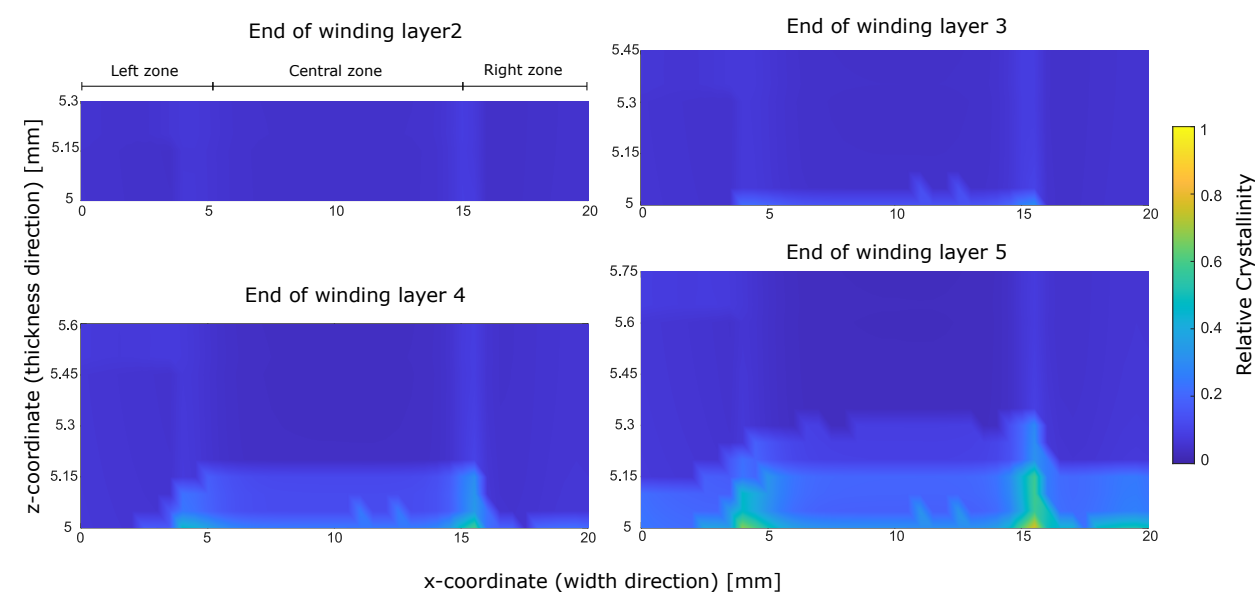

Figure 3.18 The cross-sectional distribution of the crystallinity degree of the row 2 after winding layers 2-5.

In the width direction, however, the maximum DoC variation for layer 1 and 5 was approximately $270 \%$ ( 0.78 to 0.21$)$ and $167 \%$ (0.08 to 0.03 ) at the end of winding layer 5 , respectively. The maximum DoCs were predicted at $x=4.5 \mathrm{~mm}$ and $x=15.5 \mathrm{~mm}$ across the substrate width. At the end of winding layer 5, the averaged DoC of the left and right zones were 0.12 and 0.14 , respectively. For the central zone the mean DoC was lower and equaled to 0.1 as shown in Fig. 3.18. This suggests that the double heating increased the relative DoC level in general.

The measured DoC for left, central, and right zones of the row 2 are depicted in Fig. 3.19 In order to compare the predicted DoC with the measured one, the average DoC of the calculation nodes within each zone as annotated in 3.18 was calculated. Reasonable agreement is seen regarding the trend of average crystallinity distribution through the investigated zones as the central zone had the least Doc $=0.53$ and right side had highest $\mathrm{DoC}=0.58$ based on the performed DSC analysis. On the other hand, a discrepancy can be observed between the overall predicted and experimental values. As the input parameters for the used crystallization model were verified experimentally, we further investigated the influence of the programmed melting behavior. The measured DoC were in between two extreme cases, one where no melting took place and one case where melting of all crystals was set once the temperature reached above the melting temperature (current situation). The experimental values from DSC were closer to the case without any melting. It is likely that, during the LATW process, the amount of melting is very low due to the rapid heating rates and short durations above the melting temperature. Also, it is known that incomplete melting of crystals increases the rate of crystallization during subsequent cooling as the (partially molten) crystals act as nucleating agents, increasing the final crystallinity in a layer [110]. The consequence of incomplete melting on crystallization during cooling shows the importance of the melting behaviour during LATW process, which needs to be considered for a more realistic crystallinity prediction. 


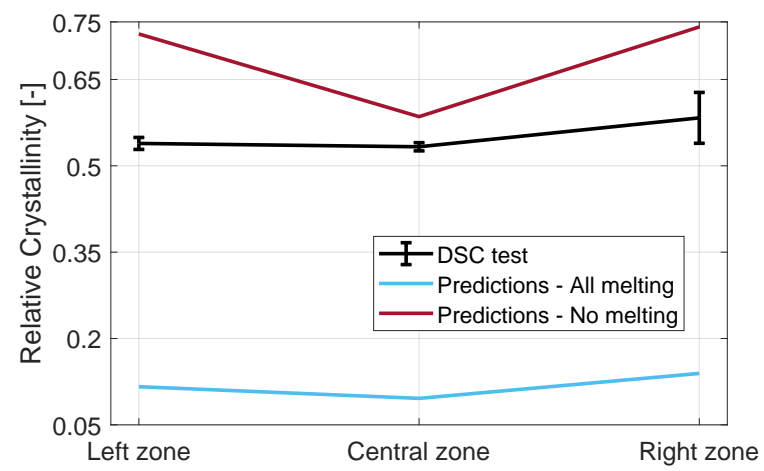

Figure 3.19 A comparison between measured and predicted average DoC for each investigated zone considering two extreme melting behavior for the crystallinity model.

\subsection{Conclusion}

The temperature and crystallization evolution during the LATW process with adjacent hoop pattern were investigated both experimentally and numerically for manufacturing of C/PA12 pipes. A numerical kinematic-optical-thermal (KOT) model was developed considering the substrate mass growth both in thickness and in-plane directions. Besides, the anisotropic reflections of laser rays were modeled leading to an accurate prediction of absorbed heat flux on the substrate and tape surfaces. The crystallinity distribution was predicted by forwarding the KOT model to a non-isothermal crystallization model taking the melting kinetics into account. The temperate history was well captured during manufacturing of three small pipes by means of thermocouples in the through thickness direction. The temperature distributions on the substrate surface were obtained by utilizing a thermal imaging camera. The KOT model was validated by comparing the temperature predictions with the experimentally measured temperature.

Multiple heating and cooling histories at the edges of the substrate were captured by the temperature measurements and predictions which resulted in a significant temperature gradients for the substrate in the width direction. The edges of the substrate were heated two times which resulted in a temperature increase of approximately $50{ }^{\circ} \mathrm{C}$ at the edges as compared with the central region of the substrate. The non-uniform temperature distribution caused a non-uniform distribution of the degree of crystallinity across the width of substrate. It was found that the layers close to the liner had a higher degree of crystallinity up to 0.78 due to the annealing effect during winding of subsequent layers. The maximum crystallinity variation in the width and through thickness directions were found to be of $270 \%$ and $875 \%$ at the end of winding layer 5, respectively. A comparison between the measured and predicted degree of crystallinity across the width of the substrate was made with agreements in the trends. In this work, the rate of melting was overestimated. It is likely that limited melting occurred due to the high heating rates and short melting times throughout the process. It was shown that the melting behavior 
should be considered in more detail for a more realistic prediction. It was observed that complex temperature and crystallinity distributions were obtained even with constant process parameters during adjacent hoop winding of tapes. Therefore, the heat flux distribution on the substrate needs to be optimized by creating a near-uniform laser power distribution instead of top-hat distribution with a same laser spot width as the prepreg width to minimize the temperature and crystallinity gradients across the wound tape. The developed KOT model paves the road toward an accurate process design tool for reliable manufacturing of continuous thermoplastic pipes with high and uniform quality. The accuracy of the KOT model can be further improved by taking different winding angles into account causing a change to the illuminated substrate geometry, which is considered as a future work. 


\title{
CHAPTER 4
}

\section{HELICAL WINDING}

\begin{abstract}
A new global kinematic-optical-thermal (KOT) model is proposed to provide a proper understanding and description of the temperature evolution during laser-assisted tape winding and placement (LATW/LATP) on any arbitrary shaped tooling geometry. Triangular facets are utilized in the kinematic model to define a generic tooling together with a user-defined fiber path and time-dependent process settings such as the tape feeding rate. The time-dependent heat flux distribution on the surfaces is calculated by the optical model and subsequently coupled to the thermal model. The numerical implementation of the developed KOT model is first verified for process simulations of the LATP on a flat tooling by comparing the temperature predictions with the available literature data. To validate the KOT model, a total of four pressure vessels are manufactured with in-line temperature measurements. The process temperature predictions are found to agree well with the measured temperature during the helical winding. The influence of the changing tooling curvature and process speed on the process temperature is found to be significant as shown by the experimental and numerical findings.
\end{abstract}




\subsection{Introduction}

The laser-assisted tape winding (LATW) is an automated manufacturing process to produce fiber-reinforced thermoplastic composites with high strength-to-weight ratio. Relatively large and complex-geometry composite parts can be manufactured by LATW in which the material is deposited layer by layer which is similar to the laser-assisted tape placement process (LATP). The incoming prepreg tape and the already deposited substrate are locally heated by the laser source in LATW and LATP process. The insitu consolidation which takes place at the so-called nip point under the compaction roller is the main mechanism to form the composite parts. A variety of products can be manufactured in a single step such as pressure vessels, tubes, and pipes produced by LATW.

The final product quality and performance are highly dependent on the process temperature together with the speed, consolidation force, and surface preparation [50, 111, 112, 113]. The process temperature has a direct influence on intimate contact development [33, 34], bonding quality [114], and process-induced residual stresses [115]. Since the thermal phenomena play a vital role in the LATW and LATP process of thermoplastic composites, the process temperature has been researched extensively in literature as summarized in the following.

The effects of laser settings and lay-up speed on the processing temperature were investigated in [116, 23, 59] for LATP processes. An optical-thermal model was developed in [24] and the process temperature was found to be affected slightly by the substrate fiber orientation. The effect of roller temperature, geometry, and thermal contact resistance on the substrate and tape temperature was studied in [61] in an LATP process. The role of the thermal contact resistance between the deposited layers was investigated in [70, 117] for LATP on flat tooling geometries. The effect of winding direction on the process temperature was studied for a constant curvature tooling in [60] considering a LATW process. The temperature distribution during adjacent placement of thermoset prepregs was studied in [64] experimentally and numerically. The nonuniform temperature distribution on the part and tooling was described. The temperature distribution in the successively wound hoop layers was investigated in [57, 38] using a LATW setup. The overlapping of the incoming tape with the already deposited substrate in the case of helical LATW process was investigated experimentally in [55]. It was observed that due to the local variation of the substrate geometry a considerable peak in temperature during the step-off stage was taking place. The temperature distributions effect on the polymeric structural parameters such as degradation weight loss and crystallinity were investigated with respect to the process parameters [10]. Advanced optical models were developed in [26, 24, 25] to predict the anisotropic reflection behavior of the composite tapes which directly affects the heat flux distribution on the tape and substrate surface. An inverse thermal model was introduced in [31] for LATP of thermoplastic prepreg tapes on flat tooling. The required heat flux distribution was obtained for a given desired heating zone temperature distribution. An analytical process model was employed in [58, 29] for the LATP process using a flat tooling geometry. Guidelines for the thermal process design, optimum heat flux distribution and control were drawn based on the laser power and heating length. 
To date there has been limited research completed on the temperature characterization of the LATP and LATW processes on complex tooling geometries such as helical winding of the doubly-curved dome part of the pressure vessel. The substrate temperature was predicted in [118] for a thermosetting resin-based AFP process with a complex tooling geometry in aerospace applications. In order to calculate the transient heat flux from an arrayed-infrared emitter heat source, view factors were used for the discretized substrate and heater surfaces. The effect of the fiber path on the temperature development was quantified by comparing two fiber paths with an offset on the part surface. The temperature variation due to the change in local tooling curvatures was studied in [30] for a 2.5 dimensional $(2.5 \mathrm{D})$ geometry. It was shown that the temperature increased due to the local decrease in process speed and increase in the local surface curvature. An adaptive vertical-cavity surface-emitting laser (VCSEL) source was employed to regulate the power for a more uniform process temperature.

Since the local geometry varies while depositing the prepreg tape on complex tooling geometries and fiber paths, e.g. [119, [120, 121, 48], the temperature near nip point is inherently affected which has not yet been investigated comprehensively. The timeand location-dependent process settings need to be adjusted and optimized to obtain the desired process temperature in complex cases of LATP and LATW processes. To this end, a 3D generic kinematic-optical-thermal (KOT) model is developed for the first time to predict the temperature history and evolution in LATW/LATP processes with complex tooling geometries and arbitrary fiber paths accompanying time-dependent process settings. A computer-aided-design (CAD) model of an arbitrary tooling surface is first discretized into a triangulated mesh. The thickness distribution history based on the trajectory of the tape on the tooling surface is calculated by the kinematic model which provides also the calculated position of the tape laying head (TLH) for the optical model. The transient heat flux distribution translated from the laser irradiation and reflections is estimated by the optical model taking the varying curvature of the substrate into account. The substrate temperature is modeled with stationary 1D through-thickness thermal domains defined for each triangular facet of the tooling surface. The incoming tape is modeled independently with a $2 \mathrm{D}$ transient Eulerian thermal model considering the advection term for the material flow. A mesh study is performed to have a converged result and the numerical implementation of the developed KOT model is verified with the literature data. To validate the effectiveness of the KOT model, a total of four pressure vessels are manufactured and the measured process temperature by the thermal camera is compared with the predictions. The effect of the dome surface curvature and tape feeding rate (TFR) variation on the temperature evolution is quantified using the developed model. As compared with the reported literature which is summarized in Table 4.1, the proposed KOT modeling approach is advantageous to simulate the LATW and LATP process for 3D arbitrary geometries with varying fiber paths and process settings such as process speed and laser power. 
Table 4.1 Overview of the reported literature on numerical simulation of ATW and AFP processes with considered features in studies focusing on the investigation of temperature development in AFP and ATW processes.

\begin{tabular}{|c|c|c|c|c|c|c|}
\hline $\begin{array}{l}\text { Process - } \\
\text { Ref. }\end{array}$ & $\begin{array}{c}\text { Tooling } \\
\text { geometry }\end{array}$ & $\begin{array}{c}\text { Fiber path } \\
\text { direction }\end{array}$ & Process speed & Laser power & $\begin{array}{c}\text { Anisotropic } \\
\text { reflection }\end{array}$ & $\begin{array}{c}\text { Model } \\
\text { validation }\end{array}$ \\
\hline $\begin{array}{l}\text { AFP } \\
118\end{array}$ & 3D arbitrary & Constant & Constant & Constant & No & No \\
\hline AFP [30] & $\begin{array}{l}2.5 \mathrm{D} \text { single- } \\
\text { curved }\end{array}$ & Constant & Time-dependent & Time-dependent & No & Pyrometer \\
\hline AFP [59] & Flat & Constant & Time-dependent & Time-dependent & No & IR camera \\
\hline AFP [24] & Flat & Constant & Constant & Constant & Yes & $\begin{array}{l}\text { IR camera and } \\
\text { thermocouples }\end{array}$ \\
\hline ATW 23 & $\begin{array}{l}\text { Single- } \\
\text { curved }\end{array}$ & Constant & Constant & Constant & No & No \\
\hline $\begin{array}{l}\text { Current } \\
\text { study }\end{array}$ & 3D arbitrary & Varying & Time-dependent & Time-dependent & Yes & IR camera \\
\hline
\end{tabular}

\subsection{Experimental}

The unidirectional prepreg used in this study was Celstran ${ }^{\circledR}$ glass fiber GF70-01/ highdensity polyethylene (HDPE) with $70 \%$ fiber weight fraction and $47 \%$ fiber volume fraction manufactured by Celanese. It is well suited for applications where cost and processability are critical providing excellent toughness and chemical resistance. The liners of the pressure vessels (type-IV) were made of pure HDPE thermoplastic by blow molding process which has been exploited in hydrogen storage [122] and compressed natural gas shells [123].

The TLH of the tape placement system used for the manufacturing of the pressure vessel consisted of the relevant laser source, incoming tape, and roller as depicted in Figs. 4.1a and 4.1b. The position of each part was determined with respect to the roller center. A total of 4 pressure vessels were manufactured using the LATW setup and the pictures of one of the vessels are shown in Fig. 4.2a. As it is seen, the cylindrical part of the liner made of blow molding process was first reinforced with three layers by hoop winding. Subsequently, the whole vessel including the cylindrical and dome parts was covered with four additional layers via helical winding where each layer consisted of 29 circuits. As seen in Fig. 4.2a, the already wound helical layers were overlapped at a certain point which resulted in cross over points. It should be noted that the focus of this work is on the helical winding process for cylinder and dome parts, for which a geodesic path was generated by the CAD/CAM-software ComposicaD as depicted in Fig. 4.2b The designed fiber path was then post-processed as a machine code for the robot actuator.

Each helical circuit of the tank winding process took $\sim 24 \mathrm{~s}$ consisting of $2 \times 5.46 \mathrm{~s}$ for tape placement on the cylindrical part and $2 \times 6.54 \mathrm{~s}$ for tape placement on the dome parts. The complex geometry of the dome required significant orientation changes of the robot positioning and the tape winding applicator. Therefore, the TFR in the dome part was varied and considerably lower with an average value of $46.4 \mathrm{~mm} \mathrm{~s}^{-1}$, as compared to the constant TFR for the cylinder part $\left(150 \mathrm{~mm} \mathrm{~s}^{-1}\right)$. The robot controller converted the fiber path to the synchronized movement of the robotic arm and the liner rotation while following the time-dependent TFR history. In this case, the TLH ran back and forth in the plane along the symmetrical axis of the liner with a varying velocity at the domes. 


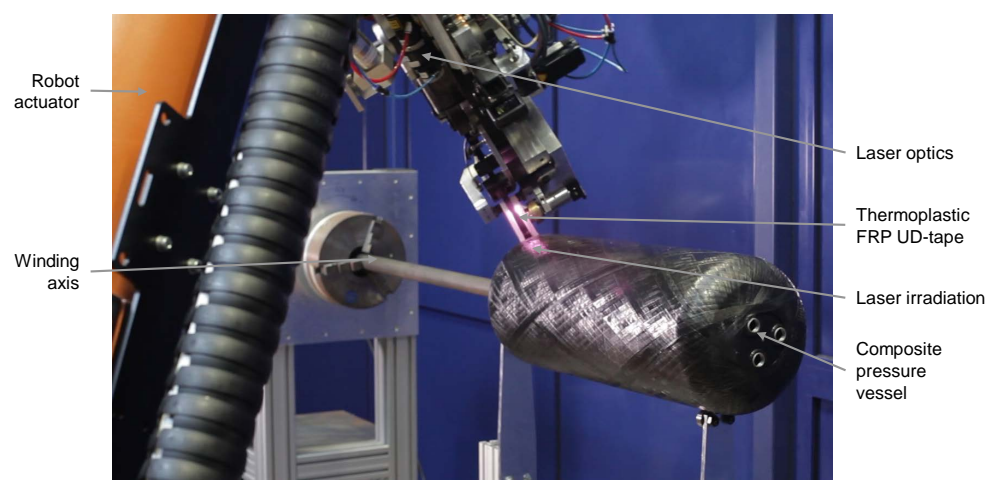

(a)

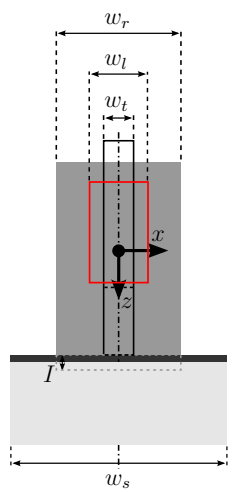

Front view
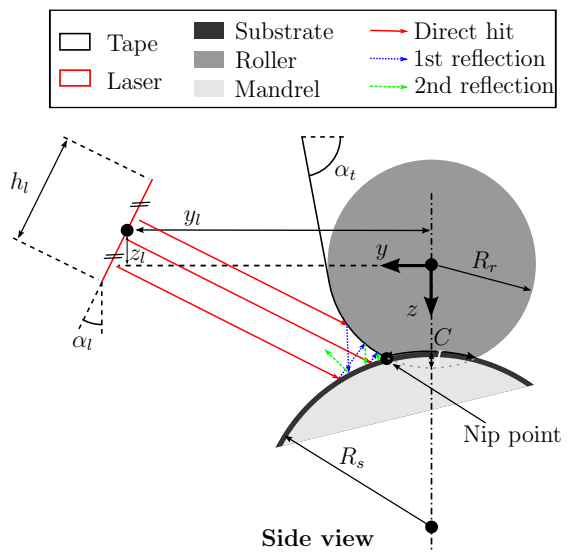

Side view

(b)

Figure 4.1 (a) A snapshot of the LATW process set-up during pressure vessel winding (@Fraunhofer IPT). (b) Schematic view of the tape laying head (TLH) geometry including laser source, incoming tape, and compaction roller to be used in the optical model (reproduced with permission from [26])

The liner rotated with a time-dependent angular velocity as well. As the TLH gradually reversed at the poles of domes, the corresponding winding angle needed to be adapted transiently as a consequent. In addition, pretrials with systematic parameter variation were performed in order to determine the separate laser power values for cylinder and domes parts. The laser power was instantaneously changed at predetermined points along the fiber path during the continuous winding process.

The parameters relevant to process stability and consolidation quality like the temperature distribution in the laser-irradiated zone, the compression force applied by the consolidation roller and the TFR were continuously monitored during the process. The temperature distribution was captured with an infrared thermographic camera by DIAS Infrared (Pyroview 380Lc type) and was evaluated by extracting characteristic average 


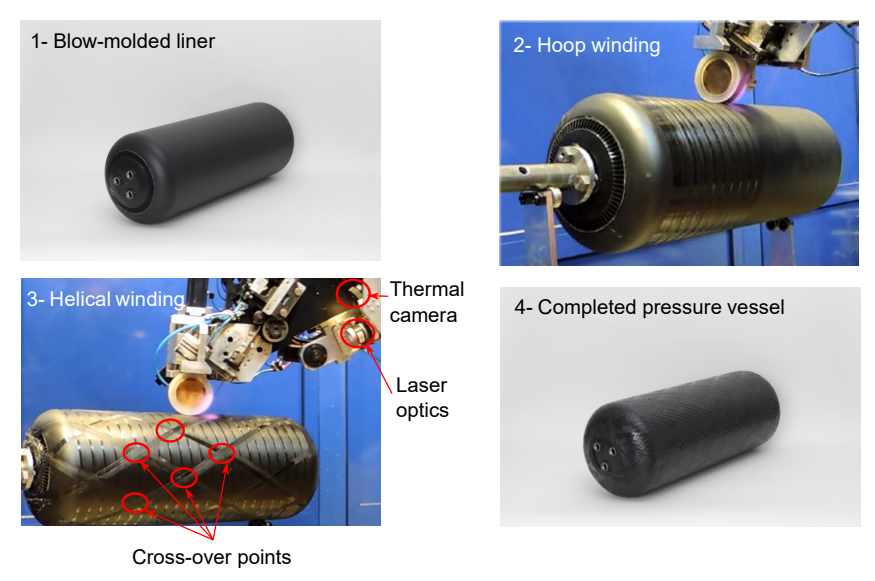

(a)

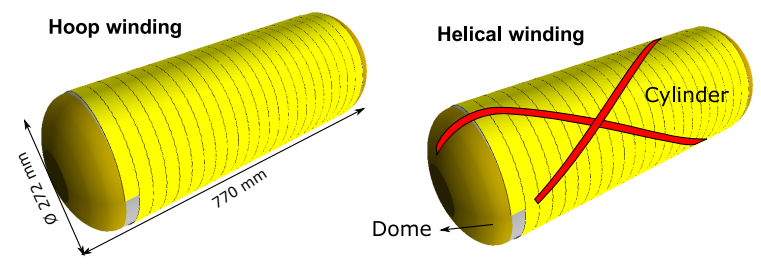

(b)

Figure 4.2 (a) Pictures of the manufactured pressure vessel in each step of the LATW process (@Fraunhofer IPT). (b) Designed fiber paths visualized by CAD/CAM-software ComposicaD program for the helical and hoop winding of pressure vessel manufacturing. Hoop winding of 1 layer and helical winding of 1 circuit are visualized.

values from predetermined areas defined in the thermographic image in the associated software Pyrosoft Professional as shown in Fig. 4.3. The averaged temperature within the characteristic boxes for the tape, nip point and substrate were extracted from the thermal video stream with a frequency of $6.3 \mathrm{~Hz}$ and used for comparison with the simulation results. The dimensions of the tape and substrate characteristic boxes equaled half of the tape width. The distance of the measurement box center to the visible nip point in the $2 \mathrm{D}$ thermal image was approximately $5 \mathrm{~mm}$ as shown in Fig. 4.3 , however, the thermal camera was installed above the laser optics as seen in Fig. 4.2a which means that the thermal camera did not have a visual on the actual nip point. It was estimated that the distance of the measuring box for the tape and substrate to the actual nip point was approximately $25-30 \mathrm{~mm}$ and $5-10 \mathrm{~mm}$, respectively. A constant emissivity coefficient of 0.9 was set in the thermal camera for tape and substrate based on the experiments performed in [38]. 


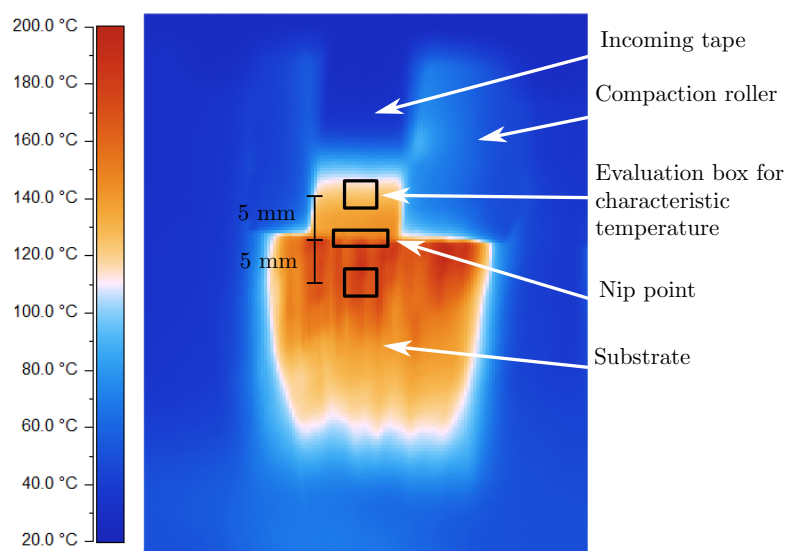

Figure 4.3 A snapshot of the thermographic video with the characteristic components and the predetermined areas defined for averaging the characteristic temperature of the substrate, tape, and nip point

\subsection{Generic kinematic-optical-thermal (KOT)}

model An overview of the developed coupled KOT process model for generic LATW/LATP is presented as a flowchart in Fig. 4.4. The utilized geometry, mesh, winding path, as well as the process and material properties, were first defined by the user. Accordingly, the trajectory of the tape on the surface mesh and the thickness distribution were defined in the kinematic model. The heat flux distribution on the surface mesh calculated in the optical model was used as an input for the thermal model in order to predict the transient temperature distribution and evolution on the tape and substrate surfaces. Each block of the flowchart in Fig. 4.4 is described in detail in the following sections.

\subsubsection{Tooling mesh and fiber path generations}

The tooling geometry and fiber path were considered as the user-defined inputs. The tooling was described by standard geometries, e.g. a cylinder, or by generic stereolithography (STL) format with a 3D triangular surface mesh. The input fiber path was defined as scatter points in 3D space on the tooling surface mesh. The space between the fiber path points was adjusted based on the desired time-dependent TFR value considering a constant time step.

\subsubsection{Kinematic model}

The kinematic model was used to support the thermal and optical models by providing the TLH position for the optical model and the thickness distribution history in each time step for the thermal model. The global inputs and outputs of the kinematic model were defined 


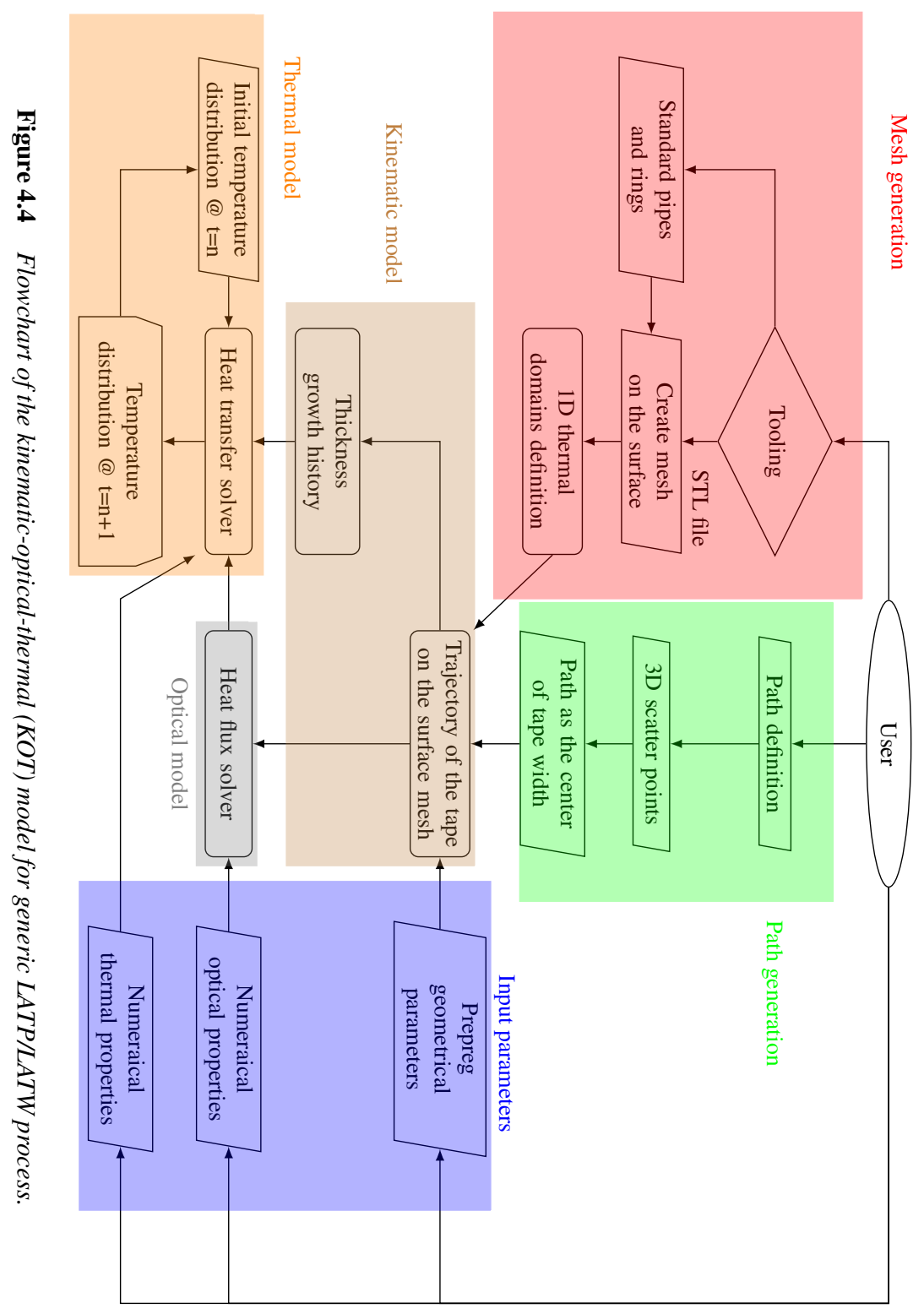




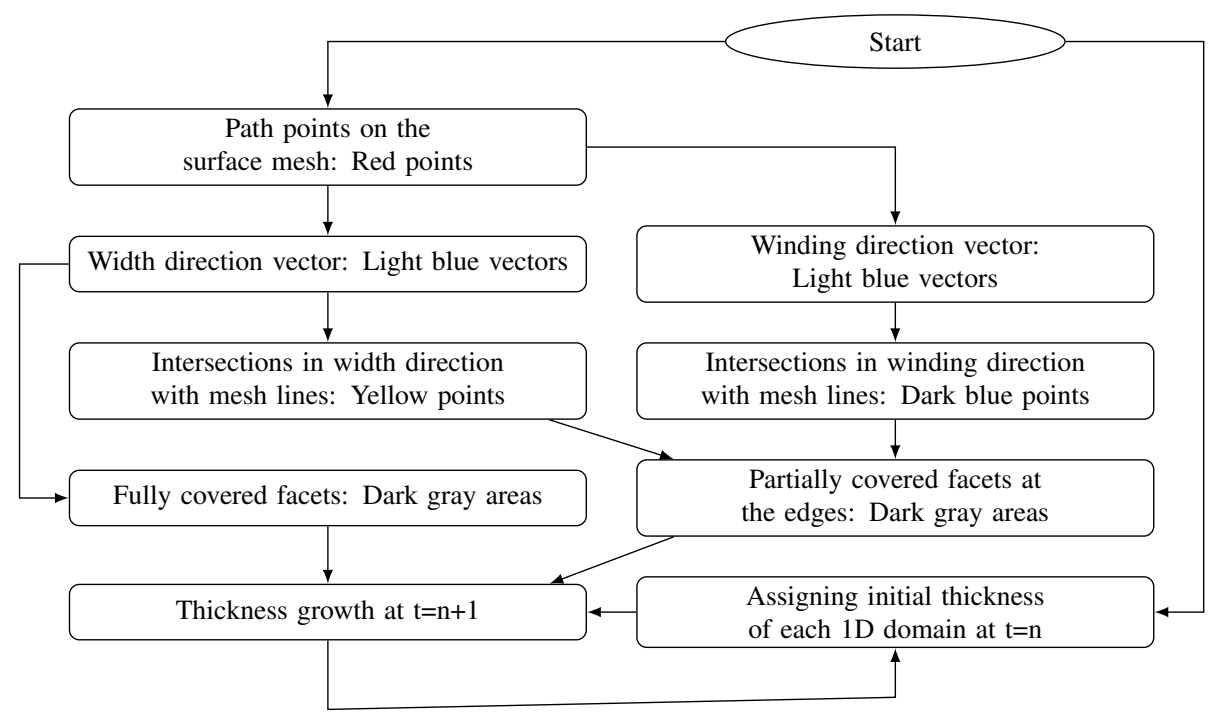

Figure 4.5 Flowchart of the of the kinematic model describing the tape trajectory and thickness growth algorithm. (see also Fig. 4.6)

in the flowchart of Fig. 4.4 and a detailed flowchart of the kinematic model description is presented in Fig. 4.5. A schematic view of the kinematic model is presented in Fig. 4.6 for a cylindrical shaped tooling. The path points indicated in Fig. 4.6 with the red points were defined in the 3D domain. The location of each path point was defined at the center of the depositing tape. A valid assumption in the kinematic model was the geodesic fiber deposition due to the in-situ consolidation i.e. the deposited tape follows the fiber path after the deposition. The details of the kinematic model implementation are explained in the following.

\section{Vectors in width and winding directions}

The computational winding direction was defined by the vector connecting two consecutive path points. This vector was then projected on the plane of the former path point's facet. Then the width direction vector $\left(\hat{\mathbf{V}}_{w i d t h}\right)$ was determined as the cross product of the facet normal ( $\hat{\mathbf{n}})$ and winding vector $\left(\hat{\mathbf{V}}_{\text {wind }}\right)$, i.e. $\hat{\mathbf{V}}_{\text {width }}=\hat{\mathbf{V}}_{\text {wind }} \times \hat{\mathbf{n}}$ since both winding and width directions laid in the same plane and perpendicular to each other as shown in Fig. 4.6 by the blue vectors.

\section{Width intersections}

To determine which facets were covered by the deposited tape, the path point needed to be extended in the width direction. The line starting from the path point as the tape center to the intersection of $\hat{\mathbf{V}}_{\text {width }}$ with the facet edge was the first segment of the tape extension to one side. The adjacent facet of the intersected edge can be determined since 


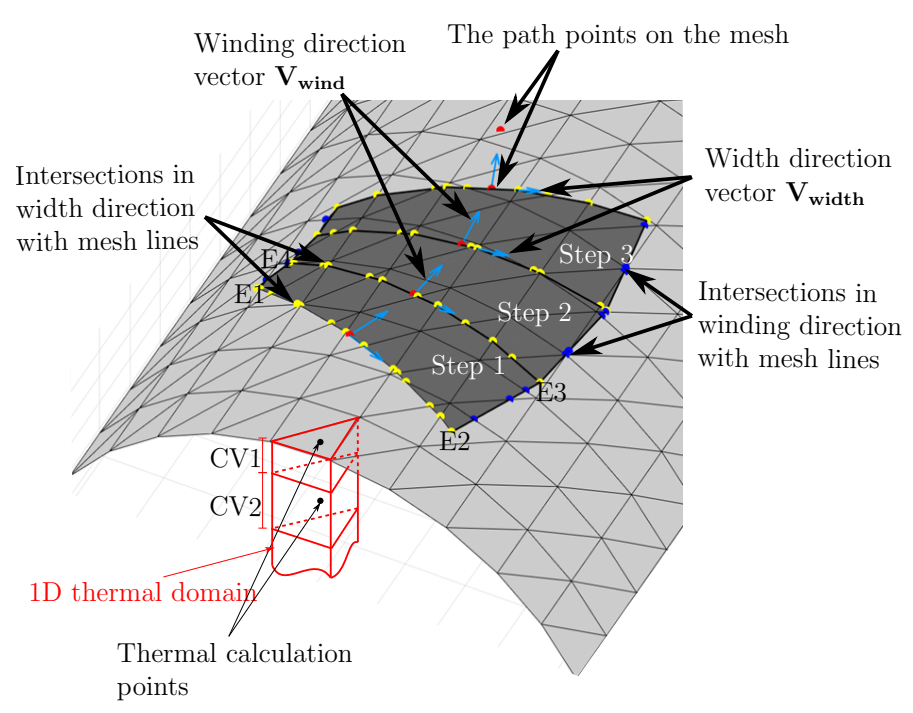

Figure 4.6 A visualized description of the kinematic model and the $1 D$ substrate thermal domains positioned in the $3 D$ space.

each edge was common for two facets. The second segment considered the adjusted width direction by projecting the $\hat{\mathbf{V}}_{\text {width }}$ to the adjacent facet plane and the starting point was the intersection point on the edge. This process continued until the cumulative length of the line segments reached half of the tape width at point E2 in Fig. 4.6 The same procedure was also employed in the reverse direction to cover the other half of the tape width (point E1). The intersections of the deposited tape with the edges in the width direction are shown by the yellow points in Fig. 4.6 .

\section{Winding intersections}

The intersection of the tape edges in $\hat{\mathbf{V}}_{\text {wind }}$ was calculated in the next step with the same approach in the width direction. The starting points were the right-most e.g. E2 and leftmost e.g. E1 points across the width. The line segments were added in winding direction until reaching the width line segments of the next time step (points between E3 to E4). If the two right-most (E2 and E3) or left-most (E1 and E4) points of the width direction were in the same facet for two consecutive time steps, no intersection in winding direction was defined. The intersections of the deposited tape with the edges in winding direction are shown by the dark blue points in Fig. 4.6. Uniform thickness distribution in the width direction was assumed in the developed kinematic model.

\section{Covered facets and thickness increase}

Knowing the intersection points and corresponding facets, the fully and partially covered facets were determined in the final step of the kinematic model. To identify the fully 
covered facets, the facets at the vicinity of the intersection points were considered except the already partially covered facets. The endpoints of the width intersections for two consecutive time steps e.g. points E1, E2, E3, and E4 shown in Fig. 4.6, were projected to the query facet plane. If all the vertices of the facet were found to be on the polygon formed by the projected E1-E4 points, the corresponding facet was defined as fully covered.

During depositing the new layer $i$, the increase in the thickness $\left(t_{d i}\right)$ on the calculation domain $j$ with facet area of $A f_{i j}$ was defined based on the amount of covered facet area $\left(A c_{i j}\right)$ :

$$
t_{d i}=A c_{i j} / A f_{i j} \times t_{p}
$$

where $t_{p}$ was the nominal prepreg thickness. The thickness increment equaled to the prepreg thickness $\left(t_{d i}=t_{p}\right)$ for fully covered facets since $A c_{i j}=A f_{i j}$ and $t_{d i}<t_{p}$ for partially covered facets which were located at the tape edges as seen in Fig. 4.6 The timedependent thickness distribution was therefore determined accordingly and forwarded to the thermal model.

\subsubsection{Optical model}

The triangulated surface in the KOT model was considered as stationary and the TLH followed the fiber path defined on the tooling surface. Therefore, the TLH was positioned in each time step according to path point location, the normal of the surface, and the winding direction. The surface of the tape and roller were also triangulated in the optical model. The geometrical parameters of TLH consisted of the laser source, incoming tape, and compaction roller are explained in Fig. 4.1b The relative position of the roller and laser source was assumed to remain constant throughout the process.

The optical model developed in [26] was the basis of the current optical modeling approach. A summary of the optical model implementation is explained briefly in the following. Once the geometry was constructed, a set of collimated rays were launched from the laser position using the Sobol sampling. The rays were modeled based on the ray-tracing approach. It calculated the locations where the rays hit on the tape, substrate, and roller. The interaction between a single ray and the hit body was described by the optical micro-model. The micro-model simulates the anisotropic reflection behavior of the composite surface using a bidirectional reflectance distribution function (BRDF). The reflection behavior was modeled by generating new rays based on the microfacet distribution function imitating the reflection patterns observed by the composite surface. The reflected ray energy was calculated using the Fresnel equation based on the relevant microfacets considering the initial ray incident angle in the macro-model. Further details can be found in [26].

The optical and thermal computational nodes for the substrate were the same following the triangulated mesh as seen in Fig. 4.6. Therefore, the absorbed light collected by each facet on the substrate mesh was introduced as the input heat flux for the corresponding substrate 1D thermal model. On the other hand, the optical and thermal nodes did not match each other for the incoming tape. The tape heat flux would post-processed to match to the fixed tape geometry with structured square bins of $1 \mathrm{~mm}^{2}$ in the feeding 
and width directions [26]. Although the tape geometry complying with the roller profile together with the relative position of the laser was fixed, the heat flux was varying due to the reflections coming from the substrate which had a location-dependent geometry. Only one reflection of the incoming laser ray was considered in the present work. The output of the optical model applied to the tape and substrate surfaces in the 3D space coordinates $(X)$ was a time-dependent heat flux field $q_{i}^{\prime \prime}(X, t)$. The heat flux distribution on the tape and facets for the substrate were then forwarded to the thermal model as a heat flux boundary condition in each time step to calculate the transient temperature distribution.

\subsubsection{Thermal models}

The incoming tape and substrate were modeled separately because the tape geometry remained constant, i.e. complying the roller geometry as mentioned before, whereas the substrate geometry had a varying profile, i.e. time-dependent geometry. The tape was therefore modeled up to the nip point, while the substrate computational domain on the fiber path included all the heating, deposition, consolidation i.e. under the compaction roller, and cooling to the surrounding air phases. The tape and substrate thermal models were coupled at the nip point where the tape model provided tape nip point temperature for the substrate model.

\section{Substrate model}

A schematic view of the 1D thermal domains in 3D space is demonstrated in Fig. 4.6 Each triangular facet of the tooling surface was defined as one control volume (CV)-based thermal domain through the thickness direction. The governing equation for the transient 1D heat transfer problem in the Lagrangian framework was defined as [98]:

$$
\rho c_{p} \frac{\partial T}{\partial t}=k_{z} \frac{\partial^{2} T}{\partial z^{2}}
$$

where $\rho, c_{p}$ and $k_{z}$ were the density, specific heat capacity, and thermal conductivity in the thickness direction, respectively. The substrate in-plane heat conduction rate is much lower than the relative velocity of the laser source and heated surface, therefore, only the dominant through-thickness conduction was considered as done in [79] as well. Therefore, a considerable computational cost was saved by neglecting the in-plane heat conduction to the adjacent thermal domains while having a negligible loss in the prediction accuracy. An implicit finite volume-finite difference (FV-FD) based numerical solution scheme was used.

A total of $5 \mathrm{CVs}$ ( 3 full and 2 half CVs) per layer in the thickness direction was utilized as depicted in Fig. 4.7 Thus, the CV sizes in the thickness direction depended on the thickness increment calculated by Eq. 4.1 in the kinematic model for each layer. Hence, the CV size variation through the thickness was implemented for each facet using Eq. 4.1 Considering a single 1D growing thermal domain on the deposition fiber path as shown in Fig. 4.7 the one-layer-thick substrate had a thickness of $t_{p}$ and a CV size of $\Delta z_{s}=t_{p} / 4$. The first depositing tape had a thickness of $t_{d 1}$ and a CV size of $\Delta z_{d 1}=t_{d 1} / 4$. 


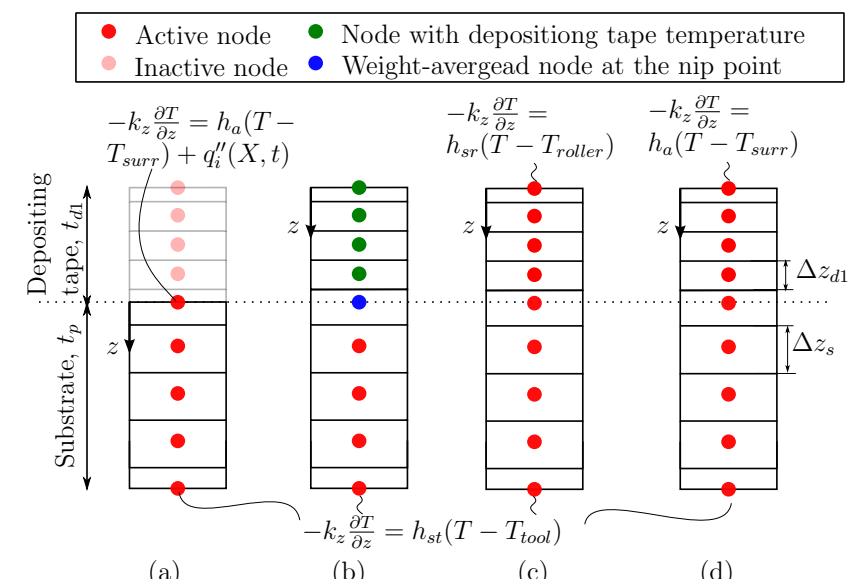

Figure 4.7 (a) Phase 1: Heating phase before the nip point, (b) Phase 2: At the depositing step, (c) Phase 3: Consolidation region after nip point, (d) Phase 4: Cooling after passing

The time-dependent boundary condition at $z=0$ was determined based on four phases. During phase 1 , laser heat flux $\left(q_{i}^{\prime \prime}(X, t)\right)$ and the air cooling applied on the surface based on $-k_{z} \partial T / \partial z=h_{a}\left(T-T_{\text {surr }}\right)+q_{i}^{\prime \prime}(X, t)$ where $h_{a}$ was the convective heat transfer coefficient with respect to surrounding temperature $T_{\text {surr }}$. In phase 2 when the tape was deposited, 4 new CVs were activated in the 1D thermal domain with the calculated tape temperature by a dedicated tape thermal model explained in the following section. Besides, the temperature of the nip point node (blue node in Fig. 4.7) was defined as the weight-averaged of the substrate and tape temperatures using the following expression:

$$
T_{\text {nip }}=\frac{\Delta z_{d 1} T_{\text {tape }}+\Delta z_{t} T_{\text {subs }}}{\Delta z_{d 1}+\Delta z_{s}}
$$

During phase 3 in the consolidation region, the roller heat loss with a temperature of $T_{\text {roller }}$ was described as $-k_{z} \partial T / \partial z=h_{t r}\left(T-T_{\text {roller }}\right)$ where $h_{t r}$ was the heat transfer coefficient at the roller-substrate interface. The consolidation region length was defined based on the roller indentation $(I)$ into the tooling surface and the substrate profile as shown in Fig. $4.1 \mathrm{~b}$ During phase 4 after the roller passed the thermal domain, air convection boundary condition was applied as $-k_{z} \partial T / \partial z=h_{a}\left(T-T_{\text {surr }}\right)$ at $z=0$. In all the four phases, $h_{s t}$ was defined as the the heat transfer coefficient at the substratetooling interface at $z=t_{p}+t_{d 1}$. The heat loss to the tooling with a constant temperature of $T_{\text {tool }}$ was defined with a convective heat transfer boundary condition using the expression $-k_{z} \partial T / \partial z=h_{s t}\left(T-T_{\text {tool }}\right)$. Perfect thermal contact between layers was assumed since the possible thermal contact resistance at the layer interfaces is negligible according to [70]. 


\section{Incoming tape model}

The incoming tape was modeled in the Eulerian framework where the computational mesh was stationary and the material had a flow in the feeding direction. A description of the 2D thermal domain for the tape and the boundary conditions are depicted in Fig. $4.8 \mathrm{a}$ The corresponding governing equation for the 2D transient heat conduction problem considering the advection term is given as [98]:

$$
\rho c_{p}\left(\frac{\partial T}{\partial t}+u \frac{\partial T}{\partial y}\right)=k_{y} \frac{\partial^{2} T}{\partial y^{2}}+k_{z} \frac{\partial^{2} T}{\partial z^{2}}
$$

where $u$ was the linear time-dependent TFR. The advection term $(u \partial T / \partial y)$ represented the transport due to bulk tape motion through the finite volumes in the feeding $(y-)$ direction. The in-plane conductivity was neglected in the width $(x-)$ direction as was done also in [79]. Therefore, multiple 2D slices were considered adjacent to each other instead of using a full 3D thermal model for the tape to save some computational cost as shown in Fig. $4.8 \mathrm{~b}$ Total of 12 slices $(\Delta x=1 \mathrm{~mm})$ in the width direction were used which covered the whole tape width and therefore able to capture the variation of the heat flux distribution. Total of 5 and $40 \mathrm{CVs}\left(\Delta z=t_{p} / 5 \mathrm{~mm}, \Delta y=1 \mathrm{~mm}\right)$ were used in the through-thickness direction ( $z$-direction) and feeding direction ( $y$-direction), respectively. The total number of CVs used for the tape was 2400.

The water-cooled roller was the main mechanism of the heat loss for the tape which was formulated by using a heat transfer coefficient at the tape-roller interface $h_{t r}$ and the roller temperature $T_{\text {roller }}$. Hence, the boundary condition $-k_{z} \partial T / \partial z=h_{t r}\left(T-T_{\text {roller }}\right)$ was applied at $z=t_{p}$ as shown in Fig. 4.8a. The inlet temperature of the tape at $y=0$ was set to the surrounding temperature $T_{\text {surr }}$. An adiabatic boundary condition was applied at $y=L_{T}$, i.e. at nip-point, because the heat transfer after the nip point was taken into account in the substrate thermal model by coupling the tape and substrate nip point temperatures. The calculated heat flux $q_{i}^{\prime \prime}$ in the optical model and convective cooling to $T_{\text {surr }}$ with a heat transfer coefficient of $h_{a}$ were used as a boundary condition at $z=$ 0mm as shown in Fig. 4.8a. An implicit scheme was exploited to solve Eq. 4.4 The discretization of advection term $(u \partial T / \partial y)$ played a critical role in the solution stability since it was the dominant term compared to the diffusion term in velocity direction. To have a stable numerical solution by using the FV-FD method, an upwind scheme was employed as used also in [100].

The depositing tape temperature at the nip point was the input for the substrate thermal model as explained earlier in section 4.3.4. This temperature was considered as the average nip point temperature across the tape width considering all the $2 \mathrm{D}$ slices defined in the tape thermal model. 


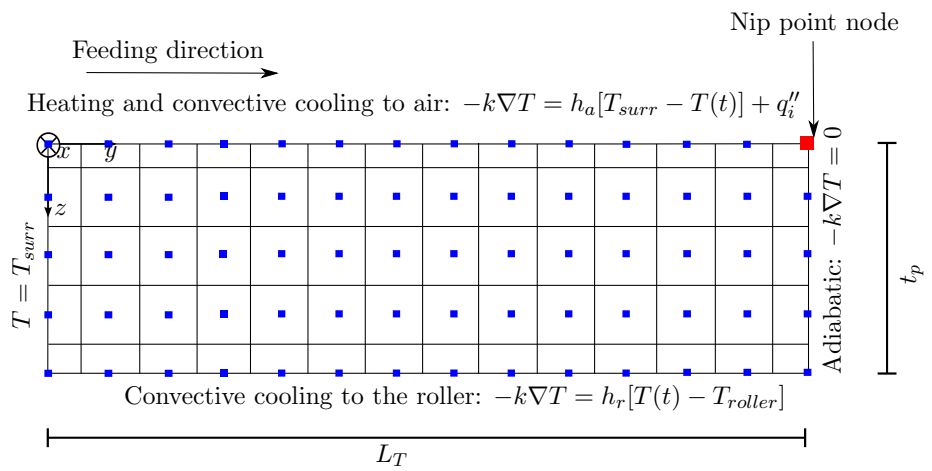

(a)

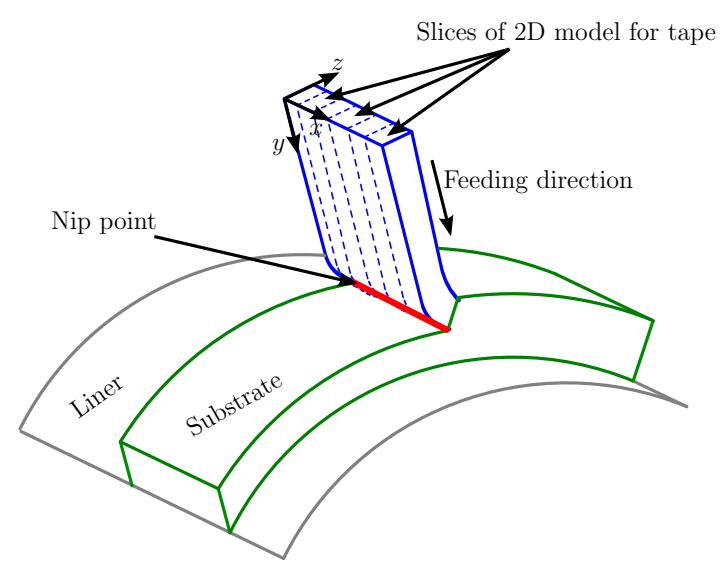

(b)

Figure 4.8 (a) The positioning of the 2D slices of the thermal domains for the incoming tape. (b) Computational thermal model in the feeding and thickness direction for the incoming tape in a Eulerain framework.

\subsection{Case studies}

Three case studies were carried out by using the developed KOT model as seen in Fig. 4.9

- Case-1: The helical winding of the cylindrical part of the liner described in Fig. $4.2 \mathrm{~b}$ was simulated in order to ensure a converged predicted temperature distribution with a sufficient number of laser rays and facet size. The considered helical fiber path on the cylinder is shown in Fig. 4.9a. The fiber path was $150 \mathrm{~mm}$ long and it took $1 \mathrm{~s}$ to place the tape on a 1-layer-thick substrate. The convergence of the results highly depends on the number of laser rays $\left(N_{0}\right)$ used in the optical model and the number of the illuminated facets $\left(e_{I F}\right)$ which were the computational parameters investigated in this case study. The mesh size was defined based on the 
smallest edge of the triangles.

- Case-2: The developed KOT model was used to simulate the AFP process of C/PEEK composites reported in [24] for verifying the numerical implementation. Fiber placement on flat tooling was simulated for the defined placement path as seen in Fig. 4.9b which was based on the process configuration presented in [24].

- Case-3: The helical winding of the dome and cylindrical parts of the pressure vessel indicated in Fig. 4.2b were simulated by using the developed KOT model. The corresponding winding paths on the cylinder and dome are shown in Fig. 4.9c The KOT model predictions were evaluated by comparing the results with the measured temperatures during the LATW process of the pressure vessels. The modeled fiber path started $1.2 \mathrm{~s}$ before the dome part which was on the cylindrical part to make sure that the whole dome was heated according to the performed experiments. Therefore, a coarse mesh size was considered for the cylindrical part of the winding path as seen in Fig. 4.9c The dome had a doubly-curved surface with three curvature values of $0.021,0.01,0.005 \mathrm{~m}^{-1}$.

The corresponding process settings and constant material properties used in the KOT model are given in Table 4.2 The values for geometrical parameters depicted in Fig. 4.1b and the boundary conditions parameters are reported in Table 4.3 for each case study. The heat transfer coefficient used in all case studies were chosen within the range of reported values in the literature [61, 64, 9, 76, 22]. Theses values were assumed uniform and constant during the process to reduce the complexity of the problem. The values of the $h_{s r}$ and $h_{t r}$ for case studies 1 and 3 were much higher than the case study 2 as the roller was water-cooled. Also, the corresponding value of the $h_{s t}$ was lower in case 1 and 3 than case 2 as the tooling was made of pure thermoplastic in case 1 and 3 with low thermal conductivity while in case study 2 a metal mold was employed.

The TFR and substrate surface curvature varied during the helical winding on the dome part as explained in Section 4.2. The corresponding varying TFR and curvature evolution are illustrated in Fig. 4.10. The time $t=0 \mathrm{~s}$ corresponds to the beginning of helical winding on the cylinder part. As it is seen, the dome winding started at $5.46 \mathrm{~s}$ and took $6.54 \mathrm{~s}$. Facets $\mathrm{A}, \mathrm{B}$, and $\mathrm{C}$ with corresponding surface curvatures were considered on the dome surface for further investigation. In addition to varying TFR, a constant TFR of $46.4 \mathrm{~mm} \mathrm{~s}^{-1}$ on the dome part was employed in the process simulations which was averaged from 5.46 to $12 \mathrm{~s}$. The absolute value of the varying winding angle which was incorporated in the kinematics of the fiber path is also plotted in Fig. 4.10 


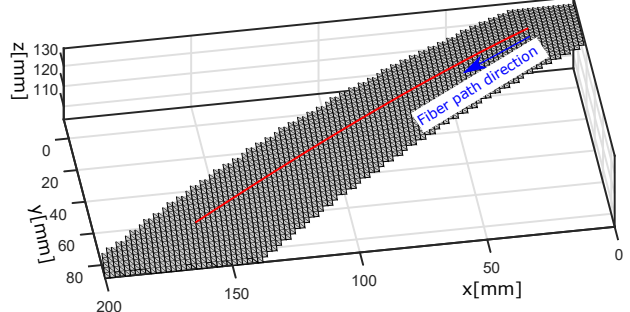

(a) Case study 1

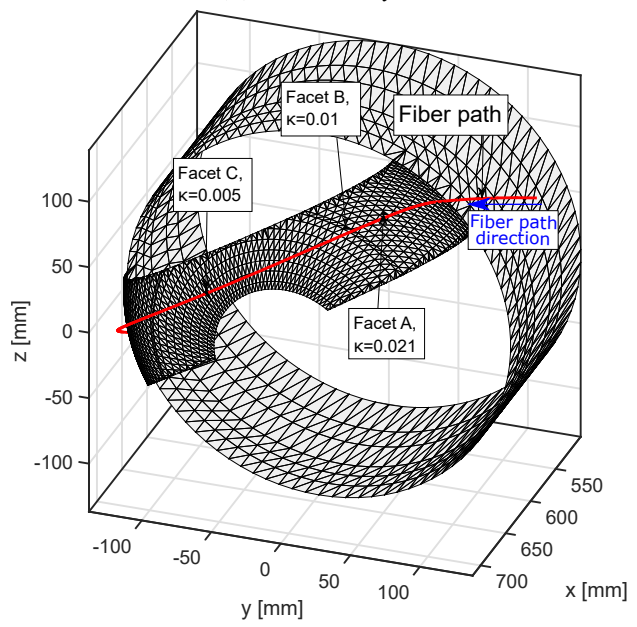

(c) Case study 3

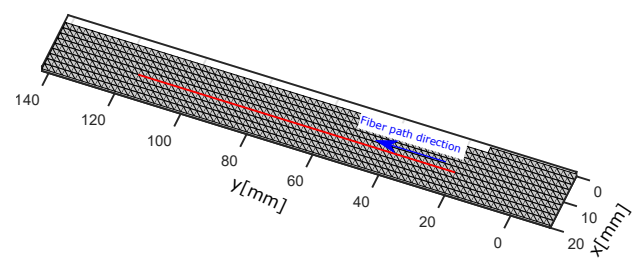

(b) Case study 2

Figure 4.9 The STL representation of the tooling and the fiber path (red solid line) which the TLH follows during the process for (a) case study 1: helical winding on the cylinder, (b) case study 2: AFP process, (c) case study 3: helical winding on the dome part of the vessel.

Table 4.2 Process settings and prepreg thermal properties used for simulation of each case study. The thermal properties of G/HDPE and C/PEEK were taken from [124] and [24], respectively

\begin{tabular}{|c|c|c|c|c|}
\hline Parameter (Symbol) & Unit & $\begin{array}{c}\text { Case study 1: } \\
\text { Helical on } \\
\text { cylinder }\end{array}$ & $\begin{array}{c}\text { Case study 2: } \\
\text { AFP }\end{array}$ & $\begin{array}{c}\text { Case study 3: } \\
\text { Helical on dome }\end{array}$ \\
\hline Laser power $(P)$ & $\mathrm{W}$ & 850 & 1056 & 400 \\
\hline Laser power distribution & - & Top-hat & $\begin{array}{l}\text { Spatial emittance } \\
\text { function }\end{array}$ & Top-hat \\
\hline Tape feeding rate (TFR, $v$ ) & $\mathrm{mm} \mathrm{s}^{-1}$ & 150 & 100 & $\begin{array}{c}\text { varying - mean of } \\
46.4\end{array}$ \\
\hline Prepreg & - & G/HDPE & C/PEEK & G/HDPE \\
\hline Specific heat capacity $\left(c_{p}\right)$ & $\mathrm{J} \mathrm{kg}^{-1}{ }^{\circ} \mathrm{C}^{-1}$ & 1180 & 1425 & 1180 \\
\hline Density $(\rho)$ & $\mathrm{kg} \mathrm{m}^{-3}$ & 1710 & 1560 & 1710 \\
\hline $\begin{array}{l}\text { Conductivity in fiber } \\
\text { direction }\left(k_{y}\right)\end{array}$ & $\mathrm{W} \mathrm{m}{ }^{-1}{ }^{\circ} \mathrm{C}^{-1}$ & 0.98 & 5 & 0.98 \\
\hline $\begin{array}{l}\text { Conductivity transverse to } \\
\text { fiber direction }\left(k_{x}, k_{z}\right)\end{array}$ & $\mathrm{W} \mathrm{m}{ }^{-1}{ }^{\circ} \mathrm{C}^{-1}$ & 0.72 & 0.72 & 0.72 \\
\hline
\end{tabular}


Table 4.3 Geometrical and boundary conditions reference values used for simulation of each case study.

\begin{tabular}{|c|c|c|c|}
\hline Symbol & $\begin{array}{l}\text { Case study } \\
\text { 2: AFP }[24]\end{array}$ & $\begin{array}{l}\text { Case studies 1,3: } \\
\text { Helical winding }\end{array}$ & Description (Unit) \\
\hline$R_{r}$ & 40 & 45 & Roller radius $(\mathrm{mm})$ \\
\hline$w_{r}$ & 40 & 58 & Roller width (mm) \\
\hline$I$ & 2 & 10 & Roller indentation into the tooling surface $(\mathrm{mm})$ \\
\hline$C$ & 28 & 46 & Consolidation region length $(\mathrm{mm})$ \\
\hline$w_{p}$ & 12 & 12 & Prepreg width $(\mathrm{mm})$ \\
\hline$t_{p}$ & 0.15 & 0.25 & Prepreg thickness $(\mathrm{mm})$ \\
\hline$t_{s}$ & 1.65 & $0.25,0.5$ & Substrate thickness $(\mathrm{mm})$ \\
\hline$\alpha_{t}$ & 67.4 & 60 & Incoming tape angle $\left({ }^{\circ}\right)$ \\
\hline$R_{s}$ & Flat & 136 & Substrate radius $(\mathrm{mm})$ \\
\hline$y_{l}$ & 185.6 & 370 & Laser spot y-position (mm) \\
\hline$z_{l}$ & 61.1 & 165 & Laser spot z-position (mm) \\
\hline$h_{l}$ & 45 & 67 & Laser spot height $(\mathrm{mm})$ \\
\hline$w_{l}$ & 16 & 32 & Laser spot width $(\mathrm{mm})$ \\
\hline$\alpha_{l}$ & 32 & 30 & Laser beam angle $\left({ }^{\circ}\right)$ \\
\hline$\theta$ & - & 28 , Varying & Winding angle of cylindrical region $\left({ }^{\circ}\right)$ \\
\hline$T_{\text {surr }}$ & 20 & 25 & Surrounding / initial temperature $\left({ }^{\circ} \mathrm{C}\right)$ \\
\hline$T_{\text {roller }}$ & 50 & 25 & Water-cooled roller temperature $\left({ }^{\circ} \mathrm{C}\right)$ \\
\hline$T_{\text {tool }}$ & 20 & 50 & Tooling surface temperature $\left({ }^{\circ} \mathrm{C}\right)$ \\
\hline$h_{a}$ & $10[76]$ & $10[76$ & Composite-air convection coefficient $\left(\mathrm{W} \mathrm{m}^{-2}{ }^{\circ} \mathrm{C}^{-1}\right.$ ) \\
\hline$h_{t r}$ & $40[9]$ & $600[22] 76$ & Tape-roller convection coefficient $\left(\mathrm{W} \mathrm{m}^{-2}{ }^{\circ} \mathrm{C}^{-1}\right)$ \\
\hline$h_{s r}$ & $500[61]$ & $1000[61]$ & Substrate-roller convection coefficient $\left(\mathrm{W} \mathrm{m}^{-2}{ }^{\circ} \mathrm{C}^{-1}\right.$ ) \\
\hline$h_{s t}$ & 200077 & 500 & $\begin{array}{l}\text { Substrate-tooling convection coefficient } \\
\qquad\left(\mathrm{W} \mathrm{m}^{-2}{ }^{\circ} \mathrm{C}^{-1}\right)\end{array}$ \\
\hline
\end{tabular}

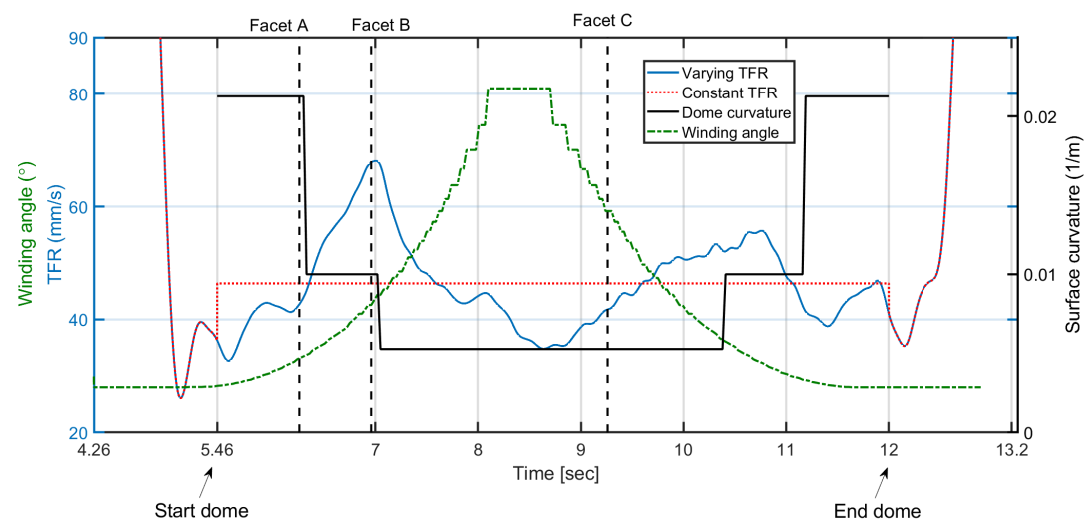

Figure 4.10 The time-dependent TFR, dome surface curvature, and absolute winding angle history along the fiber path during helical winding. The time when the TLH passed facets A, B, C are indicated by the dashed lines. Refer to Fig. 4.9c for the location of the facets and the fiber path on the liner surface. 


\subsection{Results and discussions}

\subsubsection{Convergence analysis (Case-1)}

The helical winding on the cylindrical part of the pressure vessel described in section 4.2 was considered for the convergence study of the KOT model. The steady-state temperature distribution on the tape and substrate surface which was obtained at $0.6 \mathrm{~s}$ is plotted in Fig. 4.11 with $N_{0}=5000$ and $e_{I F}=43$. The unfolded 2D tape domain reversely mapped to its original $3 \mathrm{D}$ shape which looks like the real geometry of the process. It is seen that the temperature variation along the nip point line was larger for substrate than tape. The reason was that the tape was irradiated fairly uniformly by the laser, on the other hand, a non-uniform heat flux distribution was the case for the substrate due to the helical winding and liner curvature with respect to the TLH position. The substrate temperature was reported at $5 \mathrm{~mm}$ prior to the nip point across the tape depositing edges indicated as the reporting line in Fig. 4.11 The weight-averaged substrate temperature was defined based on the length of line segments across the width direction which is illustrated in Fig. 4.6 i.e. between the yellow dots. The weight-average substrate temperature across the width direction was found to be approximately $150^{\circ} \mathrm{C}$ and this was approximately $130^{\circ} \mathrm{C}$ for the tape. The effect of $N_{0}$ and $e_{I F}$ on the mean and standard deviation of the temperature as well as the computational time is discussed in the following.

The computational time of the optical model highly depended on $N_{0}$ and $e_{I F}$ as seen in Fig. 4.12a. It is seen that there was a rapid increase in the computational time as $N_{0}$ and $e_{I F}$ increased. Note that the process simulations were run on a PC having a quadcore CPU (eight threads), with $2.6 \mathrm{GHz}$ and $16 \mathrm{~GB}$ of RAM. Therefore, it is desirable to keep the ratio of the launched rays to the number of illuminated facets $\left(N_{0} / e_{I F}\right)$ as low

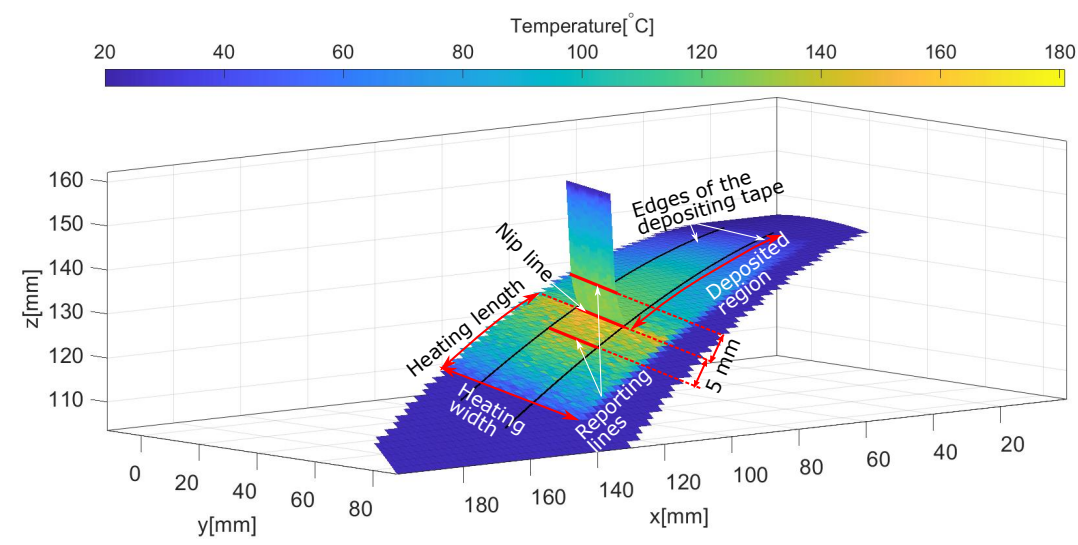

Figure 4.11 Steady-state temperature distribution of the case study 1 on the substrate and tape surfaces at $0.6 \mathrm{~s}$. The red lines located at $5 \mathrm{~mm}$ away from the nip point were used to extract the temperature for the convergence study. 
as possible without losing temperature accuracy. However, a higher $N_{0} / e_{I F}$ values lead to more accurate predictions due to the more detailed heat flux information. To find the optimum point out at which a sufficient accuracy was achieved, the average temperatures across the width for both the tape and substrate at $5 \mathrm{~mm}$ away from the nip point for various mesh sizes were investigated and the obtained results are depicted in Fig. $4.12 \mathrm{~b}$ The temperature converged approximately with $N_{0} / e_{I F}=330$ and 133 for the substrate and tape, respectively. These values were therefore used for the rest of the case studies in this work. According to Fig. 4.12b finer mesh did not necessarily lead to a higher accuracy, however, to avoid any uncertainty in the results a mesh size of $2 \mathrm{~mm}$ was used for the rest of the study.

The standard deviation of the substrate and tape temperature across the width with respect to $N_{0} / e_{I F}$ is plotted in Fig. $4.12 \mathrm{c}$ in order to have a more elaborate in-depth analysis of the model convergence. It is seen that the temperature variation was inversely proportional to the $N_{0} / e_{I F}$. Generally, the tape temperature converged earlier than the substrate since the $2 \mathrm{D}$ tape thermal domains together with the TLH were remained constant and positioned along the winding direction in each time step. The standard deviation in the tape temperature was estimated approximately $3{ }^{\circ} \mathrm{C}$ for $N_{0} / e_{I F}=133$. On the other hand, the stationary 1D thermal domains for the substrate were unstructured with respect to the winding direction which resulted in a larger standard deviation of approximately $10^{\circ} \mathrm{C}$ for the substrate.

The time step i.e. the incremental displacement of the TLH did not affect the temperature distribution in the steady-state phase. However, the transition period to reach steady-state distribution was affected slightly. In order to capture the transient temperature evolution on the dome part accurately due to a variation in tooling geometry and TFR, a relatively small time step of $\Delta t=30 \mathrm{~ms}$ was used in the KOT model simulations.

\subsubsection{KOT model verification (Case-2)}

The predicted substrate surface temperature distribution prior to the nip point is depicted in Fig. 4.13a using the proposed KOT model for the LATP process reported in [24]. Generally, a more uniform temperature distribution was achieved compare to Case-1 due to the winding angle of the helical winding. The obtained results were compared with the reported predicted and measured temperature distribution at the centerline of the substrate as shown in Fig. 4.13b. It is seen that the predicted temperature distribution by the KOT model agreed well with the prediction for the similar top hat laser power distribution in [24]. However, the actual laser power distribution in the experimental test was a spatial emittance function, therefore, the prediction curve with top hat laser power distribution deviated from the measured temperature for the substrate as seen in Fig. $4.13 \mathrm{~b}$. Although a generic triangulated mesh with the 1D thermal model was used in the proposed KOT model, similar laser irradiation length and temperature evolution were obtained as compared with the observations reported in [24]. The predicted substrate temperature by the KOT model and the corresponding predictions in [24] at $5 \mathrm{~mm}$ away from the nip point were found to be approximately $488^{\circ} \mathrm{C}$ and $520^{\circ} \mathrm{C}$, respectively.

A Dirichlet boundary condition at the mold-substrate interface with a constant tem- 


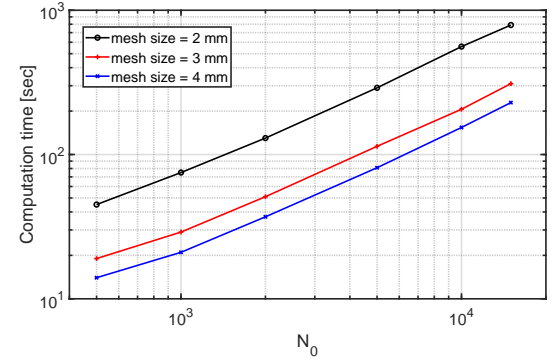

(a)

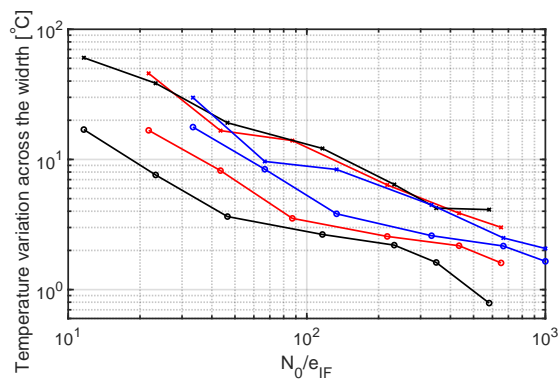

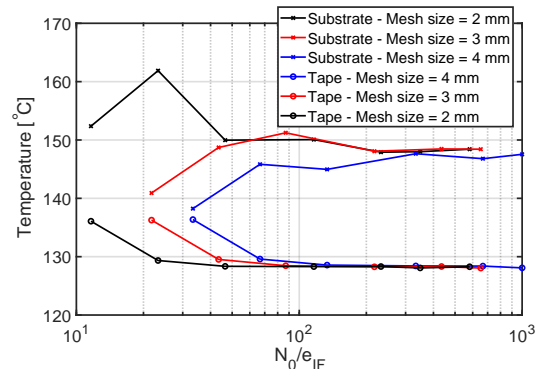

(b)

(c)

Figure 4.12 (a) Computational time of the KOT model based on the number of rays $\left(N_{0}\right)$ and liner mesh size. (b) The tape and substrate temperature averaged across the width at $5 \mathrm{~mm}$ away from the nip point and (c) the corresponding temperature deviation across the width with respect to the ratio of number of rays to the number of irritated facets on the substrate $\left(N_{0} / e_{I F}\right)$.

perature of $T_{\text {mold }}$ was considered in [24]. However, in the KOT model, a convective boundary condition with the relevant coefficient in Table 4.3 was applied. This difference of the mold-substrate interface boundary condition would have a negligible effect on the surface temperature since the relatively thick substrate acted as a semi-infinite medium. The substrate thickness was $1.65 \mathrm{~mm}$ which consisted of 11 layers as presented in Table 4.3

\subsubsection{KOT model validation for helical winding (Case-3)}

After verification of the KOT model implementation with optimum $N_{0} / e_{I F}$ ratio, the temperature evolution during helical winding on the dome and cylindrical parts of the pressure vessels was investigated numerically and the obtained results were compared with the experiments which are discussed in the following. 


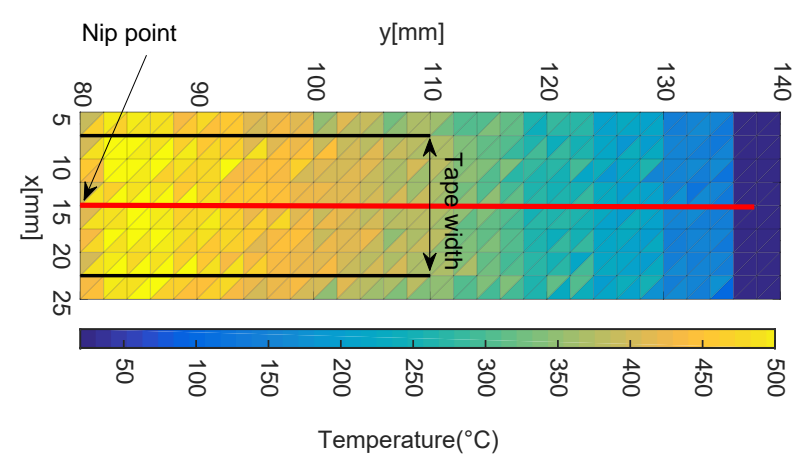

(a)

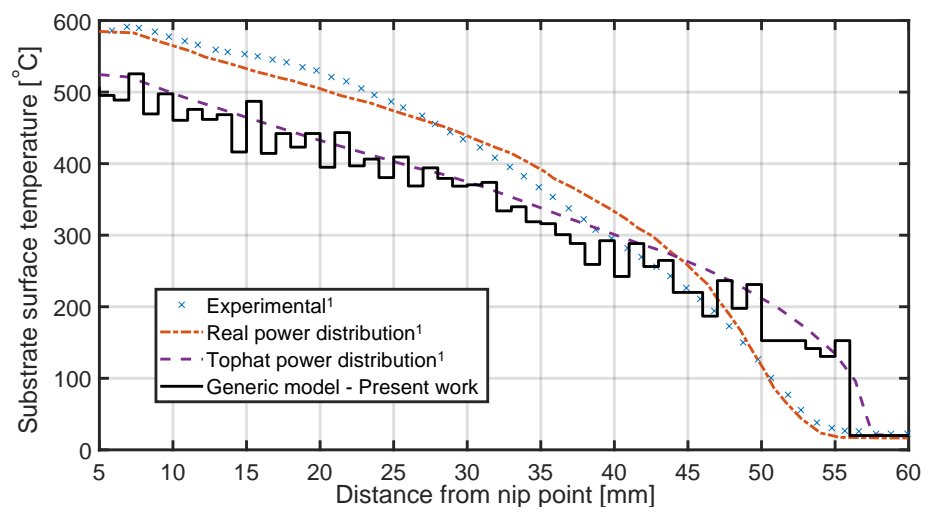

(b) ${ }^{1} 24$

Figure 4.13 (a) Steady-state temperature distribution of the case study 2 on the substrate surface at $0.6 \mathrm{~s}$. The red line shows the centerline where the temperature would extracted for verifying KOT model. (b) The validation study of the generic KOT model with already developed model for a simple AFP case. Measured and predicted temperature along the centerline of the substrate surface as a function of distance to the nip point.

\section{Experimental results}

The measured substrate and tape surface temperatures by the IR camera on the fiber path seen in Fig. 4.9c are plotted in Fig. 4.14 Here, only the helical layers 2-4 were considered since the substrate of the layer 1 was the pure HDPE liner which caused unreliable measurements due to different emissivity for the thermal camera than the already wound layers [39]. Similar trends were obtained for the temperature evolution of helical layers 2-4 as seen in Fig. 4.14. The measured surface temperatures of the substrate and tape according to Fig. 4.3 during the manufacturing of different pressure vessels had also very similar trends. Therefore, the IR camera measurements were found to be reproducible with a certain degree. During winding of the cylindrical part, i.e. between 0-4 s, the 


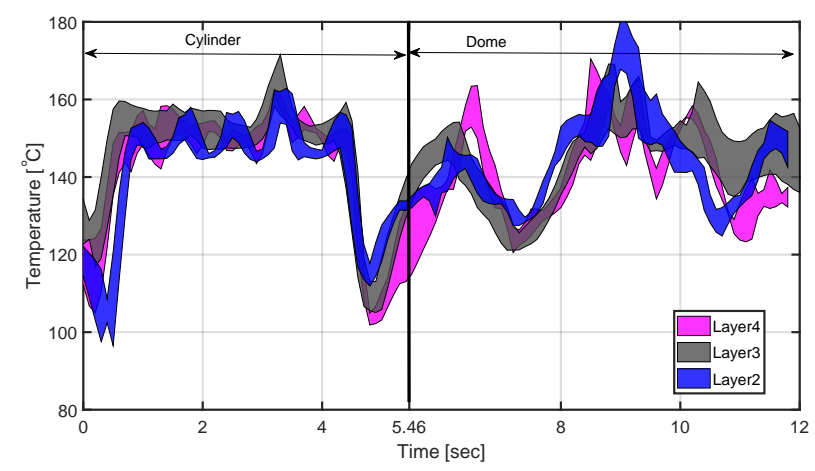

(a) Substrate temperature history

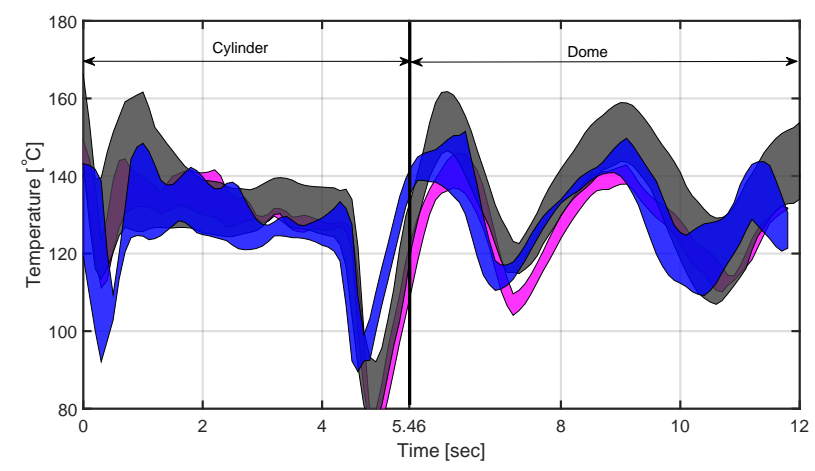

(b) Tape temperature history

Figure 4.14 Measured surface temperature by IR imaging camera considering the standard deviation of 4 trials for the first circuit of the helical layers 2, 3, and 4. The upper and lower limits of the shaded regions indicate the variation based on the mean and standard deviation.

substrate and tape temperature were found to slightly vary with a mean temperature of approximately $150{ }^{\circ} \mathrm{C}$ and $130{ }^{\circ} \mathrm{C}$, respectively. The variation in temperature evolution was approximately $10-15{ }^{\circ} \mathrm{C}$ and mainly due to the geometrical disturbances such as eccentricity and unroundness in the LATW system fixation [39].

In addition, the already wound helical layers caused a thickness variation at the crossover points as shown in Fig. 4.2a which resulted in a variation in the process temperature as also observed in [55]. A higher temperature variation was observed during winding on the dome part of the pressure vessels, i.e. between 5.46-12 s, mainly due to the varying TFR and surface curvature. The increase and decrease in the substrate and tape temperature followed the varying TFR profile presented in Fig. 4.10, e.g. the lower the TFR, the higher the temperature. The drop in temperature at around $5 \mathrm{~s}$ was due to the sudden laser power reduction which took place in the cylinder-to-dome transition region as mentioned in Table 4.2. The substrate and tape temperature variation in the dome region were approximately $80{ }^{\circ} \mathrm{C}$ and $70{ }^{\circ} \mathrm{C}$, respectively. The mean tape temperature of 


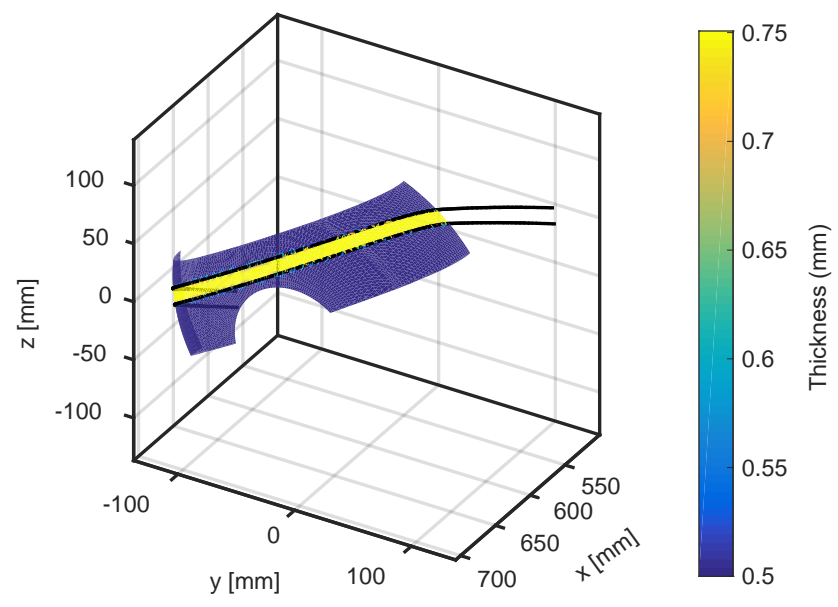

Figure 4.15 Thickness distribution of the dome part after winding the first circuit of layer 3. The dashed lines define the edge of the deposited tape on the dome surface.

the dome part was almost the same as the cylindrical part. However, the mean substrate temperature of the dome part was $10^{\circ} \mathrm{C}$ less than the cylindrical part. The mean substrate temperature was higher than the tape temperature by $10^{\circ} \mathrm{C}$ during winding the dome part. In order to compare the process model predictions with the experimental measurements to validate its effectiveness, the measured temperatures from the layer 3 was utilized as explained in the following section.

\section{Numerical results}

The calculated thickness distribution after winding layer 3 using the kinematic model is illustrated in Fig. 4.15 based on the fiber path defined in Fig. 4.9. It is seen that the substrate thickness in the depositing region was $0.75 \mathrm{~mm}$ as two layers of the helical winding were already deposited forming a $0.5 \mathrm{~mm}$-thick substrate for layer 3 .

The 3D heat flux and corresponding temperature distributions on the substrate and tape for different TLH locations (facet A, B, and C) on the dome part are illustrated in Fig. 4.16 and Fig. 4.17 respectively. The effect of the substrate geometry on the heat flux magnitude was visualized for three dome curvatures. It is seen that the larger curvature resulted in a higher heat absorption by the substrate due to the larger incident angle of the laser rays hitting the surface. On the other hand, the heat flux distributions on tape and roller were remained almost constant since their geometry did not change during winding. The laser ray reflections coming from tape on the non-irradiated region of the dome took place for the facet $\mathrm{A}$ as seen in Fig. 4.16a. They diminished for the facet $\mathrm{C}$ location due to the local geometry. The tape reflections resulted in a slight increase in the temperature as compared with the non-irradiated region seen in Fig. $4.17 \mathrm{a}$ Further discussion on the temperature evolution for facet $\mathrm{A}, \mathrm{B}$ and $\mathrm{C}$ is given in Section 4.5 .3 


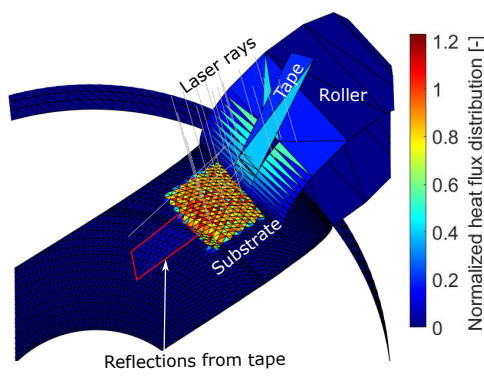

(a)

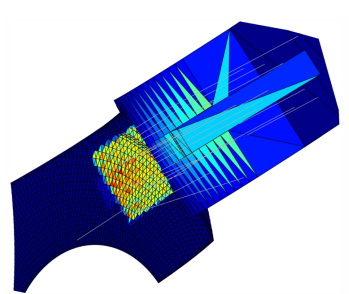

(b)

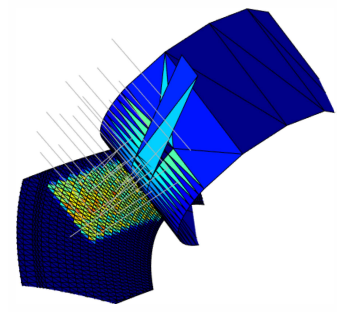

(c)

Figure 4.16 A computational view of the irradiated facets for the tape, roller, and liner when the $T L H$ is located at facet (a) A, (b) B, (c) C (refer to Fig. 4.9c for location of the facets). Selected laser rays launched from laser source and the corresponding reflections are plotted.

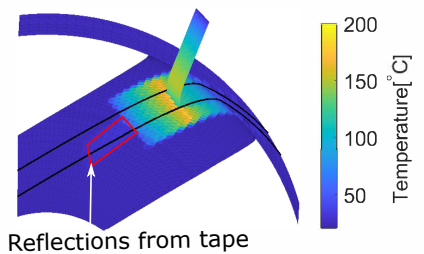

(a)

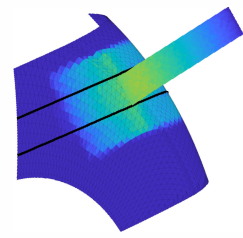

(b)

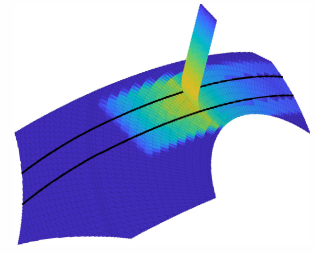

(c)

Figure 4.17 A computational view of the temperature distribution for tape and liner when the $T L H$ is located at facet (a) A, (b) B, (c) C (refer to Fig. 4.9c for location of the facets).

The measured surface temperatures by the IR imaging camera prior to the nip point were compared with the corresponding predicted temperatures during winding the dome part for the substrate and tape in Fig. 4.18a and Fig. 4.18b, respectively. The standard deviation shown as the shadow area used for the model predictions was defined based on the temperature variation along the width direction at 5 and $25 \mathrm{~mm}$ prior to the nip point for the substrate and tape, respectively. According to Fig. 4.10, the dome winding started at $5.46 \mathrm{~s}$ and ended at $12 \mathrm{~s}$ where the surface curvature was $0.021 \mathrm{~m}^{-1}$. The corresponding predicted trends of the surface temperatures agreed reasonably well with the measured temperatures. The temperature peaks at $\sim 6$ and $11.5 \mathrm{~s}$, and the drops around $\sim 7$ and $10 \mathrm{~s}$ due to the TFR variations were captured accordingly. The variation in the predicted average temperature was mainly due to the varying TFR and laser irradiation/reflections which were affected by the varying surface curvature as expected.

The substrate temperature prediction deviated from the measurements at $\sim 6 \mathrm{~s}$ by $26{ }^{\circ} \mathrm{C}(17 \%)$ where the TFR dropped from $150 \mathrm{~mm} \mathrm{~s}^{-1}$ to $25 \mathrm{~mm} \mathrm{~s}^{-1}$. This deviation could be due to the local change in the position of the measurement box used by the IR camera. The actual distance of the measurement box to the nip point in 3D space depended on the 


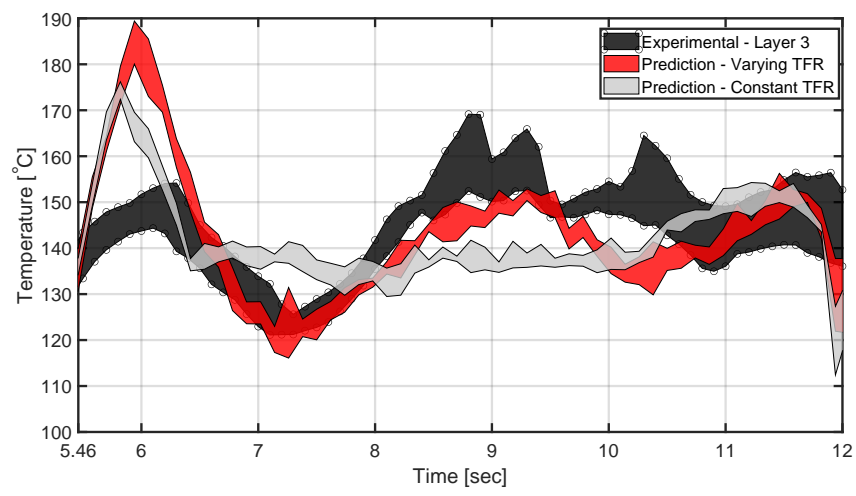

(a) Substrate temperature history

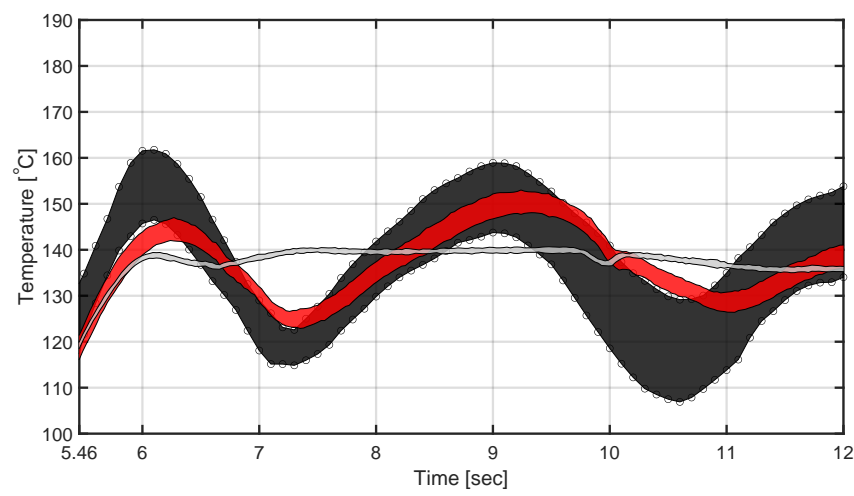

(b) Tape temperature history

Figure 4.18 Comparing the IR camera measurements and numerical results during winding dome at the first circuit of the third layer. The shaded area of the predictions shows the temperature standard deviation in the width direction of the substrate deposition region (refer to Fig. 4.15), while for the measurements the standard deviation of 4 trials were considered.

geometry of the substrate which was changing drastically in the range of 5-6 s as seen in Fig. 4.10 .

In addition to actual varying TFR, the temperature evolution with a constant TFR of $46.4 \mathrm{~mm} \mathrm{~s}^{-1}$ is plotted in Figs. $4.18 \mathrm{a}$ and $4.18 \mathrm{~b}$ following the same fiber path as the actual varying TFR. The substrate temperature reached a plateau of approximately $138^{\circ} \mathrm{C}$ in the range of $\sim 7-10.5 \mathrm{~s}$ for the constant TFR. Higher temperatures were predicted at the range of of $5.46-7 \mathrm{~s}$ and $10.5-11.5 \mathrm{~s}$ mainly due to the larger liner curvature (refer to Fig. 4.10, as the TFR was constant. The direction of the surface normal was more parallel to the incoming laser ray direction for higher curvature which means that more of the laser ray energy was absorbed rather than reflected rays based on the Fresnel definition implemented in the optical model [26]. Hence, the peak in the substrate temperature 


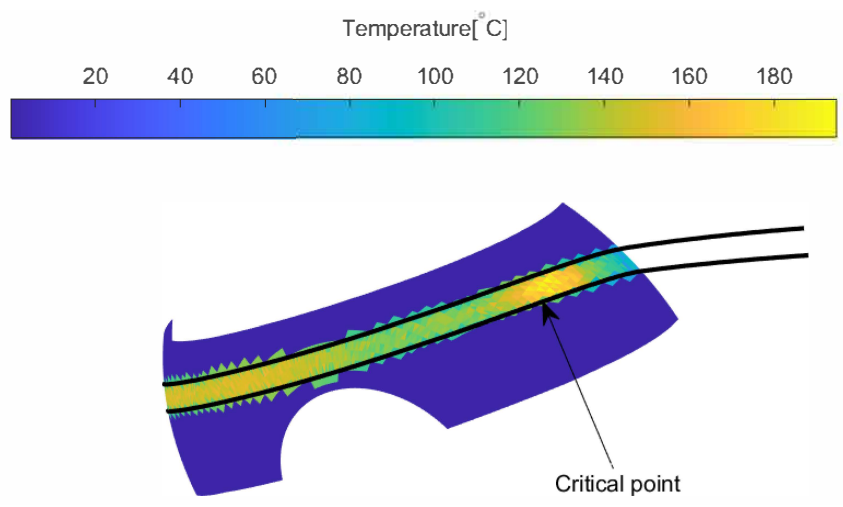

Figure 4.19 A process window for the nip point temperature history of the substrate on the dome part.

took place at the location which had the largest curvature value. The maximum substrate temperature difference between constant and varying TFR was $18{ }^{\circ} \mathrm{C}(15 \%)$ which took place at the first drop at $7.3 \mathrm{~s}$ due to the relatively large TFR difference. The tape reached a steady temperature of $140{ }^{\circ} \mathrm{C}$ in the range of $\sim 6.5-10 \mathrm{~s}$. The tape steady-state range was $\sim 0.5 \mathrm{~s}$ behind than the substrate since the tape prediction was at $25 \mathrm{~mm}$ away from the nip point while the for the substrate this value was $5 \mathrm{~mm}$ as mentioned earlier. The tape temperature was lower than the steady-state temperature in the range of $5.46-6.5 \mathrm{~s}$ and $10-11 \mathrm{~s}$. This behavior was opposite to the substrate due to the reduced energy of reflected rays from the substrate at higher curvature locations.

The predicted substrate nip point temperature during the helical winding of layer 3 is visualized on the dome surface in Fig. 4.19 for the defined winding path. In other words, Fig. 4.19 shows the history of the location-dependent nip point temperature evolution during the helical winding process of the dome part. At the cylinder-to-dome transition region indicated as the critical point, a maximum temperature of $203{ }^{\circ} \mathrm{C}$ was predicted. The reason for this was the change in the local tooling geometry at the transition from cylinder to dome part which resulted in a more localized heat absorption on the substrate surface.

\section{Temperature history of a single facet}

The surface temperature history of facet A, B and C shown in Fig. 4.9, reassembling a thermocouple measurement installed at the facet surface, is depicted in Fig. 4.20 considering varying and constant TFR histories. As shown in Fig. 4.10, the time when the TLH was located at the facet A, B and C was at $6.26,6.96$, and $9.26 \mathrm{~s}$, respectively. The heating of the facet A started before $5.46 \mathrm{~s}$ while the TLH was on the cylindrical part for both varying and constant TFR. For facet $B$ the heating with varying TFR started $0.06 \mathrm{~s}$ later and for facet $\mathrm{C} 0.12 \mathrm{~s}$ earlier as compared with the case of constant TFR. The time lags depended on the difference between the constant TFR $\left(46.4 \mathrm{~mm} \mathrm{~s}^{-1}\right)$ and the average of varying TFR from $t=5.46 \mathrm{~s}$ to the starting of the heating. To illustrate, the averaged 


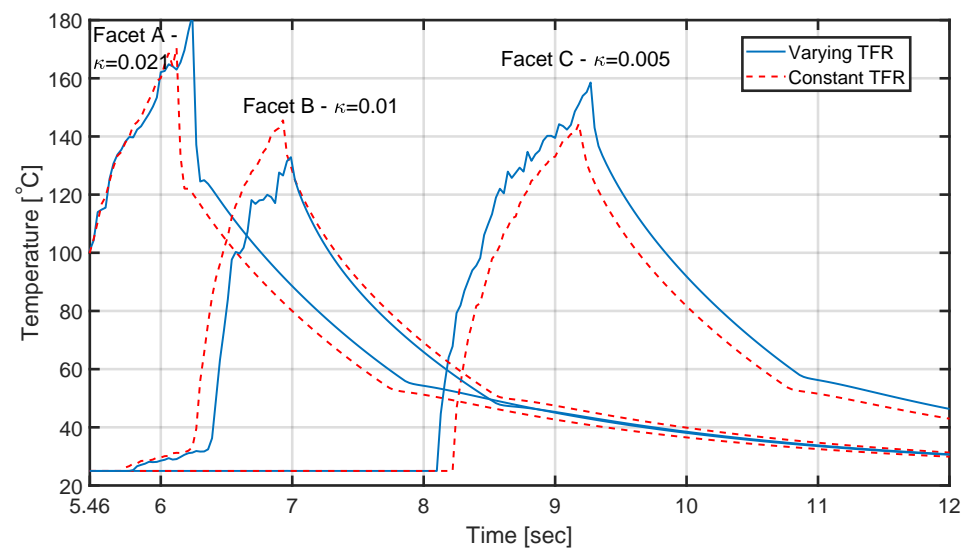

Figure 4.20 The surface temperature history of facets $A, B$, and $C$ located at the substrate width center. The time is corresponding to the TFR history in Fig. 4.10. The effect of varying curvature and varying TFR during dome winding are quantified.

varying TFR for facet $\mathrm{C}$ before heating was $48.6 \mathrm{~mm} \mathrm{~s}^{-1}$, therefore, the heating started earlier than the constant TFR case.

The average initial heating rate for facet $\mathrm{B}$ from 5.76 to $6.36 \mathrm{~s}$ was $12.4{ }^{\circ} \mathrm{C} \mathrm{s}^{-1}$, while after $6.36 \mathrm{~s}$ it rose up to $362.3^{\circ} \mathrm{C} \mathrm{s}^{-1}$. The reason for this was that the facet $\mathrm{B}$ was heated from 5.76 to $6.36 \mathrm{~s}$ while the TLH was on the dome with a curvature of $0.021 \mathrm{~m}^{-1}$. Therefore, the positing of the TLH and the resulting incident angle of the laser rays hitting the surface were different from the case in which the TLH was located on the dome with a curvature of $0.01 \mathrm{~m}^{-1}$. The steep drop in the temperature of facet $\mathrm{A}$ at $6.26 \mathrm{~s}$ i.e. the nip point, caused by the colder tape deposition. What can be clearly seen after the nip point is the two major cooling slopes for all the facets. The first slope was dominated by the roller heat loss at the consolidation region followed by the second less intensive air cooling slope due to the convective cooling to the ambient air. The average cooling rates of facet $\mathrm{A}$ at the consolidation region (6.26-7.86 s) and during air cooling (7.86-12 s) were $43.5^{\circ} \mathrm{C} \mathrm{s}^{-1}$ and $5.4^{\circ} \mathrm{C} \mathrm{s}^{-1}$, respectively. The variations in the peak temperatures, averaged heating rates, and averaged cooling rates at the consolidation region are summarized in Table. 4.4 for facets $\mathrm{A}, \mathrm{B}$, and $\mathrm{C}$. The maximum temperature was found to be inversely proportional to the mean TFR during heating phases. The averaged TFR during heating the facets $A, B$, and $\mathrm{C}$ were $37.8,50.7$, and $38.3 \mathrm{~mm} \mathrm{~s}^{-1}$ while the constant TFR was $46.4 \mathrm{~mm} \mathrm{~s}^{-1}$. The peak temperature varied up to $37 \%$ when the curvature dropped from 0.021 to $0.01 \mathrm{~m}^{-1}$ i.e., from facets $\mathrm{A}$ to $\mathrm{B}$. In addition, the heating and cooling rates had a maximum variation of $52 \%$ and $41 \%$, respectively. In general, the cooling rates had lower dependence on the curvature variation since the cooling rates mainly affected by the temperature gradient and $h_{s r}$. By assuming constant TFR shown in Fig. 4.10, the isolated effect of the surface curvature on the process temperature evolution can be analyzed. The heating rate and the consecutive maximum temperature, as well as the cooling rate, dropped by reducing the curvature. For instance, the peak temperature dropped by $17 \%$ with a reduction in the curvature by $110 \%$ (from 0.021 to $0.01 \mathrm{~m}^{-1}$ ). The highest curvature had a significant 
Table 4.4 Temperature values and gradients evolution considering various surface curvatures and TFR.

\begin{tabular}{|c|c|c|c|c|}
\hline Parameter & \multicolumn{2}{|c|}{ Varying TFR } & \multicolumn{2}{c|}{ Constant TFR } \\
& facet $\mathrm{A} \rightarrow \mathrm{B}$ & facet $\mathrm{B} \rightarrow \mathrm{C}$ & facet $\mathrm{A} \rightarrow \mathrm{B}$ & facet $\mathrm{B} \rightarrow \mathrm{C}$ \\
\hline $\begin{array}{c}\text { Change in maximum } \\
\text { temperature }\left({ }^{\circ} \mathrm{C}\right)\end{array}$ & $-49(37 \%)$ & $27(19 \%)$ & $-24(17 \%)$ & $1.4(1 \%)$ \\
\hline $\begin{array}{c}\text { Change in the average } \\
\text { heating rate }\left({ }^{\circ} \mathrm{C} \mathrm{s}^{-1}\right)\end{array}$ & $-46(52 \%)$ & $26(30 \%)$ & $-40(41 \%)$ & $26(27 \%)$ \\
\hline $\begin{array}{c}\text { Change in the average } \\
\text { cooling rate }\left({ }^{\circ} \mathrm{C} \mathrm{s}^{-1}\right)\end{array}$ & $-22(41 \%)$ & $8(15 \%)$ & $-12(23 \%)$ & $1(2 \%)$ \\
\hline
\end{tabular}

effect on the temperature evolution. However, by reducing the curvature linearly even further for $100 \%$ i.e., comparing facets $\mathrm{B}$ and $\mathrm{C}$, the variation in the peak temperature and heating/cooling rates significantly reduced. This clearly showed that there is a nonlinear relationship between the surface curvature and the temperature evolution.

\subsection{Conclusion}

A new generic kinematic-optical-thermal (KOT) model was developed to describe and predict the transient temperature evolution during the LATW/LATP process of fiberreinforced thermoplastic composites. The complex tooling surface, the fiber path, and the time-dependent process settings were simultaneously included in the process model. An optimum mesh size was determined based on a parameter study for the irradiated facet size and number of laser rays. The numerical implementation of the generic KOT model was subsequently verified with the available data reported in the literature for the LATP process of C/PEEK composites. The predicted substrate temperature distribution on a flat tooling was correctly captured by considering heat conduction only in the through-thickness direction in the facets. More specifically, the non-uniform temperature distribution was captured reasonably well by the KOT model.

The developed process model was further validated with the dedicated experiments carried out during helical winding on the cylindrical and dome part of a pressure vessel. Total of four vessels consisted of G/HDPE layers were produced while measuring the tape and substrate temperatures by the thermal camera. A good agreement was found between the predicted and measured trends of the tape and substrate temperature evolution. The surface curvature-dependent heat flux distributions were predicted and it was found that the largest surface curvature resulted in larger substrate temperature. Overall, less variations in process temperature were obtained during the helical winding of the cylindrical part as compared with the dome part. The time-dependent local geometry near the nip point and varying tape feeding rate (TFR) were the main reasons for the relatively larger temperature variations up to $37 \%$ during helical winding of the dome part. By assuming a constant TFR, the temperature variation dropped to $17 \%$.

The visualized predicted nip point temperature on the 3D tooling geometry revealed the critical location where the substrate had the highest temperature which may not be within the desired processing temperature range. The optimization of the process 
settings to achieve a desired temperature near the nip point can be performed by using the proposed KOT process model to eliminate the expensive trial-and-error based manufacturing experiments, especially for complex geometries. Although the proposed 1D thermal model was fast and applicable to any complex geometry used in LATP and LATW processes, the in-plane conduction was neglected which limits the accuracy of the KOT model. In addition, the temperature dependency of the thermal properties was neglected in the current model. Therefore, 2D/3D thermal modeling employing temperature-dependent properties is considered as a future work to improve the KOT model. 


\title{
CHAPTER 5
}

\section{OPTIMIZATION OF LATW PROCESS}

\author{
Abstract \\ A new inverse kinematic-optical-thermal model is introduced to control the \\ process temperature in laser assisted tape winding and placement processes. \\ The optimum time-dependent laser power distribution is obtained by \\ employing a grid of independent laser cells while keeping the temperature \\ of substrate and tape at the target temperature. Multi-layer cylindrical hoop \\ winding with laser grids of $1 \times 1,28 \times 1$, and $28 \times 11$ and helical winding \\ of a pressure vessel with laser grids of $22 \times 1$ and $22 \times 11$ are considered. \\ It is found that the optimized laser power distribution pattern remains the \\ same during the consecutive hoop winding process while the total power \\ reduces to compensate the heat accumulation. A more non-uniform laser \\ power distribution is obtained for the helical winding because the substrate \\ curvature changes drastically at the dome section of the pressure vessel. \\ The change in the optimum total laser power is found to be almost constant \\ for the helical winding case. Finally, the IKOT model is evaluated by \\ analyzing the effect of the computational parameters on the optimized \\ process temperature.
}




\subsection{Introduction}

The laser-assisted tape winding (LATW) process is gaining more traction as a highlyautomated manufacturing method for tubular fiber-reinforced thermoplastic composite products. The LATW process, in which a rotating mandrel or liner is utilized, allows the production of large parts without the need for a curing step, enhancing the production rate. Similar to the laser-assisted tape placement (LATP) process, in which the tooling is stationary, the incoming pre-impregnated (prepreg) tape and substrate are heated above the melting temperature with the use of a diode laser before touching each other at the "nip point'. The tape is compressed onto a mandrel or liner substrate by means of a deformable compaction roller to establish consolidation, which is the main mechanism to form the final product as seen in Fig. 5.1. The process temperature, speed, compaction pressure [50, 111, 33, 78], fiber path planning [125, 126, 127, 128], and process-induced defects [129, 130, 131] are the important factors for developing a proper bonding quality at the interface between the tape and substrate to manufacture defect-free products with high mechanical performance. In addition, optimal ranges of the tape winding and placement parameters such as tape tension and roller force were provided to reduce the void content [132, 133] and residual stress [134, 135] and to increase the tensile strength [132, 134], interlaminar shear strength [136, 137], peel strength [116, 46], and production rate [137, 116, 135

The nip point temperature serves as an indicator for the process temperature and might vary during the LATW process, possibly resulting in a substantial variation in the consolidation quality. For instance, the nip point temperature increased significantly with the increase of substrate thickness during the continuous multi-layer hoop winding process due to heat accumulation in previously wound layers [138, 75]. Besides, an increase in the winding angle resulted in higher temperatures for the tape and lower

Helical widning of a Type-IV pressure vessel

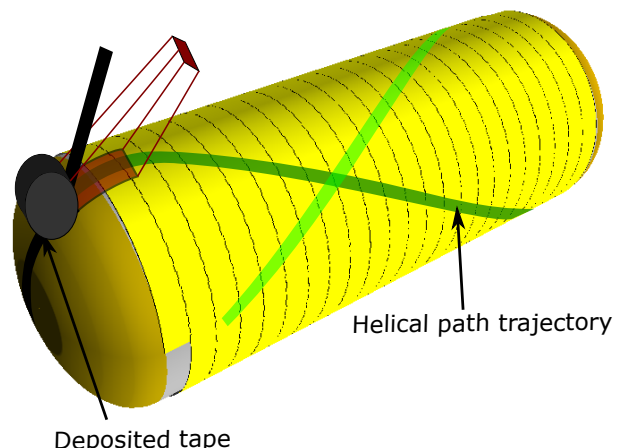

Heating area on the

substrate and incoming tape

Figure 5.1 A schematic view of the laser-assisted tape winding (LATW) process depicting the tape, substrate, mandrel, laser and roller with helical (left) and hoop (right) winding patterns. 
ones for the substrate as shown in [27]. Maintaining the nip point temperature near the processing temperature is a key challenge for the current LATW technology. Therefore, initial numerical efforts were performed to optimize the process settings. An inverse thermal model was developed to calculate the required heat fluxes to achieve a target temperature profile on the substrate surface for an LATP process with a flat tooling [31]. In another attempt for the tape lay-up process [139], the unknown heat transfer coefficients were determined by correlating the measured and predicted temperatures, which is known as inverse heat conduction problems (IHCPs). In [140], the laser power was adjusted in order to ensure a constant target temperature for an AFP process on a flat tooling using the proper generalized decomposition (PGD) method.

The current LATW technology is mostly limited by the use of laser sources that mainly generate uniform power distribution. The introduction of the vertical-cavity surfaceemitting laser (VCSEL) paved the road for optimization procedures by allowing realtime control in the laser power distribution [141, 29, 21]. To this end, so far there has been limited research focusing on finding the optimum laser power distribution during LATW and LATP processes. An inverse analytical thermal model was developed to tailor the power of the individual emitters of a VCSEL, which was validated by a simplified test setup in [29]. The transient total power of a VCSEL was introduced during the AFP process of a single-curved tooling with a uniform process temperature [141]. In a recent study [142], an inverse optical-thermal (IOT) model was developed to optimize the laser power distribution for a LATP process on a flat tooling by introducing a gridbased laser source based on the principles of a VCSEL source. The steady-state target temperature profiles defined on the tape and substrate surfaces were achieved quite well with the optimized laser power distribution.

The goal of this work is to optimize the laser power distribution for the LATW process of complex parts, while keeping the transient process temperature within a target temperature range. To this end, a new inverse kinematic-optical-thermal (IKOT) model is developed to calculate the desired heat flux and to find the time-dependent laser power distribution for varying winding paths and a growing-in-time substrate domain which has not been considered in literature up to now. The IKOT model is based on the recently developed KOT model by the current authors [28]. Two case studies are considered based on the previous works which described the temperature variation during i) multi-layer hoop winding [75] and ii) single-layer helical winding of a doubly-curved pressure vessel [28]. For the first case, the optimized power distributions are presented for each layer of hoop winding at the steady-state phase since the geometry and the fibre path are constant. Whereas for the second case, a time-dependent laser power distribution is described as the substrate geometry and fiber path (winding angle) are changing as a function of time. After having the optimum laser power distributions, the development of the total laser power and the optimized process temperature are compared with the non-optimized cases presented in [28, 75]. The developed IKOT model is evaluated by performing a parametric study based on the computational parameters. 


\subsection{Summary of the case studies to be optimized}

In this work, two different winding cases were defined to be optimized in terms of the laser power distribution: i) a multi-layer hoop winding process on a cylindrical mandrel [75] and ii) a helical winding process on the dome section of a pressure vessel [28]. The variation of the nip point temperature in these winding cases were studied both numerically and experimentally [28, 75].

Shortly summarizing, the evolution of the process temperature was predicted by using the KOT model in which the kinematics of the process were coupled with an opticalthermal model. The kinematics of the winding process presented in [75] were defined as the growing-in-time substrate domain for the hoop winding case, since new layers were wound on top of the already deposited layers. The varying tooling curvature and winding path for the dome section of the pressure vessel, together with the growing-intime substrate, were considered in the kinematics of the helical process [28]. In both winding cases (hoop and helical), an anisotropic reflection model was employed by using a laser ray-tracing technique which was first introduced in [26]. However, in the current study the reflections of the laser rays were neglected to simplify the optimization problem which is explained in the next section. Therefore, the increase in the heat flux intensity due to the reflections and resulting decrease in the shadow area as shown in [75] were not considered in this work.

The STL meshes representing a part of the cylindrical mandrel for the hoop winding case and the dome section of the pressure vessel for the helical winding case are shown in Figs. 5.2a and 5.2b respectively. A circular arc on the cylinder surface and a helical winding trajectory on the dome as the fiber paths were defined. The used process settings are listed in Table 5.1. After defining the STL mesh and fiber path together with geometrical properties of the prepreg, the trajectory of the deposited tape on the surface mesh and the growing-in-time substrate thickness were calculated using the kinematic model. The heat flux distribution on the surface mesh, calculated by the optical model, was used as an input for the thermal model in order to predict the transient temperature distribution and evolution for the tape and substrate. Further details of the developed process models can be found in [75, 28] wherein it is shown that the KOT model is suitable for parts with complex geometries together with an arbitrary fibre path and timedependent process settings.

Table 5.1 Overview of numerical parameters for IKOT model

\begin{tabular}{ccccc} 
Symbol & Case 1: Hoop & Case 2: Helical & Unit & Description \\
\hline$v$ & 100 & 50 & $\mathrm{~mm} \mathrm{~s}^{-1}$ & Tape laying head (TLH) velocity \\
$P$ & 400 & 400 & $\mathrm{~W}$ & Validation laser power \\
$\Delta t$ & 0.08 & 0.10 & $\mathrm{~s}$ & Time step \\
$\Delta x^{2}$ & 2 & 2.8 on average & $\mathrm{mm}^{2}$ & Surface mesh area \\
$N_{0}$ & 40,000 & 50,000 & - & Number of simulated rays from the laser \\
\hline
\end{tabular}




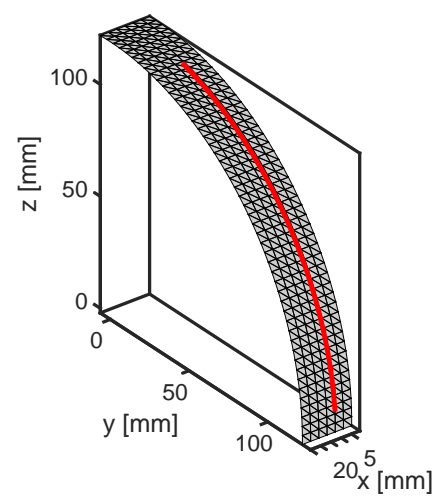

(a)

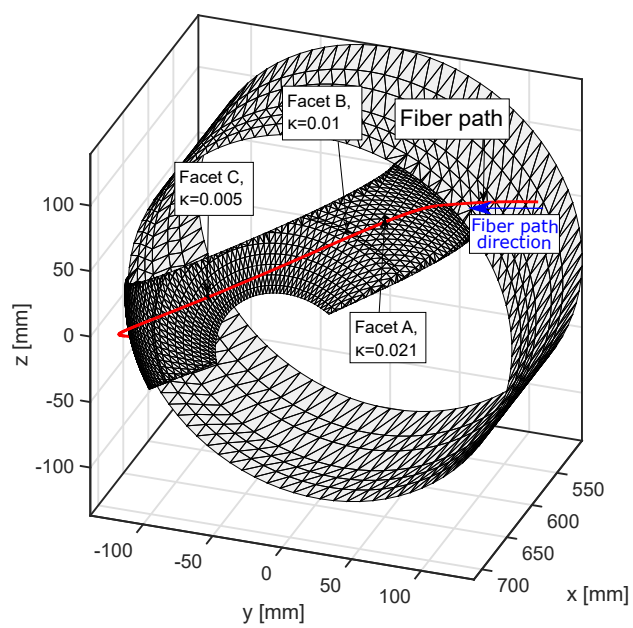

(b) $[28]$

Figure 5.2 Surface STL meshes and fiber paths used for the KOT simulations representing (a) part of a cylinder for hoop winding and $(b)$ the dome of a type-IV pressure vessel with helical winding pattern.

\section{Hoop winding:}

The hoop winding process was performed in 4 cycles of 5 continuous layers starting with a 5-layers-thick substrate. The used unidirectional carbon fibre reinforced prepreg tape was TC1200 AS-4/PEEK (Toray, the Netherlands). The material properties and process settings can be found in [75]. In order to reduce the computational cost, only one sixth of the cylinder circumference was simulated (see Fig. 5.2a) which equals to a winding process time of $1.3 \mathrm{~s}$. A cooling duration of $6.5 \mathrm{~s}$ was considered for the remaining time needed for completing a full circle. The thickness of the $1 \mathrm{D}$ thermal domains on the substrate was increasing during consecutive winding with each of the hoop layers. The temperature distribution of the last time step of a layer was used as the initial condition for the next layer. The kinematic and optical models were only calculated for the first layer of hoop winding since the substrate geometry and fiber path were the same for all the layers. The gradual change of roller indentation was neglected in the present work assuming that the increase of thickness did not have an influence on the nip point location and the absorbed heat flux distribution. The predicted tape and substrate temperatures are given in Fig. 5.3. Here, the location of the reported temperatures was at $2 \mathrm{~mm}$ prior to the nip point averaged during the steady-state phase.

It can be seen in Fig. 5.3 that the tape temperature was almost constant at $390^{\circ} \mathrm{C}$ during the process. On the other hand, the substrate temperatures varied in between $325{ }^{\circ} \mathrm{C}$ and $530{ }^{\circ} \mathrm{C}$. The substrate temperature increased due to the heat accumulation in the already wound layers during winding of consecutive layers on top each other. Although the substrate thickness increased with each added layer, the substrate temperature of each cycle started with a temperature of $308{ }^{\circ} \mathrm{C}$ which was due to the semi-infinite behavior 


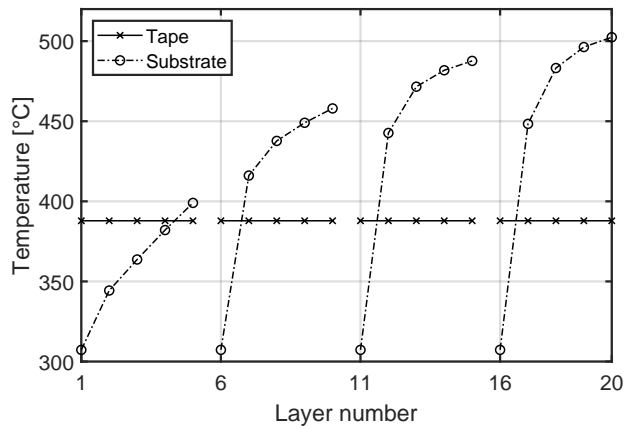

Figure 5.3 Predicted temperatures for multi-layer hoop winding process using KOT model. The tape and substrate temperatures are considered $2 \mathrm{~mm}$ away from the nip point (refer to 75 to interpret the nip point location).

of the thick substrate thermal domain. The details of the temperature evolutions can be found in [75].

\section{Helical winding:}

Regarding the helical winding of the pressure vessel's dome section, the CELSTRAN ${ }^{\circledR}$ glass fiber GF70-01/ high-density polyethylene (HDPE) [124] prepreg material was used. The material properties and process settings can be found in [28]. The time-dependent process velocity presented in [28] was neglected to simplify the helical process even further with a constant velocity of $v=50 \mathrm{~mm} \mathrm{~s}^{-1}$. However, the winding angle and the substrate surface curvature were varying during the helical winding on the dome part are shown in Fig. 5.4. During 0-2.25 s the helical process was taking place on the cylindrical part with constant winding angle. The dome winding started at $2.25 \mathrm{~s}$ and took $6.45 \mathrm{~s}$. The varying temperatures of the tape and substrate were acquired at $2 \mathrm{~mm}$ prior to the nip point and are shown in Fig. 5.5 which are not the same as the results shown in [28] due to the applied simplifications, yet following the same trend.

A constant temperature of $125^{\circ} \mathrm{C}$ on the tape surface was achieved whereas large fluctuations in the substrate temperature were found mainly due to the change in the local tooling curvature. The reason for having a constant tape temperature was due to the fact that the absorbed heat flux on the tape surface was not influenced by the change in the local substrate curvature, since the reflections of the rays from substrate to tape were neglected as aforementioned. The maximum temperature on the substrate was slightly over $225^{\circ} \mathrm{C}$ followed by a semi-steady temperature. The peak temperature was mainly due to the lower incident of the laser beams leading to a higher energy absorption according to the Fresnel law. In order to manufacture a product with uniform and reliable quality, the observed variations in the process temperature needs to be minimized and keep close to the target temperature range. Therefore, a process optimization framework is developed based on the inverse KOT model which is explained in the following section. 


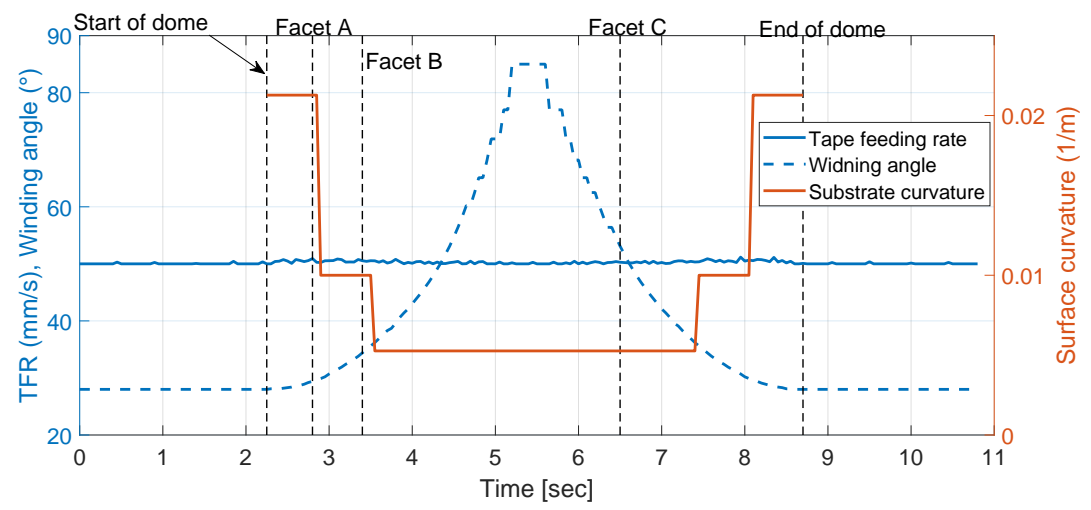

Figure 5.4 History of the substrate curvature and winding angle for the helical winding process with constant tape laying head velocity.

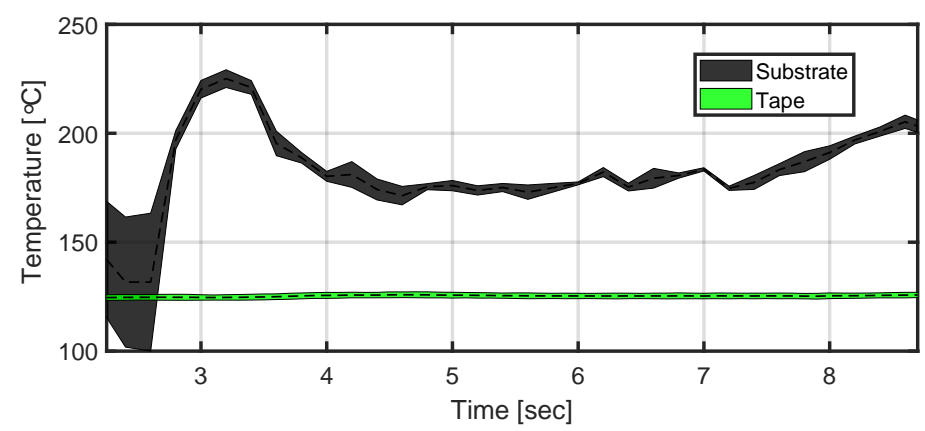

Figure 5.5 Predicted temperatures for the helical winding process using KOT model. The tape and substrate temperatures are considered $2 \mathrm{~mm}$ away from the nip point. The shaded area shows the standard deviation of the temperature across the tape and substrate width. Refer to [28] to interpret the nip point location.

\subsection{Inverse Kinematic-Optical-Thermal (IKOT) model}

A new inverse kinematic-optical-thermal (IKOT) model was developed by coupling the KOT model with the inverse optical-thermal (IOT) model introduced in [142]. The IOT model developed in [142] was based on a steady-state temperature distribution, whereas the current IKOT model is more comprehensive and therefore can optimize the process for transient temperature evolutions with any geometry used for LATW and LATP processes such as dome's helical winding process. The transient laser power distribution for the tape and substrate during the process is defined as the design variable in the current optimization problem. The IOT model consisted of two sub-models i.e. the inverse thermal (IT) model and a laser power distribution (LPD) model. The IOT model needed a definition of target temperature profiles and introduced the method to calculate the 
required heat flux to reach the target temperature. A flowchart diagram of the IKOT process model is shown in Fig. 5.6 in which the transferred data between sub-models are designated with A1, A2, B, and $\mathbf{C}$.

The kinematic model provided the history of the substrate thickness distribution (A2 in Fig. 5.6 and the tape laying head (TLH) position with respect to a surface mesh (A1). The TLH consisted of the laser source, compaction roller, and the incoming tape which followed a given input fiber path. The latter is discretized according to the distance that the TLH can travel in 3D space, depending on the time-dependent tape feeding rate during the constant time step $(\Delta t)$. For each time step, the TLH location (A1) and the thickness distribution (A2) were passed into the optical and the inverse thermal (IT) model, respectively. A normalized heat flux distribution $\left(\tilde{q}_{f w}(X, t)\right)$ on the tape and substrate surfaces (B) was calculated using the optical model as a function of time $(t)$ and the 3D space $(X)$. The thickness distribution (A2) and the $\tilde{q}_{f w}(X, t)(\mathbf{B})$ were used in the IT model to determine the required heat flux distribution $\left(q_{i v}(X, t)\right)$ on the tape and substrate surfaces $(\mathbf{C})$ needed to maintain the nip point temperature as close as possible to the target temperature. Finally, the magnitude of the required heat flux $(\mathbf{C})$ and the normalized heat flux distribution $(\mathbf{B})$ were used to calculate the optimized laser power distribution by using the laser power distribution (LPD) model. The details of the IT and LPD models are explained in the following sections.

\subsubsection{Inverse Thermal (IT) model}

The tape and substrate temperature distributions in the KOT model were obtained by using two independent thermal models which were coupled at the nip point. Multiple slices of $2 \mathrm{D}$ thermal domains were considered along the winding direction and through the thickness direction for the tape while multiple triangulated through-thickness 1D thermal domains were used at the substrate mesh locations as described in [28]. In the thermal model the objective was to calculate the temperature evolution as the output, while in the IT model the required heat flux distribution needed to be calculated on the heating surface to achieve the target temperatures at the tape and substrate nip point $\left(T_{\text {target }}^{\text {nip }}\right)$.

\section{Defining target temperature profiles}

As discussed in section 5.2, the substrate temperature variations in the helical process occurred due to the change in the heating flux distribution e.g. heating length, as a result of the local variation in the surface curvature. Besides, the substrate surface temperature at the beginning of the heating region was not the same for all the hoop layers due to the heat accumulation during continuous hoop winding process. Therefore, it was not trivial to define a unique target temperature profile on the substrate surface as was done in [142] for flat lay-up process. To this end, various linear temperature profiles for each of the triangulated 1D substrate thermal domains on the heating surface were defined. The aim was to evolve the surface temperature linearly to reach $T_{\text {target }}^{\text {nip }}$ at $t=t_{n i p}$ which was the time step when the nip point located at each of the 1D thermal domains.

To illustrate the variation in the required linear target temperature profile, an example 


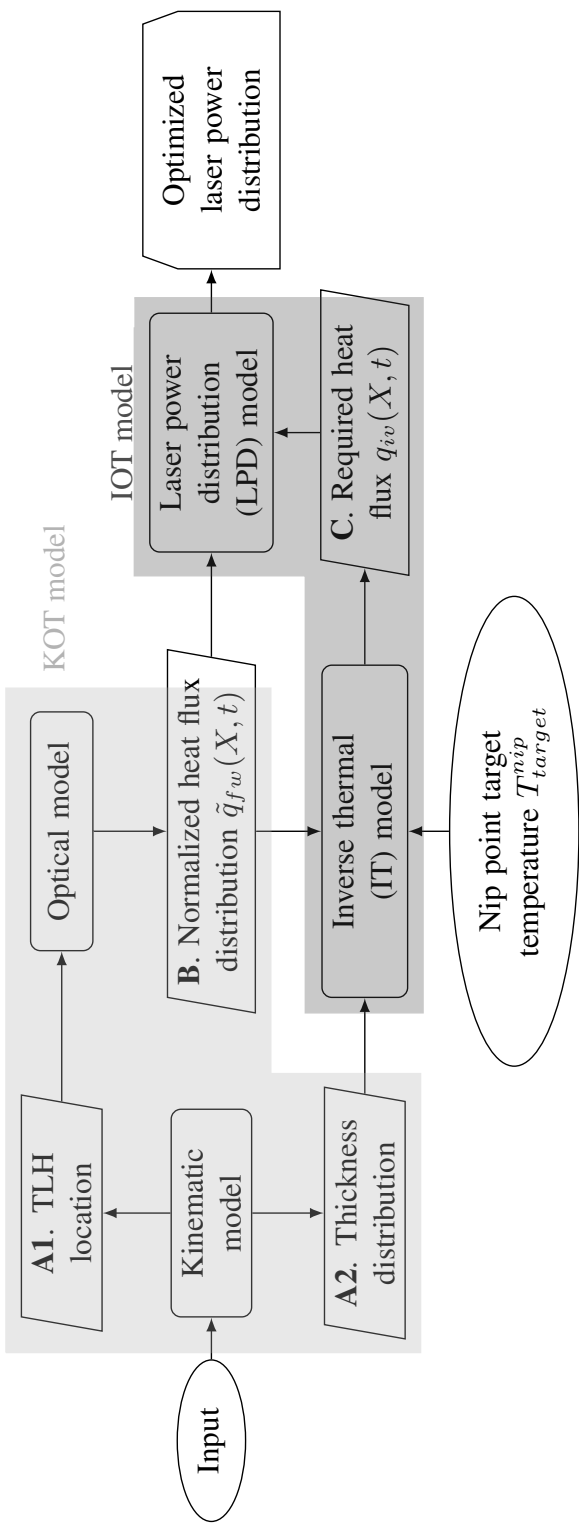

Figure 5.6 Flowchart diagram of the Inverse Kinematic-Optical-Thermal (IKOT) model. 
is given in Fig. 5.7 in which the fibre path orientation was changing in one case and was constant in another case. A schematic view of heating zones at three time stamps ( $t 1$ to $t 3)$ is represented by the highlighted areas. The inner and outer edge of the fibre path trajectory depict the region on the substrate on which the tape was deposited. For both cases, the top surface of the highlighted thermal domains i.e. triangular elements P1 and $\mathrm{P} 2$, were located on the nip line at $t=t 3$ at the inner and outer edges, respectively. Initially, all the thermal domains had the same temperature of $T_{\text {target }}^{i}$ at $t=t_{i}$. For the case with changing path orientation (Fig. 5.7(left)) at $t=t 1$, the element P1 on the inner edge was out of the heating zone while element P2 was heated as seen in Fig. 5.7 (left), while both elements were heated during $t 2$ to $t 3$. Besides, P1 was partially heated and P2 was fully heated. Therefore, element P1 had a different heat flux history with a shorter heating duration ( $t 2$ to $t 3$ ) to achieve the $T_{\text {target }}^{\text {nip }}$ compared to element P2 ( $t 1$ to $t 3$ ) which was on the outer edge. As a result, a higher temperature gradient and therefore higher laser power was required for the inner edge of the curved trajectory to maintain an uniform temperature distribution along the width of the nip point. On the other hand, in the case of constant fiber path orientation, both P1 and P2 elements were illuminated for the same amount of time from $t 1$ to $t 3$. Therefore, the linear target temperature profile for both points were the same as depicted in Fig. 5.7(right-bottom).

The linear target temperature profile was determined by using Eq. 5.1 as also visualized in Fig. 5.7. Eq. 5.1 explains the gradient definition of the linear temperature profiles.

$$
T_{\text {target }}=\frac{T_{\text {target }}^{\text {nip }}-T_{\text {target }}^{i}}{\Delta t_{h}-\Delta t} \times t+T_{\text {target }}^{i}
$$

where $T_{\text {target }}^{\text {nip }}$ was the target temperature at the nip point, $T_{\text {target }}^{i}$ was the initial temperature at the beginning of the heating zone at $t=t_{i}$, i.e. $t_{i}=t 1$ and $t_{i}=t 2$ for $\mathrm{P} 2$ and $\mathrm{P} 1$, respectively. $t_{n i p}$ was the time at which the nip point was located on the desired triangular element, i.e. at the end of the heating zone. $\Delta t_{h}=t_{n i p}-t_{i}$ was the heating duration to achieve $T_{\text {target }}^{\text {nip }}$, which depended on the transient heat flux distribution obtained from the KOT model. In each time step, the illuminated and nonilluminated triangular elements of the substrate were known by the KOT model and used to calculated the $\Delta t_{h}$. It was assumed that the $T_{\text {target }}^{\text {nip }}$ was achieved one time step $(\Delta t)$ prior to the nip point as was done also in [142] and illustrated in Fig. 5.7

\section{Calculating the required surface heat flux}

Once the target temperature profile was defined at the surface of the substrate $\left(T_{\text {target }}\right)$, the required heat flux profile to reach $T_{\text {target }}$ was calculated for 1D thermal domains shown in Fig. 5.8 based on the heat transfer governing equation (Eq. 5.2):

$$
\rho c_{p} \frac{\partial T}{\partial t}=k_{z} \frac{\partial^{2} T}{\partial z^{2}}
$$

where $\rho, c_{p}$ and $k_{z}$ are the density, specific heat capacity, and thermal conductivity in the thickness direction, respectively. Eq. 5.2 was solved using an implicit control volume based finite difference (CV/FD) scheme which was implemented in MATLAB. There 

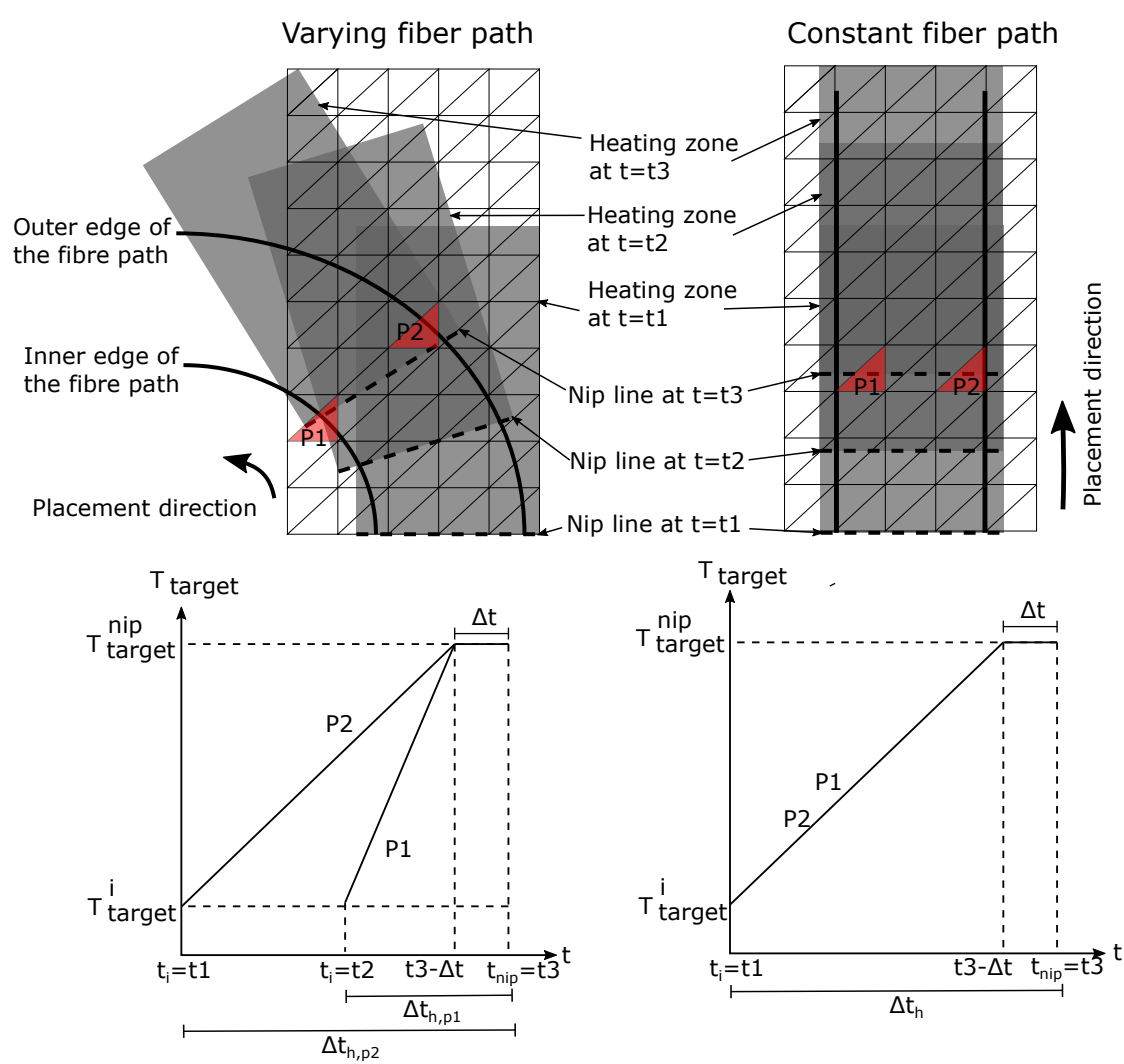

Figure 5.7 A schematic view of the heating zones (highlighted areas) during placement with changing and constant fibre path orientation. This is used to show the variation of heating duration for $1 D$ thermal domains on the top surface depending the corresponding location.

were three main types of nodes in the 1D domain i.e., the interior nodes and two boundary nodes (top and bottom surface of the substrate domain). The finite difference expressions of these nodes are given in Eq. 5.3 for the interior nodes and in Eqs. 5.4 and 5.5 for the boundary nodes.

$$
\begin{gathered}
T_{c v}^{n+1}(1+2 F o)-2 F o\left(T_{c v-1}^{n+1}+T_{c v+1}^{n+1}\right)=T_{c v}^{n}, \quad 1<c v<K \\
T_{c v}^{n+1}\left(1+2 F o\left(1+B i_{a}\right)\right)-2 F o \cdot T_{c v+1}^{n+1}=T_{c v}^{n}+2 F o \cdot B i_{a} \cdot T_{a}+q_{i v}^{n+1} \cdot \Delta z / k_{z}, \quad c v=1
\end{gathered}
$$

$$
T_{c v}^{n+1}\left(1+2 F_{o} \cdot B i_{t}\right)-2 F_{o} \cdot T_{c v-1}^{n+1}=T_{c v}^{n}+2 F_{o} \cdot B i_{t} \cdot T_{t}, \quad c v=K
$$

where $F_{o}=\alpha \cdot \Delta t / \Delta z$ was the dimensionless Fourier number, $\alpha=k_{z} /\left(\rho c_{p}\right)$ was the diffusivity of the material, and $B i=h \cdot \Delta z / k_{z}$ was the dimensionless Biot number. Here, 


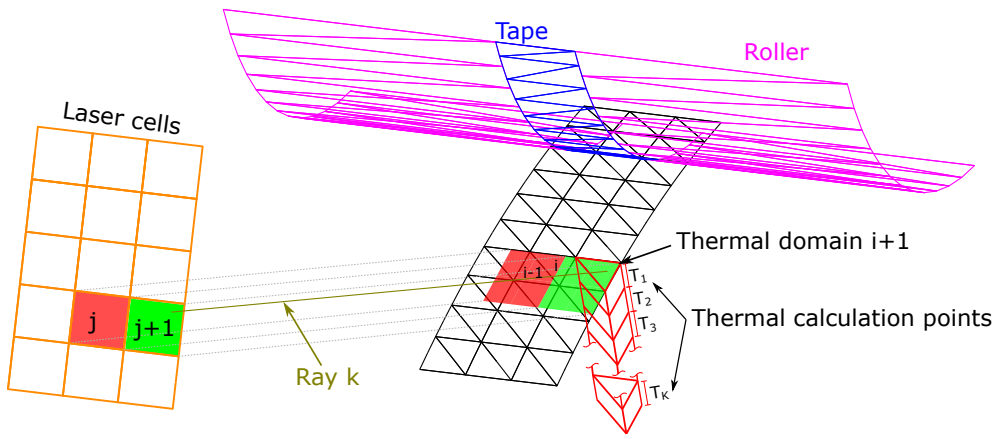

Figure 5.8 A schematic view of the grid-based laser source. The heated area by a laser cell over the substrate triangulated surface and the way each laser cell is heating the thermal nodes on the substrate are presented.

$\Delta z$ was the mesh size in thickness direction, $h_{a}$ and $h_{t}$ were the heat transfer coefficients for the surfaces in contact with air and tooling at the corresponding temperature of $T_{a}$ (for $c v=1$ ) and $T_{t}$ (for $c v=K$ ), respectively. $c v$ was the counter for the control volumes of the $1 \mathrm{D}$ thermal domains in the range of 1 to $K . T_{c v=1}$ was the temperature of the control volume at the heating surface and $T_{c v=K}$ was the temperature at the substrate-tooling interface. $q_{i v}^{n+1}$ was the unknown required absorbed heat flux on the surface induced by the laser source.

In the IT model the condition $T_{1}^{n+1}=T_{\text {target }}^{n+1}$ was defined as the temperature at the top surface which should follow the target temperature profile. In order to find unknown $q_{i v}^{n+1}$, Eq. 5.4 is rewritten for the $c v=1$ as:

$$
-q_{i v}^{n+1} \cdot \Delta z / k_{z}-2 F_{o} \cdot T_{2}^{n+1}=T_{1}^{n}+2 F_{o} \cdot B i_{a} \cdot T_{a}-T_{\text {target }}^{n+1}\left(1+2 F_{o}\left(1+B i_{a}\right)\right)
$$

The linear system of equations out of the discretized governing equations for each control volume in the 1D thermal domain in the through-thickness direction is given in Eq. 5.7 by using Eqs. 5.3, 5.5, and 5.6

$$
\left[\begin{array}{ccccc}
-1 & -2 F_{O} & 0 & \cdots & 0 \\
-2 F_{o} & 1+2 F_{O} & -2 F_{O} & & \\
0 & -2 F_{O} & 1+2 F_{O} & & \\
\vdots & & & \ddots & \\
0 & & & & 1+2 F_{o}\left(1+B i_{t}\right)
\end{array}\right]\left[\begin{array}{c}
q_{i v}^{n+1} \cdot \Delta z / k_{z} \\
T_{2}^{n+1} \\
T_{3}^{n+1} \\
\vdots \\
T_{K}^{n+1}
\end{array}\right]=\left[\begin{array}{c}
d_{1} \\
d_{2} \\
d_{3} \\
\vdots \\
d_{K}
\end{array}\right]
$$

where vector $d$ was the right hand side of Eqs. 5.3.5.5.

The temperature distribution through the thickness at $t=n+1$ for $1<c v \leq K$ and the required heat flux for $c v=1$ were calculated simultaneously as seen in the unknown vector at the left hand side of Eq. 5.7.

Note that the same procedure in Fig. 5.9 was used for the tape as well. The tape temperatures remained almost constant as compared with the substrate temperatures as shown for the non-optimized cases in Figs. 5.3 and 5.5 due to the constant TLH geometry 


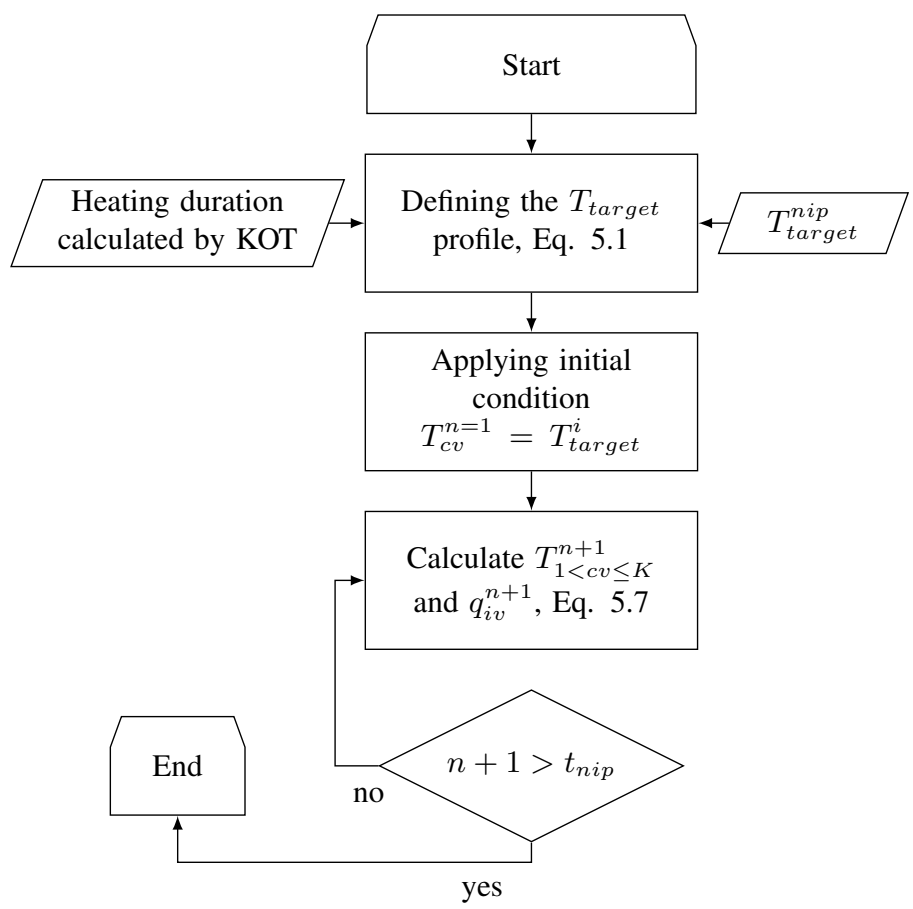

Figure 5.9 Flowchart diagram of the inverse thermal (IT) model for each of the $1 D$ thermal domains of the substrate.

and the consequent constant heating zone during the process. The target temperature profile was then constant during the process and considered as a linear profile from the room temperature at the beginning $\left(T_{\text {target }}^{i}\right.$ at $\left.t_{i}=t 1\right)$ of the heating zone to $T_{\text {target }}^{\text {nip }}$ at the nip point as shown also in Fig. 5.7

\subsubsection{Laser power distribution (LPD) model}

The LPD model was based on the arrays of laser cells which were independently controllable to optimize the time-dependent laser power distributions during the process as shown in Fig. 5.8 for an exemplary case. The reflections of the laser rays were neglected to simplify the LDP model. As seen in Fig. 5.6 the inputs of the LDP model were the time-dependent absorbed heat flux which was normalized with respect to laser power intensity $\left(\tilde{q}_{f w}(X, t)\right)$ and the required absorbed heat flux $\left(q_{i v}(X, t)\right)$, which were generated by the KOT and IT models, respectively.

The normalized absorbed surface heat flux $\left(\tilde{q}_{f w}^{j}(i, n)\right)$ by the thermal domain ' $\mathrm{i}$ ' which was illuminated by laser cell ' $j$ ' for the time step ' $n$ ' is schematically shown in Fig. 5.8 It is seen that also the laser cell ' $\mathrm{j}+1$ ' had a contribution to the heat flux exerted on the triangular thermal domain ' $i$ '. Therefore, the total heat flux on the substrate thermal node 'i' $\left(q_{f w}(i, n)\right)$ was determined by summing up all the (fractions of) contributing laser cells 
as described in Eq. 5.8 which was the procedure for the modified KOT model.

$$
q_{f w}(i, n)=\sum_{j=1}^{N_{c}} \frac{P_{j}^{n}}{A_{j}} \cdot \tilde{q}_{f w}^{j}(i, n)
$$

where $P_{j}$ equaled to the laser cell power, $n$ was the time step, $A_{j}$ was the cell area, and $N_{c}$ was the total number of laser cells heating the thermal node 'i'.

The power of each laser cell was determined based on the required heat flux $\left(q_{i v}(i, n)\right)$ of the illuminated triangulated elements on the substrate surface. In Fig. 5.8, up to eight triangular thermal elements are illuminated on the substrate surface by the laser cell ' $\mathrm{j}$ ' as an exemplary case which depends on the substrate surface mesh and laser cell sizes. As a result, a weight-averaging approach was considered to estimate the required laser power as shown in Eq. 5.9 .

$$
\begin{gathered}
P_{j}^{n}=\frac{1}{N_{t}} \sum_{i=1}^{N_{t}} \frac{q_{i v}(i, n) A_{j}}{\tilde{q}_{f w}^{j}(i, n)} \cdot R_{j}(i, n) \\
R_{j}(i, n)=\frac{\tilde{q}_{f w}^{j}(i, n)}{\sum_{j=1}^{N_{c}} \tilde{q}_{f w}^{j}(i, n)}
\end{gathered}
$$

where $N_{t}$ was the total number of triangular thermal elements illuminated by the laser cell ' $\mathrm{j}$ ' and $R_{j}(i, n)$ was the ratio of normalized heat flux from laser cell ' $\mathrm{j}$ ' divided by the total normalized heat flux for the top surface of thermal domain ' $i$ '.

The major advantage of the IKOT model as an optimization technique was the relatively low computational cost which is similar to the KOT model. This was because the optical and kinematical models were the same for IKOT and KOT models. The IT solver had the same size of system of equations to be solved as in the KOT model. The additional LPD model was not computationally expensive since only Eq. 5.9 needed to be solved.

\subsubsection{Absorption ratio}

The laser cell absorption ratio was used to calculate the efficiency of the illuminated surfaces to absorb the irradiated heat by the laser source with uniform power distribution. In addition, it is used to identify the laser cells responsible for heating the tape or substrate. In other words, how the tape and substrate are heated is quantified by the laser cell absorption ratio $\left(R_{a b s}^{j}\right)$ which is defined as:

$$
R_{a b s}^{j}=\frac{1}{N_{r} \cdot I_{0}} \sum_{k=1}^{N_{r}} I_{a b s}^{k, j}
$$

where $I_{a b s}^{k, j}$ term was the absorbed energy of the ray ' $k$ ' launched from the laser cell ' $j$ ' as indicated in Fig. 5.8. This term was calculated by the KOT model considering the Fresnel equation and the geometry of the setup which determined the incident angle of the laser rays. In Eq. 5.10, $I_{0}$ was the initial energy of the ray ' $k$ ' which was the same for all the rays due to the uniform power distribution of the laser source, and $N_{r}$ was the number of rays coming from the laser cell ' $j$ '. 


\subsection{Process optimization studies}

The developed IKOT model was used to optimized the laser power distribution for the cases studied in [75] for the hoop winding and in [28] for the helical winding as explained in Section 5.2 together with the process settings listed in Table 5.1

- Case-1: Three laser grids settings were considered to evaluate the performance of the IKOT model for multi-layer hoop winding process, namely a $1 \times 1,28 \times 1$ and $28 \times 11$ grids. As the laser spot size was $28 \mathrm{~mm} \times 11 \mathrm{~mm}$, the individual laser cells sizes were $1 \mathrm{~mm} \times 11 \mathrm{~mm}$ and $1 \mathrm{~mm} \times 1 \mathrm{~mm}$ for $28 \times 1$ and $28 \times 11$ grids, respectively. The target nip point temperature for the substrate and tape was determined at $400{ }^{\circ} \mathrm{C}$ for the hoop winding of C/PEEK tapes [143]. The corresponding linear target temperature profiles were determined based on the initial non-optimized results obtained from the KOT model. To illustrate, the target temperature history for a single thermal element on top of the substrate during the steady-state phase of layer 1 and 5 are shown in Fig. 5.10a with the heating time of $0.32 \mathrm{~s}$. It is seen that the temperature near the nip point, in the range of $0.32-0.24 \mathrm{~s}$ which was equal to the one time step $(\Delta t=0.08 \mathrm{~s})$, was kept constant at $400{ }^{\circ} \mathrm{C}$. The temperature was reduced linearly from $0.24 \mathrm{~s}$ to $0 \mathrm{~s}$ in the thermal domain of the substrate. The inlet temperature of the substrate domain at $0 \mathrm{~s}$ was determined from the initial non-optimized temperature distributions obtained from the KOT model. The initial temperature of the layer 5 was higher than the layer 1 due to the accumulated heat during winding of layers 1 to 4 which was also obtained from the KOT model. The target temperature profile for the tape was also linearly changing from room temperature $\left(25^{\circ} \mathrm{C}\right)$ to $400{ }^{\circ} \mathrm{C}$ at the nip point with a heating length of $39 \mathrm{~mm}$ calculated by the KOT model.

- Case-2: To study the performance of the IKOT model for parts with complex geometries and winding pattern, the helical winding of a type-IV pressure vessel made of glass/HDPE was optimized using $22 \times 1$ and $22 \times 11$ laser grid sources. As the laser spot size was $67 \mathrm{~mm} \times 32 \mathrm{~mm}$, the individual laser cells sizes were $3 \mathrm{~mm} \times 32 \mathrm{~mm}$ and $3 \mathrm{~mm} \times 3 \mathrm{~mm}$ for $22 \times 1$ and $22 \times 11$ grids, respectively. The facets $\mathrm{A}, \mathrm{B}$, and $\mathrm{C}$ as shown in Fig. $5.2 \mathrm{~b}$ were chosen with various surface curvatures to illustrate the target temperature distributions. The facets were located at the nip point at 2.8, 3.4 and $6.5 \mathrm{~s}$ as shown in Fig. 5.4. The target temperature profile for the facets $\mathrm{A}$ to $\mathrm{C}$ are shown in Fig. $5.10 \mathrm{~b}$ The initial temperature were the same as the room temperature $\left(25^{\circ} \mathrm{C}\right)$ since a single helical layer was simulated. However, due to the doubly-curved geometry and changing winding angle, the heating duration of $1.1 \mathrm{~s}$ for facet $\mathrm{A}$ and $0.9 \mathrm{~s}$ for facets $\mathrm{B}$ and $\mathrm{C}$ were obtained. The target temperature was set to $T_{\text {target }}^{\text {nip }}=140{ }^{\circ} \mathrm{C}$ [124] for one time step $(\Delta t=0.1 \mathrm{~s})$ before the nip point.

The calculated optimal laser power distributions by IKOT model were used as the input in the KOT model to predict the temperature distributions of the tape and substrate as a result of optimized laser power distribution as aforementioned in the flowchart in Fig. 5.9. 


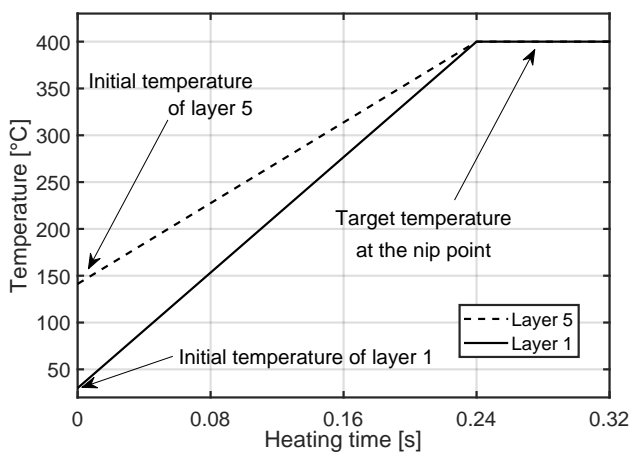

(a)

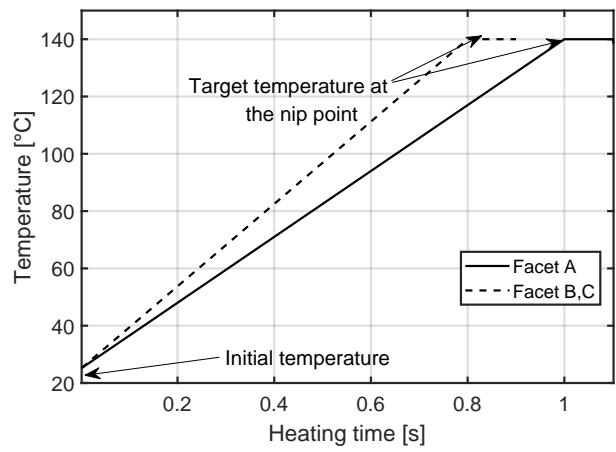

(b)

Figure 5.10 Target temperature history for (a) hoop layers 1 and 5 with the target temperature of $T_{\text {target }}^{\text {nip }}=400{ }^{\circ} \mathrm{C}$ at the nip point based on the processing temperature of C/PEEK [143] and (b) the helical layer at facets $A$ to $C$ with the target temperature of $T_{\text {target }}^{\text {nip }}=140^{\circ} \mathrm{C}$ at the nip point based on the processing temperature of

G/HDPE [124].

\subsection{Results and discussions}

\subsubsection{Hoop winding}

The distribution of the laser cell absorption ratio is plotted on the laser surface for $28 \times 1$ and $28 \times 11$ laser grids in Fig. 5.11 The laser cell rows 1 to 11 and 13 to 28 irradiated the tape and substrate, respectively. For the $28 \times 11$ grid, left-hand side of Fig. 5.11, the first and last three columns of the tape region were illuminating the roller. The laser row 12 which illuminated the vicinity of the nip point, had the least absorption ratio $\left(R_{a b s}=\right.$ 0.59 ) due to the lower incident angles of laser rays. The tape had lower $R_{a b s}=0.82$ on average compare to the substrate $R_{a b s}=0.87$. The roller, however, had the highest 


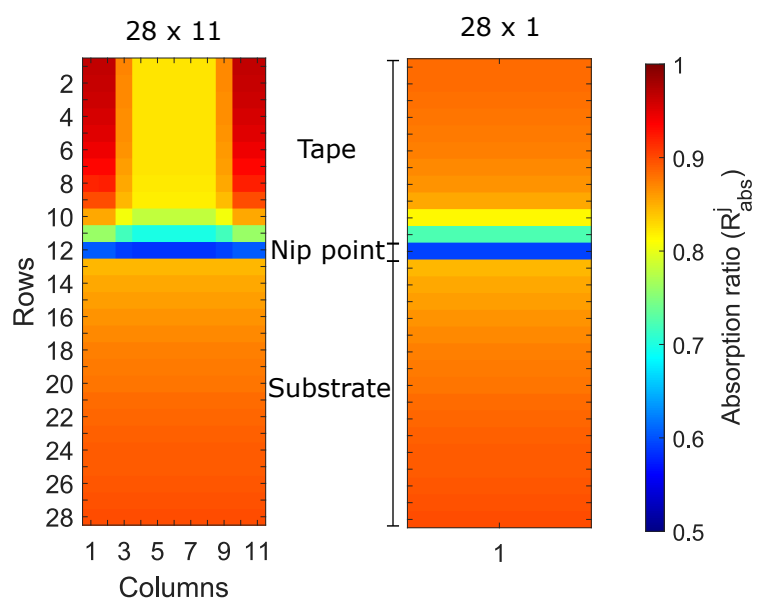

Figure 5.11 The absorption ratio distribution of grid-based laser source during hoop winding process considering the $28 \times 11$ (left) and $28 \times 1$ (right) laser grids.

$R_{a b s}=0.96$ due to the lower refractive index compared to the composite surface. The absorption ratio for the $1 \times 1$ grid was 0.82 which included all the tape, substrate, and roller components.

The optimized laser power distributions required to achieve the target temperature profile during hoop winding are shown in Figs. 5.12 and 5.13 for $28 \times 1$ and $28 \times 11$ laser grids, respectively. As expected, the laser power distribution of the area which heated the tape, i.e. rows 1 to 11 , remained the same for each added layer. The power of laser cells in columns $1,2,10$, and 11 of the tape region was zero for the $28 \times 11$ laser grid which means that the corresponding laser cells were not active. By excluding the deactivated laser cells, the average power (intensity) of all laser cells were $12.8 \mathrm{~W}\left(1.16 \mathrm{~W} \mathrm{~mm}^{-2}\right)$ and $1.17 \mathrm{~W}\left(1.17 \mathrm{~W} \mathrm{~mm}^{-2}\right)$ for $28 \times 1$ and $28 \times 11$ laser grids, respectively. It is seen that the power of the cells that were used to heat the substrate was gradually decreasing with each added layer to compensate for the accumulated heat in the substrate. The nonuniform power distribution across the width of the laser source for the $28 \times 11$ laser grid was due to the unstructured substrate mesh elements with respect to the laser source as depicted earlier in Fig. 5.8 The laser cells heating the nip points of the tape and substrate (row 12) had the largest power to compensate for the relatively low absorption ratio up to 45 and $4.4 \mathrm{~W}$ for $28 \times 1$ and $28 \times 11$ laser grids, respectively.

The heat flux and temperature history for the surface control volume of a 1D thermal domain at the middle of tape width in the steady-state phase (far enough from the starting point) is depicted in Fig. 5.14 for layers 1 and 5. The optimized laser power distribution was utilized as the input for the KOT model to generate the optimized heat flux and temperature histories. Although only 5 time steps were considered in the heating region, a good match between the target temperature profile and optimized results generated by the IKOT model was achieved. It should be noted that the IT results were actually the same as the target temperature profile. The obtained temperatures from the IKOT model at the nip point, i.e. at $0.32 \mathrm{~s}$, were found to be higher than the target temperature by 

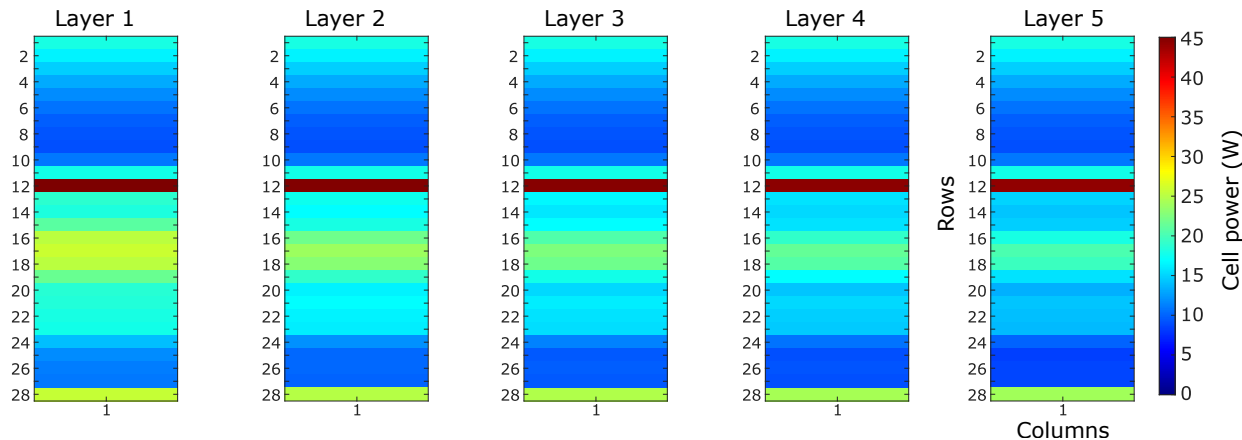

Figure 5.12 Optimized laser power distribution with $28 \times 1$ laser grid for hoop layers 1-5.
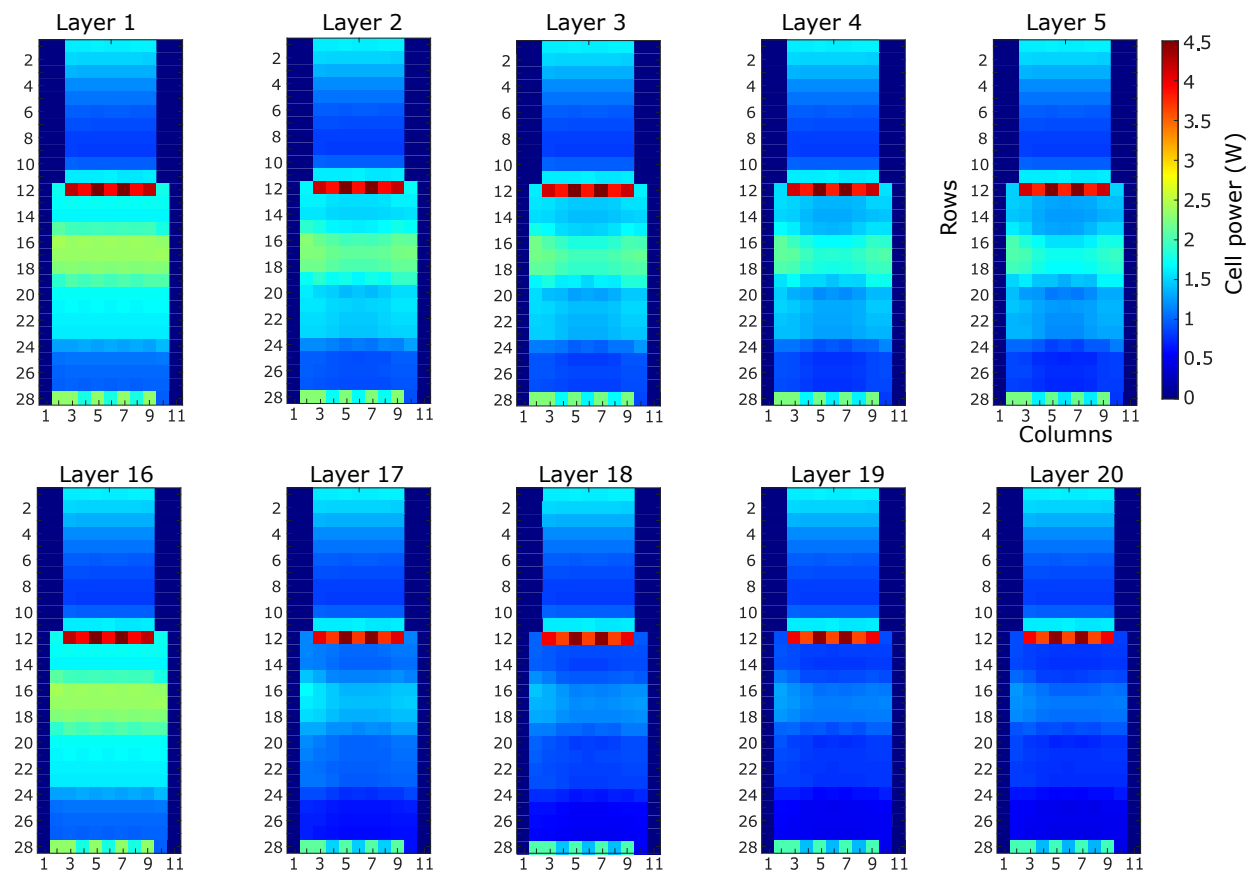

Figure 5.13 Optimized laser power distribution with $28 \times 11$ laser grid for hoop layers $1-5$ and 16-20. 


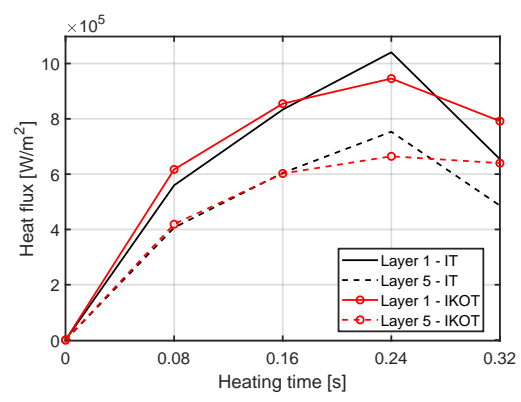

(a)

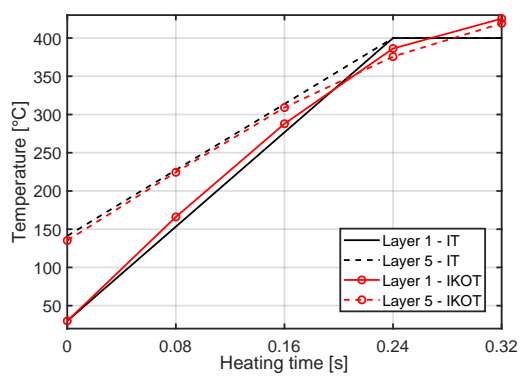

(b)

Figure 5.14 The (a) heat flux and (b) temperature history for a single substrate $1 D$ thermal domain in the steady-state phase during winding hoop layers 1 and 5 using laser grid of $28 \times 11$.

$19{ }^{\circ} \mathrm{C}$ (4.7\% deviation) and $25^{\circ} \mathrm{C}(6.2 \%$ deviation) for layers 1 and 5. This relatively small deviation was mainly due to the mismatch in the used grid distribution and the triangular thermal domains.

The optimized heat flux and temperature distributions along the centerline of the substrate at the steady-state phase during winding of layer 1 and 5 are plotted in Fig. 5.15 for the $28 \times 11$ laser grid. In addition, the heat flux and temperature distributions obtained from the IT model were added in order to evaluate the effectiveness of the IKOT model. Note that the results illustrated in Fig. 5.15 were extracted from the triangular elements at the top surface of the substrate at a specific process time, i.e. the time at which the nip point temperature reached a steady-state phase [28]. A step-wise temperature distribution was predicted because of the relatively large time step of $0.08 \mathrm{~s}$ which resulted in the heat flux movement of $8 \mathrm{~mm}$ per time step $\left(v \times \Delta t=100 \mathrm{~mm} \mathrm{~s}^{-1} \times 0.08 \mathrm{~s}\right)$. Note the difference of the linear target temperature profile shown in Fig. 5.10a which was defined in time domain for each triangular thermal element, whereas the temperature distribution was obtained at a specific time stamp of the process.

In general, a very good match between the obtained heat flux from the IKOT model by using the optimized laser power distribution and the required heat flux from the IT model $\left(q_{i v}(X)\right)$ was achieved. However, the IKOT heat fluxes were slightly larger than IT results around 8,15 , and $23 \mathrm{~mm}$ prior to the nip point which, as a consequence, led to the overestimation of the temperature distribution as seen in Fig 5.15b The required heat flux was increasing in the range of 8 to $33 \mathrm{~mm}$ away from the nip point up to $1.1 \mathrm{~W} \mathrm{~mm}^{-2}$ and $0.78 \mathrm{~W} \mathrm{~mm}^{-2}$ for layers 1 and 5 , respectively. However, a decreasing trend was predicted in the region of $0-8 \mathrm{~mm}$ since the target temperature profile was in the plateau region (Fig. 5.15a). This trend was also observed in Figs. 5.12 and 5.13 in which the laser power distribution reached to a peak at row 17 and then the required laser power reduced for rows 13 to 15 just before the nip point. The target temperature profile was also followed by the IT and IKOT models with a relatively good match shown in Fig. 5.15b. However, around the nip point and 13,21, $29 \mathrm{~mm}$ away from the nip point the IKOT temperature was higher than IT model as the consequence of the large heat fluxes shown and explained 


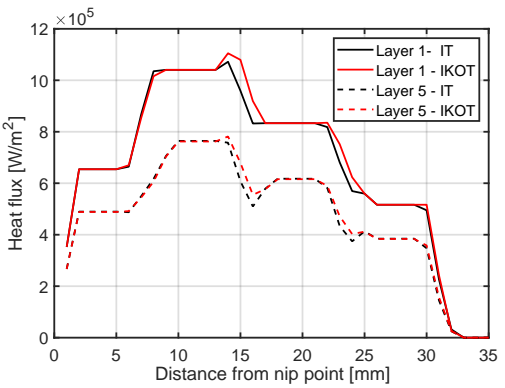

(a)

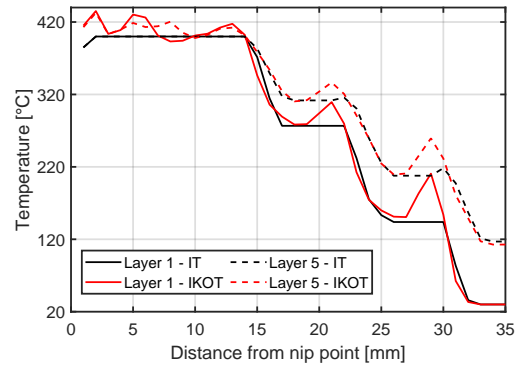

(b)

Figure 5.15 The (a) heat flux and (b) temperature distributions as a function of the distance to the nip point which was averaged during the steady-state phase of hoop layers 1 and 5 using laser grid of $28 \times 11$.

in Fig. $5.15 \mathrm{a}$

The evolution of the optimized substrate and tape temperatures at the centerline and $2 \mathrm{~mm}$ away from the nip point are presented for each hoop layer in Fig. 5.16 for $1 \times 1$, $28 \times 1$ and $28 \times 11$ laser grids. Note that the temperatures were obtained at the steady-state phase of each layer. It is seen that the heat accumulation during consecutive winding was eliminated by using $28 \times 1$ and $28 \times 11$ laser grid configurations. The uniform laser power distribution, i.e. $1 \times 1$ laser grid, was sufficient to have the temperature near the nip point close to the target temperature of $400{ }^{\circ} \mathrm{C}$.

The $1 \times 1$ laser grid configuration resulted in significant temperature variations for both tape and substrate. The $28 \times 1$ and $28 \times 11$ laser grids resulted in a much closer tape temperatures $\left(395{ }^{\circ} \mathrm{C}\right)$ at $2 \mathrm{~mm}$ prior to nip point as compared with the target tape temperature of $400{ }^{\circ} \mathrm{C}$. On the other hand, the optimized substrate temperature during consecutive winding of 5 layers using the $28 \times 1$ and $28 \times 11$ laser grids varied in the range of $410{ }^{\circ} \mathrm{C}$ to $420{ }^{\circ} \mathrm{C}$ (up to $5 \%$ mismatch) and $405^{\circ} \mathrm{C}$ and $395{ }^{\circ} \mathrm{C}$ (up to $1.25 \%$ mismatch), respectively. Therefore, the $28 \times 11$ laser grid was found to provide a process temperature evolution closer to the target temperature than the $28 \times 1$ laser grid.

The evolution of the optimized total power for each layer which was obtained by summing up the power of each optimized laser cells is depicted in Fig. 5.17 The required total power to maintain the desired nip point temperature showed a similar pattern for all the laser grids. The total power decreased during consecutive winding of 5 layers. The lowest average total power was obtained for the $28 \times 11$ laser grid configuration as approximately $300 \mathrm{~W}$ which was $25 \%$ lower than the total power of the non-optimized case. The average total power for the $28 \times 1$ and $1 \times 1$ laser grid configurations was found to be relatively higher as compared with the $28 \times 11$ laser grid. Therefore, $28 \times 11$ laser grid was found to be most effective based on the obtained process temperature evolution and the required average total laser power. 


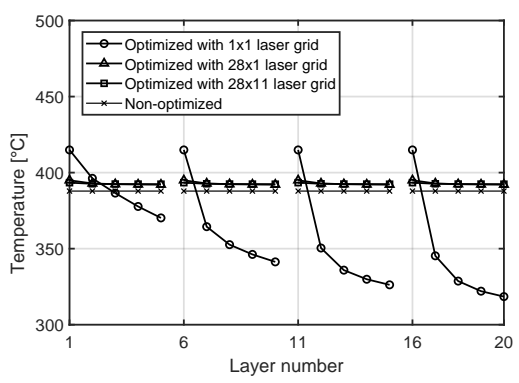

(a) Tape

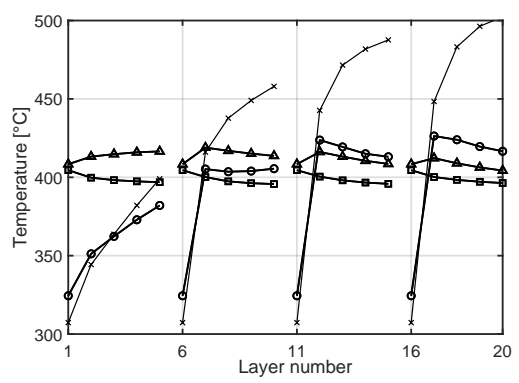

(b) Substrate

Figure 5.16 The optimized tape and substrate nip point temperatures of multi-layer hoop winding process with $a 1 \times 1, a 28 \times 1$ and $28 \times 11$ laser grids.

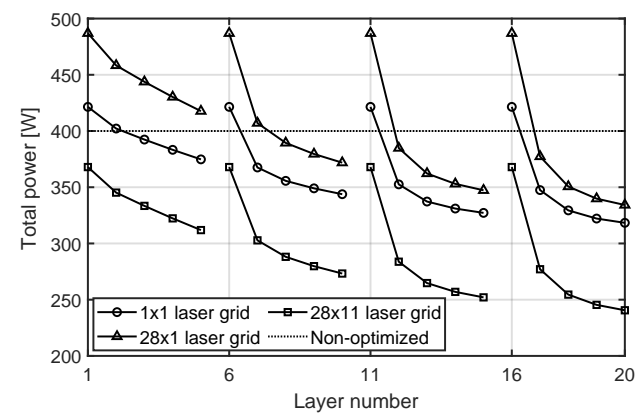

Figure 5.17 The required laser power by optimizing the laser power distribution for each layer of hoop winding process.

\subsubsection{Helical winding}

The $22 \times 1$ and $22 \times 11$ laser grids were used to optimize the helical winding process of the dome section of the pressure vessel. The $1 \times 1$ laser grid was not used here since it did not converge to the desired process temperature in the hoop winding optimization. The distributions of the absorption ratio for the laser sources are shown in Fig. 5.18 as an exemplary case when the nip point was located at facet $C$ at $6.5 \mathrm{~s}$ of the winding time. The rows 1 to 14 and 16 to 28 were considered to irradiate the tape and substrate, respectively. The first and last three columns of the laser grid of the tape region were pointing the roller for the $22 \times 11$ grid as aforementioned for the hoop winding as well. Generally, the pattern of absorption ratio distributions were found to be the same for the hoop and the helical cases as seen in Figs. 5.11 and 5.18 with a minimum $R_{a b s}=0.71$ for the nip point cells due to the lower incident angles. Besides, a lower averaged $R_{a b s}$ for the tape cells as compared with the substrate cells was obtained also for the helical winding case. However, the absolute value of $R_{a b s}$ was found to be different than the hoop winding case due the geometry of the TLH set-up and substrate geometry. 


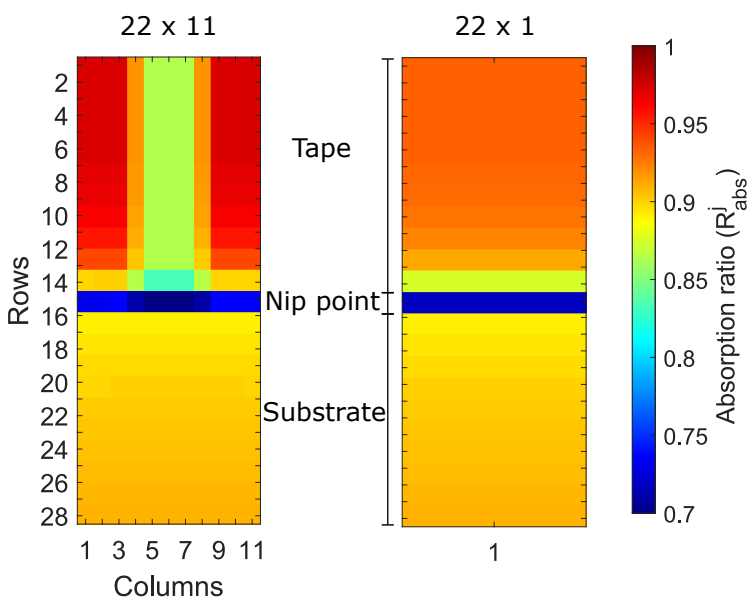

Figure 5.18 The absorption ratio distribution of grid-based laser source at $t=6.5 \mathrm{~s}$ of the helical winding process.

The transient laser power distribution required to achieve the target temperature profile at 2.8, 3.4, and $6.5 \mathrm{~s}$ are plotted in Figs. 5.19 and 5.20 for laser grids $22 \times 1$ and $22 \times 11$, respectively. The highest required power was found to be approximately $55 \mathrm{~W}$ and $5 \mathrm{~W}$ for $22 \times 1$ and $22 \times 11$ laser grids resulting in a power intensity of 0.57 and $0.56 \mathrm{~W} \mathrm{~mm}^{-2}$, respectively. The laser power distributions in Fig. 5.20 clearly show a rectangular area for heating the tape which coincided with the tape area shown in Fig. 5.18 Row 1 of the laser source was not active in both laser grid configurations as this row was not needed to achieve the target temperature profile on the tape surface. The laser power distribution with $22 \times 11$ laser grids showed a skewed pattern for the substrate region at 3.4 and $2.8 \mathrm{~s}$ as seen in Fig. 5.20. In other words, some of the laser cells in columns 3 and 9 were not active, i.e. had a power of $0 \mathrm{~W}$ at 3.4 and $2.8 \mathrm{~s}$, while these cells were active at $6.5 \mathrm{~s}$. This behavior showed a direct relationship between the substrate curvature seen in Fig. 5.4 and the evolution of laser power distribution. The curvature of the illuminated substrate at the $6.5 \mathrm{~s}$ (when the nip point was at facet $\mathrm{C}$ ) was constant with $\kappa=0.005 \mathrm{~m}^{-1}$ since the heating duration was $\sim 1 \mathrm{~s}(6.5-7.5 \mathrm{~s})$. While at 2.8 and $3.4 \mathrm{~s}$ (facet $\mathrm{A}$ and $\mathrm{B}$ ) the curvature of the illuminated substrate was varied in the range of $\kappa=0.02 \mathrm{~m}^{-1}$ to $\kappa=0.005 \mathrm{~m}^{-1}$ during $2.8-4.4 \mathrm{~s}$.

The transient heat flux and temperature histories for the selected facets $\mathrm{A}, \mathrm{B}$, and C during the helical winding are shown in Fig. 5.21 Similar to the hoop winding process, good agreement between the optimized results obtained from the IKOT model and the target temperature profile was achieved. At the nip point and after $1.1 \mathrm{~s}$, a relatively small temperature deviation of $9{ }^{\circ} \mathrm{C}(6.4 \%)$ was predicted for facet $\mathrm{B}$ based on the target nip point temperature of $140{ }^{\circ} \mathrm{C}$.

The optimized distributions of the heat flux and temperature on the substrate surface as a function of distance from the nip point are shown in Fig. 5.22 for the time when the nip point was located at facets A, B, and C. It is seen that the profiles had a stepwise trend due to the contribution of multiple triangular elements at the top surface of the 

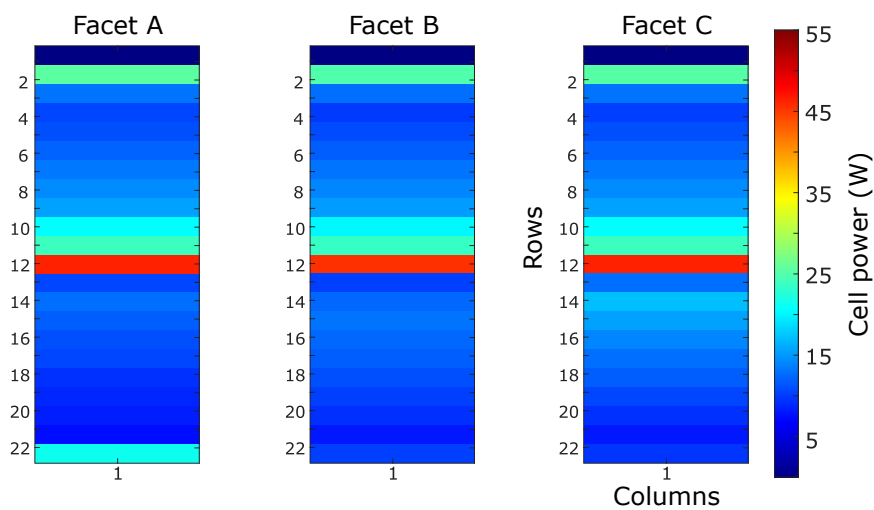

Figure 5.19 Laser power distribution found for the $22 \times 1$ laser grid during the helical winding process when the nip point was located at facet $A, B$, and $C$ at 2.8,3.4, and $6.5 \mathrm{~s}$ of the winding time, respectively.
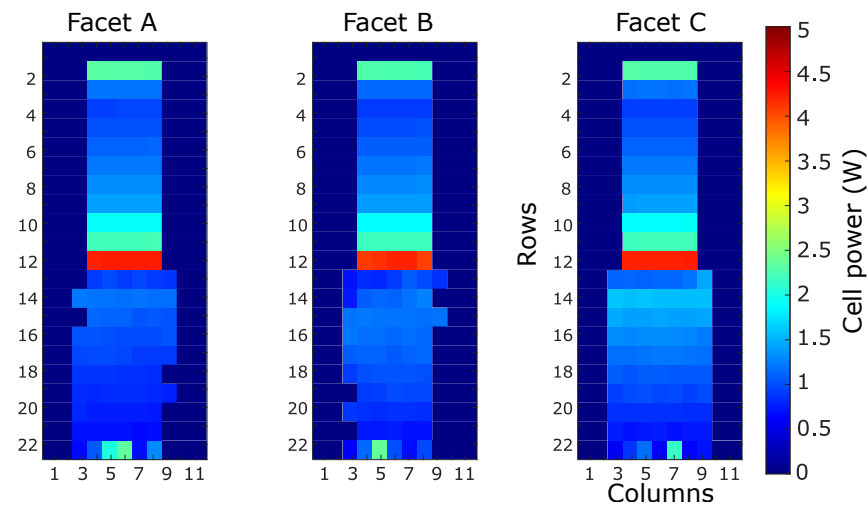

Figure 5.20 Laser power distribution found for the $22 \times 11$ laser grid during the helical winding process when the nip pint was located at facet $A, B$, and $C$ at 2.8, 3.4, and $6.5 \mathrm{~s}$ of the winding time, respectively.

substrate along the winding direction as also predicted for the hoop winding shown (Fig. 5.15. The heat flux movement per time step was $5 \mathrm{~mm}\left(v \times \Delta t=50 \mathrm{~mm} \mathrm{~s}^{-1} \times 0.1 \mathrm{~s}\right)$ and $8 \mathrm{~mm}$ for helical and hoop windings, respectively. Therefore, smoother temperature distribution were predicted for helical winding as compared with the hoop winding. The substrate heat flux distributions calculated by the IT model and IKOT model showed a good agreement by getting closer to the nip point. Similarly, the optimized substrate temperature distributions matched well with the target temperature profile which was the same as the results obtained from the IT model. Although the target temperature profiles had different heating lengths, the $T_{\text {target }}^{\text {nip }}=140{ }^{\circ} \mathrm{C}$ was achieved near the nip point. The optimized nip point temperatures for Facet $\mathrm{A}, \mathrm{B}$, and $\mathrm{C}$ were found to be approximately $145^{\circ} \mathrm{C}, 150^{\circ} \mathrm{C}$, and $140^{\circ} \mathrm{C}$ with a deviation of $3.6 \%, 7.1 \%$, and $0 \%$, respectively. Based on the relatively small deviation in the obtained nip point temperatures by using the $22 \times 11$ 


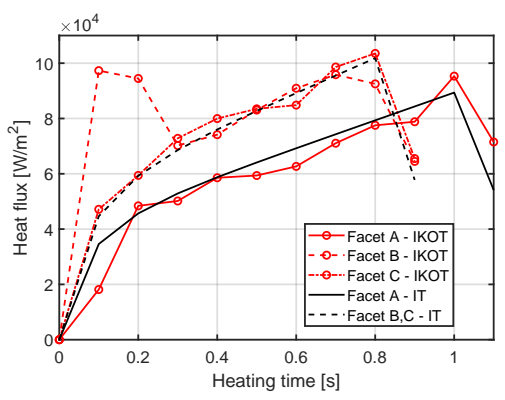

(a)

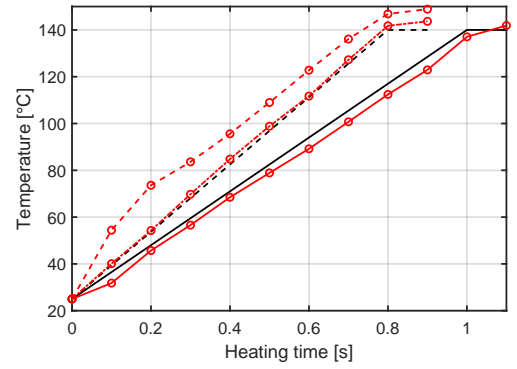

(b)

Figure 5.21 The (a) heat flux and (b) temperature history of facets A to $C$ using laser grid of $22 \times 11$.

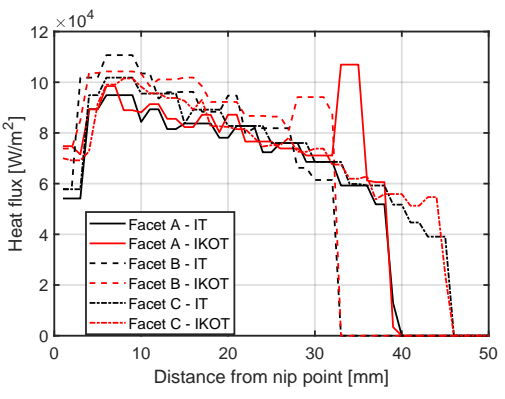

(a)

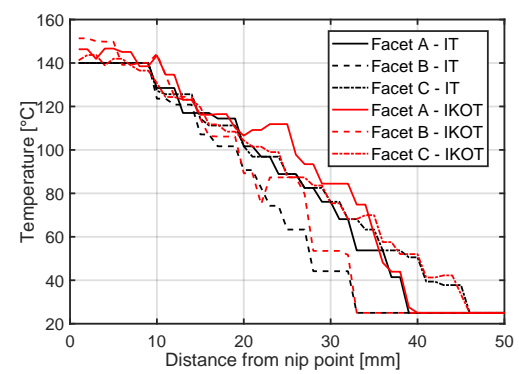

(b)

Figure 5.22 The (a) heat flux and (b) temperature distributions as a function of the distance to the nip point during helical winding at facets A to C using laser grid of $22 \times 11$.

laser grid configuration, the IKOT model for the transient helical winding of the dome section of the pressure vessel was found to be efficient.

The history of the averaged temperature across the substrate at $5 \mathrm{~mm}$ prior to the tape and substrate nip points are shown in Fig. 5.23 using the $22 \times 1$ and $22 \times 11$ laser grids. The undesired variations in the substrate temperature history of the non-optimized case (up to $60^{\circ} \mathrm{C}$ ) due to the change in the local tooling curvature were stabilized appropriately with a maximum deviation of $20^{\circ} \mathrm{C}$. At the beginning of the dome winding (before $3.5 \mathrm{~s}$ ), the temperature was not close to $140{ }^{\circ} \mathrm{C}$ due to the relatively course mesh of the cylindrical part which contributed to the calculation of the optimum power of the common laser cells for the dome and cylindrical parts. The non-optimized and optimized tape temperature was calculated around $125^{\circ} \mathrm{C}$ and $137^{\circ} \mathrm{C}$, respectively. However, the temperature deviation across the tape width was the same $\left(\sim 1^{\circ} \mathrm{C}\right)$ since the laser power distribution were uniform for both optimized and non-optimized case.

The resulting total laser power for the tape and substrate are shown in Fig. 5.24. The 


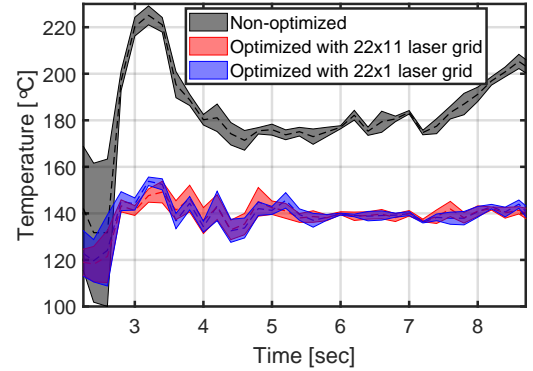

(a) Substrate

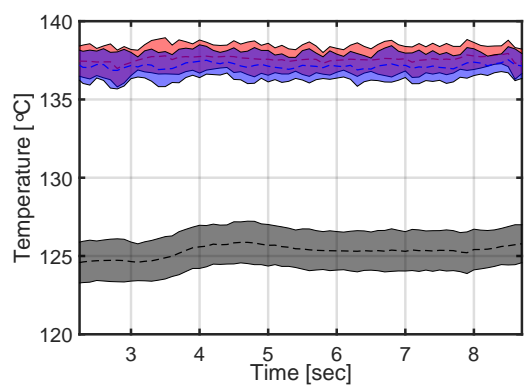

(b) Tape

Figure 5.23 The history of the optimized tape and substrate temperatures at $5 \mathrm{~mm}$ away from the nip point. The shaded area of the predictions shows the temperature standard deviation in the width direction of the substrate deposition region [28].

corresponding laser cells heating the tape and substrate were determined based on the Fig. 5.18. Both laser grids resulted in a more or less similar pattern for the total power. The tape power was almost constant at $204 \mathrm{~W}$ and $93 \mathrm{~W}$ for the $22 \times 1$ and $22 \times 11$ laser grids, respectively. However, the required power for heating the substrate was fluctuating due to the changing substrate curvature and winding angle. It is noteworthy that for both investigated laser grids the tape needed higher power as compared with the substrate. This was mainly due to the higher tape target temperature as compared to the non-optimized tape temperature, while the target substrate temperature was lower that the non-optimized substrate temperature. Fig. 5.24 shows that $22 \times 11$ laser grid required an averaged power of $160 \mathrm{~W}$ which was half of the required power for $22 \times 1$ laser grid, however, both configurations resulted in almost the same optimized temperature history according to Fig. 5.23

\subsubsection{Evaluation of the IKOT model}

The IKOT model was evaluated by analyzing the effect of computational parameters on the optimized temperature. In this parametric study the effects of laser grid size, surface mesh size, and mesh size in the thickness direction on the substrate temperature at the centerline and $2 \mathrm{~mm}$ away from the nip point were examined. The laser grid sizes of 0.25 , 1 and $4 \mathrm{~mm}^{2}$ equivalent to the laser grid of $56 \times 22,28 \times 11$ and $14 \times 5$, respectively were employed. Total of five surface mesh sizes were utilized, i.e. $0.125,0.5,2,8$ and $32 \mathrm{~mm}^{2}$ ). The mesh sizes in the thickness direction were $0.0125,0.01875,0.025,0.0375$ and $0.75 \mathrm{~mm}$ equivalent to $12,8,6,4$ and 2 computational nodes per layer, respectively used in the parametric study. Here, the first layer of the hoop winding case described in Section 5.2 was considered for the parametric study in which the total number of rays was kept constant as 40,000.

It seen in Fig. 5.25 that the optimized substrate temperature converged to the target temperature (shown by the plane at $400{ }^{\circ} \mathrm{C}$ ) by reducing the surface mesh size. However, 


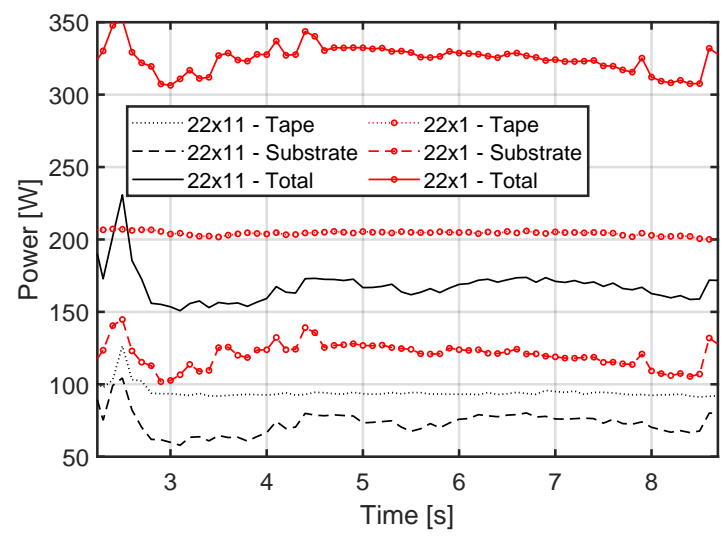

Figure 5.24 The history of the optimized laser power for helical winding of the dome's pressure vessel.

the laser grid size had negligible effect on the optimized temperature. The effect of the mesh size in the thickness direction is shown in Fig. 5.25 $\mathrm{p}$. It is seen that there was hardly any change in the optimized process temperature (maximum deviation of $0.5 \%$ ) by the IKOT model for different mesh sizes in the thickness direction. Fig. 5.26 shows the computational time for different laser grid and surface mesh sizes. The IKOT model (KOT+IOT+LDP) almost had the same computational time as the KOT model. For instance, for laser grid size of $4 \mathrm{~mm}^{2}$ and surface mesh size of $8 \mathrm{~mm}^{2}$ the KOT model took $398 \mathrm{~s}$ and this was only $10 \mathrm{~s}(2.5 \%)$ for the IOT and LDP models. The increase in the computational time due to the reduction in the laser grid size was found to be more dominant than the reduction in the surface mesh size for the IOT+LPD models. 


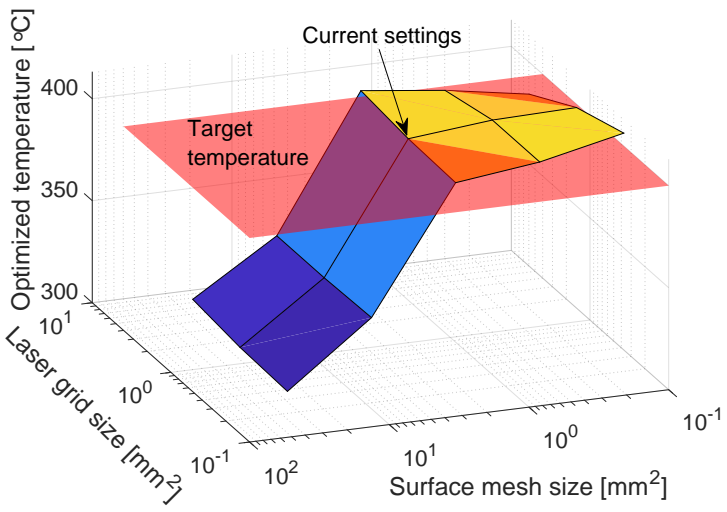

(a)

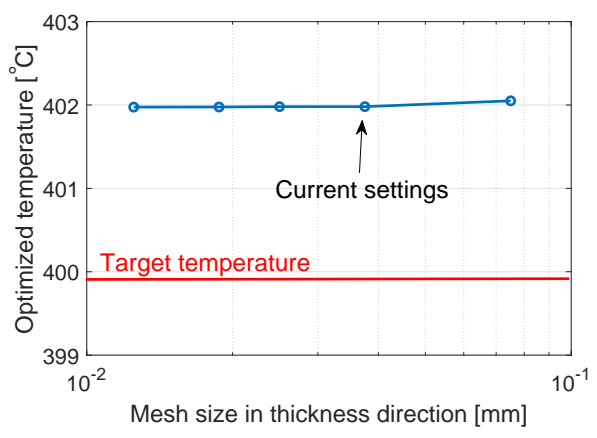

(b)

Figure 5.25 The substrate temperature as a function of $(a)$ surface mesh and laser grid sizes and (b) mesh size in the thickness direction.

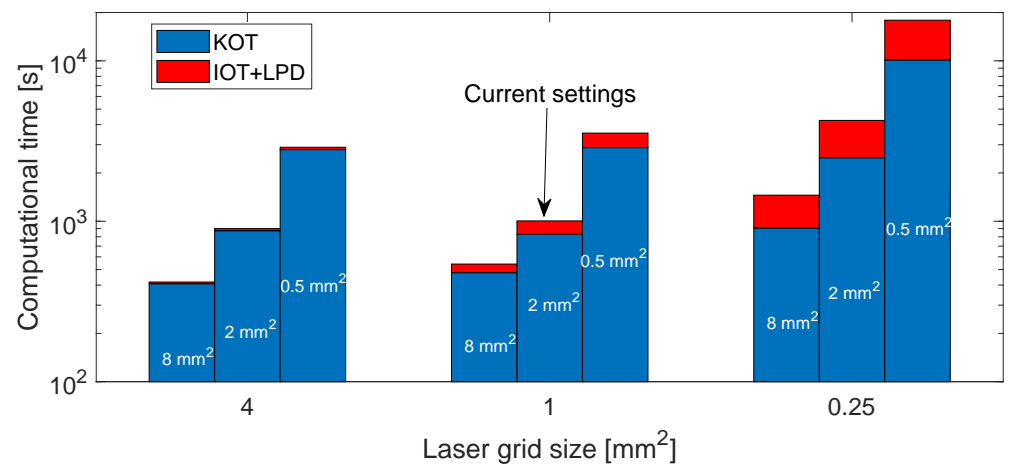

Figure 5.26 Computational time of the KOT and IKOT model by varying the surface mesh (shown for each bar) and laser grid size. 


\subsection{Conclusion}

A new inverse model is introduced to optimize the laser power distribution for laserassisted tape winding and placement (LATW/LATP) process for manufacturing complex composite parts with arbitrary geometry, fiber path, and process settings. The objective of the inverse kinematic-optical-thermal (IKOT) model was to maintain the nip point temperature of the tape and substrate as close as possible to the target prepreg processing temperature. For this purpose, a grid of independent laser cells was used as the heat source which was inspired by the vertical-cavity surface-emitting laser (VCSEL) technology.

Two case studies were considered to evaluate the capabilities of the IKOT model: multilayer hoop winding and single-layer helical winding of a doubly-curved dome's pressure vessel. A global increase in the substrate temperature during the hoop winding process was observed. Optimized laser power distributions were found to maintain a constant nip point temperature for each layer by using laser grids of $1 \times 1,28 \times 1$ and $28 \times 11$. The $28 \times 11$ laser grid provided nip point temperatures closer to target temperature with a lower total laser power consumption as compared to the $28 \times 11$ laser grid. The $1 \times 1$ was found to be not suitable for the optimization because tape and substrate required different power to achieve the desired nip point temperature. The laser grids of $22 \times 1$ and $22 \times 11$ were used to optimize the transient laser power distribution during helical winding process. The IKOT model was able to minimize the major nip point temperature variations, although undesired deviations from the target temperature were present due to the coarse and unstructured mesh used in the KOT. The laser grid of $22 \times 11$ resulted in a lower power consumption while having almost the same optimized temperature output as compared to $22 \times 1$ grid configuration. Based on the parametric study it was found that the optimized temperature was closer to the target temperature for smaller surface mesh sizes.

The reflections of the laser rays was not taken into account in the current IKOT model which might alter the obtained optimum laser power distribution. Therefore, as a future work, it is necessary to include the laser reflection in the IKOT model to achieve a more comprehensive process optimization. In addition, a validation of the obtained laser power distribution with the experiments, e.g. by using a VCSEL heat source, is also suggested as a future work. 


\section{CHAPTER 6}

\section{DiSCUSSION}

The present chapter puts the work presented in the previous chapters in a broader perspective and discusses the main achievements obtained in each chapter towards reaching the main goal of this thesis. Based on the obtained results, a roadmap towards an accurate process design tool for manufacturing of fiber reinforced composites parts is elaborated, including some of the challenges that inherently exist in the manufacturing process.

\subsection{Overview of main achievements}

Multi-physics based kinematic-optical-thermal (KOT) models were developed to study the ring winding of C/PEEK tapes (Chapter 2), hoop winding of C/PA12 tapes (Chapter 3 ), helical winding of G/HDPE tapes (Chapter 4) and to optimize the LATW process (Chapter 5). The main results obtained from the previous chapters are summarized in the following.

\subsubsection{The effect of heat accumulation and roller deformation}

Multi-layer hoop winding on a cylindrical mandrel for the manufacturing of composite rings was studied in Chapter 2. Although the hoop winding process involves a relatively simple geometry, there were some underlying phenomena observed affecting the nip point temperature. Assuming constant process settings, the nip point temperature was not constant due to the continued heat accumulation during consecutive winding. The shadow region prior to the nip point was shown to have a significant effect on the local temperature development. In addition, the increase in the roller indention due to the growing substrate domain in the thickness direction during the process alters the process temperature. The combined as well as the individual effects of heat accumulation and roller indention were addressed comprehensively. It was shown that the heating length and heat flux distribution are affected by the roller deformation, however to a lower extent as compared with the effect of the shadow region. This suggests that the roller deformation should indeed be considered in the process modeling to obtain an accurate 
prediction of the temperature, as the shadowing region prior to the nip point is affected significantly by the deformed state of the roller. Also the contact area between the roller and substrate was influenced by the roller deformation, which alters the cooling history of the substrate. Therefore, the roller indentation was included as a significant geometrical parameter in the process model, which affects the heating as well as the cooling history of the wound tapes. To achieve a reliable temperature measurement, the temperatures measured by the thermal camera were analyzed carefully, as the local geometry in the vicinity of the nip points was subjected to a gradual change during the process due to the roller deformation. The relocation of the nip point was taken into account to analyze the experimentally obtained thermographic images properly. Besides, the size of the area projected on the pixel depends on the respective local orientation of the surface, which was also analyzed in detail. The trends of the predicted tape and substrate temperatures were found to agree well with the measurements.

\subsubsection{Non-uniform temperature and crystallinity distributions}

The adjacent hoop winding process of composite pipes was studied in Chapter 3 in which the substrate domain is growing in both the thickness and in-plane direction. The kinematic model was embedded into the thermal model, incorporating the expanding thermal domain. The temperature non-uniformity across the substrate width was found to be significant by means of the developed KOT model and the thermal camera observations. The through thickness temperature measurements and predictions revealed that the locations near the substrate edge had multiple heating and cooling histories during adjacent hoop winding. The edges of the substrate were heated two times, therefore the temperature increase at the substrate edges was higher than for the central region of the substrate. This non-uniform temperature distribution resulted in a non uniform degree of crystallinity (DoC) distribution across the width, which was captured by the incorporated non-isothermal crystalinity model and validated by DSC tests of the final processed samples. The predicted trends for the DoC distribution across the substrate width was found to agree well with the measured crystallinity level distribution by the DSC tests. More specifically, the DoC at the edges of the substrate was higher than in the central region due to the multiple heating and cooling cycles. It was found that further improvements in the modelling approach can be obtained by including a more detailed melting model, describing the local melting of crystals during the (multiple) heating cycles.

\subsubsection{Effect of tooling geometry and tape feeding rate}

The novel KOT model developed in Chapter 4 is capable of predicting the thermal history during the LATW process of pressure vessels and pipes with complex tooling geometries and varying process parameters. The complicated kinematics of the changing fiber path were fully coupled with the optical and thermal models. The product geometry, fiber path, and time-dependent process settings were defined as fully arbitrary and user-defined. The kinematic model was utilized and the required information of the thickness distribution history and the tape laying head location was forwarded to the thermal and optical models. 
It was shown that varying both the curvature and processing speed affected the processing temperature significantly during helical winding of the dome part of a pressure vessel. A practical result of this model is a $3 \mathrm{D}$ digital process temperature shadow on the surface of the product, showing the critical locations where the temperature deviates from the ideal range.

\subsubsection{Process optimization and optimum laser power distribution}

An important step was taken in Chapter 5 toward a systematic process design tool which can be used for process optimization. The developed KOT models in the previous chapters were treated inversely to determine the optimal laser power distribution while maintaining the nip point temperature at the target temperature. First, an inverse thermal model was developed to calculate the required heat flux distribution to achieve the target processing temperature. Next, the inverse optical model was employed to translate the determined heat flux distribution into a laser power distribution. A time-dependent laser power distribution (which can be realized with recently introduced VCSEL sources) was obtained for both the hoop and helical winding cases presented in Chapter 2 and Chapter 4 , respectively. It was shown that the inverse KOT model was capable of maintaining the nip point temperature close to the target temperature distributions by using the optimized laser power distributions.

\subsection{Roadmap towards accurate process design tool}

In this section, next steps and challenges to achieve an accurate process design tool for the LATW processes by using the proposed KOT models are discussed. Multiphysical phenomena, namely the kinematics, the optics, the heat transfer and the mechanics are required to be considered to obtain an accurate process model. The relevant interrelations between these physical phenomena are illustrated in Fig 6.1 A number of investigations were already performed in the foregoing chapters, e.g. the interrelation between the kinetics, optics and heat transfer in Chapter 4 and the coupling of mechanics and optics in Chapter 2. A few of these interrelations nonetheless have not yet been addressed in the current framework which are indicated as dashed arrows in Fig. 6.1. Temperature dependent optical properties require a detailed optical characterization of the used tapes. The deconsolidation prior to the nip point has a direct effect on the optical, thermal and mechanical properties due to the formation of voids. In order to describe the mechanics properly, coupled thermo-mechanical models including temperature dependent mechanical properties are required. The aforementioned is required to obtain a detailed description of the local tape deformations during the process. Towards full exploitation of the process design tool, the structural performance prediction, the stochastic process modelling for robust manufacturing and the analysis of local geometrical irregularities are considered to be important. These are explained in the following. 


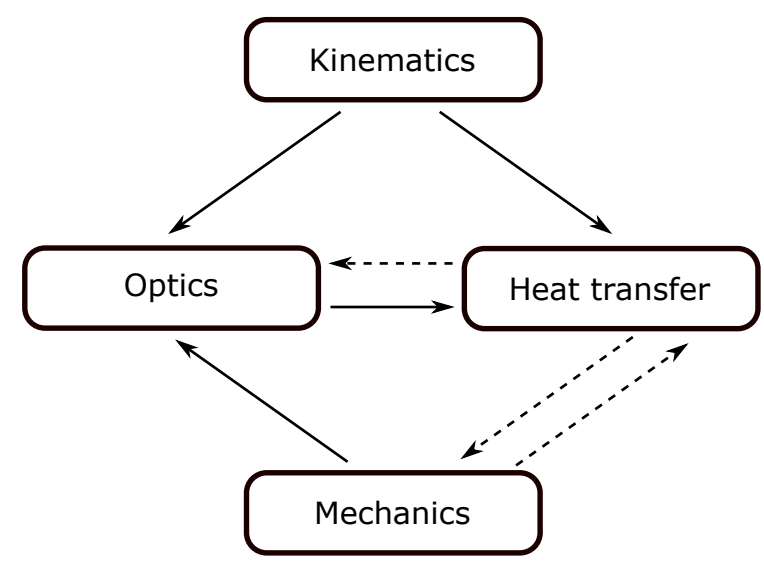

Figure 6.1 Flow chart for the interrelations between the kinematics, the optics, the heat transfer and the mechanics in LATW processes.

\subsubsection{Coupling of the KOT model with mechanical and structural models}

The final structural performance of the TPC part is governed by multiple factors such as the fiber distribution, polymer crystallinity, presence of voids, interlaminar bonding and residual stresses. The local geometrical irregularities such as gaps and overlaps present during the LATW process influence the local mechanical properties by affecting the local fiber content and orientation not only at macro scale but also at the micro scale. Similarly, the final crystallinity level of the polymer is important for the stiffness, strength and toughness of the matrix. By performing a post annealing step it is possible to have a desired crystallinity distribution within the TPC parts. The intra- and interlaminar voids may be present in the original material as well as originate from the deconsolidation state prior to the nip point. Further, the intimate contact development and polymer healing drive the interlaminar bonding at the tape and substrate interface. To address these mechanisms and predict the final structural performance, the KOT models developed in this thesis can be coupled with mechanical models. The final structural performance, in the end, depends on the foregoing process i.e. the full thermo-mechanical history. It is seen in Fig. 6.1 that the complex physical processes during manufacturing are inherently coupled. As an example, the deconsolidation of the tape and substrate prior to the nip point affects the local fiber and void distributions and thereby the optical and thermal properties. Next to the process models, the aforementioned mechanisms are required to be characterized and corresponding material models need to be developed. For example, it was suggested in recent work [32] that there is even an impregnation of the dry fibers involved in the interlaminar bonding mechanism. The material models can be coupled with the multi physical modelling of the LATW processes, which is the first step to build a process design tool box. The process models need to be developed step by step, gradually increasing the complexity by adding further interrelations. 


\subsubsection{Uncertainties in model parameters}

Composite materials and their manufacturing processes have statistical variations which may be due to the variability in the material constitution (e.g. fibre/matrix distribution). To asses the possible consequences of these variations, a probabilistic or reliability analysis of the LATW processes can be carried out by using the process design tools. In contrast to the deterministic analysis of the composite manufacturing processes, a statistical analysis gives a better understanding of the effect of the variations and uncertainties inherently being present in e.g. the tape thickness, the fiber volume content and orientation and the heat transfer coefficients on the process design. This makes it easier and more practical to predict the sensitivity of the output parameters, e.g. the nip point temperature, with respect to the scatter in the input parameters, e.g. material properties and geometry. A stochastic modelling framework can be coupled with the developed KOT models in this thesis.

An example is presented in Appendix Aby analyzing the effect of statistical variations in the optical, geometrical and thermal parameters on the variation in tape and substrate temperatures. The developed KOT model was coupled with a Monte Carlo Simulation (MCS) as explained in Appendix A. Based on defined normal distributions for the input parameters, cumulative distribution functions for the tape and substrate temperatures at the nip point were calculated. The variation in the averaged nip point temperate was found to be between the variation in substrate and tape temperatures at nip point. It was found that the probability of the substrate temperature at nip point being less than $400^{\circ} \mathrm{C}$ was approximately $50 \%$ for supposedly realistic variability in the input parameters, while this value was $60 \%$ for the tape for the given range of input parameters. Moreover, the probability of the studied PEEK polymer temperature being higher than the thermal degradation temperature (assumed as $580^{\circ} \mathrm{C}$ [144]) was found to be approximately $4 \%$. It should be noted that the time period for which the polymer was above this degradation temperature was approximately $0.1 \mathrm{~s}$. The MCS results were analysed to estimate the linear correlation coefficients between the input and output parameters. It was found that the volumetric heat capacity and the prepreg thickness had the highest effect on the substrate and tape temperature, respectively. Among the optical parameters, the refractive index had the highest effect. Relatively lower correlation coefficients were found between the parameters used in the thermal boundary conditions and the temperatures of tape and substrate.

\subsubsection{Local geometrical irregularities}

One of the challenges in LATW process analyses is the cross-over of the tapes during winding. A preliminary research was conducted to address the temperature change at the tape edges during placing of a cross-over layer experimentally and numerically as explained in Appendix B. When an incoming prepreg tape is deposited on an already placed tape with an angle, the local geometrical irregularity, i.e. the step thickness of the already deposited tape, alters the thermal field locally at the vicinity of the tape edges. In other words, the temperature distribution at the tape edges as observed in the experiments depends on the local geometry and the cross-over angle (winding angle). 
The resulting local irregularities directly affect the local optical properties and thermal boundary conditions, which needs to be taken into account in the process design tool in order to accurately predict these temperature variations at the tape edges. The cross-over situation was simulated by the developed generic KOT model in this thesis. It was found that the effect of the step thickness on the substrate temperature was significant during the cross-over, qualitatively agreeing with the approximate experimental results. The temperature increased approximately by $20^{\circ} \mathrm{C}, 140^{\circ} \mathrm{C}$ and $200^{\circ} \mathrm{C}$ at the step-off location for steps with 1-, 3-, and 5-layer thick, respectively. To avoid the observed temperature variations at the tape edges during the cross-over, the process settings need to be adjusted at the specific location of the cross-overs in the actual LATW process. This requires very short response times of the hardware system, able to change the laser power with up to $50 \%$ in $1 \mathrm{~ms}$ and correspondingly accurate timing of these variations. 


\section{CHAPTER 7}

\section{CONCLUSIONS AND \\ RECOMMENDATIONS}

\subsection{Conclusions}

The objective of this thesis as stated in Section 1.3 was to take the first steps in developing a generic and quantitatively accurate process design tool for LATW, ultimately leading to predictable part properties and performance which is suited for product and process optimization. To this end, validated KOT simulation models were developed to predict the heat flux and temperature history during the LATW process of parts having complex geometries and winding paths. The main conclusions among several discussed topics are summarized in the following.

1. The heat accumulation during continuous hoop winding has a significant effect on the substrate temperature evolution.

2. The roller deformation alters the heating length and heat flux distribution as well as the cooling history at the roller-substrate interface.

3. A significant variation in temperature and crystallinity distributions across the substrate width is present in the adjacent hoop winding process.

4. The changing substrate curvature of complex parts has a significant effect on the processing temperature although the laser power and tape feeding rate were kept constant.

5. A time-dependent optimum laser power distribution was achieved by using the IKOT model for helical winding and multi-layer hoop winding processes. The transient nip point temperature could be kept within the target processing temperature limit.

6. The temperature measurements either by thermocouples or by IR thermal camera were found to be in good agreement with the predictions by the KOT model for various winding patterns, local geometries and process parameters, which showed the effectiveness of the developed modeling techniques and frameworks. 
7. Monte Carlo simulations showed that the volumetric heat capacity and the prepreg thickness were found to have the highest effect on the substrate and tape temperatures. Among the optical parameters, the refractive index had the highest effect on the temperature variation. Relatively lower correlation coefficients were found between the parameters used in the thermal boundary conditions and the process temperature.

8. The local geometrical irregularity due to the cross-over of the deposited tapes was studied experimentally and numerically. The effect of step thickness of the overlapped tapes on the substrate temperature was found to be significant. An increase in step thickness resulted in a larger temperature increase at the step-off location.

\subsection{Recommendations}

In order to further develop a generic and quantitatively accurate process design tool leading to predictable part properties and performance, the following recommendations are considered as future work.

1. It is recommended to improve the accuracy of the representation of the multi physical phenomema involved by considering further interrelations of the involved physics, where primarily the thermomechanical modelling requires extensive model development.

2. Deeper or more accurate analysis is required to improve the accuracy of the process design tool which also enables subsequent process control. Accordingly, the process settings can be regulated at the specific locations during the process which is recommended to minimize the local temperature variations.

3. Probabilistic or reliability analysis of the LATW processes needs to be carried out by using the process design tools to quantify the variations in the material properties and geometrical parameters.

4. In order to provide a realistic prediction of the structural performance, the process first needs to be described accurately, after which the thermo-mechanical models can and need to be extended by including e.g. residual stress development. 


\title{
UNCERTAINTIES IN MODEL
}

\section{PARAMETERS: A STOCHASTIC}

\author{
ANALYSIS
}

\section{Introduction}

The developed KOT model in Chapter 3 was coupled with Monte Carlo Simulation (MCS) to study the effect of statistical variation in the model parameters on the substrate and tape temperatures during winding a hoop layer on a 5-layer-substrate. MCS is one of the most common techniques used for uncertainty analyses [145]. The details of the MCS utilized in this preliminary work and the main results obtained are explained.

\section{KOT model with MCS}

The statistical variations in the model parameters were described by a normal distribution with a mean $(\mu)$ and a coefficient of variation (COV) as listed in Table A.1. The corresponding distributions are depicted in Fig. A.1. Here, the standard deviation $(\sigma)$ was described as $\sigma=\mu \times \mathrm{COV}$. In the present stochastic analysis, the mean values of the random variables were taken from the deterministic analysis presented in Chapter 2. The determination of the COVs for the input parameters is explained in the following.

The refractive index $(n)$ of the fiber reinforced prepreg tapes varies between 1.5 and 2.45 as reported in [146, 79, 147, 25, 148]. The variation in $n$ is mainly due to the type of the polymer, the microstructure (e.g. the the type, distribution and amount of fibers, etc.), the temperature and the wavelength of the laser rays and material. Therefore, a COV of 0.1 was defined for $n$ which resulted in a normal distribution shown in Fig. A.1. According to [149], the standard deviation of the fiber orientation $\phi_{i}$ can be up to $1.8^{\circ}$ which was used also in this work. The corresponding COV was set to 0.04 for $\phi_{i}=45^{\circ}$, i.e. $\sigma=45^{\circ} \times 0.04=1.8^{\circ}$. The same $\mathrm{COV}=0.04$ was assumed for the parameters describing the spread of the reflected rays ( $\sigma_{f}$ and $\sigma_{t}$ in Table A.1) used in the 
Table A.1 The statistical characterizations of the parameters causing temperature variation during the LATW process.

\begin{tabular}{|c|c|c|c|c|}
\hline Type & Symbol & $\mu$ & $\mathrm{COV}$ & Description (Unit) \\
\hline \multirow{4}{*}{ Optical } & $\mathrm{n}$ & 1.8 & \begin{tabular}{|l|l|l|l|l|l|l|}
0.1 & 146 & 79 & 147 & 25 & 148 \\
\end{tabular} & Refractive index (-) \\
\hline & $\phi_{i}$ & 45 & $0.04[149$ & Fiber orientation $\left({ }^{\circ}\right)$ \\
\hline & $\sigma_{f}$ & 0.05 & 0.04 & $\begin{array}{l}\text { The spread of the reflected rays in } \\
\text { the fiber direction }[26](-)\end{array}$ \\
\hline & $\sigma_{t}$ & 0.5 & 0.04 & $\begin{array}{l}\text { The spread of the reflected rays in } \\
\text { the transverse to the fiber direction } \\
\text { [26] (-) }\end{array}$ \\
\hline \multirow{2}{*}{ Geometrical } & $\delta$ & 2 & 0.1 & Roller indentation (mm) \\
\hline & $\mathrm{t}$ & 0.15 & $0.204[150]$ & Prepreg thickness (mm) \\
\hline \multirow{6}{*}{ Thermal } & $k_{z}$ & 0.72 & 0.079 & $\begin{array}{l}\text { Thermal conductivity in the } \\
\text { through thickness direction } \\
\left(\mathrm{W} / \mathrm{m} /{ }^{\circ} \mathrm{C}\right)\end{array}$ \\
\hline & $\rho C_{p}$ & 2223 & 0.122 [150] & $\begin{array}{l}\text { Volumetric } \\
\left(\mathrm{kJ} / \mathrm{m}^{3} /{ }^{\circ} \mathrm{C}\right)\end{array}$ heat capacity \\
\hline & $T C C_{s m}$ & 2000 & 0.2 & $\begin{array}{l}\text { Thermal contact conductance co- } \\
\text { efficient at the substrate-mandrel } \\
\text { interface }\left(\mathrm{W} \mathrm{m}^{-2}{ }^{\circ} \mathrm{C}^{-1}\right)\end{array}$ \\
\hline & $h_{s r}$ & 1000 & 0.2 [61] & $\begin{array}{l}\text { Heat transfer coefficient at } \\
\text { the substrate-roller interface } \\
\left(\mathrm{W} \mathrm{m}^{-2}{ }^{\circ} \mathrm{C}^{-1}\right)\end{array}$ \\
\hline & $h_{t r}$ & 40 & 0.2 & $\begin{array}{l}\text { Heat transfer coefficient at the tape- } \\
\text { roller interface }\left(\mathrm{W} \mathrm{m}^{-2}{ }^{\circ} \mathrm{C}^{-1}\right)\end{array}$ \\
\hline & $h_{a}$ & 10 & 0.2 & $\begin{array}{l}\text { Heat transfer coefficient of air } \\
\left(\mathrm{W} \mathrm{m}^{-2}{ }^{\circ} \mathrm{C}^{-1}\right)\end{array}$ \\
\hline
\end{tabular}

optical model [26] because there has been no experimental work to quantify the values for $\sigma_{f}$ and $\sigma_{t}$. The presence of variation in the roller indentation $(\delta)$ can be due to the geometrical disturbance in the process such as gaps and overlaps between the wound layers as described in [39]. The COV of $\delta$ was assumed to be 0.1. Based on the study presented in [150], the COV of the prepreg thickness $(t)$, the volumetric heat capacity $\left(\rho C_{p}\right)$, and the conductivity in the through thickness direction $\left(k_{z}\right)$ was set to $0.204,0.079$ and 0.122 , respectively. The range for the heat transfer coefficient between the substrate and roller $\left(h_{s r}\right)$ was reported as $400-1500 \mathrm{~W} \mathrm{~m}^{-2}{ }^{\circ} \mathrm{C}^{-1}$ in [61]. Therefore, the COV of $h_{s r}$ was defined as 0.2 , which was assumed to be the same for the heat transfer coefficient of air $\left(h_{a}\right)$, tape-roller interface $\left(h_{t r}\right)$ and the thermal contact conductance coefficient at the substrate-mandrel interface $\left(T C C_{s m}\right)$. 

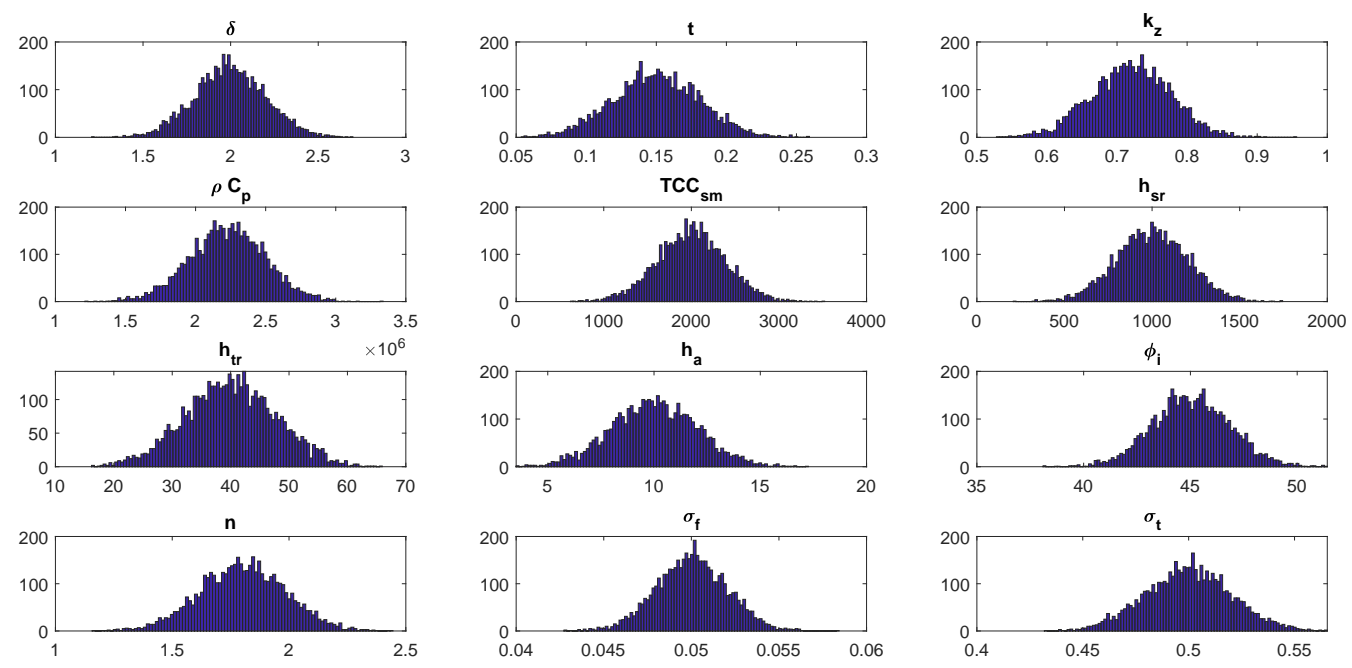

Figure A.1 Normal distribution of the input variables for the MCS analysis.

\section{Results of MCS}

A total of 5000 samples (function evaluations) was used in the MCS analysis with a total 6.5 hours of computational time. The anisotropic optical part was the computational barrier for the MCS simulation, although the computationally efficient thermal model in Chapter 3 was used to reduce the MCS run time. The output parameters in the MCS were defined as the substrate and tape temperatures averaged along the width direction at the nip point, i.e. $T_{\text {sub }}$ and $T_{\text {tape }}$, respectively. In addition, the averaged nip point temperature calculated as $T_{\text {nip }}=\left(T_{\text {sub }}+T_{\text {tape }}\right) / 2$ was also defined as the output. The histogram and the cumulative distribution functions (CDFs) distributions of the nip point, substrate, and tape temperatures are plotted in Figs. A.2a and A.2b, respectively. The substrate temperature at nip point was found to vary approximately between $320^{\circ} \mathrm{C}$ and $540^{\circ} \mathrm{C}$ with a normal distribution. On the other hand, the tape temperature at nip point had a larger and non symmetric variation which was approximately between $200^{\circ} \mathrm{C}$ and $700^{\circ} \mathrm{C}$. The variation in the averaged nip point temperate $(\mathrm{COV}=0.13)$ was found to be in between of the variation in substrate and tape temperatures at nip point, i.e. $\mathrm{COV}=0.07$ and $\mathrm{COV}=0.22$, respectively. The $\mathrm{CDF}$ of the obtained results can be translated into the corresponding probabilities. To illustrate, the probability of the substrate temperature being less than $400^{\circ} \mathrm{C}$, i.e. $P\left(T_{s u b} \leq 400^{\circ} \mathrm{C}\right)$ was approximately $51 \%$ while this value was $60 \%$ for the tape temperature and $57^{\circ} \mathrm{C}$ for the nip point temperature. Based on the onset degradation temperature of the PEEK matrix which was stated as $580^{\circ} \mathrm{C}$ in [144], $P\left(T_{\text {tape }} \geq 580^{\circ} \mathrm{C}\right)$ was found to be approximately $4 \%$ as depicted in Fig. A.2b. It should be noted that the time period for which the polymer was above this degradation temperature was approximately $0.1 \mathrm{~s}$. For the substrate and the nip point temperatures, the probability of degradation was zero and $1 \%$, i.e. $P\left(T_{\text {sub }} \geq 580^{\circ} \mathrm{C}\right)=0$ and $P\left(T_{\text {nip }} \geq\right.$ $\left.580^{\circ} \mathrm{C}\right)=1 \%$, respectively. 


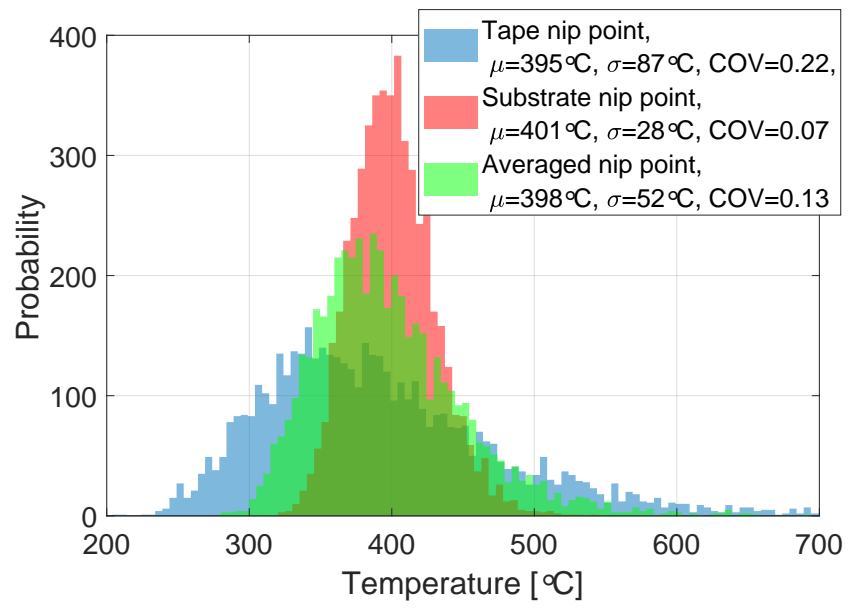

(a)

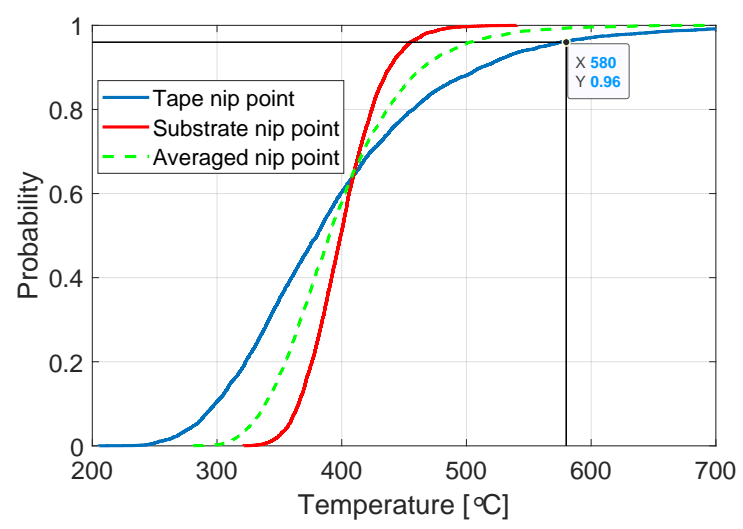

(b)

Figure A.2 (a) Histogram and (b) CDF distribution of the substrate, tape, and averaged temperatures at the nip point averaged across the width.

The temperature sensitivities to the input parameters were obtained by calculating the linear correlation coefficients which are visualized in Fig. A.3 with pie and bar plots. A positive value for the correlation indicates that an increase in the input parameter provides an increase in the output parameter and vice versa. The volumetric heat capacity $\left(\rho C_{p}\right)$ and the prepreg thickness $(t)$ had the largest effect on the substrate and tape temperature, respectively, as also observed by [150]. Both input parameters had a negative linear correlation coefficient of approximately 0.83 which indicates that their variation strongly correlated with the output parameters. Similarly, $t$ and $\rho C_{p}$ had the largest negative linear correlation coefficient for the averaged nip point temperature. The uncertainty in the 


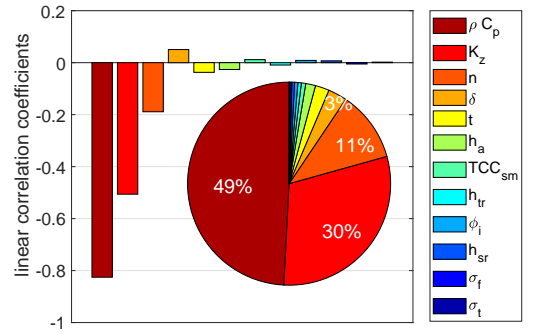

(a)

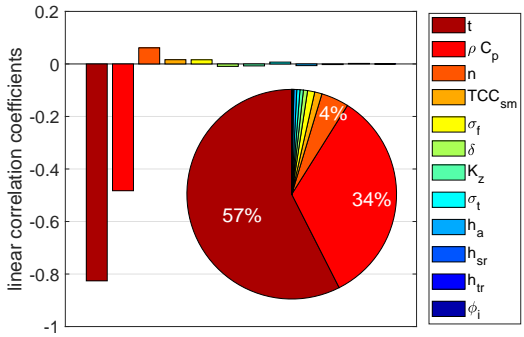

(b)

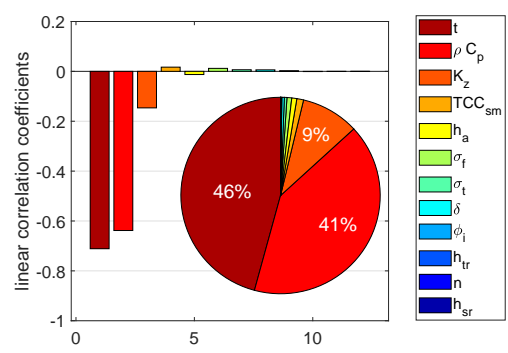

(c)

Figure A.3 The linear correlation coefficients for the (a) substrate temperature $T_{\text {sub }}$ and $(b)$ tape temperature $T_{\text {tape }}(c)$ averaged nip point temperature $T_{\text {nip }}$.

thermal conductivity in the through thickness direction $\left(k_{z}\right)$ was found to have a more significant on the substrate temperature than on the tape temperature. Among the optical parameters, the refractive index $(n)$ had the third highest linear correlation coefficient for the tape and substrate. Overall, the linear correlation coefficients of the other input parameters were found to be negligible as compared with $\rho C_{p}, k_{z}, n$ and $t$. 


\section{Introduction}

One of the common geometrical irregularities in the LATW processes is the cross-over or overlapping of the deposited tapes as shown in Chapter 4 (Fig. 4.2a) during helical winding. The overlapping of the wound layers is also occurring during hoop winding due to the feeding and cutting locations of the already deposited layers as briefly discussed in Chapter2. It was shown that the local temperature changes at the overlapped or cross-over locations which are schematically indicated in Fig. B.1. In this section, the preliminary experimental and modelling efforts to quantify the temperature change at the cross-over locations are explained and the obtained results are presented.

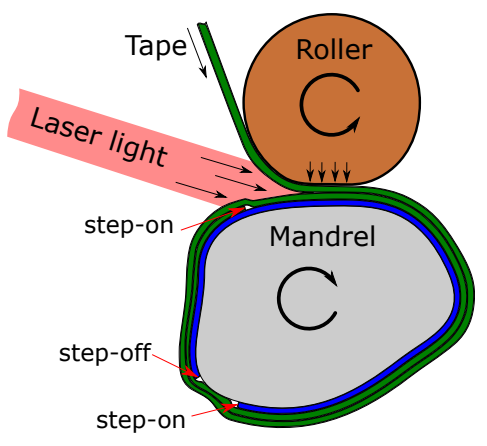

(a)

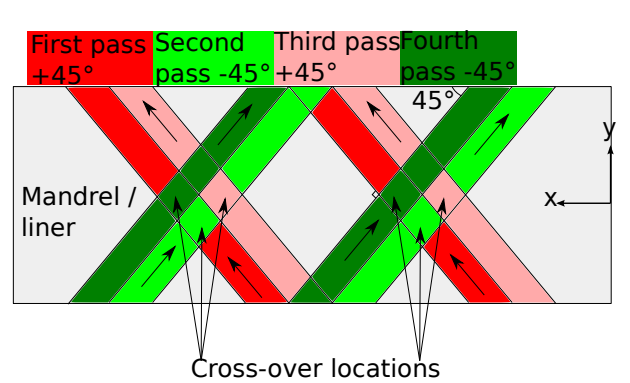

(b)

Figure B.1 A schematic view of the cross-over locations in a hoop and a helical winding. 


\section{Preliminary experimental work}

In order to investigate the local temperature change in a more detailed way, a set of preliminary experiments were performed in [55]. A simplified experimental case study was designed by using a flat laminate. Artificial steps with thickness of 1, 3, and 5 layers and a length of $100 \mathrm{~mm}$ were made as depicted in Fig. B.2. A longer tape was placed on top of the step in the designated direction, crossing the start and end point of the already placed step, i.e. step-on and -off. A microscopic view of the step-off location shows the large gap area formed after tape deposition.

The substrate temperature was measured at approximately $15 \mathrm{~mm}$ before the nip point by an IR camera and plotted in Fig. B.3 The substrate temperature was found to be almost constant until the step-on, where a relatively small decrease in local temperature was observed at $0.65 \mathrm{~s}$. The substrate temperature reached the steady-state in the range of 0.7-1.6 s. When the tape approached the step-off location, the local temperature increased significantly at $1.7 \mathrm{~s}$. Afterwards, the temperature of the substrate became steady again. The reason for the temperature drop during step-on was the shadow area where the laser light did not heat the step-on location. These peak temperatures at the step-off locations are very crucial since the polymer may be degraded thermally during the process although the time interval of the peak temperature is relatively very short $(\sim 0.1 \mathrm{~s})$.

The incident angle of the laser light with respect to the surface normal becomes smaller at the step-off location. In other words, the direction of the laser beam hitting the surface at the step-off location is more perpendicular as seen in Fig. B.3. According to the Fresnel equations, as the incident angle becomes smaller, more energy is absorbed by the surface rather than being reflected which causes a higher energy absorption at the stepoff location. On the other hand, the laser rays cannot reach the step-on location and the substrate is not heated properly which leads a decrease in the local temperature.

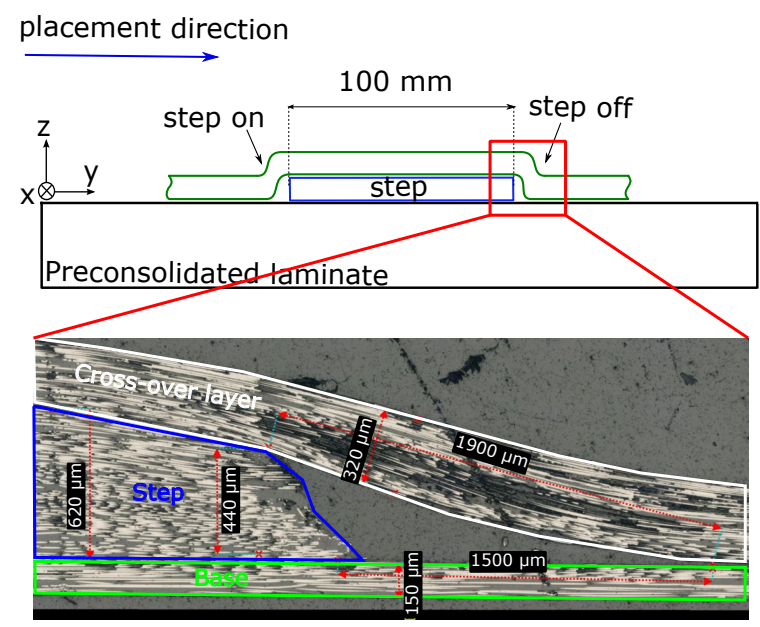

Figure B.2 A schematic view of the simplified case study for cross-over phenomenon. Microscopy of the step-off location where the temperature peak was observed. 


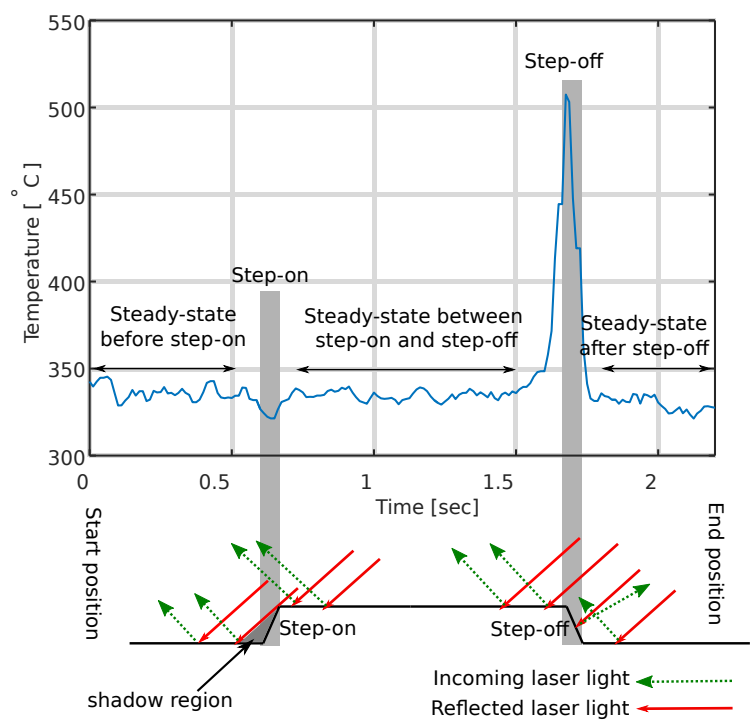

Figure B.3 The temperature history of the substrate during placing a tape crossing the 5-layers-thick step.

\section{Modelling the local irregularities}

In order to capture the effect of the local geometrical irregularities, the generic KOT model developed in Chapter 4 was used to predict the thermal history with the presence of a cross-over geometry. The STL geometry of the substrate and the fiber path defined in the experiments were the inputs to the KOT model. The substrate geometry was defined based on the step profile with the cross-section as shown in Fig. B.3. The deposition of the prepreg tape started before the step-on location and ended after the step-off location.

\section{KOT model results}

The thickness distribution obtained after placing the cross-over layer is depicted in Fig. B.4. The deposited elements on the step had a thickness of $1.05 \mathrm{~mm}$ (7 layers), while the thickness of other step elements were 0.9 (6 layers) $\mathrm{mm}$. The difference between the temperatures at the step-off location and at steady-state region (see Fig. B.3) observed by the IR camera is plotted in Fig. B.5. The effect of step thickness on the substrate temperature was found to be significant during the cross-over. The temperature at the step-off location increased approximately by $20^{\circ} \mathrm{C}, 140^{\circ} \mathrm{C}$ and $200^{\circ} \mathrm{C}$ for steps with 1-, 3-, and 5-layers-thick, respectively. A similar trend for the temperature increase a the step-off location was also obtained from the KOT model predictions. The predicted temperatures were higher than the measured values, which is attributed to the heat conduction being considered only in the through thickness direction in the KOT model. Neglecting the inplane heat conduction resulted in a heat accumulation at the step-off location and hence 


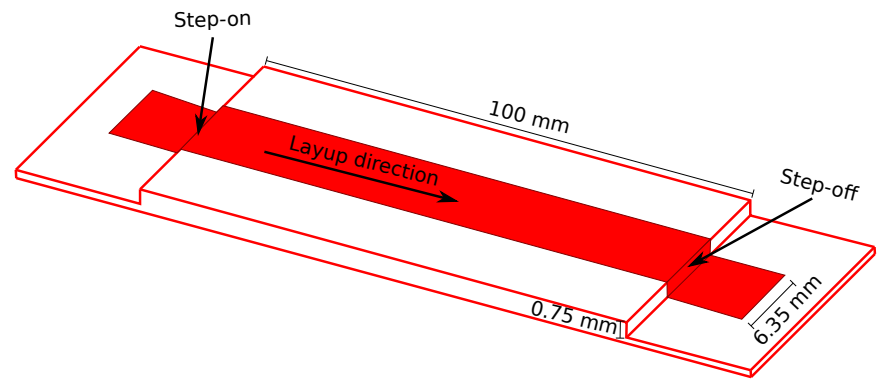

Figure B.4 The thickness distribution after laying a tape which crosses a 5-layers-thick step.

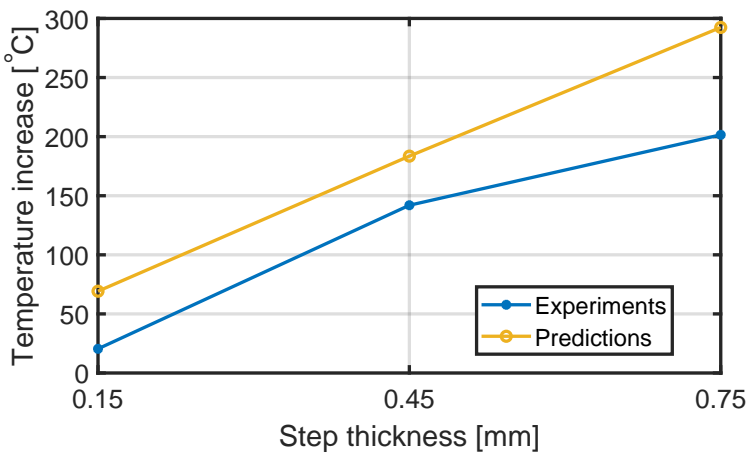

Figure B.5 The comparison of the experimental and predicted temperature increase at the step-off location due to the cross-over for various step thickness.

an overprediction of the temperature. It should be noted that the emissivity values used in the thermal camera were assumed constant during the experiments. In order to measure the absolute temperature increase at the step-off location with the thermal camera, the emissivity coefficient of the camera should be adjusted according to the temperature change. 


\section{References}

[1] Yu Qing Cui, Zhong Wei Yin, and Hu Lin Li. Influence of tension in T300/epoxy prepreg winding process on the performance of the bearing composites. J. Reinf. Plast. Compos., 36(15):1099-1115, 2017.

[2] Guillaume A Vincent, Thomas A. de Bruijn, Sebastiaan Wijskamp, Mohammed Iqbal Abdul Rasheed, Martin van Drongelen, and Remko Akkerman. Shredding and sieving thermoplastic composite scrap: Method development and analyses of the fibre length distributions. Compos. Part B Eng., 176:107197, nov 2019.

[3] S.T. Peters. Engineered Materials Handbook, Vol.1, Composites, chapter Filament winding, pages 503-509. Ohio: Metals Park, 1987.

[4] S.T. Peters, R.F. Foral, and W.D Humphrey. International Encyclopedia of Composites, chapter Filament winding, pages 503-518. New York: VCH, 1987.

[5] Dominick V Rosato and Cornelius Sherman Grove. Filament winding: its development, manufacture, applications, and design. Interscience Publishers, 1964.

[6] Y.M. Tarnopol'skii, S.T. Peters, and A.I. Beil'. Handbook of Composites, chapter 21 Filament Winding, pages 456-475. Springer, 1998.

[7] EU. European Commission. adaptive model-based control for laser-assisted fibrereinforced tape winding, Grant agreement No. 678875, 2015.

[8] Alexander Paolini, Stefan Kollmannsberger, and Ernst Rank. Additive manufacturing in construction: A review on processes, applications, and digital planning methods. Addit. Manuf., 30:100894, dec 2019.

[9] X. Guan and R. Pitchumani. Modeling of spherulitic crystallization in thermoplastic tow-placement process: heat transfer analysis. Compos. Sci. Technol., 64(9):1123-1134, jul 2004.

[10] Fazil O. Sonmez and H. Thomas Hahn. Modeling of Heat Transfer and Crystallization in Thermoplastic Composite Tape Placement Process. J. Thermoplast. Compos. Mater., 10(3):198-240, may 1997.

[11] Arthur Levy, Steven Le Corre, and Vincent Sobotka. Heat transfer and crystallization kinetics in thermoplastic composite processing. A coupled modelling framework. page 170038, 2016.

[12] John J. Tierney and J.W. Gillespie Jr. Crystallization kinetics behavior of PEEK based composites exposed to high heating and cooling rates. Compos. Part A Appl. Sci. Manuf., 35(5):547-558, may 2004. 
[13] Erin Patricia Quinlan. Thermal and crystallinity profiles in laminates manufactured with the automated thermoplastic tow placement process, 2011.

[14] Marius Dackweiler, Tobias Mayer, Sven Coutandin, and Jürgen Fleischer. Modeling and optimization of winding paths to join lightweight profiles with continuous carbon fibers. Prod. Eng., (0123456789), jul 2019.

[15] Jianhui Fu, Jaedeuk Yun, Yoong Ho Jung, and Deugwoo Lee. Generation of filament-winding paths for complex axisymmetric shapes based on the principal stress field. Compos. Struct., 161:330-339, 2017.

[16] Ji Zhou, Jianqiao Chen, Yaochen Zheng, Zhu Wang, and Qunli An. Dome shape optimization of filament-wound composite pressure vessels based on hyperelliptic functions considering both geodesic and non-geodesic winding patterns. $J$. Compos. Mater., 51(14):1961-1969, jun 2017.

[17] Chiara Colombo and Laura Vergani. Optimization of filament winding parameters for the design of a composite pipe. Compos. Part B Eng., 148:207-216, sep 2018.

[18] J. Halbritter, Ramy Harik, A. Zuloaga, and M. VanTooren. Tool path generation on doubly-curved free-form surfaces. Comput. Aided. Des. Appl., 14(6):844-851, 2017.

[19] Michaël Bruyneel and Samih Zein. A modified Fast Marching Method for defining fiber placement trajectories over meshes. Comput. Struct., 125:45-52, 2013.

[20] Bijan Shirinzadeh, Gary Cassidy, Denny Oetomo, Gursel Alici, and Marcelo H. Ang. Trajectory generation for open-contoured structures in robotic fibre placement. Robot. Comput. Integr. Manuf., 23(4):380-394, 2007.

[21] T Weiler, M Emonts, P Striet, S Gronenborn, and H Janssen. Optical Modelling of VCSEL-Assisted Thermoplastic Tape Placement. In ECCM17 - 17th Eur. Conf. Compos. Mater., 2016.

[22] Cyril Dedieu, Anaïs Barasinski, Francisco Chinesta, and Jean-Marc Dupillier. About the origins of residual stresses in in situ consolidated thermoplastic composite rings. Int. J. Mater. Form., 10(5):779-792, oct 2017.

[23] P.M. Schaefer, D. Gierszewski, A. Kollmannsberger, S. Zaremba, and K. Drechsler. Analysis and improved process response prediction of laser- assisted automated tape placement with PA-6/carbon tapes using Design of Experiments and numerical simulations. Compos. Part A Appl. Sci. Manuf., 96:137-146, may 2017.

[24] C.M. Stokes-Griffin and P. Compston. A combined optical-thermal model for nearinfrared laser heating of thermoplastic composites in an automated tape placement process. Compos. Part A Appl. Sci. Manuf., 75:104-115, aug 2015.

[25] C.M. Stokes-Griffin and P. Compston. Optical characterisation and modelling for oblique near-infrared laser heating of carbon fibre reinforced thermoplastic composites. Opt. Lasers Eng., 72:1-11, sep 2015.

[26] Jasper Reichardt, Ismet Baran, and Remko Akkerman. New analytical and numerical optical model for the laser assisted tape winding process. Compos. Part A Appl. Sci. Manuf., 107:647-656, apr 2018.

[27] Amin Zaami, Ismet Baran, Ton C. Bor, and Remko Akkerman. 3D Numerical Modeling of Laser Assisted Tape Winding Process of Composite Pressure Vessels and Pipes-Effect of Winding Angle, Mandrel Curvature and Tape Width. Materials, 13(2449), 2020.

[28] S.M. Amin Hosseini, Martin Schäkel, Ismet Baran, Henning Janssen, Martin 
van Drongelen, and Remko Akkerman. A new global kinematic-optical-thermal process model for laser-assisted tape winding with an application to helical-wound pressure vessel. Mater. Des., 193:108854, aug 2020.

[29] Thomas Weiler, Philipp Striet, Annika Voell, Jochen Stollenwerk, Henning Janssen, and Michael Emonts. Tailored irradiation by VCSEL for controlled thermal states in thermoplastic tape placement. In Henry Helvajian, Bo $\mathrm{Gu}$, and Alberto Piqué, editors, Laser 3D Manufacturing V, volume 10523, pages 58 - 73. SPIE, 2018.

[30] C. Brecher, M. Emonts, P. Striet, A. Voell, J. Stollenwerk, and H. Janssen. Adaptive tape placement process control at geometrically changing substrates. Procedia CIRP, 85:207-211, 2019.

[31] C.M. Stokes-Griffin and P. Compston. An inverse model for optimisation of laser heat flux distributions in an automated laser tape placement process for carbonfibre/PEEK. Compos. Part A Appl. Sci. Manuf., 88:190-197, sep 2016.

[32] Thijs Kok. On the consolidation quality in laser assisted fiber placement: the role of the heating phase. $\mathrm{PhD}$ thesis, University of Twente, Enschede, The Netherlands, sep 2018.

[33] Ozan Çelik, Daniël Peeters, Clemens Dransfeld, and Julie Teuwen. Intimate contact development during laser assisted fiber placement: Microstructure and effect of process parameters. Compos. Part A Appl. Sci. Manuf., 134:105888, jul 2020.

[34] Arthur Levy, Dirk Heider, J. Tierney, and J.W. Gillespie Jr. Inter-layer thermal contact resistance evolution with the degree of intimate contact in the processing of thermoplastic composite laminates. J. Compos. Mater., 48(4):491-503, 2014.

[35] George Marsh. Automating aerospace composites production with fibre placement. Reinf. Plast., 55(3):32-37, may 2011.

[36] Malte Krack, Marc Secanell, and Pierre Mertiny. Rotor Design for High-Speed Flywheel Energy Storage Systems. In Energy Storage Emerg. Era Smart Grids, number May 2014, pages 41-68. InTech, sep 2011.

[37] K. Takahashi, S. Kitade, and H. Morita. Development of high speed composite flywheel rotors for energy storage systems. Adv. Compos. Mater., 11(1):40-49, jan 2002.

[38] Martin Schäkel, John McNab, Neville Dodds, Tido Peters, H Janssen, and C. Brecher. Data Collection and Analysis for the Creation of a Digital Shadow During the Production of Thermoplastic Composite Layers in Unbonded Flexible Pipes. In Proc. ASME 2018 37th Int. Conf. Ocean. Offshore Arct. Eng. ASME, jun 2018.

[39] Amin Zaami, Martin Schäkel, Ismet Baran, Ton C Bor, Henning Janssen, and Remko Akkerman. Temperature variation during continuous laser-assisted adjacent hoop winding of type-IV pressure vessels: An experimental analysis. $J$. Compos. Mater., 54(13):1717-1739, jun 2020.

[40] Noha Hassan, Joseph E. Thompson, R. C. Batra, A. Bruce Hulcher, Xiaolan Song, and Alfred C. Loos. A Heat Transfer Analysis of the Fiber Placement Composite Manufacturing Process. J. Reinf. Plast. Compos., 24(8):869-888, may 2005.

[41] Z. Li, T. Yang, and Y. Du. Dynamic finite element simulation and transient temperature field analysis in thermoplastic composite tape lay-up process. $J$. 
Thermoplast. Compos. Mater., 28(4):558-573, 2015.

[42] Jonghyun Kim, Tess J. Moon, and John R. Howell. Transient Thermal Modeling of In-Situ Curing During Tape Winding of Composite Cylinders. J. Heat Transfer, 125(1):137, 2003.

[43] Bih-cherng Chern, Tess J. Moon, and John R. Howell. On-Line Processing of Unidirectional Fiber Composites Using Radiative Heating: I. Model. J. Compos. Mater., 36(16):1905-1934, aug 2002.

[44] Darryl L. James and W. Z. Black. Thermal Analysis of Continuous FilamentWound Composites. J. Thermoplast. Compos. Mater., 9(1):54-75, jan 1996.

[45] T. K. Slange, L.L. Warnet, W.J.B. Grouve, and R. Akkerman. Deconsolidation of C/PEEK blanks: on the role of prepreg, blank manufacturing method and conditioning. Compos. Part A Appl. Sci. Manuf., 113(3):189-199, oct 2018.

[46] W.J.B. Grouve, L.L. Warnet, B. Rietman, H. A. Visser, and R. Akkerman. Optimization of the tape placement process parameters for carbon-PPS composites. Compos. Part A Appl. Sci. Manuf., 50:44-53, 2013.

[47] W.J.B. Grouve, L.L. Warnet, B. Rietman, and R. Akkerman. On the weld strength of in situ tape placed reinforcements on weave reinforced structures. Compos. Part A Appl. Sci. Manuf., 43(9):1530-1536, sep 2012.

[48] Gearóid Clancy, Daniël Peeters, Vincenzo Oliveri, David Jones, Ronan M. O'Higgins, and Paul M. Weaver. A study of the influence of processing parameters on steering of carbon Fibre/PEEK tapes using laser-assisted tape placement. Compos. Part B Eng., 163(July 2018):243-251, apr 2019.

[49] Tilman Orth, Michael Krahl, Patricia Parlevliet, and Niels Modler. Optical thermal model for LED heating in thermoset-automated fiber placement. Adv. Manuf. Polym. Compos. Sci., 4(3):73-82, jul 2018.

[50] Khaled Yassin and Mehdi Hojjati. Processing of thermoplastic matrix composites through automated fiber placement and tape laying methods. J. Thermoplast. Compos. Mater., 31(12):1676-1725, dec 2018.

[51] C.M. Stokes-Griffin, A. Kollmannsberger, P. Compston, and K. Drechsler. The effect of processing temperature on wedge peel strength of CF/PA 6 laminates manufactured in a laser tape placement process. Compos. Part A Appl. Sci. Manuf., 121:84-91, jun 2019.

[52] C.M. Stokes-Griffin and P. Compston. Investigation of sub-melt temperature bonding of carbon-fibre/PEEK in an automated laser tape placement process. Compos. Part A Appl. Sci. Manuf., 84:17-25, 2016.

[53] Elizabeth D. Gregory and Peter D. Juarez. In-situ thermography of automated fiber placement parts. In AIP Conf. Proc., volume 1949, page 060005, 2018.

[54] C. Schmidt, Berend Denkena, Klaas Völtzer, and Tristan Hocke. Thermal Imagebased Monitoring for the Automated Fiber Placement Process. Procedia CIRP, 62:27-32, 2017.

[55] S. M. A. Hosseini, I. Baran, and R. Akkerman. An experimental investigation on the thermal field of overlapping layers in laser-assisted tape winding process. In AIP Conf. Proc., volume 1960, page 020011. AIP Publishing LLC, may 2018.

[56] Berend Denkena, C. Schmidt, Klaas Völtzer, and Tristan Hocke. Thermographic online monitoring system for Automated Fiber Placement processes. Compos. Part B Eng., 97:239-243, 2016. 
[57] Martin Schäkel, S.M. Amin Hosseini, Henning Janssen, Ismet Baran, and Christian Brecher. Temperature analysis for the laser-assisted tape winding process of multilayered composite pipes. Procedia CIRP, 85:171-176, 2019.

[58] T Weiler, Michael Emonts, Lukas Wollenburg, and Henning Janssen. Transient thermal analysis of laser-assisted thermoplastic tape placement at high process speeds by use of analytical solutions. J. Thermoplast. Compos. Mater., 31(3):311338, mar 2018.

[59] Mattia Di Francesco, Laura Veldenz, Giuseppe Dell'Anno, and Kevin Potter. Heater power control for multi-material, variable speed Automated Fibre Placement. Compos. Part A Appl. Sci. Manuf., 101:408-421, oct 2017.

[60] Amin Zaami, Ismet Baran, and Remko Akkerman. Non-hoop winding effect on bonding temperature of laser assisted tape winding process. In AIP Conf. Proc., volume 1960, page 020041, 2018.

[61] C.M. Stokes-Griffin, Paul Compston, Timothy I Matuszyk, and Michael J CardewHall. Thermal modelling of the laser-assisted thermoplastic tape placement process. J. Thermoplast. Compos. Mater., 28(10):1445-1462, oct 2015.

[62] Yves M.P. Toso, Paolo Ermanni, and Dimos Poulikakos. Thermal Phenomena in Fiber-reinforced Thermoplastic Tape Winding Process: Computational Simulations and Experimental Validations. J. Compos. Mater., 38(2):107-135, jan 2004.

[63] S.M.A. Hosseini, I. Baran, and R. Akkerman. Thermal Modeling Strategies For Laser Assisted Tape Winding (LATW) Process. In 21st Int. Conf. Compos. Mater., Xi'an, China, 2017.

[64] R. Lichtinger, P. Hörmann, D. Stelzl, and R. Hinterhölzl. The effects of heat input on adjacent paths during Automated Fibre Placement. Compos. Part A Appl. Sci. Manuf., 68:387-397, jan 2015.

[65] Amin Zaami, Ismet Baran, and Remko Akkerman. Numerical modeling of laser assisted tape winding process. In AIP Conf. Proc., page 180004, Dublin, 2017.

[66] Airtech. Polyimide high temperature pressure sensitive tape. Technical report, 2019.

[67] Micro-Epsilon. Operating Instructions thermoIMAGER TIM. Technical report, 2012.

[68] I.M Sobol'. On the distribution of points in a cube and the approximate evaluation of integrals. USSR Comput. Math. Math. Phys., 7(4):86-112, jan 1967.

[69] Michael Ashikmin, Simon Premože, and Peter Shirley. A microfacet-based BRDF generator. In Proc. 27th Annu. Conf. Comput. Graph. Interact. Tech. - SIGGRAPH '00, pages 65-74, New York, New York, USA, 2000. ACM Press.

[70] Andreas Kollmannsberger, Roland Lichtinger, Franz Hohenester, Christoph Ebel, and Klaus Drechsler. Numerical analysis of the temperature profile during the laser-assisted automated fiber placement of CFRP tapes with thermoplastic matrix. J. Thermoplast. Compos. Mater., 31(12):1563-1586, dec 2018.

[71] George Marsh. Thermoplastic composite solution for deep oil and gas reserves. Reinf. Plast., 57(4):26-29, jul 2013.

[72] John Osborne. Thermoplastic pipes - lighter, more flexible solutions for oil and gas extraction. Reinf. Plast., 57(1):33-38, jan 2013.

[73] Leen Zhang, Xiaoping Wang, Jingyu Pei, and Yu Zhou. Review of automated fibre 
placement and its prospects for advanced composites. J. Mater. Sci., 55(17):7121$7155,2020$.

[74] Roham Rafiee. On the mechanical performance of glass-fibre-reinforced thermosetting-resin pipes: A review. Compos. Struct., 143:151-164, may 2016.

[75] S. M. Amin Hosseini, Ismet Baran, Martin van Drongelen, and Remko Akkerman. On the temperature evolution during continuous laser-assisted tape winding of multiple C/PEEK layers: The effect of roller deformation. Int. J. Mater. Form., jun 2020.

[76] Angel Leon, Marta Perez, Anaïs Barasinski, Emmanuelle Abisset-Chavanne, Brigitte Defoort, and Francisco Chinesta. Multi-Scale Modeling and Simulation of Thermoplastic Automated Tape Placement: Effects of Metallic Particles Reinforcement on Part Consolidation. Nanomaterials, 9(5):695, may 2019.

[77] Pan Zhao, Bijan Shirinzadeh, Yaoyao Shi, Simeon Cheuk, and Leon Clark. Multipass layup process for thermoplastic composites using robotic fiber placement. Robot. Comput. Integr. Manuf., 49(August 2017):277-284, feb 2018.

[78] Tao Yu, Yaoyao Shi, Xiaodong He, Chao Kang, and Bo Deng. Modeling and optimization of interlaminar bond strength for composite tape winding process. $J$. Reinf. Plast. Compos., 36(8):579-592, 2017.

[79] W.J.B. Grouve. Weld strength of laser-assisted tape-placed thermoplastic composites. Phd thesis, University of Twente, Enschede, The Netherlands, aug 2012.

[80] Z. Qureshi, T. Swait, R. Scaife, and H. M. El-Dessouky. In situ consolidation of thermoplastic prepreg tape using automated tape placement technology: Potential and possibilities. Compos. Part B Eng., 66:255-267, 2014.

[81] A. J. Comer, D. Ray, W. O. Obande, D. Jones, J. Lyons, I. Rosca, R. M. O'Higgins, and M. A. McCarthy. Mechanical characterisation of carbon fibrePEEK manufactured by laser-assisted automated-tape-placement and autoclave. Compos. Part A Appl. Sci. Manuf., 69:10-20, 2015.

[82] M. Manoj Prabhakar, N. Rajini, Nadir Ayrilmis, K. Mayandi, Suchart Siengchin, K. Senthilkumar, S. Karthikeyan, and Sikiru O. Ismail. An overview of burst, buckling, durability and corrosion analysis of lightweight FRP composite pipes and their applicability. Compos. Struct., 230:111419, dec 2019.

[83] Roham Rafiee, Amin Ghorbanhosseini, and Shiva Rezaee. Theoretical and numerical analyses of composite cylinders subjected to the low velocity impact. Compos. Struct., 226:111230, oct 2019.

[84] G. H. Li, W. J. Wang, Z. J. Jing, X. C. Ma, and L. B. Zuo. Experimental Study and Finite Element Analysis of Critical Stresses of Reinforced Thermoplastic Pipes Under Various Loads. Strength Mater., 48(1):165-172, jan 2016.

[85] Shang Lin Gao and Jang-kyo Kim. Cooling rate influences in carbon fibre/PEEK composites. Part 1. Crystallinity and interface adhesion. Compos. Part A Appl. Sci. Manuf., 31(6):517-530, 2000.

[86] M. N. Bureau, J. Denault, K. C. Cole, and G. D. Enright. The role of crystallinity and reinforcement in the mechanical behavior of polyamide-6/clay nanocomposites. Polym. Eng. Sci., 42(9):1897-1906, 2002.

[87] W.J.B. Grouve, G Vanden Poel, L.L. Warnet, and R. Akkerman. On crystallisation and fracture toughness of poly(phenylene sulphide) under tape placement 
conditions. Plast. Rubber Compos., 42(7):282-288, 2013.

[88] Jicai Liang, Yuqiang Xu, Zhiyong Wei, Ping Song, Guangyi Chen, and Wanxi Zhang. Mechanical properties, crystallization and melting behaviors of carbon fiber-reinforced PA6 composites. J. Therm. Anal. Calorim., 115(1):209-218, 2014.

[89] Natassia Lona Batista, Philippe Olivier, Gérard Bernhart, Mirabel Cerqueira Rezende, and Edson Cocchieri Botelho. Correlation between degree of crystallinity, morphology and mechanical properties of PPS/carbon fiber laminates. Mater. Res., 19(1):195-201, 2016.

[90] Francisco Sacchetti, W.J.B. Grouve, L.L. Warnet, and Irene Fernandez Villegas. Effect of cooling rate on the interlaminar fracture toughness of unidirectional Carbon/PPS laminates. Eng. Fract. Mech., (October 2017):0-1, 2018.

[91] Ebrahim Oromiehie, B. Gangadhara Prusty, P. Compston, and Ginu Rajan. In-situ simultaneous measurement of strain and temperature in automated fiber placement (AFP) using optical fiber Bragg grating (FBG) sensors. Adv. Manuf. Polym. Compos. Sci., 0340(May):1-10, 2017.

[92] Hebing Xu and Jun Hu. Study of polymer matrix degradation behavior in CFRP short pulsed laser processing. Polymers (Basel)., 8(8), 2016.

[93] Stefan Buchner, Christian Baron, Terry Sheldrake, Ralf Tu“llmann, Andreas Dowe, and Graeme Bulmer. PA 12 for Flexible Flowlines and Risers. In Vol. 1 Offshore Technol. Spec. Symp. Ocean Meas. Their Influ. Des., pages 711-718. ASMEDC, jan 2007.

[94] Jinxiang Cheng, Dongbiao Zhao, Kai Liu, Yangwei Wang, and Huaiyuan Chen. Modeling and impact analysis on contact characteristic of the compaction roller for composite automated placement. J. Reinf. Plast. Compos., 37(23):1418-1432, dec 2018.

[95] Michael R Kessler. Advanced topics in characterization of composites. Trafford publishing, 2004.

[96] A. Salazar, A. Rico, J. Rodríguez, J. Segurado Escudero, R. Seltzer, and F. Martin de la Escalera Cutillas. Monotonic loading and fatigue response of a bio-based polyamide PA11 and a petrol-based polyamide PA12 manufactured by selective laser sintering. Eur. Polym. J., 59:36-45, oct 2014.

[97] B. Van Hooreweder, F. De Coninck, D. Moens, R. Boonen, and P. Sas. Microstructural characterization of SLS-PA12 specimens under dynamic tension/compression excitation. Polym. Test., 29(3):319-326, may 2010.

[98] Frank P Incropera and David P DeWitt. Fundamentals of heat and mass transfer. J. Wiley, New York, 5th ed. edition, 2002.

[99] Jürgen E.K. Schawe and Stefan Ziegelmeier. Determination of the thermal short time stability of polymers by fast scanning calorimetry. Thermochim. Acta, 623:80-85, 2016.

[100] I. Baran, Jesper H. Hattel, and Cem C. Tutum. Thermo-chemical modelling strategies for the pultrusion process. Appl. Compos. Mater., 20(6):1247-1263, 2013.

[101] Urs I. Thomann, Michael Sauter, and Paolo Ermanni. A combined impregnation and heat transfer model for stamp forming of unconsolidated commingled yarn preforms. Compos. Sci. Technol., 64(10-11):1637-1651, aug 2004.

[102] H Janssen, Tido Peters, and C. Brecher. Efficient Production of Tailored Structural 
Thermoplastic Composite Parts by Combining Tape Placement and 3d Printing. Procedia CIRP, 66:91-95, 2017.

[103] K. Nakamura, K. Katayama, and T. Amano. Some aspects of nonisothermal crystallization of polymers. II. Consideration of the isokinetic condition. J. Appl. Polym. Sci., 17(4):1031-1041, apr 1973.

[104] Melvin Avrami. Kinetics of Phase Change. I General Theory. J. Chem. Phys., 7(12):1103-1112, dec 1939.

[105] M. van Drongelen, T.B. van Erp, and G.W.M. Peters. Quantification of nonisothermal, multi-phase crystallization of isotactic polypropylene: The influence of cooling rate and pressure. Polymer (Guildf)., 53(21):4758-4769, sep 2012.

[106] Fabian Neugebauer, Vasily Ploshikhin, Janick Ambrosy, and Gerd Witt. Isothermal and non-isothermal crystallization kinetics of polyamide 12 used in laser sintering. J. Therm. Anal. Calorim., 124(2):925-933, may 2016.

[107] Meng Zhao, Katrin Wudy, and Dietmar Drummer. Crystallization Kinetics of Polyamide 12 during Selective Laser Sintering. Polymers (Basel)., 10(2):168, feb 2018.

[108] A. Maffezzoli, J.M. Kenny, and L.Nicolais. Welding of PEEK/Carbon Fiber Composite laminates. Sampe J., 25:35-39, 1989.

[109] F. Paolucci, D. Baeten, P.C. Roozemond, B. Goderis, and G.W.M. Peters. Quantification of isothermal crystallization of polyamide 12: Modelling of crystallization kinetics and phase composition. Polymer (Guildf)., 155(June):187198 , oct 2018.

[110] G. C. Alfonso and Andrzej Ziabicki. Memory effects in isothermal crystallization II. Isotactic polypropylene. Colloid Polym. Sci., 273(4):317-323, apr 1995.

[111] W.J.B. Grouve, L.L. Warnet, R. Akkerman, S. Wijskamp, and J.S.M. Kok. Weld strength assessment for tape placement. Int. J. Mater. Form., 3(SUPPL. 1):707710, 2010.

[112] Ebrahim Oromiehie, B. Gangadhara Prusty, Paul Compston, and Ginu Rajan. Automated fibre placement based composite structures: Review on the defects, impacts and inspections techniques. Compos. Struct., 224(May):110987, sep 2019.

[113] C.M. Stokes-Griffin, S. Ehard, A. Kollmannsberger, P. Compston, and K. Drechsler. A laser tape placement process for selective reinforcement of steel with CF/PA6 composites: Effects of surface preparation and laser angle. Mater. Des., 116:545-553, feb 2017.

[114] C. M. Stokes-Griffin and P. Compston. Laser-Assisted Tape Placement of Thermoplastic Composites: The Effect of Process Parameters on Bond Strength. In Jörg Wellnitz, Aleksandar Subic, and Ramona Trufin, editors, Sustain. Automot. Technol. 2013, Lecture Notes in Mobility, pages 133-141. Springer International Publishing, Cham, 2014.

[115] F. Chinesta, A. Leygue, B. Bognet, Ch Ghnatios, F. Poulhaon, F. Bordeu, A. Barasinski, A. Poitou, S. Chatel, and S. Maison-Le-Poec. First steps towards an advanced simulation of composites manufacturing by automated tape placement. Int. J. Mater. Form., 7(1):81-92, mar 2014.

[116] Dennis Maurer and Peter Mitschang. Laser-powered tape placement process simulation and optimization. Adv. Manuf. Polym. Compos. Sci., 1(3):129-137, jul 2015. 
[117] Anaiis Barasinski, Adrien Leygue, Eric Soccard, and Arnaud Poitou. Identification of non uniform thermal contact resistance in automated tape placement process. Int. J. Mater. Form., 7(4):479-486, dec 2014.

[118] Kaishu Xia, Ramy Harik, Jeremy Herrera, Josh Patel, and Brian Grimsley. Numerical simulation of AFP nip point temperature prediction for complex geometries. Int. SAMPE Tech. Conf., 2018-May, 2018.

[119] Nima Bakhshi and Mehdi Hojjati. An experimental and simulative study on the defects appeared during tow steering in automated fiber placement. Compos. Part A Appl. Sci. Manuf., 113(July):122-131, oct 2018.

[120] Muhsan Belhaj and Mehdi Hojjati. Wrinkle formation during steering in automated fiber placement: Modeling and experimental verification. J. Reinf. Plast. Compos., 37(6):396-409, mar 2018.

[121] Jinxiang Cheng, Dongbiao Zhao, Huaiyuan Chen, Yingru Zhang, and Yangwei Wang. Effect of the attitude fine-adjustment of compaction roller on automated fiber placement defects and trajectory. J. Reinf. Plast. Compos., 38(12):539-555, jun 2019.

[122] Ramin Moradi and Katrina M Groth. Hydrogen storage and delivery: Review of the state of the art technologies and risk and reliability analysis. Int. J. Hydrogen Energy, 44(23):12254-12269, may 2019.

[123] E.S. Barboza Neto, M. Chludzinski, P.B. Roese, J.S.O. Fonseca, S.C. Amico, and C.A. Ferreira. Experimental and numerical analysis of a LLDPE/HDPE liner for a composite pressure vessel. Polym. Test., 30(6):693-700, sep 2011.

[124] Celstran. Technical data sheet Celstran ${ }^{\circledR}$ GF70-01/ CFR-TP HDPE GF70-01, celanese.com/engineered-materials.

[125] Vahid Ghaffari Mejlej, Paul Falkenberg, Eiko Türck, and Thomas Vietor. Optimization of Variable Stiffness Composites in Automated Fiber Placement Process using Evolutionary Algorithms. In Procedia CIRP, volume 66, pages 79 84. Elsevier B.V., jan 2017.

[126] Guillaume Rousseau, Roudy Wehbe, Joshua Halbritter, and Ramy Harik. Automated Fiber Placement Path Planning: A state-of-the-art review. Comput. Aided. Des. Appl., 16(2):172-203, aug 2018.

[127] Christopher J. Brampton, K. Chauncey Wu, and H. Alicia Kim. New optimization method for steered fiber composites using the level set method. Struct. Multidiscip. Optim., 52(3):493-505, sep 2015.

[128] Mahdi Arian Nik, Kazem Fayazbakhsh, Damiano Pasini, and Larry Lessard. Optimization of variable stiffness composites with embedded defects induced by Automated Fiber Placement. Compos. Struct., 107(1):160-166, 2014.

[129] Daniël Peeters, Michael Deane, Ronan O'Higgins, and Paul M. Weaver. Morphology of ply drops in thermoplastic composite materials manufactured using laser-assisted tape placement. Compos. Struct., 251(March):112638, nov 2020.

[130] Thomas Zenker, Fabian Bruckner, and Klaus Drechsler. Effects of defects on laminate quality and mechanical performance in thermoplastic Automated Fiber Placement-based process chains. Adv. Manuf. Polym. Compos. Sci., 5(4):184-205, oct 2019.

[131] William E. Guin, Justin R. Jackson, and Cameron M. Bosley. Effects of tow-to-tow gaps in composite laminates fabricated via automated fiber placement. Compos. 
Part A Appl. Sci. Manuf., 115(September):66-75, 2018.

[132] Bo Deng and Yaoyao Shi. Modeling and Optimizing the Composite Prepreg Tape Winding Process Based on Grey Relational Analysis Coupled with BP Neural Network and Bat Algorithm. Nanoscale Res. Lett., 14(1):296, dec 2019.

[133] Zhenyu Han, Shouzheng Sun, Hongya Fu, and Yunzhong Fu. Multi-Scale LowEntropy Method for Optimizing the Processing Parameters during Automated Fiber Placement. Materials (Basel)., 10(9):1024, sep 2017.

[134] Chao Kang, Yaoyao Shi, Xiaodong He, Tao Yu, Bo Deng, Hongji Zhang, Pengcheng Sun, and Wenbin Zhang. Multi-response optimization of T300/epoxy prepreg tape-wound cylinder by grey relational analysis coupled with the response surface method. Mater. Res. Express, 4(9), 2017.

[135] Fazil O. Sonmez and Mustafa Akbulut. Process optimization of tape placement for thermoplastic composites. Compos. Part A Appl. Sci. Manuf., 38(9):2013-2023, 2007.

[136] Tao Yu, Yaoyao Shi, Xiaodong He, Chao Kang, Bo Deng, and Shibo Song. Optimization of Parameter Ranges for Composite Tape Winding Process Based on Sensitivity Analysis. Appl. Compos. Mater., 24(4):821-836, 2017.

[137] Jinxiang Cheng, Dongbiao Zhao, Kai Liu, and Yangwei Wang. Process modeling and parameter optimization based on assumed inherent sensor inversion for composite automated placement. J. Reinf. Plast. Compos., 36(3):226-238, 2017.

[138] Amin Zaami, Martin Schäkel, Ismet Baran, Ton C. Bor, Henning Janssen, and Remko Akkerman. A fully coupled local and global optical-thermal model for continuous adjacent laser-assisted tape winding process of type-IV pressure vessels. J. Compos. Mater., page 002199832094459, aug 2020.

[139] Sun K. Kim, H. J. Kim, and Woo Il Lee. Characterization of boundary conditions during thermoplastic composite tape lay-up process using an inverse method. Model. Simul. Mater. Sci. Eng., 11(4):417-426, 2003.

[140] Nicolas Bur, Pierre Joyot, and Pierre Villon. Reduced-order model of optimal temperature control for the automated fibre placement process. Comptes Rendus Mécanique, 346(7):556-570, jul 2018.

[141] C. Brecher, M. Emonts, P. Striet, A. Voell, J. Stollenwerk, and H. Janssen. Adaptive tape placement process control at geometrically changing substrates. Procedia CIRP, 85:207 - 211, 2019.

[142] F.S. Esselink, S.M. Amin Hosseini, Ismet Baran, and Remko Akkerman. Optimization of laser-assisted tape winding/placement process using inverse optical model. Procedia Manufacturing, 47:182 - 189, 2020. 23rd International Conference on Material Forming.

[143] Toray. Documentation for Toray Cetex ${ }^{\circledR}$ TC1200 PEEK Thermoplastic composite, 2019.

[144] Guillaume Dolo, Julien Férec, Denis Cartié, Yves Grohens, and Gilles Ausias. Model for thermal degradation of carbon fiber filled poly(ether ether ketone). Polym. Degrad. Stab., 143:20-25, sep 2017.

[145] I. Baran, Cem C. Tutum, and Jesper H. Hattel. Reliability estimation of the pultrusion process using the first-order reliability method (FORM). Appl. Compos. Mater, 20(4):639-653, 2013.

[146] Bih-cherng Chern, T. J. Moon, and John R. Howell. On-Line Processing of 
Unidirectional Fiber Composites Using Radiative Heating: II. Radiative Properties, Experimental Validation and Process Parameter Selection. J. Compos. Mater, 36(16):1935-1965, 2002.

[147] K. Dedecker, G. Groeninckx, and T. Inoue. Reactive compatibilization of A/(B/C) polymer blends. Part 3. Quantitative analysis of the interfacial thickness and the interfacial reaction. Polymer (Guildf)., 39(21):5001-5010, oct 1998.

[148] A. Zaami, I. Baran, and R. Akkerman. Experimental and numerical analysis of laser reflection for optical-thermal process modelling of tape winding. In 21st Int. Conf. Compos. Mater, number August, pages 20-25, Xi'an, China, 2017.

[149] M.P.F. Sutcliffe, S.L. Lemanski, and A.E. Scott. Measurement of fibre waviness in industrial composite components. Compos. Sci. Technol., 72(16):2016-2023, nov 2012.

[150] Marta Perez, Anais Barasinski, Benoit Courtemanche, Chady Ghnatios, and Francisco Chinesta. Sensitivity thermal analysis in the laser-assisted tape placement process. AIMS Mater. Sci., 5(6):1053-1072, 2018. 


\section{Acknowledgments}

Thanks for all the opportunities being gifted by the unique superpower during and at the end of this amazing journey and yet waiting for more. Not all the wishes were planned properly beforehand, however, they would come true eventually by trusting in the power of purified soul and what is guiding it.

But next, I would like to express my appreciation to Ismet Baran, for his dedicated daily supervision since the very first interview intake (except when the twins came into play!), team-working, and critical revisions of the papers. Many Thanks to our chair holder at the production technology (PT) group, Prof. Remko Akkerman, for leading such a nice scientific team. Although I missed his physical presence at the first phase of my Ph.D., his scientific remarks and humble character was always inspiring. Thanks to Martin van Drongelen who was helping me with all the readings and revisions of the thesis and also his fruitful Rheology course. Thank you also for the effort to translate the thesis summary into "samenvatting". Hope we can have "lekker" Dizi again soon. Thanks to the rest of the PT staff members; Laurent Warnet who initially involved with my supervision, Ton Bor who allowed us to be a teacher, Wouter Grouve who had initiated the nice GUI tool in Matlab saving some time, and Martin Luckabauer for his comments during Monday Morning Meetings. Thanks should also go to our lab experts, Bert Vos, Nick Helthuis, and Ivo Vrooijink. I very much appreciate the care and the support of Martina Tjapkes, Debbie Zimmerman, and Belinda Bruinink for being so kind and helpful to get through all the formalities.

I am extremely grateful to the members of the graduation committee Prof. dr. ir. van den Boogaard, Prof. dr. ir. Römer, Prof. dr. ir. Benedictus, Prof. dr. Hattel for reading my thesis and showing interest in my work.

Many thanks to all the people in the TPRC for providing the chance to manufacture laminates and rings by using the BIG AFP robot. Thanks to thermoplastic experts; Marten van der Werff, Thijs Donderwinkel, Jeroen Houwers, Mark Bouwman, Uli Sachs, GertJan Nevenzel, Edwar Boer, and Sebastiaan Wijskamp. I deeply owe Tjitse Slange, Thijs Kok, and Coen Hartjes for the AFP tutorial and how to bridle the robot. Here, we did a extensive experimental collaboration with Ozan Çelik from TUDelft which results in my mastery to operate the robot.

I kindly acknowledge the cooperation of partners in the ambliFibre project. We had many business travels around Europe to discuss our progress and of course enjoy the dinners in Prague, Brussels, Newcastle, Codroipo, Torino, Ringsted, Aachen hosted by 
Neovision, Fraunhofer Office, GE Oil \& Gas, Video Systems, Life Cycle Engineering, HBN-Teknik A/S, and Fraunhofer ILT, respectively. I would like to especially thank the coordinator of the project, Martin Schäkel, for being a great co-author and for sharing the knowledge from Fraunhofer IPT.

I want to thanks my colleagues and friends in PT for all the nice gatherings and early morning coffee get-togethers; Waqas Ali, Sam Benou, Ngoc Vu, Nick Hoksbergen, Ozan Erartsin, Onur Yuksel, Senem Aktas, Amin Zaami, Yash Guha, Jamal Zanjani, Logendra Dilli, Bharath Kumar, Lily Liu, Imrah Yusof, Leon Govaert, Sybren Jansma, Arka Bhakta, Iqbal Rasheed, Johan Van Ravenhorst, Erik Krämer, Sebastiaan van den Berg, Ramona Sitohang, Yannick Buser, Jagadeesh Swamy, Vanessa Marinosci, Francisco Sacchetti, Guillaume Vincent, Simon Veenstra. Also thanks to Victor Hoeksema and Frank Esselink who helped me to follow my plans and empower my supervision abilities during their master assignments.

Thanks to the Iranian community, from the Quran meeting to the Soccer sessions, to share their passion and kindness. Such people keep one up for the missing thing away from your home country. Thanks to Hamed \& Maryam, Mahdi \& Hadis for all the supports when we arrived at Enschede. Thanks to Alireza \& Zahra, Meisam \& Hajar, Mohammadreza \& Faegheh, Baqer \& Behnaz, Farid \& Rahele, Saeid \& Vahan, Mohsen \& Simin, Mohammadreze \& Hanieh, Mohammad \& Zahra, Afshin, Sobhan, Hossein, Mohammad(s), Abbas, Sajjad, Masoud, Davoud, and Morteza. Wish you all a lot of success and joyful life.

Finally, all of it would not be possible without the support of my parents whose advice is my way of success. Also, thanks to my brothers (Agha-Amo-jan and Amo-Moein) and their wives for the great support when we arrived at Schiphol with seven big pieces of luggage. Also thanks to my parents-in-law and the only brother-in-law (Daei-Mojtaba) and his wife. And finally Reyhaneh, you were the person who was always with me taking care of our family with your extraordinary peace of mind. Zoha was just nine-month-old when we came to Enschede. You were a great mother to her while providing such a nice home for me to prosper. So, you have a major share in this achievement. 


\section{Publications}

\section{Journal articles}

1. S.M.A. Hosseini, I. Baran, M. van Drongelen, and R. Akkerman, On the temperature evolution during continuous laser-assisted tape winding of multiple C/PEEK layers: The effect of roller deformation, Int J Mater Form (2020). doi:10.1007/s12289020-01568-7 (Chapter 2 of this thesis)

2. S.M.A. Hosseini, M. Schäkel, I. Baran, H. Janssen, M. van Drongelen, and R. Akkerman, Nonuniform crystallinity and temperature distribution during adjacent laser-assisted tape winding process of carbon/PA12 pipes, Int J Adv Manuf Technol (2020). doi:10.1007/s00170-020-06215-8 (Chapter 3 of this thesis)

3. S.M.A. Hosseini, M. Schäkel, I. Baran, H. Janssen, M. van Drongelen, and R. Akkerman, A new global kinematic-optical-thermal process model for laserassisted tape winding with an application to helical-wound pressure vessel. Material \& Design, 2020;193:108854. doi:10.1016/j.matdes.2020.108854. (Chapter 4 of this thesis)

4. S.M.A. Hosseini, F.S. Esselink, I. Baran, M. van Drongelen, and R. Akkerman, Optimization of the laser-assisted tape winding process using an inverse kinematicoptical-thermal model, Advanced Manufacturing: Polymer and Composite Sciences. doi:10.1080/20550340.2020.1859253 (Chapter 5 of this thesis)

5. O. Çelik, S.M.A Hosseini, I. Baran, W. Grouve, R. Akkerman, D. Peeters, J. Teuwen, C. Dransfeld, The Influence of Inter-laminar Thermal Contact Resistance on the Thermal History During Laser Assisted Fiber Placement, Submitted to Composite Part A. (A collaboration with TUdelft)

\section{Conference proceedings}

1. F.S. Esselink, S.M.A. Hosseini, I. Baran, R. Akkerman, Optimization Of LaserAssisted Tape Winding/Placement Process Using Inverse Optical Model. Procedia Manufacturing. 2020;47:182-9. doi:10.1016/j.promfg.2020.04.172 (Related to Chapter 5 of this thesis) 
2. O. Çelik, S.M.A. Hosseini, I. Baran, W.J.B. Grouve, R. Akkerman, D.M.J. Peeters, J.J.E. Teuwen, C.A. Dransfeld. The Influence of Thermal Contact Resistance on the Thermal History in Laser Assisted Fiber Placement. SAMPE2020.

3. M. Schäkel, S.M.A. Hosseini, H. Janssen, I. Baran, C. Brecher, Temperature analysis for the laser-assisted tape winding process of multi-layered composite pipes. Procedia CIRP. 2019;85:171-6. doi:10.1016/j.procir.2019.09.003

4. S.M.A. Hosseini, I. Baran, R. Akkerma. An experimental investigation on the thermal field of overlapping layers in laser-assisted tape winding process. AIP Conference Proceedings, vol. 1960, AIP Publishing LLC, p. 020011, Palermo, Italy, 2018. doi:10.1063/1.5034812. (Related to Appendix B of this thesis)

5. S.M.A. Hosseini, I. Baran, R. Akkerman. Thermal Modeling Strategies For Laser Assisted Tape Winding (LATW) Process. 21st International Conference on Composite Materials, Xi'an, China, 2017.

\section{Master Thesis supervision}

1. Inverse modeling and optimization of laser-assisted tape winding process, Frank Esselink, University of Twente, 2109-2020.

2. 3D transient and crystallization model for laser-assisted tape winding process, Victor Hoeksema, University of Twente, 2016-2017. 